\title{
Novel strategies to address disrupted sensing and signalling of satiety
}

Citation for published version (APA):

Klaassen, T. (2021). Novel strategies to address disrupted sensing and signalling of satiety. [Doctoral Thesis, Maastricht University]. ProefschriftMaken. https://doi.org/10.26481/dis.20210903tk

Document status and date:

Published: 01/01/2021

DOI:

10.26481/dis.20210903tk

Document Version:

Publisher's PDF, also known as Version of record

\section{Please check the document version of this publication:}

- A submitted manuscript is the version of the article upon submission and before peer-review. There can be important differences between the submitted version and the official published version of record.

People interested in the research are advised to contact the author for the final version of the publication, or visit the DOI to the publisher's website.

- The final author version and the galley proof are versions of the publication after peer review.

- The final published version features the final layout of the paper including the volume, issue and page numbers.

Link to publication

\footnotetext{
General rights rights.

- You may freely distribute the URL identifying the publication in the public portal. please follow below link for the End User Agreement:

www.umlib.nl/taverne-license

Take down policy

If you believe that this document breaches copyright please contact us at:

repository@maastrichtuniversity.nl

providing details and we will investigate your claim.
}

Copyright and moral rights for the publications made accessible in the public portal are retained by the authors and/or other copyright owners and it is a condition of accessing publications that users recognise and abide by the legal requirements associated with these

- Users may download and print one copy of any publication from the public portal for the purpose of private study or research.

- You may not further distribute the material or use it for any profit-making activity or commercial gain

If the publication is distributed under the terms of Article $25 \mathrm{fa}$ of the Dutch Copyright Act, indicated by the "Taverne" license above, 
Novel strategies to address disrupted sensing and signalling of satiety 
(C) Tim Klaassen, Maastricht, 2021.

For all articles published, the copyright has been transferred to the respective publisher. No part of this thesis may be reproduced or transmitted in any form or by any means without prior permission in writing by the author, or when appropriate, by the publishers of the publications.

Design: Tim Alards

Layout: Tiny Wouters

Printed by: Proefschriftmaken.nl

ISBN: 978-94-6423-312-4

The studies presented in this thesis were performed within the framework of NUTRIM School of Nutrition and Translational Research in Metabolism (Maastricht University) and the research group Food Innovation and Health, at the Centre for Healthy Eating \& Food Innovation (HEFI) (Maastricht UniversityCampus Venlo). HEFI is supported by the Province of Limburg. Furthermore, a part of the research has been funded by Will Pharma SA who received governmental funding (Subsidie MKB Innovatiestimulering Topsectoren, MIT). Printing of this thesis was financially supported by: Nederlandse Vereniging voor Gastroenterologie and Maastricht University. 


\title{
Novel strategies to address disrupted sensing and signalling of satiety
}

\author{
PROEFSCHRIFT \\ ter verkrijging van de graad van doctor aan de Universiteit Maastricht, \\ op gezag van de Rector Magnificus, Prof. dr. Rianne M. Letschert, \\ volgens het besluit van het College van Decanen, \\ in het openbaar te verdedigen op \\ vrijdag 3 september 2021 om 12.00 uur
}

door

Tim Klaassen 


\section{Promotoren}

Prof. dr. A.A.M. Masclee

\section{Co-promotoren}

Dr. D. Keszthelyi

Dr. F.J. Troost

\section{Beoordelingscommissie}

Prof. dr. ir. E.E. Blaak (voorzitster)

Prof. dr. R.C. Havermans

Prof. dr. T. Vanuytsel, KU Leuven, België

Prof. dr. M.S. Westerterp-Plantenga

Dr. M. Corsetti, University of Nottingham, United Kingdom 


\section{Contents}

$\begin{array}{lll}\text { Chapter } 1 \text { General introduction } & 7\end{array}$

Chapter 2 Effects of gastrointestinal delivery of non-caloric tastants on 21 energy intake: A systematic review and meta-analysis

Chapter 3 Intraintestinal delivery of tastants using a naso-duodenal-ileal catheter does not influence food intake or satiation

Chapter 4 Effect of oral or intragastric delivery of the bitter tastant quinine on 91 food intake and appetite sensations: a randomised crossover trial

Chapter 5 Effect of intragastric lidocaine on ad libitum food intake and satiation in healthy male volunteers: a double-blind randomised crossover study

Chapter 6 Psychometric evaluation of an experience sampling method-based 129 patient-reported outcome measure in functional dyspepsia

Chapter 7 The interplay between stress and fullness in functional dyspepsia and healthy controls: an exploratory Experience Sampling Method study

Chapter 8 General discussion

Impact 


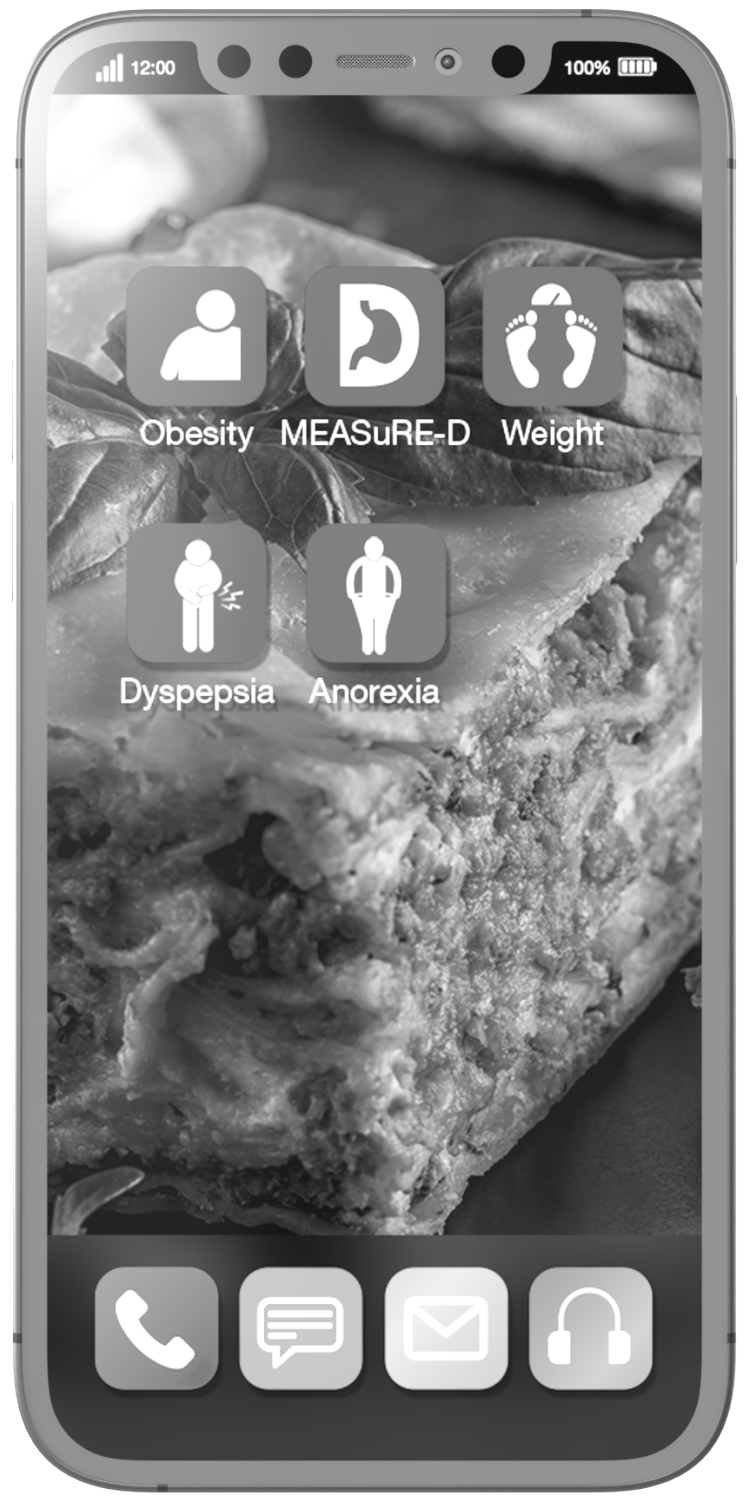




\section{Chapter 1}

General introduction 



\section{Disturbances in sensing and signalling of satiety and food intake}

Food intake and sensing and signalling of satiety can be disturbed in various clinical situations. A scenario of increased food intake and diminished satiety signalling is seen in the case of overweight and obesity. ${ }^{1,2}$ On the other hand, decreased food intake and increased satiety can be seen in the aging population, also known as anorexia of aging., 3,4 Moreover, satiety signalling and food intake can be influenced by abnormal sensations such as recurring pain, stress, anxiety, et cetera. This can result in food intake disorders such as avoidant/restrictive food intake disorder (ARFID). ${ }^{5-7}$ In other words, disturbances in satiety signalling can have important clinical repercussions and the direction of these changes will have an important impact on health outcome. In this thesis, conditions and scenarios that influence satiety signalling will be explored in order to develop more efficient treatment and monitoring strategies.

\section{Overweight and obesity}

Obesity is defined as a body mass index (BMI) of $30 \mathrm{~kg} / \mathrm{m}^{2}$ and higher and overweight is defined as a BMI of 25.0 to $29.9 \mathrm{~kg} / \mathrm{m}^{2}{ }^{1}$. The prevalence of obesity in the general population has nearly tripled since $1975 .{ }^{8}$ The burden of obesity and overweight is evident. A study has shown that every 5-unit increase in BMI above $25 \mathrm{~kg} / \mathrm{m}^{2}$ increased overall mortality (29\%), vascular mortality (41\%), and diabetes-related mortality $(210 \%) .{ }^{9}$ Moreover, medical costs of obese individuals are $30 \%$ higher compared with people with normal weight. ${ }^{10}$ This highlights the severe economic burden on healthcare systems rising from overweight and obesity.

It is generally accepted that overweight and obesity result from small, but cumulative imbalances between energy intake and energy expenditure resulting in a positive energy balance and thus weight gain. ${ }^{2}$ One of the most used treatment strategies to lose weight is to limit energy intake by means of a reduced-energy diet. However, compliance is notoriously low due to persistent hunger feelings. An energy-restricted diet often results in an initial weight loss plateau, which can be explained by a lack of diet adherence. ${ }^{11}$ Moreover, maintaining the reduced weight has proven to be difficult for the majority of individuals, resulting in regaining weight. A regain of more than half of the weight lost after 2 years and more than three-quarters after 5 years can be seen according to a meta-analysis of 
weight-loss studies. ${ }^{12}$ Currently, the only effective strategy for long term weight loss is bariatric surgery, such as the Roux-en-Y gastric bypass surgery. ${ }^{13}$ However, gastric bypass surgery is invasive and only indicated in a small group of morbidly obese subjects. This urges the need for non-invasive treatment strategies in battling the obesity epidemic that are also effective on the long term. The GI tract exerts its regulating effects on eating behaviour via its ability to produce and secrete GI peptides from food-derived triggers and neutrally, through receptors on vagal afferents. ${ }^{14-17}$ Therefore, the gastrointestinal (GI) tract is believed to play an important role in regulating eating behaviour. In order for the gut to affect eating behaviour, food constituents need to be sensed in the gut.

Satiety signalling by the intestines is hypothesised to be mainly exerted by nutritive triggers. ${ }^{18}$ It has been shown that macronutrient infusion in the intestine reduces subsequent food intake and is accompanied by the release of GI peptides. ${ }^{19-21}$ This is commonly referred to as "intestinal brake". Moreover, it has been shown that this intestinal brake is operational in a proximal to distal gradient, with generally more pronounced effects on no-absorbed nutrients in the more distal parts of the small intestine. ${ }^{22} \mathrm{~A}$ recent study showed similar decreases in food intake after high concentrations of proteins, carbohydrates, and lipids. ${ }^{21}$ This indicates nutrient sensing ability throughout the intestine for all macronutrients. However, macronutrients differ with respect to caloric contents. The use of a satiety inducing intervention without caloric content would be preferable. In this respect, much attention is given to tastants as non-caloric substances.

Currently, five prototypical tastes can be distinguished by humans: sweet, bitter, umami, sour, and salty. Stimulation of taste receptors on the taste buds on the tongue elicits the taste that we perceive. Sensing of sour and salty is mediated by ion channels, whereas sensing of sweet, bitter, and umami is mediated by two families of taste receptors. Taste receptor family 1 (TAS1) is responsible for sensing sweet and umami taste. Bitter taste is perceived by taste receptor family 2 (TAS2). ${ }^{23}$ These taste receptors are not only present on the tongue, they are expressed throughout the entire human GI tract. ${ }^{24-27}$ The taste receptors that are found in the GI tract are co-localised with entero-endocrine cells (EECs). Activation of these taste receptors in vitro results in GI peptide release. ${ }^{28-30}$ In this perspective, gastrointestinal delivery of non-caloric tastants appears to be a potentially attractive treatment option in battling the obesity epidemic. 


\section{Underweight and loss of appetite}

The gastrointestinal sensing and signalling processes can also become impaired in a way that it results in reduced food intake and weight loss. For instance, a progressing decrease in hunger and food intake can be seen during aging. This is called 'anorexia of aging. ${ }^{31-33}$ It must be noted that energy expenditure and resting metabolic rate also decline with aging. However, energy intake often decreases to a greater extent than energy expenditure, resulting in weight loss. ${ }^{34,35}$ Elderly are predisposed to weight loss and loss of muscle mass leading to sarcopenia and frailty due to this 'anorexia of aging'. ${ }^{36}$ There is still debate on the factors that contribute to 'anorexia of aging'. It is hypothesised that the GI tract is an important factor in this regard.

The initial satiating effect that occurs directly after ingesting a meal mainly results from distension of the stomach wall. The stomach is aligned with mechanoreceptors that sense an increase in stomach volume. This triggers neural circuits that inhibit food intake behaviour. ${ }^{18,37}$ It has been shown that sensations of satiation and fullness are evoked after small increases in stomach volume, whereas sensations of pain and nausea are evoked after larger increases in stomach volume. ${ }^{38}$ Moreover, several studies have shown that hunger feelings are negatively correlated with feelings of distension after inflation of a gastric balloon. ${ }^{39,40}$ Most studies describe protocols using balloons placed in the proximal stomach. However, other studies showed that distal stomach filling is also a determinant of satiation. ${ }^{3,41}$ Moreover, a recent study displayed comparable mechanosensitivity in the proximal and distal stomach. ${ }^{42}$ In elderly, postprandial fullness and satiation are found to be increased compared to younger subjects. It is hypothesised that this results from delayed gastric emptying, a larger antral area and overactive sensing profile of GI mechanoreceptors. ${ }^{3,4}$ These findings point to an impaired accommodation response to meal intake in elderly, possibly attributable to an altered sensing profile of mechanoreceptors.

Therefore, interventions aimed at reducing the sensing of mechanoreceptors in the stomach could prove to be a therapy for underweight and loss of appetite. This could be achieved by using a local topical anaesthetic to block the mechanoreceptor signalling. Application of a local anaesthetic in rats' stomachs has been shown to significantly increase food intake of a subsequent meal. ${ }^{43}$ Currently, no human studies have been performed to investigate the effects of intragastric application of local anaesthetics on food intake. 


\section{Functional dyspepsia and patient reported outcome measures (PROMs)}

Another clinical condition that can be associated with altered perception of foodinduced stimuli is functional dyspepsia (FD). Functional dyspepsia symptoms are common with an estimated prevalence of $10-15 \%$ in the general population, making it one of the most common functional gastrointestinal disorders. ${ }^{44}$ The Rome IV criteria for disorders of the brain-gut interaction are used to define FD. FD is defined by the presence of various symptoms in the absence of evidence for systemic, metabolic, or organic diseases that could explain the complaints. ${ }^{45}$ Four core symptoms have been defined among the heterogeneous presentation of FD patients: epigastric pain, epigastric burning, early satiation, and postprandial fullness. ${ }^{45,46}$ Based on the occurrence of these core symptoms, three subtypes of FD can be distinguished: postprandial distress syndrome (PDS), epigastric pain syndrome (EPS), and overlap syndrome (OS). ${ }^{45}$ The pathophysiology of FD is currently incompletely understood and multifactorial.45,47,48 It has been hypothesised that different pathophysiological mechanisms can contribute to the variety of predominant symptoms. Commonly accepted pathophysiological mechanisms are visceral (hyper)sensitivity, gastric emptying time, and gastric accommodation. Moreover, it has been shown that the extent to which these symptoms add to the existence of FD can vary between FD subtypes. ${ }^{49-51}$ As mentioned before, impaired gastric accommodation could be a product of hypersensitivity of mechanoreceptors, resulting in a decrease in food intake. Moreover, a recent meta-analysis showed an association between delayed gastric emptying and early satiation/fullness. ${ }^{52}$ Visceral hypersensitivity and pain resulting from food intake can lead to a clinical phenomenon called ARFID. ARFID is a fairly novel diagnostic category defined by the DSM V and represents a distinct eating disorder characterised by reduced food intake without body image distortion. ${ }^{5-7}$ ARFID can lead to nutritional deficiency and subsequent weight loss. Visceral hypersensitivity could result in avoiding overall food intake or specific food products that trigger symptoms.

There is a need to develop effective treatment strategies, as economic and societal burdens of FD are high. Up to $40 \%$ of FD patients consults a physician, indicating financial implications. ${ }^{53}$

Moreover, quality of life and work productivity are impaired in FD patients. ${ }^{54}$ Dividing patients into subtypes according to their predominant symptoms helped to develop 'symptom-based' treatment strategies as opposed to 'FD diagnosis- 
based' treatment strategies. ${ }^{55}$ However, new treatment strategies should be thoroughly evaluated.

The Food and Drug Administration (FDA) recommends the use of well-defined patient reported outcome measures (PROMs) in clinical trials to evaluate treatment outcome. ${ }^{56}$ The definition of a PRO is "a measurement of any aspect of a patient's health status that comes directly from the patient (i.e., without the interpretation of the patient's responses by a physician or anyone else). ${ }^{56}$ According to a recent review, 20 PROMs can be used to assess dyspeptic symptoms. However, not a single of those instruments underwent all the development steps recommended by the FDA. Therefore, there is currently no consensus on the most relevant outcome measure in FD patients. ${ }^{57}$ Current assessment methods that evaluate dyspeptic symptoms are self-reported retrospective questionnaires characterised by daily or weekly monitoring. This generates limitations such as recall bias, ${ }^{58}$ ecological bias, ${ }^{59-61}$ and lack of compliance or fake compliance. ${ }^{62}$ Monitoring symptoms in FD patients is cardinal, as this is the only available clinical outcome measure to evaluate treatment efficacy. However, abovementioned limitations indicate that currently available questionnaires are suboptimal. This underlines the need for a more reliable assessment method of symptom monitoring to evaluate treatment efficacy in functional dyspepsia.

The Experience Sampling Method (ESM), also referred to as Ecological Momentary Assessment (EMA), might be able to overcome aforementioned limitations. ESM is an electronic structured questioning method that is characterised by random, repeated assessments in a patient's current state and environment. A digital device is used to complete ESM assessments shortly after an auditory signal is emitted. This makes sure that the patient's response to questions adequately reflects their current symptoms. ESM takes into account contextual, social and psychological factors, which might affect symptom reporting. ${ }^{63,64}$ Therefore, ESM might be able to capture symptom variability over time and reduce the risk of recall bias. ESM has been extensively used in psychologic and psychiatric disorders. However, the use of ESM for GI disorders is currently limited. Two studies evaluated the use of ESM in patients with irritable bowel syndrome (IBS). Those studies found significant correlations between symptom scores on ESM and on commonly used questionnaires. However, significantly higher scores for abdominal pain were reported on retrospective questionnaires compared with mean scores derived with ESM. Interestingly, these abdominal pain scores seemed to be represented by the peak scores recorded with ESM. ${ }^{65,66}$ 
According to the FDA criterium for IBS, research in IBS should mainly focus on abdominal pain and bowel habits. ${ }^{67}$ As these are core symptoms in IBS, questionnaires for FD should thus focus on core symptoms in the various subtypes of FD. Moreover, ESM has the potential to assess individual triggers that can result in complaints of early satiation/postprandial fullness. This could provide more insight in the factors that play a role in the emergence of satiety related complaints in patients with FD. Additionally, triggers for other symptoms can also be investigated using ESM, which could lead to personalised therapeutic strategies.

Therefore, ESM has the potential to assist in disease self-management and to assess factors that play a role in the emergence of satiety related complaints. The use of ESM in FD patients has not been described previously. Recently, an FD ESM-questionnaire was created by item selection after a systematic literature search, patient focus groups, and an international expert meeting. ${ }^{68}$

\section{Aim and outline of the thesis}

This thesis aims to provide an in-depth understanding of food-gut interactions in order to develop and optimise therapeutic strategies aiming at correcting conditions with disturbed (i.e., too high or too low) energy intake. Moreover, a novel tool to provide more insight into disturbed sensing and signalling of satiety as seen in FD was investigated.

Taste receptors can be found throughout the entire GI tract. A function of these taste receptors is to sense the presence of food in the gut. The systematic review and meta-analysis described in Chapter 2 provides an overview of the effects of gastrointestinal taste receptor activation on eating behaviour.

Previous research showed a decrease in food intake after activation of duodenal taste receptors using a tastant mixture of bitter, sweet, and umami. The optimal location of taste receptor activation to affect eating behaviour is unknown. The study in Chapter 3 aimed to assess the optimal location(s) of intestinal taste receptor activation to affect eating behaviour.

Chapter 2 showed that, among tastants, bitter agents seem to be the most potent tastant to affect eating behaviour. However, the optimal location to exert their effect is still unknown. Since bitter taste is linked to toxic substances, more 
proximal activation of bitter tastants could exert a larger inhibitory effect on food intake. The study in Chapter 4 aimed to assess the effect of gastric-, oral-, and synchronous gastric- and oral delivery of a bitter tastant on eating behaviour.

Conditions such as FD and anorexia of aging can negatively influence food intake behaviour. A possible explanation for this is an increase in sensitivity of mechanoreceptors. In Chapter 5, we aimed to explore the effect of lidocaine infusion directly into the stomach on eating behaviour.

Dyspeptic symptoms can be triggered by food intake. Current assessment methods to evaluate dyspeptic symptoms and treatment efficacy have several limitations. In the studies depicted in Chapter $\mathbf{6}$ and 7, we examined a novel tool to assess symptoms and treatment efficacy in FD patients.

Finally, in Chapter 8, the main findings of the studies presented in this thesis will be presented. Moreover, our findings will be discussed in relation to data from other studies and implications for future research will be mentioned. 


\section{References}

1. Jensen MD, Ryan DH, Apovian CM, Ard JD, Comuzzie AG, Donato KA, et al. 2013 AHA/ACC/TOS guideline for the management of overweight and obesity in adults: a report of the American College of Cardiology/American Heart Association Task Force on Practice Guidelines and The Obesity Society. J Am Coll Cardiol. 2014;63(25 Pt B):2985-3023.

2. Schwartz MW, Seeley RJ, Zeltser LM, Drewnowski A, Ravussin E, Redman LM, et al. Obesity Pathogenesis: An Endocrine Society Scientific Statement. Endocr Rev. 2017;38(4):267-96.

3. Sturm K, Parker B, Wishart J, Feinle-Bisset C, Jones KL, Chapman I, et al. Energy intake and appetite are related to antral area in healthy young and older subjects. Am J Clin Nutr. 2004;80(3):656-67.

4. Wysokinski A, Sobow T, Kloszewska I, Kostka T. Mechanisms of the anorexia of aging-a review. Age (Dordr). 2015;37(4):9821.

5. Fisher MM, Rosen DS, Ornstein RM, Mammel KA, Katzman DK, Rome ES, et al. Characteristics of Avoidant/Restrictive Food Intake Disorder in Children and Adolescents: A "New Disorder" in DSM-5. Journal of Adolescent Health. 2014;55(1):49-52.

6. Norris ML, Robinson A, Obeid N, Harrison M, Spettigue W, Henderson K. Exploring Avoidant/Restrictive Food Intake Disorder in Eating Disordered Patients: A Descriptive Study. International Journal of Eating Disorders. 2014;47(5):495-9.

7. Zimmerman J, Fisher M. Avoidant/Restrictive Food Intake Disorder (ARFID). Curr Probl Pediatr Adolesc Health Care. 2017;47(4):95-103.

8. WHO. Obesity and Overweight 2018 [updated 16 February 2018. Accessed on 10 December 2019]. Available from: https://www.who.int/en/news-room/fact-sheets/detail/obesity-and-overweight.

9. Prospective Studies C, Whitlock G, Lewington S, Sherliker P, Clarke R, Emberson J, et al. Body-mass index and cause-specific mortality in 900000 adults: collaborative analyses of 57 prospective studies. Lancet. 2009;373(9669):1083-96.

10. Withrow D, Alter DA. The economic burden of obesity worldwide: a systematic review of the direct costs of obesity. Obes Rev. 2011;12(2):131-41.

11. Thomas DM, Martin CK, Redman LM, Heymsfield SB, Lettieri S, Levine JA, et al. Effect of dietary adherence on the body weight plateau: a mathematical model incorporating intermittent compliance with energy intake prescription. Am J Clin Nutr. 2014;100(3):787-95.

12. Anderson JW, Konz EC, Frederich RC, Wood CL. Long-term weight-loss maintenance: a meta-analysis of US studies. Am J Clin Nutr. 2001;74(5):579-84.

13. Manning S, Pucci A, Batterham RL. Roux-en-Y gastric bypass: effects on feeding behavior and underlying mechanisms. J Clin Invest. 2015;125(3):939-48.

14. Lieverse RJ, Jansen JB, Masclee AA, Lamers CB. Satiety effects of a physiological dose of cholecystokinin in humans. Gut. 1995;36(2):176-9.

15. Lieverse RJ, Jansen JB, van de Zwan A, Samson L, Masclee AA, Lamers CB. Effects of a physiological dose of cholecystokinin on food intake and postprandial satiation in man. Regul Pept. 1993;43(1-2): 83-9.

16. Verdich C, Flint A, Gutzwiller JP, Naslund E, Beglinger C, Hellstrom PM, et al. A meta-analysis of the effect of glucagon-like peptide-1 (7-36) amide on ad libitum energy intake in humans. J Clin Endocrinol Metab. 2001;86(9):4382-9.

17. Cummings DE, Overduin J. Gastrointestinal regulation of food intake. J Clin Invest. 2007;117(1):13-23.

18. Powley TL, Phillips RJ. Gastric satiation is volumetric, intestinal satiation is nutritive. Physiol Behav. 2004;82(1):69-74.

19. Maljaars PW, Peters HP, Mela DJ, Masclee AA. Ileal brake: a sensible food target for appetite control. A review. Physiol Behav. 2008;95(3):271-81.

20. Shin HS, Ingram JR, McGill AT, Poppitt SD. Lipids, CHOs, proteins: can all macronutrients put a 'brake' on eating? Physiol Behav. 2013;120:114-23.

21. van Avesaat M, Troost FJ, Ripken D, Hendriks HF, Masclee AA. Ileal brake activation: macronutrientspecific effects on eating behavior? Int J Obes (Lond). 2015;39(2):235-43.

22. Alleleyn AM, van Avesaat M, Troost FJ, Masclee AA. Gastrointestinal Nutrient Infusion Site and Eating Behavior: Evidence for A Proximal to Distal Gradient within the Small Intestine? Nutrients. 2016;8(3):117. 
23. Depoortere I. Taste receptors of the gut: emerging roles in health and disease. Gut. 2014;63(1): 179-90.

24. Young RL, Sutherland K, Pezos N, Brierley SM, Horowitz M, Rayner CK, et al. Expression of taste molecules in the upper gastrointestinal tract in humans with and without type 2 diabetes. Gut. 2009;58(3):337-46.

25. van der Wielen N, van Avesaat M, de Wit NJ, Vogels JT, Troost F, Masclee A, et al. Cross-species comparison of genes related to nutrient sensing mechanisms expressed along the intestine. PLoS One. 2014;9(9):e107531.

26. Bezencon C, le Coutre J, Damak S. Taste-signaling proteins are coexpressed in solitary intestinal epithelial cells. Chem Senses. 2007;32(1):41-9.

27. Gu F, Liu X, Liang J, Chen J, Chen F, Li F. Bitter taste receptor mTas2r105 is expressed in small intestinal villus and crypts. Biochem Biophys Res Commun. 2015;463(4):934-41.

28. Jang HJ, Kokrashvili Z, Theodorakis MJ, Carlson OD, Kim BJ, Zhou J, et al. Gut-expressed gustducin and taste receptors regulate secretion of glucagon-like peptide-1. Proc Natl Acad Sci U S A. 2007;104(38): 15069-74.

29. Sternini C, Anselmi L, Rozengurt E. Enteroendocrine cells: a site of 'taste' in gastrointestinal chemosensing. Curr Opin Endocrinol Diabetes Obes. 2008;15(1):73-8.

30. Rozengurt N, Wu SV, Chen MC, Huang C, Sternini C, Rozengurt E. Colocalization of the alpha-subunit of gustducin with PYY and GLP-1 in L cells of human colon. Am J Physiol Gastrointest Liver Physiol. 2006;291(5):G792-802.

31. Clarkston WK, Pantano MM, Morley JE, Horowitz M, Littlefield JM, Burton FR. Evidence for the anorexia of aging: gastrointestinal transit and hunger in healthy elderly vs. young adults. Am J Physiol. 1997;272(1 Pt 2):R243-8.

32. Wurtman JJ, Lieberman H, Tsay R, Nader T, Chew B. Calorie and nutrient intakes of elderly and young subjects measured under identical conditions. J Gerontol. 1988;43(6):B174-80.

33. Morley JE. Anorexia of aging: physiologic and pathologic. Am J Clin Nutr. 1997;66(4):760-73.

34. Poehlman ET, Berke EM, Joseph JR, Gardner AW, Katzman-Rooks SM, Goran MI. Influence of aerobic capacity, body composition, and thyroid hormones on the age-related decline in resting metabolic rate. Metabolism. 1992;41(8):915-21.

35. Roberts SB, Fuss P, Heyman MB, Young VR. Influence of age on energy requirements. Am J Clin Nutr. 1995;62(5 Suppl):1053S-8S.

36. Fielding RA, Vellas B, Evans WJ, Bhasin S, Morley JE, Newman AB, et al. Sarcopenia: an undiagnosed condition in older adults. Current consensus definition: prevalence, etiology, and consequences. International working group on sarcopenia. J Am Med Dir Assoc. 2011;12(4):249-56.

37. Phillips RJ, Powley TL. Tension and stretch receptors in gastrointestinal smooth muscle: re-evaluating vagal mechanoreceptor electrophysiology. Brain Res Brain Res Rev. 2000;34(1-2):1-26.

38. Feinle C, Grundy D, Read NW. Effects of duodenal nutrients on sensory and motor responses of the human stomach to distension. Am J Physiol. 1997;273(3 Pt 1):G721-6.

39. Rigaud D, Trostler N, Rozen R, Vallot T, Apfelbaum M. Gastric distension, hunger and energy intake after balloon implantation in severe obesity. Int J Obes Relat Metab Disord. 1995;19(7):489-95.

40. Nieben OG, Harboe H. Intragastric balloon as an artificial bezoar for treatment of obesity. Lancet. 1982;1(8265):198-9.

41. Darwiche G, Bjorgell O, Thorsson O, Almer LO. Correlation between simultaneous scintigraphic and ultrasonographic measurement of gastric emptying in patients with type 1 diabetes mellitus. J Ultras Med. 2003;22(5):459-66.

42. Lee KJ, Vos R, Janssens J, Tack J. Differences in the sensorimotor response to distension between the proximal and distal stomach in humans. Gut. 2004;53(7):938-43.

43. Broekkamp CLE, Peeters BWMM. Means to facilitate food intake and food retention. Patent application WO2013/171252.

44. Tack J, Talley NJ, Camilleri M, Holtmann G, Hu P, Malagelada JR, et al. Functional gastroduodenal disorders. Gastroenterology. 2006;130(5):1466-79.

45. Stanghellini V, Chan FK, Hasler WL, Malagelada JR, Suzuki H, Tack J, et al. Gastroduodenal Disorders. Gastroenterology. 2016;150(6):1380-92. 
46. Taylor F, Reasner DS, Carson RT, Deal LS, Foley C, Iovin R, et al. Development of a Symptom-Based Patient-Reported Outcome Instrument for Functional Dyspepsia: A Preliminary Conceptual Model and an Evaluation of the Adequacy of Existing Instruments. Patient. 2016;9(5):409-18.

47. Vanheel H, Vicario M, Vanuytsel T, Van Oudenhove L, Martinez C, Keita AV, et al. Impaired duodenal mucosal integrity and low-grade inflammation in functional dyspepsia. Gut. 2014;63(2):262-71.

48. Keely S, Walker MM, Marks E, Talley NJ. Immune dysregulation in the functional gastrointestinal disorders. Eur J Clin Invest. 2015;45(12):1350-9.

49. Di Stefano M, Miceli E, Tana P, Mengoli C, Bergonzi M, Pagani E, et al. Fasting and postprandial gastric sensorimotor activity in functional dyspepsia: postprandial distress vs. epigastric pain syndrome. Am J Gastroenterol. 2014;109(10):1631-9.

50. Vanheel H, Carbone F, Valvekens L, Simren M, Tornblom H, Vanuytsel T, et al. Pathophysiological Abnormalities in Functional Dyspepsia Subgroups According to the Rome III Criteria. Am J Gastroenterol. 2017;112(1):132-40.

51. Karamanolis G, Caenepeel P, Arts J, Tack J. Association of the predominant symptom with clinical characteristics and pathophysiological mechanisms in functional dyspepsia. Gastroenterology. 2006;130(2):296-303.

52. Vijayvargiya P, Jameie-Oskooei S, Camilleri M, Chedid V, Erwin PJ, Murad MH. Association between delayed gastric emptying and upper gastrointestinal symptoms: a systematic review and meta-analysis. Gut. 2019;68(5):804-13.

53. Ford AC, Forman D, Bailey AG, Cook MB, Axon AT, Moayyedi P. Who consults with dyspepsia? Results from a longitudinal 10-yr follow-up study. Am J Gastroenterol. 2007;102(5):957-65.

54. Sander GB, Mazzoleni LE, Francesconi CF, Balbinotto G, Mazzoleni F, Wortmann AC, et al. Influence of organic and functional dyspepsia on work productivity: the HEROES-DIP study. Value Health. 2011;14(5 Suppl 1):S126-9.

55. Sayuk GS. Editorial: Functional Dyspepsia Treatment: Trials and Tribulations of Targeted Strategies. Am J Gastroenterol. 2017;112(6):910-2.

56. Health USDo, Human Services FDACfDE, Research, Health USDo, Human Services FDACfBE, Research, et al. Guidance for industry: patient-reported outcome measures: use in medical product development to support labeling claims: draft guidance. Health Qual Life Outcomes. 2006;4:79.

57. Smeets FGM, Masclee AAM, Conchillo JM, Keszthelyi D. Systematic review: Disease-specific instruments to assess gastrointestinal symptoms in functional dyspepsia. Neurogastroenterol Motil. 2018.

58. Bradburn NM, Rips LJ, Shevell SK. Answering autobiographical questions: the impact of memory and inference on surveys. Science. 1987;236(4798):157-61.

59. Feinle-Bisset C, Horowitz M. Dietary factors in functional dyspepsia. Neurogastroenterol Motil. 2006;18(8):608-18.

60. Feinle-Bisset C, Azpiroz F. Dietary and lifestyle factors in functional dyspepsia. Nat Rev Gastroenterol Hepatol. 2013;10(3):150-7.

61. Aro P, Talley NJ, Johansson SE, Agreus L, Ronkainen J. Anxiety Is Linked to New-Onset Dyspepsia in the Swedish Population: A 10-Year Follow-up Study. Gastroenterology. 2015;148(5):928-37.

62. Stone AA, Shiffman S, Schwartz JE, Broderick JE, Hufford MR. Patient compliance with paper and electronic diaries. Control Clin Trials. 2003;24(2):182-99.

63. Myin-Germeys I, Oorschot M, Collip D, Lataster J, Delespaul P, van Os J. Experience sampling research in psychopathology: opening the black box of daily life. Psychol Med. 2009;39(9):1533-47.

64. Shiffman S, Stone AA, Hufford MR. Ecological momentary assessment. Annu Rev Clin Psychol. 2008;4: $1-32$.

65. Mujagic Z, Leue C, Vork L, Lousberg R, Jonkers DM, Keszthelyi D, et al. The Experience Sampling Method--a new digital tool for momentary symptom assessment in IBS: an exploratory study. Neurogastroenterol Motil. 2015;27(9):1295-302.

66. Weinland SR, Morris CB, Hu Y, Leserman J, Bangdiwala SI, Drossman DA. Characterization of episodes of irritable bowel syndrome using ecological momentary assessment. Am J Gastroenterol. 2011;106(10):1813-20. 
67. Administration USFD. Irritable Bowel Syndrome - Clinical Evaluation of Products for Treatment 2012 [updated June 2012. Accessed on 7 July 2020]. Available from: https://www.fda.gov/regulatoryinformation/search-fda-guidance-documents/irritable-bowel-syndrome-clinical-evaluation-productstreatment.

68. Smeets FGM, Keszthelyi D, Vork L, Tack J, Talley NJ, Simren M, et al. Development of a real-time patient-reported outcome measure for symptom assessment in patients with functional dyspepsia using the experience sampling method. Neurogastroenterol Motil. 2019;31(2):e13496. 


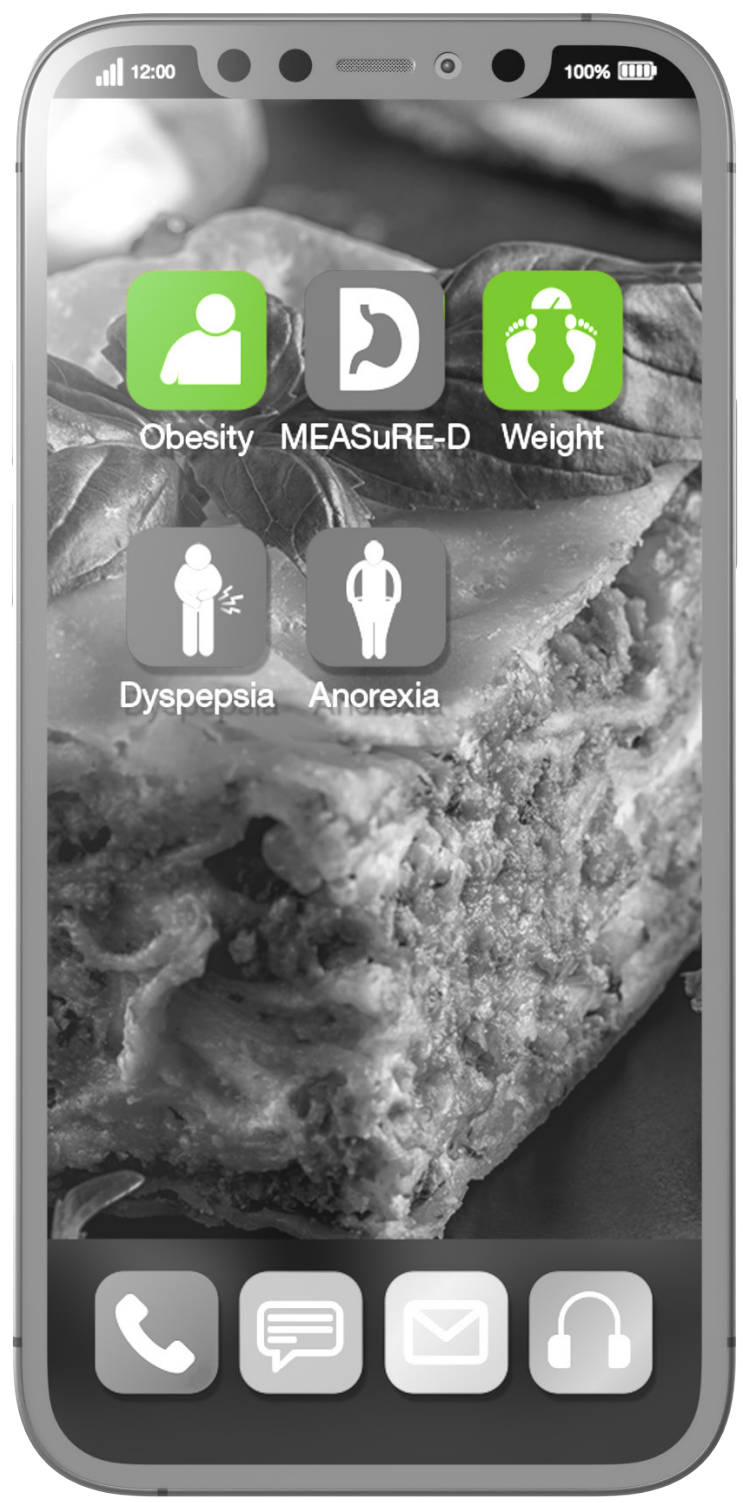




\section{Chapter 2}

Effects of gastrointestinal delivery of non-caloric tastants on energy intake: A systematic review and metaanalysis

Tim Klaassen Daniel Keszthelyi Freddy J. Troost Aalt Bast Ad A.M. Masclee 


\begin{abstract}
Purpose

Taste receptors are expressed throughout the gastrointestinal tract. Activation of post-oral taste receptors using tastants could provide a non-invasive treatment option in combating the obesity epidemic. The aim of this review was to examine the effect of post-oral delivery of non-caloric tastants on eating behaviour reflected by primary outcome energy intake and secondary outcomes GI symptoms and perceptions and potential underlying mechanisms. This review was conducted according to the PRISMA guidelines for systematic reviews.
\end{abstract}

\title{
Methods
}

A systematic literature search of the Cochrane, PubMed, Embase, and Medline databases was performed. This systematic review and meta-analysis was registered in the PROSPERO database on 26 February 2020 (ID: CRD42020171182). Two researchers independently screened 11912 articles and extracted information from 19 articles. If at least two studies investigated the effect of the same taste compound on primary outcome energy intake, a meta-analysis was performed to determine pooled effect sizes.

\section{Results}

Nineteen papers including healthy volunteers were included. In the 19 papers analysed, effects of various tastants were investigated in healthy volunteers. Most extensively investigated were bitter tastants. Meta-analysis of effects of bitter tastants showed a significant reduction in energy intake of $54.62 \mathrm{Kcal}$ (95\% CI: $-78.54--30.69, \mathrm{p}=0.0014)$.

\section{Conclusions}

Bitter stimuli are most potent to influence eating behaviour. Energy intake decreased after post-oral delivery of bitter tastants. This highlights the potential of a preventive role of bitter tastants in battling the obesity epidemic. 


\section{Introduction}

There are at least five prototypical basic tastes that can be distinguished by humans: sweet, sour, bitter, salty, and umami More recent studies have pointed to the existence of other basic tastes (i.e., fat and starch) ${ }^{1,2}$ as well as taste disorders such as metallic taste in cancer patients treated with chemotherapy. ${ }^{3}$ Moreover, there is a phenomenon known as chemesthesis, which refers to chemical sensations that are perceived as warmth, heat, irritation, cooling, or pungency. ${ }^{4} \mathrm{~A}$ prototypical pungent stimulus is capsaicin, resulting in a sizable number of studies investigating the effects of capsaicin as a weight loss intervention. 5,6

As far as the prototypical basic tastes are concerned, these can be sensed by taste buds present on the tongue. Ion channels mediate the sensing of salty and sour taste, whereas sensing sweet, bitter and umami taste is mediated by two families of taste receptors. Taste receptor family 1 (TAS1) generally senses sweet and umami taste and taste receptor family 2 (TAS2) primarily senses bitter taste. ${ }^{7}$ It is hypothesised that these prototypical tastes exist in order to predict the type of food that is ingested (i.e., sweet for saccharides, umami for glutamate, and bitter for potential toxic substances). ${ }^{8}$ However, it should be noted that several studies show that the negative affective response to bitter can be decoupled by, for instance, the positive response to caffeine. ${ }^{9,10}$ In addition, several studies have shown that the activation of oral taste receptors can result in the release of gastrointestinal (GI) peptides such as peptide YY (PYY), glucagon-like peptide 1 (GLP-1), and cholecystokinin (CCK). ${ }^{11,12}$ These GI peptides have been shown to influence eating behaviour by reducing appetite sensations and food intake after intravenous administration. ${ }^{13-18}$

Taste receptors are not only present on the tongue but are expressed throughout the entire human gut. ${ }^{19-22}$ In the GI-tract, entero-endocrine cells (EECs) are colocalised with these taste receptors. In vitro studies have shown that activation of these taste-receptors results in the release of GI peptides. ${ }^{23-25}$

Activation of taste receptors can be elicited using non-caloric tastants. Taste receptor activation using non-caloric tastants to influence eating behaviour is potentially considered as a non-invasive treatment option in combating the obesity epidemic. ${ }^{26}$ This concept deserves further evaluation. To date, a significant number of papers ${ }^{27-45}$ describing the effects of post-oral delivery of non-caloric tastants (i.e., exposure to tastants anywhere distal to the oral cavity) on eating behaviour, and in particular energy intake, have been published. However, due to inconsistent results reported in these papers, the effect of post-oral delivery of non-caloric tastants on eating behaviour remains unclear and a detailed overview 
of the literature on the effects of post-oral delivery of non-caloric tastants on eating behaviour is lacking. Therefore, we conducted a systematic review and meta-analysis using the PRISMA guidelines for systematic reviews. In order to keep this review and meta-analysis concise, we focused on the prototypical basic tastes; novel taste entities and chemesthesis were deemed out of scope.

Our aim was to systematically address randomised controlled trials investigating the effects of post-oral delivery of prototypical non-caloric tastants versus placebo on energy intake in healthy volunteers. Our secondary aims were to evaluate the effects of post-oral delivery of non-caloric tastants versus placebo on GI symptoms and perceptions and potential underlying mechanisms in healthy volunteers. We hypothesised that post-oral delivery of non-caloric tastants results in decreased energy intake compared with placebo in healthy volunteers. Moreover, we hypothesised that post-oral delivery of non-caloric tastants results in increased satiation and the release of GI peptides as the primary mechanism of action. A meta-analysis was performed in case at least two studies described the use of non-caloric tastants of the same taste on the primary outcome energy intake and clinical heterogeneity was acceptable.

\section{Methods}

\section{Search strategy}

This systematic review and meta-analysis was registered in the PROSPERO database on 26 February 2020 (ID: CRD42020171182). The present systematic review and meta-analysis was performed according to the Preferred Reporting Items for Systematic Reviews and Meta-Analyses (PRISMA) guidelines. ${ }^{46}$ The description of the PICOS (participants, intervention, comparison, outcome, and setting) criteria used to define the research question are depicted in Table 2.1. A structured search in the Cochrane, PubMed, Embase and Medline databases was performed up to 26 February 2020 with the following search strategy: (((()(((()(tastant) OR Taste) OR Taste receptor) OR bitter taste) OR quinine) OR denatonium benzoate) OR umami) OR sodium glutamate) OR monosodium glutamate) OR sweet) OR non-nutritive sweeteners $))$ AND $(((()((()((()(($ energy intake) OR intake) OR food intake) OR appetite sensation) OR satiation) OR satiety response) OR satiety) OR satiety hormones) OR glucagon-like peptide-1) OR peptide YY) OR Ghrelin) OR leptin) OR cholecystokinin) OR motilin) OR motility) OR gastric emptying). 
Table 2.1 Description of the PICOS criteria used to define the research question.

\begin{tabular}{ll}
\hline Parameter & Description \\
\hline Participants & Healthy individuals \\
Intervention & Prototypical non-caloric tastants at least once \\
Comparison & Prototypical non-caloric tastants vs. placebo \\
Outcomes & Energy intake, GI symptoms and perceptions, and mechanisms of effect \\
Setting & Randomised controlled trials with a parallel or crossover design \\
Research question & What is the effect of post-oral delivery of non-caloric tastants on energy \\
& intake in healthy volunteers? Secondary: what is the effect of post-oral \\
delivery of non-caloric tastants on GI symptoms and perceptions and what \\
is the effect of post-oral delivery of non-caloric tastants on mechanisms of \\
action in healthy volunteers
\end{tabular}

\section{Selection criteria}

Eligibility of each paper was assessed independently by two researchers (T.K. and D.K.) according to predefined criteria. Papers reporting the effects of post-oral delivery of non-caloric tastants on eating behaviour (e.g., energy intake, GI peptides, appetite sensations, GI motility, GI symptoms, brain signalling and other effects) were included. In order to investigate the function of gastrointestinal taste receptors, papers needed to properly bypass oral taste effects. Therefore, studies investigating delivery methods using catheters, capsules or other methods resulting in adequate masking of oral taste were included. Moreover, papers were excluded if they were reviews, comments, replies on an original paper, or abstracts without available full text. No limitations on publication date were set. Paper inclusion was agreed upon by both reviewers. A third reviewer (A.M.) was consulted with regard to inclusion in case of disagreement between the two reviewers.

\section{Outcome measures}

This systematic review looked at various aspects of eating behaviour after postoral delivery of non-caloric tastants. Outcome measures of interest were (1) energy intake, (2) GI symptoms and perceptions, and (3) mechanisms of effect.

\section{Data extraction}

Two reviewers (T.K.) and (D.K.) carried out the data extraction. Two authors were contacted to elaborate their data and they replied. Name of author, year of publication, country, sample size, age of subjects, BMI of subjects, tastants used, method of administration, energy intake, appetite sensations, GI symptoms, GI peptides, GI motility, and brain signalling in homeostatic and hedonic regions 
were abstracted and presented in tables. Principle summary measures are differences in means.

\section{Quality assessment}

Two independent reviewers (T.K. and D.K.) used the revised Cochrane risk of bias tool to assess risk of bias in randomised trials (RoB 2) to assess the quality of included papers. ${ }^{47}$ The quality of the paper was assessed only once when a paper described multiple studies. A third reviewer (A.M.) was consulted in case of discordance between the two reviewers. The RoB 2 tool, assessing the quality of randomised controlled trials, consists of five domains covering bias arising from the randomisation process, bias due to deviations from intended interventions, bias due to missing outcome data, bias in the measurement of the outcome, and bias in selection of the reported result. The scoring system assesses the risk of bias on these domains (low risk of bias, some concerns, high risk of bias). When an individual domain received score of a particular level of bias, overall risk of bias was determined to be at least as severe.

\section{Statistical analysis}

A meta-analysis was performed if at least two studies described the use of noncaloric tastants of the same basic taste on energy intake and clinical heterogeneity between studies was acceptable. Clinical heterogeneity was discussed by two independent reviewers (T.K and D.K). In case of discordance between these reviewers, a third reviewer (A.M.) was consulted. Meta-analyses were performed using a random effect model by the metaphor package in $\mathrm{R}$ (version 3.6.3). ${ }^{48}$ Energy intake in Kcal after tastants and control were pooled using the data provided by included studies. Sensitivity analyses were performed when same studies employed different doses of tastants in order for those subjects to not influence the results to a greater extent than subjects form other studies. The $I^{2}$ was used to quantitively measure statistical heterogeneity between studies ( $\mathrm{p}$-value $<0.05)$.

\section{Data reporting}

Paper inclusion, exclusion, and reasons for exclusion are presented in a diagram (Figure 2.1) according to the PRISMA statement for reporting a systematic review and meta-analysis. 


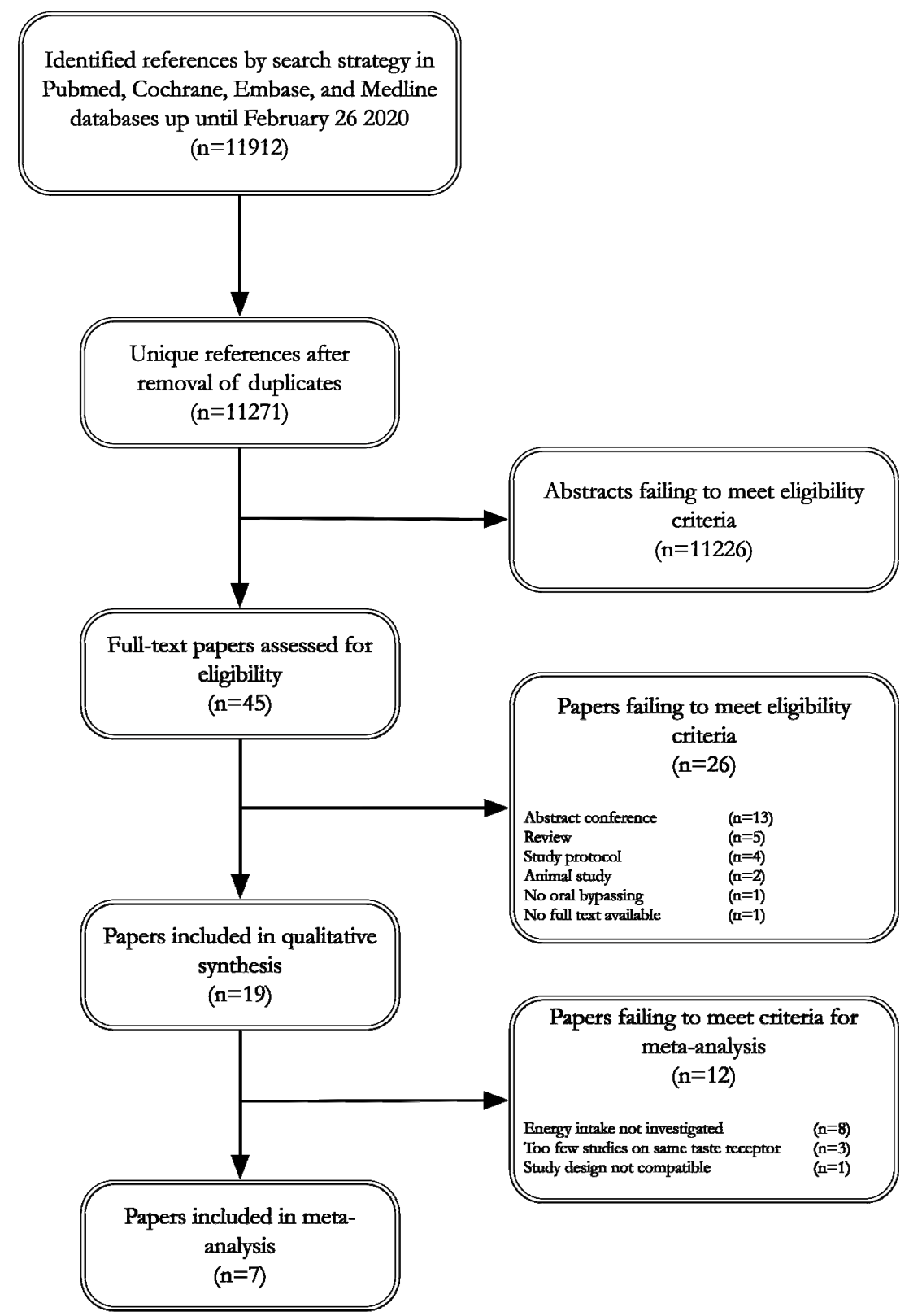

Figure 2.1 Flow chart of the selection process; from identification of possible eligible papers to papers included in this review and meta-analysis. 


\section{Results}

\section{Systematic approach to paper selection}

After removal of duplicates, a total of 11271 abstracts were assessed, and 45 full texts were screened for eligibility (Figure 2.1). A total of 19 papers, describing 25 studies met the inclusion criteria. Twenty-six papers were excluded for various reasons: abstract for a conference (13), review (5), study protocol (4), animal study (2), no adequate bypassing of oral taste receptors (1), no full text available (1). The flow-chart for screening and inclusion of papers is depicted in Figure 2.1.

Supplementary Table S2.1 provides an overview of the results of the included papers.

\section{Quality assessment}

The results of the quality assessment are summarised in Figure 2.2. Overall, papers scored decently on the risk of bias assessment. Bias arising from the randomisation process was determined to raise some concerns by the majority of papers due to lacking information on the method of randomisation. Most papers described randomisation of subjects but provided no information on the method of randomisation.

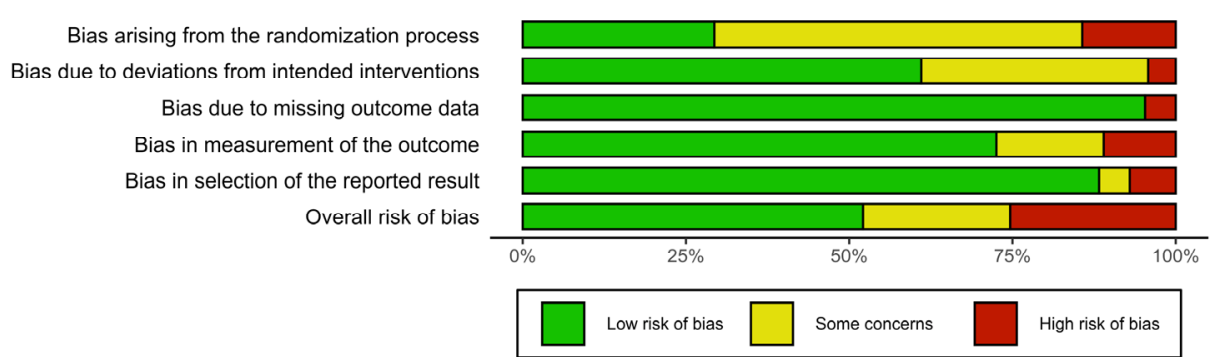

Figure 2.2 Risk of bias summary. Author's judgements broken down for the domains according to the revised tool to assess risk of bias in randomised trials (RoB 2) 
Study characteristics

\section{Study population}

The characteristics of the 25 studies described in 19 papers are summarised in Supplementary Table S2.1. All studies included healthy volunteers. ${ }^{27-45}$ Most studies included volunteers with a normal BMI between 18 and $25 \mathrm{~kg} / \mathrm{m}^{2} \cdot 27-38,40-$ 42,44,45 One study described inclusion of both subjects with a BMI between 18 and $25 \mathrm{~kg} / \mathrm{m}^{2}$ and subjects with a BMI greater than $30 \mathrm{~kg} / \mathrm{m}^{2}{ }^{2}{ }^{43}$ One study described inclusion of subjects with a BMI between 23 and $32 \mathrm{~kg} / \mathrm{m}^{2} .^{39}$ Eleven studies described inclusion of both women and men, $27,28,34-38,40-43$ four studies described inclusion of men only, ${ }^{29,30,44,45}$ and four studies described inclusion of women only. $31-33,39$

\section{Tastants used}

Table 2.2 provides an overview of the tastants used by included studies and the ligand receptors that are activated per tastant.

\section{Sweet tastants}

Nine studies (reported on in eight papers) investigated post-oral delivery of sweet tastants. Aspartame alone was used in three studies (two papers), ${ }^{40,44}$ one study used aspartame and saccharin, ${ }^{35}$ one study used aspartame, Acesulfame potassium (Ace-K), and sucralose, ${ }^{41}$ one study used sucralose, ${ }^{36}$ one study used Rebaudioside A (Reb-A), ${ }^{42}$ one study used xylitol and erythritol, ${ }^{43}$ and one study used only AceK. ${ }^{38}$ It should be noted that Reb-A, Ace-K, Saccharin, and sucralose are known to activate bitter taste receptors aside from sweet taste receptors. TAS2R4 and 14 are activated by Reb-A, TAS2R 43 and 44 are activated by Ace-K, TAS2R 43 and 44 are activated by saccharin, and TAS2R1, 4, 5, 7, 8, 10, 39, 41, 46 are activated by sucralose..$^{49}$ However, given their predominant sweet taste ${ }^{50-52}$ and their main role as non-nutritive sweeteners, for this paper, they were described as sweet tastants.

\section{Bitter tastants}

Sixteen studies (12 papers) investigated post-oral taste delivery of bitter tastants. Six of these studies used quinine alone, ${ }^{27,29-31,33,29,42}$ five studies (two papers) used denatonium benzoate (DB) alone, ${ }^{28,32}$ one study investigated quinine and naringin, ${ }^{35}$ one study used a bitter mixture consisting of raisin flavour, sucrose octa acetate, and quassia extract, ${ }^{39}$ one study used bitter secoiridoids, ${ }^{37}$ and one study used bitter New Zealand hop extracts. ${ }^{45}$ Different bitter compounds activate 
different (combinations of) TAS2 receptor subtypes in humans. ${ }^{49,53}$ However, most extensively investigated are quinine and denatonium benzoate, which both activate four of the same TAS2 receptor subtypes, among other subtypes. DB activates eight TAS2 receptor subtypes in humans (TAS2R 4, 8, 10, 13, 39, 43, 46, and 47), whereas quinine activates nine subtypes of TAS2 receptor in humans (TAS2R 4, 7, 10, 14, 39, 40, 43, 44, and 46).49,53

Table 2.2 Ligand receptors of the tastants described in the included studies. Ligand receptors for TAS2Rs adapted from BitterDB.49

\begin{tabular}{ll}
\hline Tastant & Ligand receptors \\
\hline Aspartame & TAS1R2/TAS1R3 heterodimer \\
Saccharin & TAS1R2/TAS1R3 heterodimer, TAS2R43, TAS2R44 \\
Sucralose & TAS1R2/TAS1R3 heterodimer, TAS2R1, TAS2R4, \\
& TAS2R5, TAS2R7, TAS2R8, TAS2R10, TAS2R39, \\
& TAS2R41, TAS2R41, TAS2R46 \\
Ace-K & TAS1R2/TAS1R3 heterodimer, TAS2R43, TAS2R44 \\
Reb-A & TAS1R2/TAS1R3 heterodimer, TAS2R4, TAS2R14 \\
Xylitol & TAS1R2/TAS1R3 heterodimer \\
Erythritol & TAS1R2/TAS1R3 heterodimer \\
Naringin & N/A \\
Quinine & TAS2R4, TAS2R7, TAS2R10, TAS2R14, TAS2R39, \\
QHCl & TAS2R40, TAS2R43, TAS2R44, TAS2R46 \\
& TAS2R4, TAS2R7, TAS2R10, TAS2R14, TAS2R39, \\
DB & TAS2R40, TAS2R43, TAS2R44, TAS2R46 \\
& TAS2R4, TAS2R8, TAS2R10, TAS2R13, TAS2R39, \\
Bitter secoiridoids (Gentiana lutea extract, contains & TAS2R43, TAS2R46, TAS2R47 \\
amarogentin) & TAS2R1, TAS2R4, TAS2R39, TAS2R43, TAS2R46, \\
Raisin flavour & TAS2R47, TAS2R50 \\
Sucrose Octa Acetate & N/A \\
Quassia extract & TAS2R46 \\
MSG & TAS2R4, TAS2R10, TAS2R14, TAS2R46, TAS2R47 \\
\hline
\end{tabular}

TAS1R: taste receptor 1, TAS2R: taste receptor 2Ace-K: acesulfame potassium, Reb-A: rebaudioside A, N/A: no data available, QHCL: quinine hydrochloride, DB: denatonium benzoate, MSG: monosodium glutamate.

\section{Umami tastants}

Only one study investigated post-oral delivery of an umami tastant. Monosodium glutamate was used in this study. ${ }^{42}$ 


\section{Combination of tastants}

Two studies investigated post-oral delivery of a combination of tastants (sweet, bitter, and umami). Both of these studies used quinine, Reb-A, and monosodium glutamate. ${ }^{34,42}$

\section{Comparators}

Most studies describe the use of a placebo. For studies using nasogastric, nasoduodenal or naso-duodenal-ileal delivery of tastants either tap water, ${ }^{32,34,35,38,41-43}$ saline, ${ }^{28-30,36}$ or milli-Q water ${ }^{31,33}$ was used as a comparator. Most studies that used capsules to deliver the tastants used placebo capsules as a comparator. ${ }^{27,39,40,45}$ One study used a capsule to deliver tastants and used water without a capsule as comparator. ${ }^{44}$ One study added microencapsulated bitter taste to a pudding and used only the coating as a comparator. ${ }^{37}$

\section{Energy intake}

An overview of the studies describing effects of post-oral delivery of non-caloric tastants on energy intake is provided in Table 2.3.

\section{Sweet tastants}

Four studies (three papers) reported the effect of sweet tastants on energy intake. 40,42 Two studies (one paper) showed a significant decrease of 138, 150, and $175 \mathrm{Kcal}(\mathrm{p}<0.05, \mathrm{p}<0.01$, and $\mathrm{p}<0.02$, respectively) of an ad libitum buffet meal after intragastric delivery of aspartame in various concentrations compared with placebo. ${ }^{40}$ However, another study showed no effect on energy intake or macronutrient preferences during an ad libitum buffet meal after intragastric delivery of aspartame. ${ }^{44}$ In line with this, one study failed to demonstrate a difference between Reb-A and placebo on ad libitum food intake intraduodenal delivery. ${ }^{42}$

The data reported in two papers were not described in sufficient detail to use for pooling. ${ }^{40,44}$ Authors of these papers were contacted. Both authors responded and declared that raw data were not available anymore, since the studies were performed over 30 years ago. Therefore, these studies could not be pooled. 


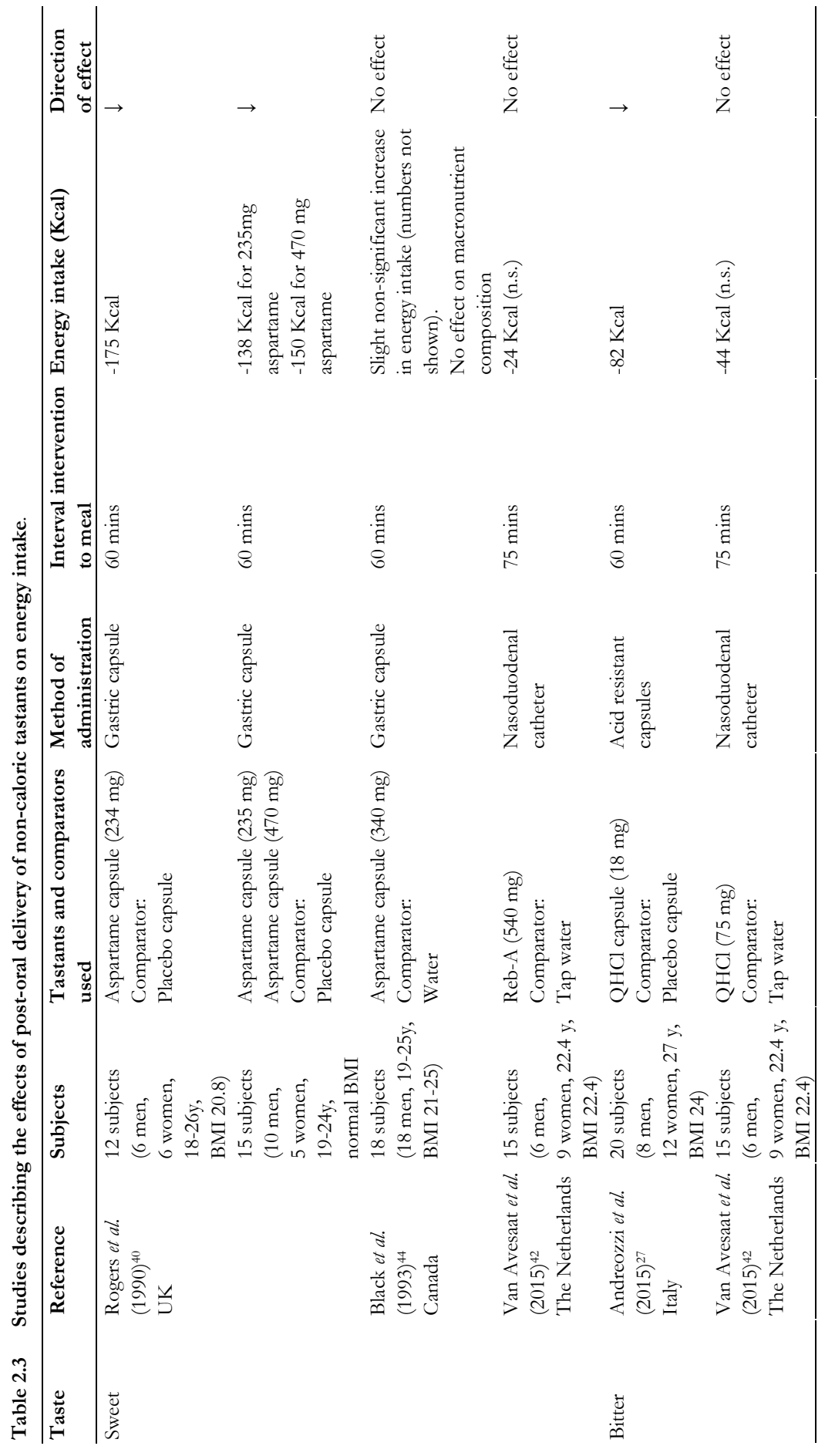


Effects of gastrointestinal delivery of non-caloric tastants on energy intake

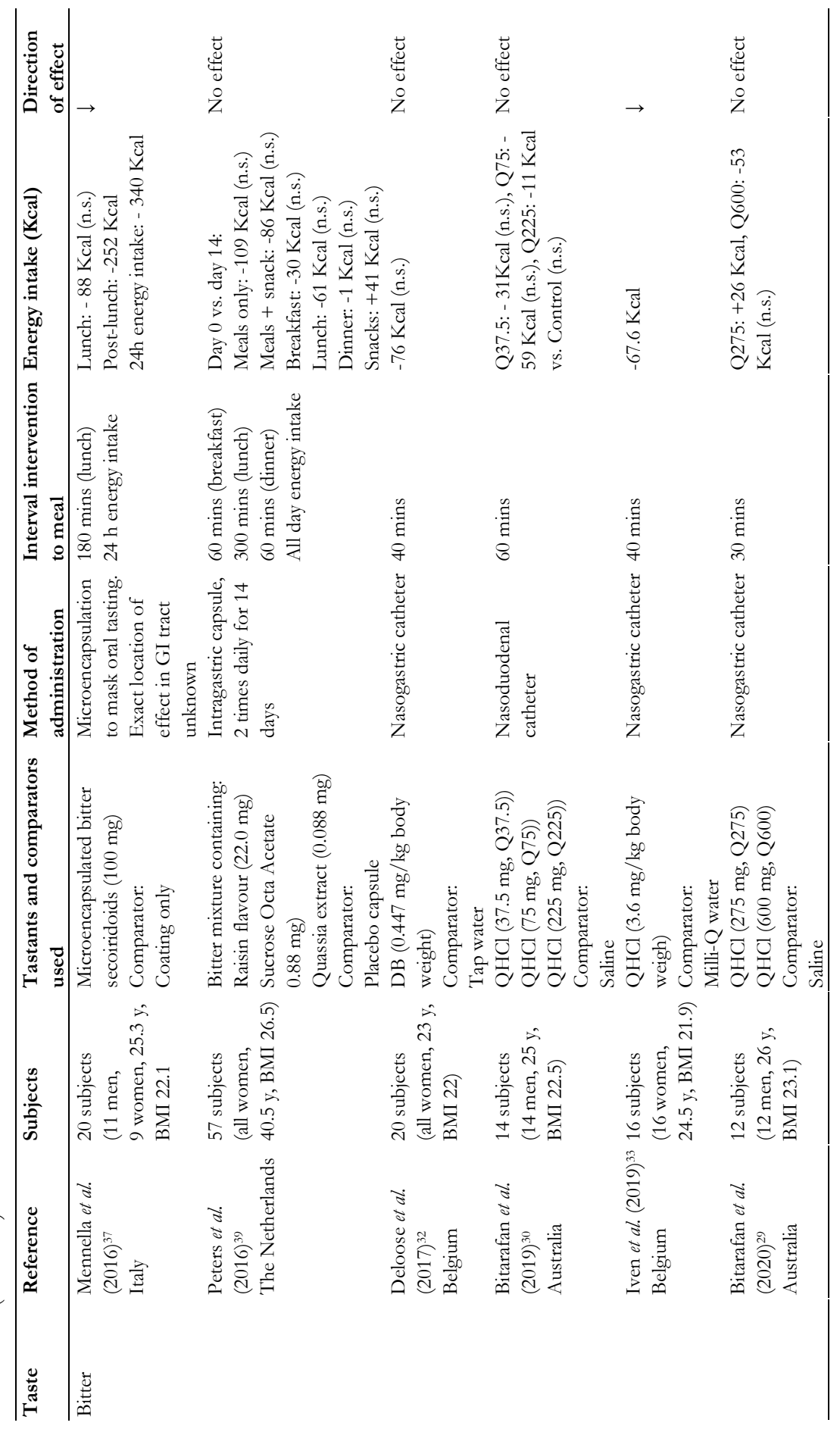




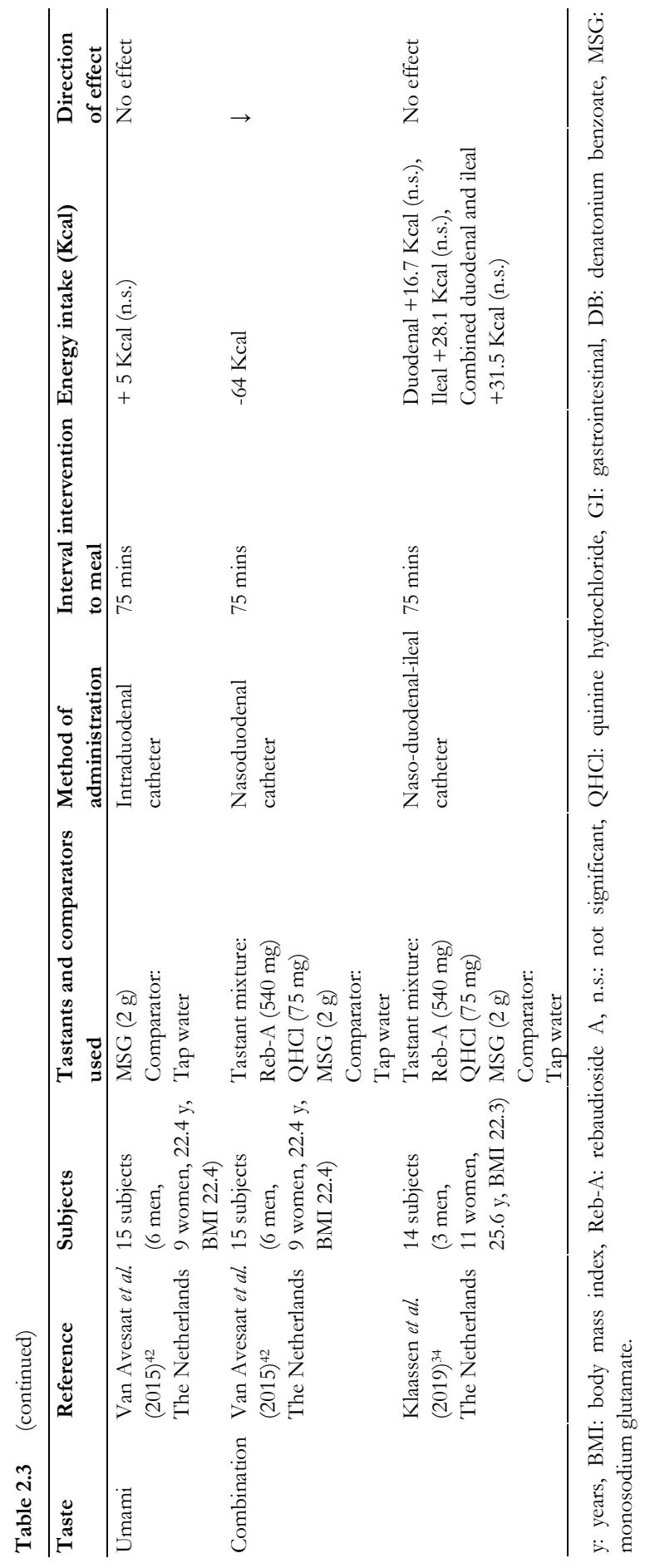




\section{Bitter tastants}

Eight studies showed the effect of post-oral delivery of bitter tastants on energy intake. Three of these described a decrease in energy intake after intragastric, ${ }^{33}$ intraduodenal, ${ }^{27}$ or post-oral delivery of bitter tastants. ${ }^{37}$ On the other hand, five studies showed no effect on energy intake after gastrointestinal delivery of bitter tastants. However, most of these studies described a modest decrease in energy intake that did not reach statistical significance. ${ }^{29,30,32,39,42}$

Iven et al. showed a decrease of $67.7 \mathrm{Kcal}$ of hedonic eating after intragastric infusion of quinine compared with control. ${ }^{33}$ Andreozzi et al. showed a decrease of $82 \mathrm{Kcal}$ after an acid resistant capsule containing quinine compared with a placebo capsule. ${ }^{27}$ Mennella et al. showed no significant decrease in lunch intake (-88 Kcal) after microencapsulated bitter secoiridoids compared with control, but a significant decrease of post-lunch energy intake $(-252 \mathrm{Kcal})$ and $24 \mathrm{~h}$ energy intake $(-340 \mathrm{Kcal}) \cdot{ }^{37}$

Van Avesaat et al. showed a non-significant decrease of $44 \mathrm{Kcal}$ after intraduodenal infusion of quinine compared with control. ${ }^{42}$ Peters et al. investigated energy intake after a two week, two times daily consumed capsule containing a bitter mixture compared with control. ${ }^{39}$ They showed a nonsignificant decrease of daily meal intake $(-109 \mathrm{Kcal})$, daily meal intake including snacks (-86 Kcal), breakfast $(-30 \mathrm{Kcal})$, lunch $(-61 \mathrm{Kcal})$, and dinner $(-1 \mathrm{Kcal})$. A non-significant increase of $41 \mathrm{Kcal}$ on snacks only was found. ${ }^{39}$ Deloose et al. showed that intragastric infusion of DB resulted in a non-significant decrease of $76 \mathrm{Kcal}$ compared with control. ${ }^{32}$ In one study, Bitarafan et al. showed a nonsignificant decrease in food intake following various doses of intraduodenally administered quinine compared with control (-31 Kcal for $37.5 \mathrm{mg}$, $-59 \mathrm{Kcal}$ for $75 \mathrm{mg}$, and $-11 \mathrm{Kcal}$ for $225 \mathrm{mg}$ ). ${ }^{30}$ In another study, Bitarafan et al. showed a non-significant increase in energy intake of $26 \mathrm{Kcal}$ after intragastric administration $275 \mathrm{mg}$ of quinine, whereas intragastric administration of $600 \mathrm{mg}$ quinine showed a non-significant decrease of $53 \mathrm{Kcal.}{ }^{29}$

Seven studies investigating the effect of gastrointestinal delivery of bitter tastants on energy intake could be pooled $27,29,30,32,33,37,42$ and are depicted in Figure 2.3. One study looked at total energy intake during the day as well as energy intake during the lunch. ${ }^{37}$ Pooled effects were calculated with the outcome of lunch intake for this study in order to minimise clinical heterogeneity. One study investigating the effect of intragastric bitter tastant delivery on energy intake could not be pooled, because the design employed in that study differed too much from the other 
designs. ${ }^{39}$ Two studies employed various doses of $\mathrm{QHCl}$ in the same population. ${ }^{29,30}$ In order for those subjects to not influence the results to a greater extent than subjects form other studies, the meta-analysis was performed for all the combinations of doses. The lowest dose for both studies is depicted in Figure 2.3. Pooled effects show a significant reduction in caloric intake of $54.62 \mathrm{Kcal}$ (95\% CI: $-78.54-30.69, \mathrm{p}=0.0014)$. A sensitivity analysis was performed for all the combinations of doses employed by Bitarafan et al. and results are depicted in Supplementary Figure S2.1. Decrease in caloric intake varies between 53 and 58 Kcal for the different combinations, all statistically significant. ${ }^{29,30}$ 

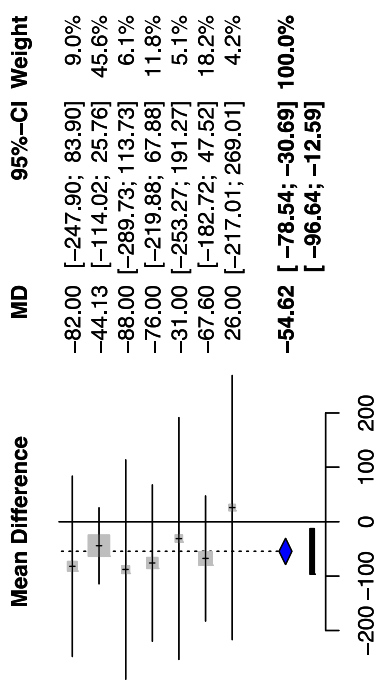

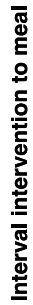
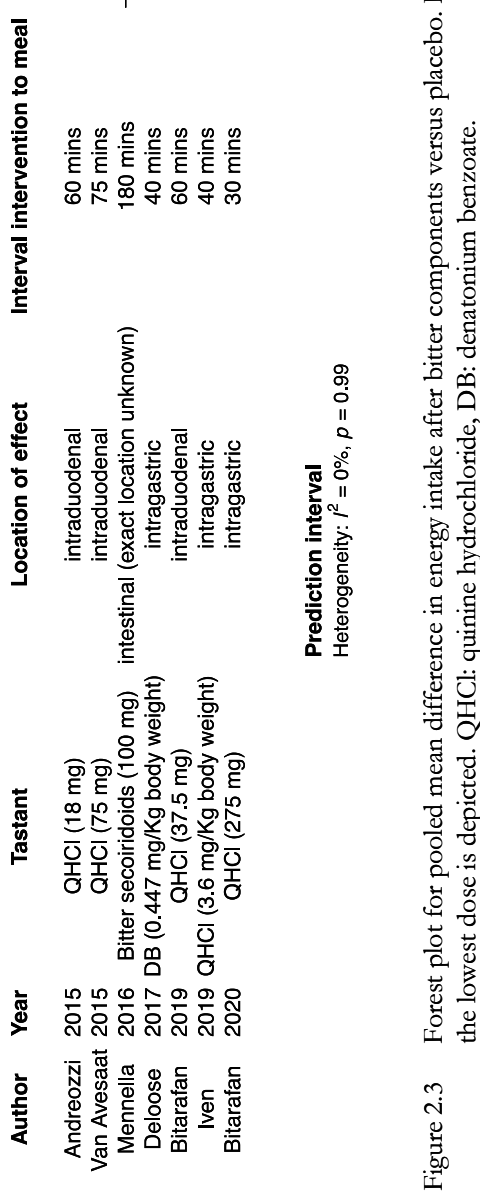


\section{Umami tastants}

Van Avesaat et al. showed no effect on energy intake after intraduodenal delivery of monosodium glutamate compared with placebo. ${ }^{42}$

\section{Combination of tastants}

Van Avesaat et al. showed a significant decrease of energy intake of $64 \mathrm{Kcal}$ after intraduodenal delivery of a combination of quinine, Reb-A and monosodium glutamate. A study conducted by the same research group showed no effects on energy intake after intraduodenal and/or intraileal delivery of the same tastant mixture. ${ }^{42}$ These studies were not pooled, due to high clinical heterogeneity. ${ }^{34}$

\section{GI symptoms and perceptions}

An overview of the studies describing effects of post-oral delivery of non-caloric tastants on GI symptoms and perceptions is provided in Table 2.4.

\section{Sweet tastants}

Seven studies investigated the effects of gastrointestinal delivery of sweet tastants on appetite sensations. Five of these studies showed no effects on appetite sensations. ${ }^{35,41-44}$ One study showed that intragastric delivery of aspartame reduced desire to eat without influencing fullness. ${ }^{40}$ Another study demonstrated a strong initial decrease in hunger and increase in satiety, with faster returns to baseline after intragastric delivery of Ace-K compared with control. ${ }^{38}$

Three studies examined the effects of post-oral administration of sweet tastants on GI symptoms and other adverse events. ${ }^{38,42,43}$ Wölnerhanssen et al. showed that intragastric administration of xylitol and erythritol leads to bloating and diarrhoea in $70 \%$ and $60 \%$ of subjects respectively. ${ }^{43}$ Other studies reported no GI symptoms or adverse events. ${ }^{38,42}$

\section{Bitter tastants}

Five studies (four papers) showed that post-oral delivery of bitter tastants resulted in a decrease of hunger and prospective food consumption and an increase of satiation/satiety and fullness. ${ }^{28,32,33,45}$ However, six studies showed no effects on appetite sensations after post-oral delivery of bitter tastants. ${ }^{27,29,30,35,37,42}$ 


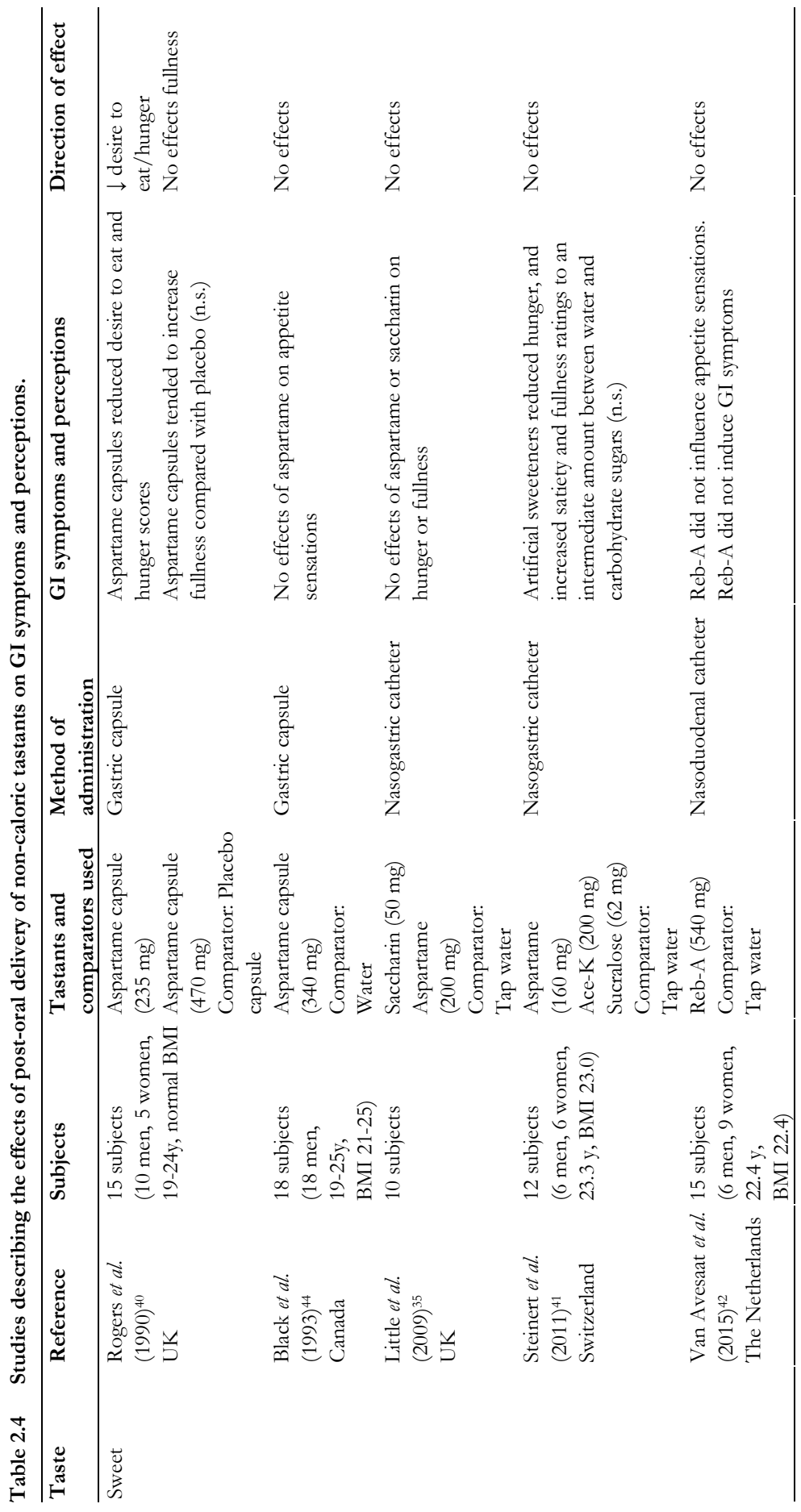




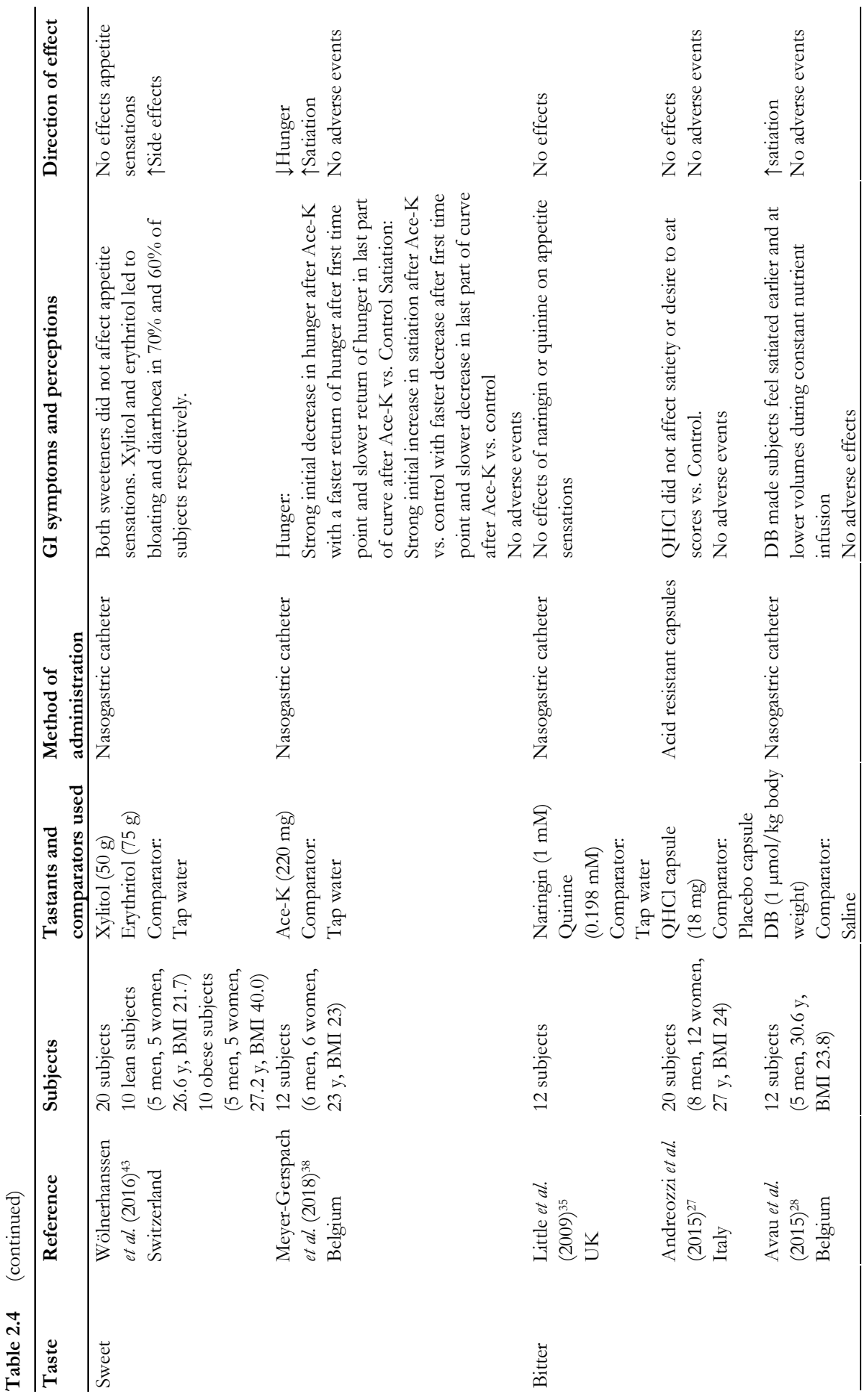

40 


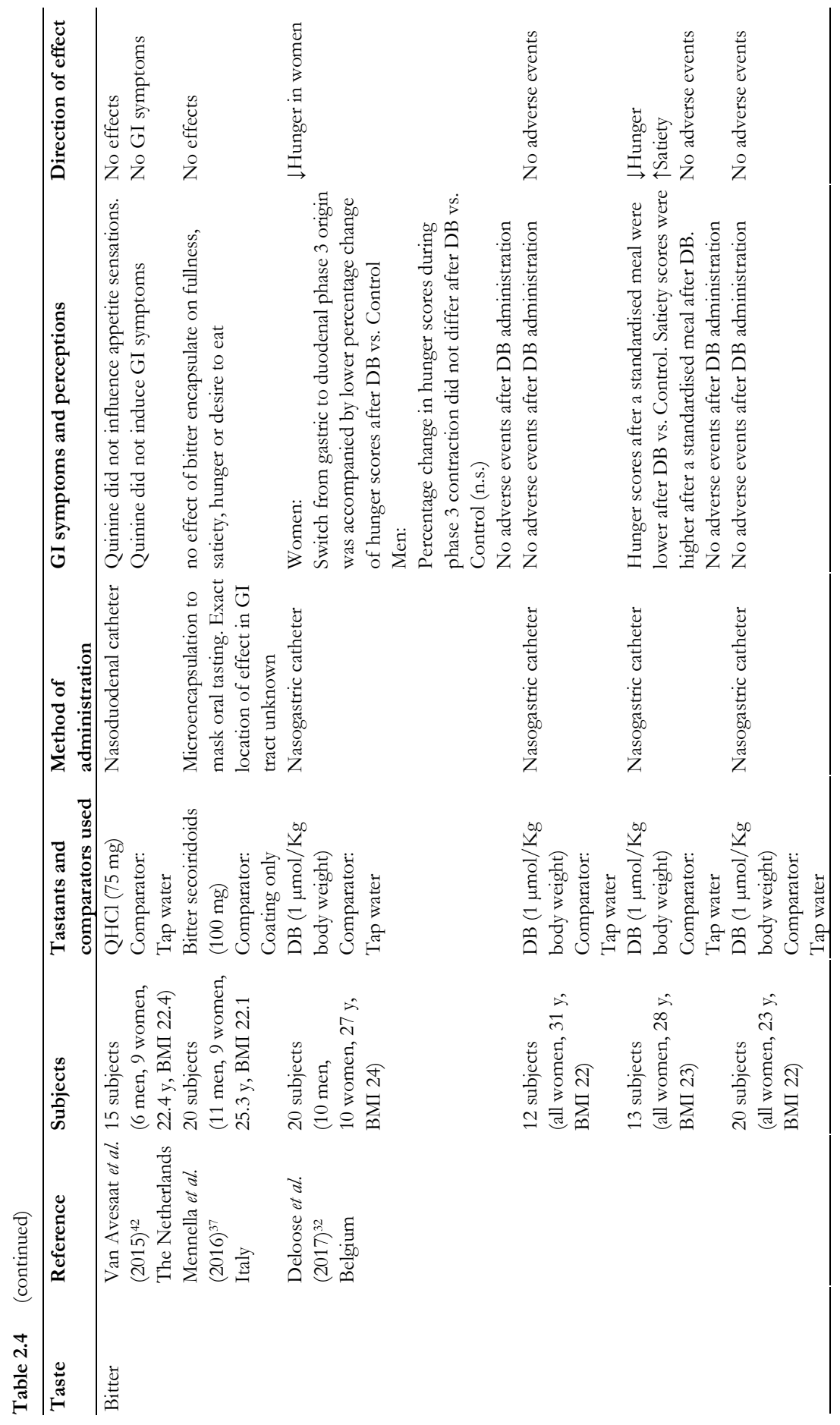




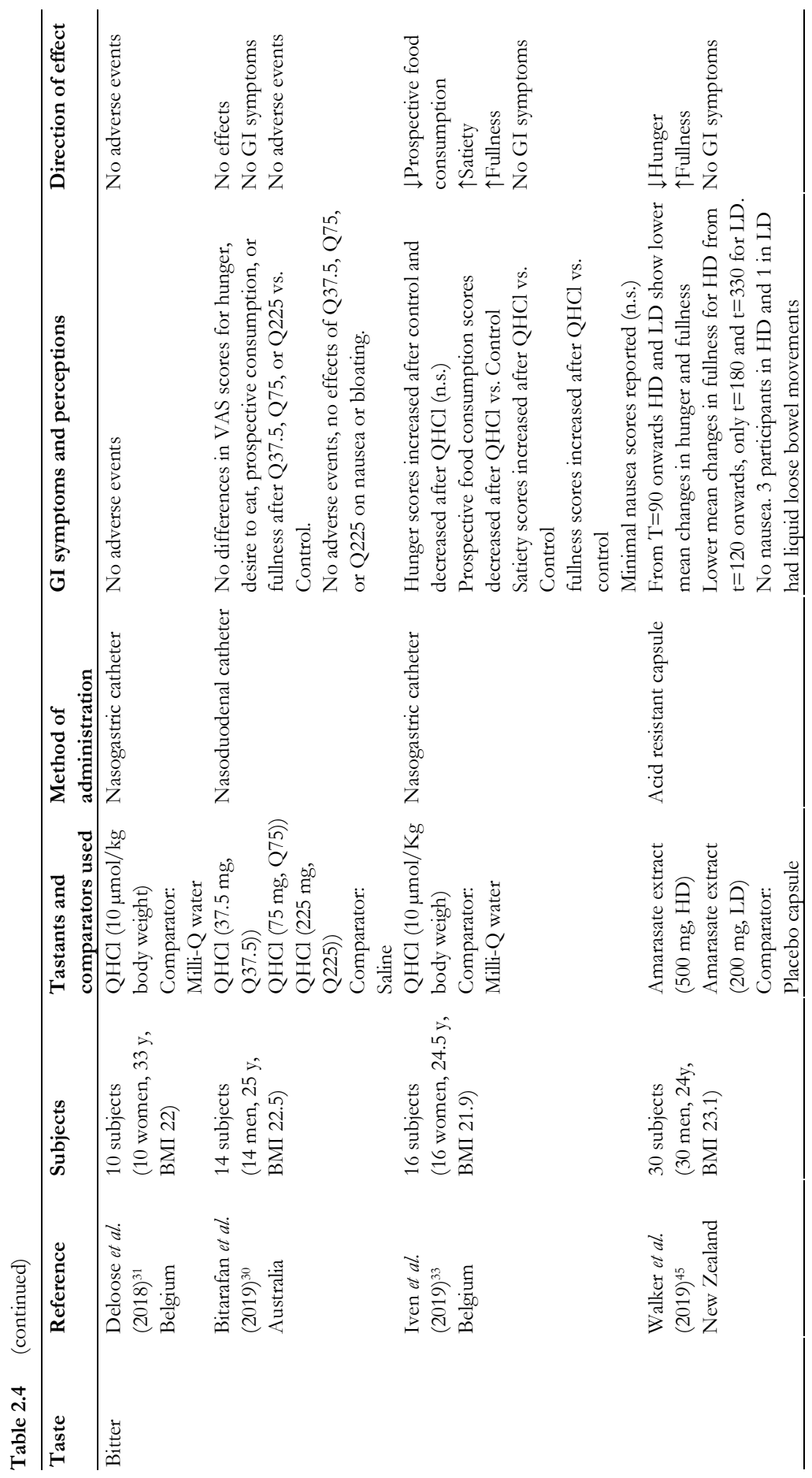


Effects of gastrointestinal delivery of non-caloric tastants on energy intake

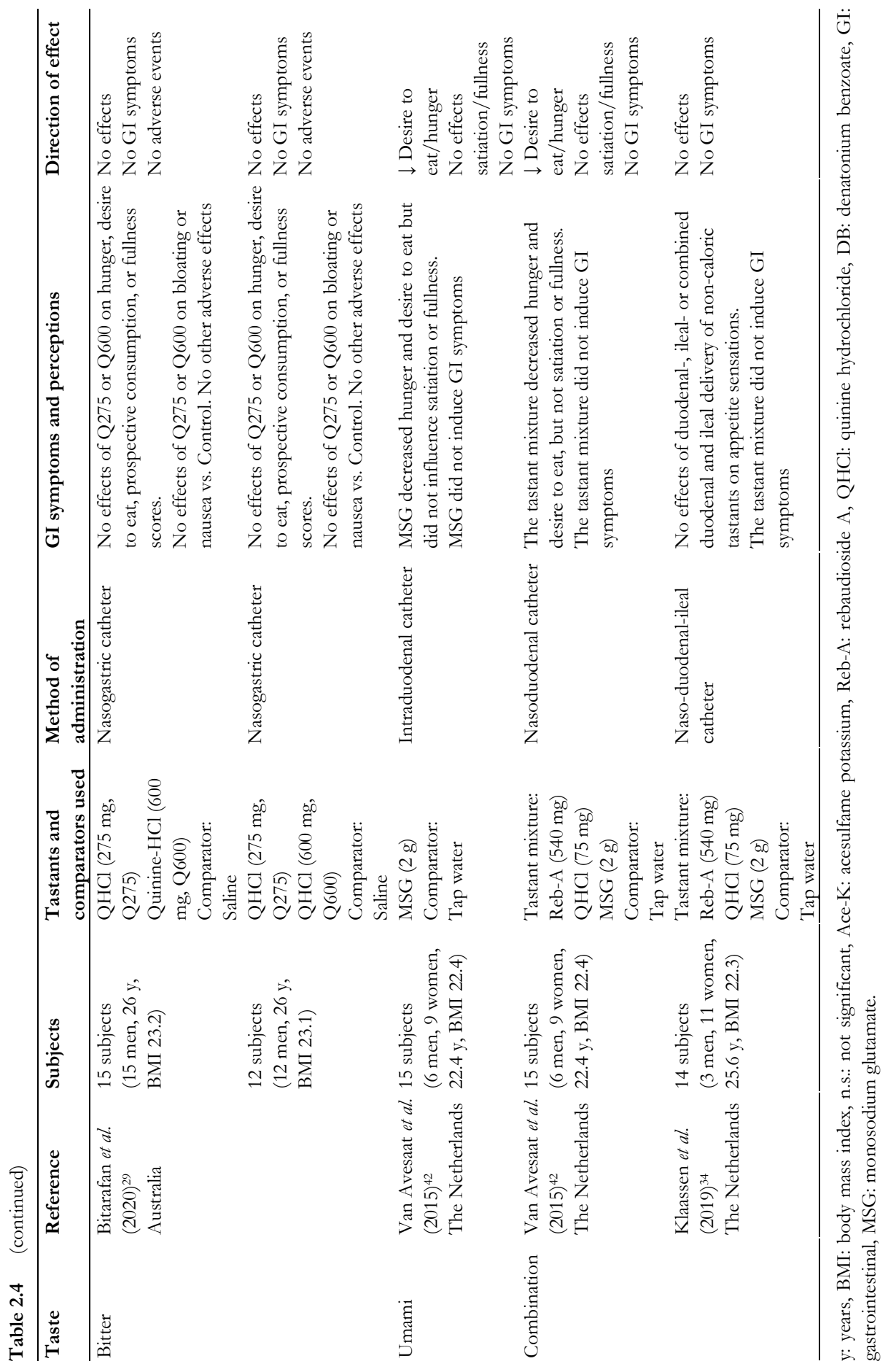


Seven studies examined the effects of post-oral delivery of bitter tastants on GI symptoms and/or adverse events. None of these reported side effects or adverse events. $27,29-33,42$

\section{Umami tastants}

One study described that post-oral delivery of umami decreased desire to eat and hunger, without influencing satiation, fullness or GI symptoms. ${ }^{42}$

\section{Combination of tastants}

Two studies described the effects of post-oral delivery of a combination of sweet, bitter and umami tastants on appetite sensations. One study described a decrease of desire to eat and hunger, whereas satiation and fullness were not attenuated. ${ }^{42}$ The other study showed no effects on appetite sensations. ${ }^{34}$

No GI symptoms or adverse events after post-oral delivery of this combination of sweet, bitter, and umami tastants were reported. ${ }^{34,42}$

\section{Mechanisms of effect}

An overview of the studies describing effects of post-oral delivery of non-caloric tastants on the mechanisms of effect involved in regulating eating behaviour is provided in Table 2.5. Mechanisms of interest were GI peptide release, GI motility, and brain signalling.

\section{Sweet tastants}

One study described a drop in intragastric pressure after intragastric administration of Ace-K. ${ }^{38}$ Intragastric administration of xylitol and erythritol also resulted in slower gastric emptying. ${ }^{43}$ However, another study showed no changes in gastric emptying after intragastric administration of saccharin or aspartame. ${ }^{35}$ Five studies investigated the effects of post-oral delivery of sweet tastants on GI peptides. ${ }^{36,38,41-43}$ Four of these showed no effects on GI peptide plasma levels. ${ }^{36,38,41,42}$ One study described that intragastric administration of xylitol and erythritol increases plasma CCK, GLP-1, and glucose. ${ }^{43}$ 
Effects of gastrointestinal delivery of non-caloric tastants on energy intake

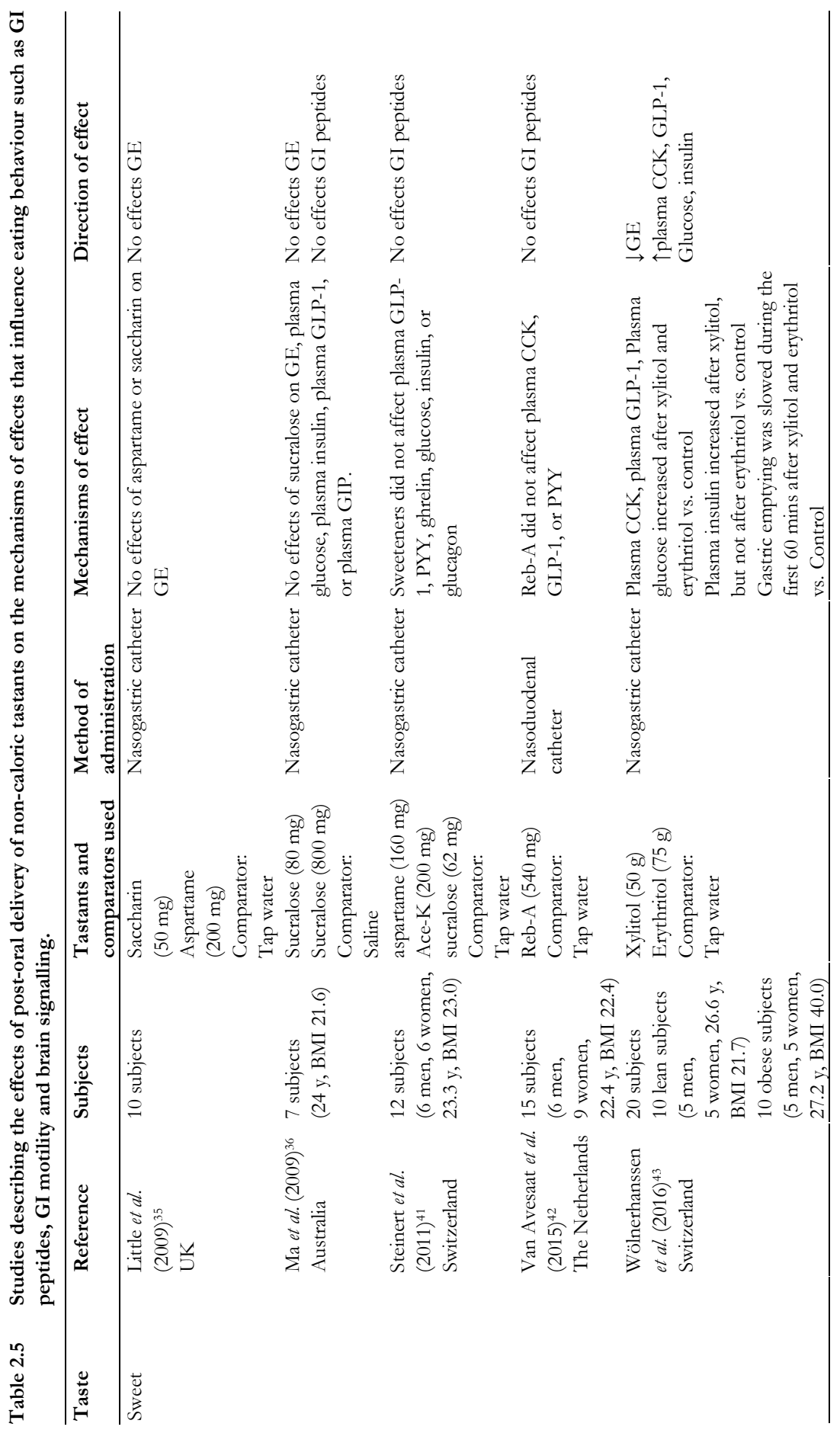




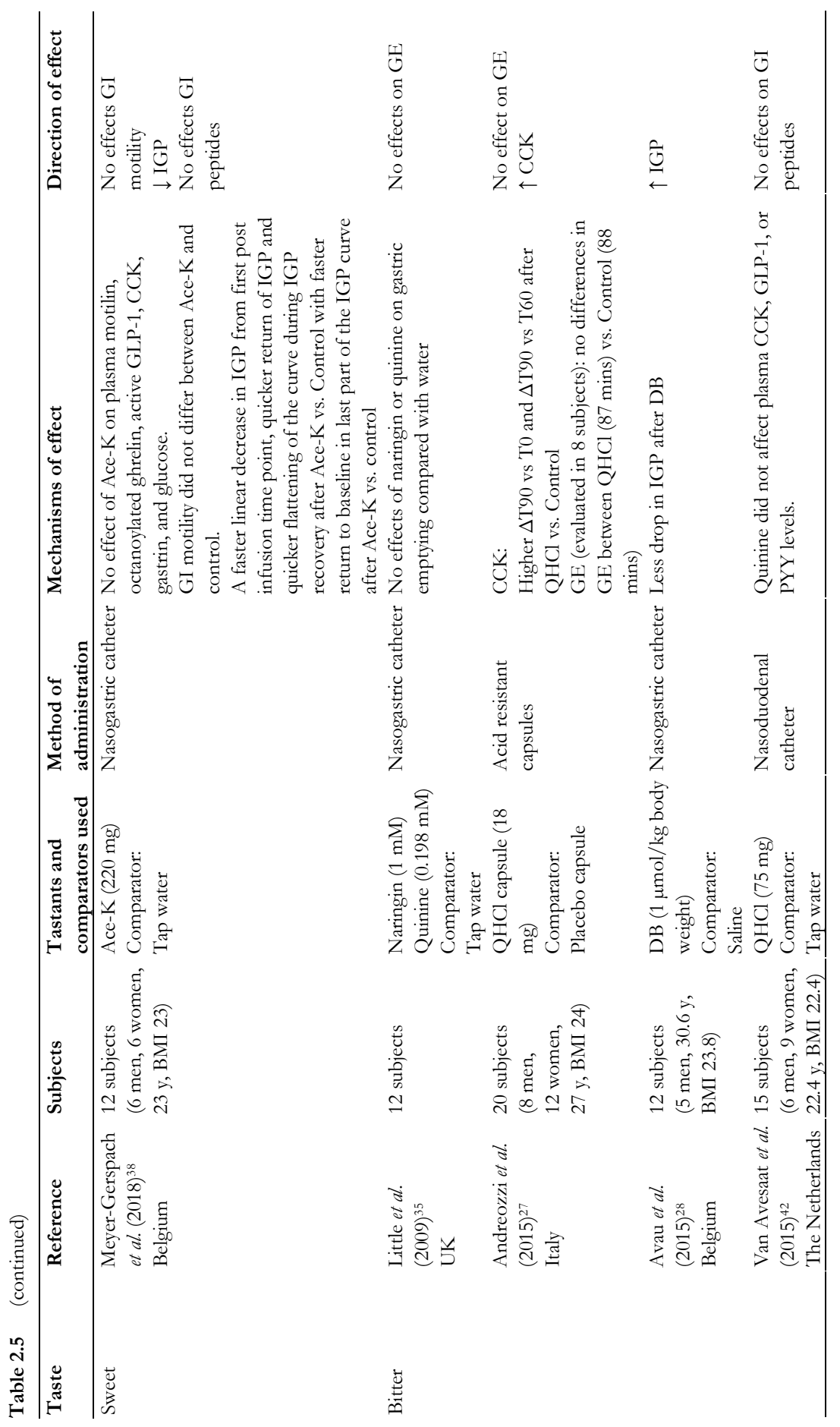




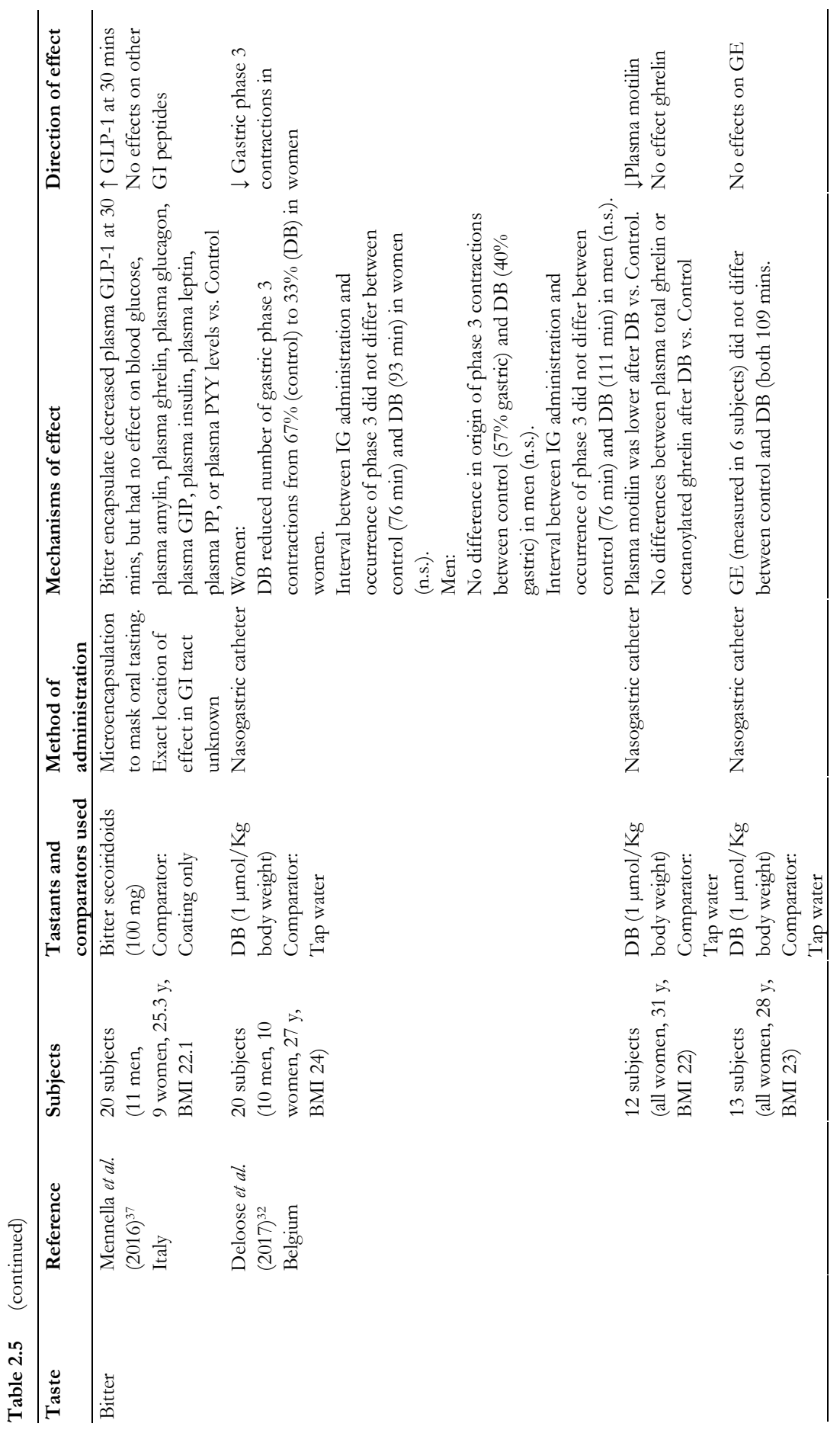




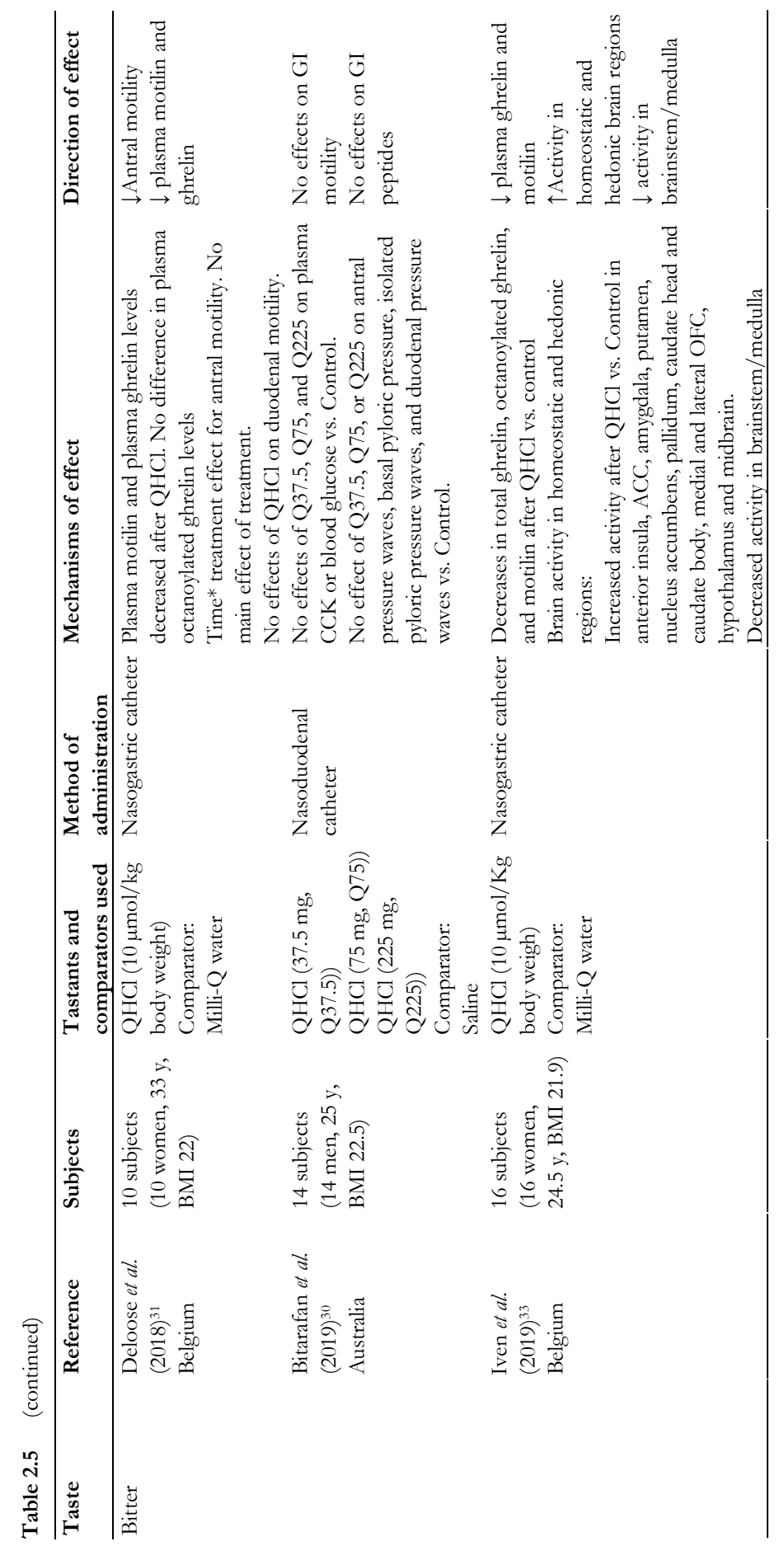




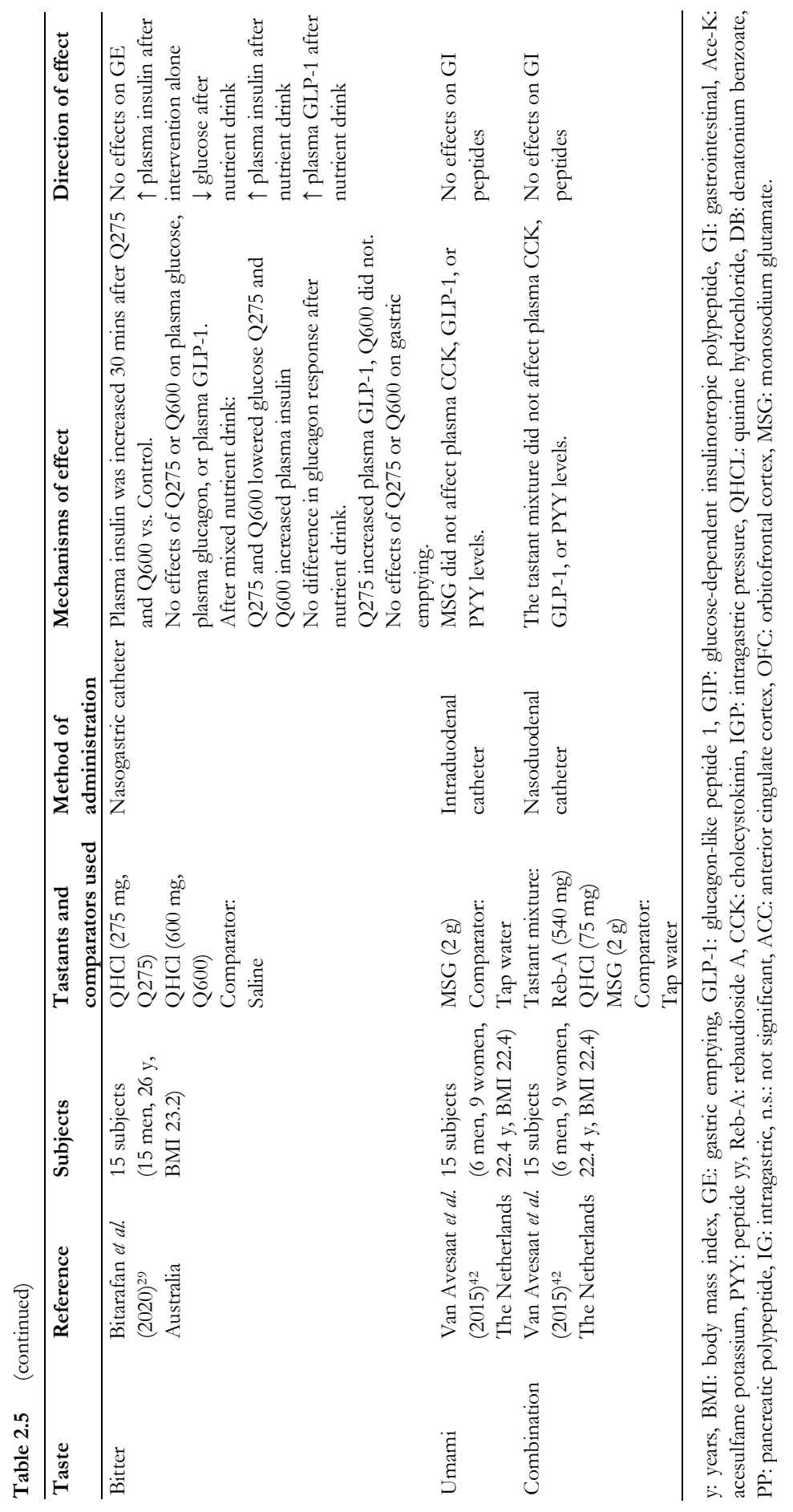




\section{Bitter tastants}

Eight studies (seven papers) investigated the effects of post-oral delivery of bitter tastants on GI motility. ${ }^{27-32,35}$ Two of these showed a decrease in gastric phase 3 contractions after intragastric delivery of bitter tastants. ${ }^{31,32}$ One study described a relative increase in intragastric pressure after DB compared with placebo. ${ }^{28}$ Four studies showed no effect of post-oral delivery of bitter tastants on gastric emptying. ${ }^{27,29,32,35}$ Another study showed no effect of intraduodenal delivery of quinine on antral, pyloric or duodenal pressure waves. ${ }^{30}$

One study showed that intragastric delivery of quinine resulted in increased brain activity in homeostatic and hedonic brain regions. ${ }^{33}$

Eight studies examined the effects of post-oral delivery of bitter tastants on GI peptides. ${ }^{27,29-33,37,42}$ Two studies showed that post-oral delivery of bitter tastants did not result in changes in GI peptides. ${ }^{30,42}$ One study showed an initial effect of quinine on plasma insulin, but not on plasma glucose, glucagon or GLP-1. However, a decrease of glucose and an increase of insulin was found after a standardised nutrient drink following quinine administration. ${ }^{29}$ Another study showed a decrease in GLP-1 30 mins after intervention, but no effects on other GI peptides, nor an overall intervention effect on plasma GLP-1 levels. ${ }^{37}$ Three studies showed a decrease in motilin and/or ghrelin after intragastric delivery of bitter tastants. ${ }^{31-33}$ Only one study showed an increase of CCK after intraduodenal delivery of quinine. ${ }^{27}$

\section{Umami tastants}

One study investigated the mechanisms of effect of post-oral delivery of monosodium glutamate, showing no changes in GI peptides (CCK, GLP-1, and PYY) after intraduodenal administration of MSG. ${ }^{42}$

\section{Combination of tastants}

Only one study investigated the effect of post-oral delivery of a combination of tastants. No effect of intraduodenal administration of a combination of sweet, bitter and umami tastant mixture on plasma CCK, GLP-1, or PYY was found. ${ }^{42}$

\section{Discussion}

In this systematic review and meta-analysis, the currently available data on the effects post-oral delivery of non-caloric tastants has been evaluated. This review 
shows that the effects of post-oral delivery of non-caloric tastants on eating behaviour are inconclusive and inconsistent thus far.

Tastants: sweet, biter and umami

Most studies described the effects of post-oral delivery of sweet $35,36,38,40-44$ or bitter $^{27-33,35,37,39,42,45}$ stimuli. Only one study used an umami stimulus ${ }^{42}$ and two studies described the effects of a tastant mixture..$^{34,42}$ It has been hypothesised that taste can predict the type of food that is being ingested (i.e., bitter for potential toxic substances, umami for glutamate and sweet for saccharides), ${ }^{8}$ although this theory is probably an oversimplification and does not sufficiently reflect the complexity of the underlying biological responses. According to traditional beliefs, carbohydrates are considered as fuel for the human body, ${ }^{54}$ whereas one wants to avoid toxic substances. ${ }^{55}$ Therefore, it is conceivable that most researchers hitherto have generally focused on sweet and bitter substances. However, umami taste is a predictor of amino acids. Up to now, little is known about solely postoral effects of umami taste, although it has been widely accepted as a basic taste since the discovery of umami taste receptors in 2002.56,57 However, more data are available on oral delivery of umami stimuli. Oral delivery of umami stimuli has been shown to elicit a GLP-1 response. ${ }^{58,59}$ Moreover, adding MSG to a novel flavour is able to condition liking for that flavour. ${ }^{60}$ Furthermore, Dermiki et al. showed that adding MSG to novel flavoured soups resulted in increased food intake in elderly subjects without eliciting increased liking. ${ }^{61}$ Given the effects of oral MSG on food liking, food intake, and GI peptides, the effect of post-oral delivery of umami tastants should be further elucidated.

\section{Energy intake}

This review and meta-analysis clearly shows that the most potent stimuli to influence eating behaviour and reduce food intake are the bitter substances. The obvious explanation for this is the innate aversion for bitter taste. ${ }^{62}$ That is, delivery of solely bitter tastants, in the absence of other flavours, would result in a warning signal with the intention to stop the intake of that particular substance. However, it should be noted that several studies show that this negative affective response to bitter can be decoupled by, for instance, the positive response to caffeine. ${ }^{9,10}$ This process is called flavour-consequence learning. ${ }^{63}$ Moreover, Higgins et al. showed an increase in pale ale intake in individuals with increased bitter perception. ${ }^{64}$ This indicates that, over the years, humans have learned to 
appreciate bitter tastes, mainly when combined with other flavours (i.e., liking for black coffee and beers).

The question, however, arises whether any such mechanism would also hold true for post-oral taste receptor stimulation.

Data on post-oral delivery of sweet tastants are limited to three studies showing contradictory results. ${ }^{40,42,44}$ Interestingly, more data are available on the effect of oral consumption of non-caloric sweeteners on energy intake. A review and metaanalysis by Rogers et al. that also included studies using oral stimulation showed a reduction of energy intake after consumption of low caloric sweeteners when compared with sugar consumption, but not when compared to consumption of water in a short-term setting. ${ }^{65}$ Since there is a preference for sweet foods and beverages in humans, further research to investigate the effects of post-oral delivery of sweet tastants on energy intake is warranted.

Eight studies described effects on energy intake after post-oral delivery of bitter tastants. These studies show a modest decrease in energy intake following postoral delivery of bitter tastants. $27,29,30,32,33,37,39,42$ These decreases in energy intake varied from 11-88 Kcal in the acute setting to $340 \mathrm{Kcal}$ on a daily basis. Pooled effects of post-oral delivery of bitter tastants show a significant decrease of 54 Kcal compared with placebo in the acute setting. In itself, a reduction of $54 \mathrm{Kcal}$ in a single meal is rather small. However, in case this reduction in energy intake can be replicated several times daily over a longer period of time, this may indeed lead to a daily caloric deficit and subsequent weight loss. It should be noted, however, that these modest effects on caloric intake point towards a role in weight control rather than weight loss.

\section{GI symptoms and perceptions}

Based on the included papers, no clear effects of post-oral delivery of non-caloric tastants on appetite sensations was found. However, it must be noted that appetite sensations are rarely measured as a primary outcome. Consequently, most studies might not have been adequately powered to detect differences in appetite sensations. Therefore, interpretation of these results should be done with care.

Interesting to point out is the finding of Deloose $e t$ al. showing a longer sustained satiation in response to bitter after a standardised test meal. ${ }^{32}$ This observation indicates that adding a bitter tastant to a caloric carrier could result in a delay until the next meal. Such a combination could result in a decrease in snacking in between meals. In line with this, Mennella et al. found in their study a reduction in 
caloric consumption during the day, after intake of a breakfast containing an encapsulated bitter mixture leading to prolonged satiation. ${ }^{37}$

Only one study investigated the effect of post-oral delivery of an umami stimulus. A decrease in desire to eat and hunger was found. ${ }^{42}$

\section{Safety}

According to the studies described in this review, noncaloric tastant administration is considered to be safe. One study reported side effects after administration of high doses of xylitol and erythritol, which was not surprising given the doses employed. ${ }^{43}$ Other studies showed no GI-symptoms or other side effects after post-oral delivery of non-caloric tastants. ${ }^{27-34,38,42,45}$ It should be taken into account that almost all studies focused on acute effects of post-oral delivery of non-caloric tastants and not on prolonged, daily administration.

The United States Food and Drug Administration (U.S. FDA) issues an acceptable daily intake (ADI) for various food components, including tastants. For example, the U.S. FDA issued a code of regulations stating soft drinks are allowed to contain 83 parts per million quinine. ${ }^{66}$ Moreover, a systematic review describing the use of quinine to treat muscle cramps showed an increase of gastrointestinal complaints, headache and tinnitus after daily intake of $200 \mathrm{mg}$ to $500 \mathrm{mg}$ of quinine for three days up to several weeks. ${ }^{67}$ Even more, the Medicines and Healthcare products Regulatory Agency (MHRA) issued a reminder on the dose-dependent effects of on the QT interval. ${ }^{68}$ Therefore, prolonged intake of high doses or combination with other drugs that prolong the QT interval should be avoided. Interestingly, in studies included in this review, the dose of the bitter tastant quinine ranged from $18 \mathrm{mg}$ to $600 \mathrm{mg} \cdot{ }^{27,29-31,33-35,42}$ This did not result in side effects in the studies investigating the acute effects of these compounds. However, when applying quinine daily to prevent obesity, the maximum dose should be carefully considered. This should be considered in future study protocols.

\section{Mechanisms of effect}

Gastric emptying was delayed by high doses of xylitol and erythritol. ${ }^{43}$ However, other studies showed no effect of post-oral delivery of non-caloric tastants on gastric emptying. ${ }^{27,29,32,35}$ Therefore, gastric emptying does not seem to be attenuated by post-oral delivery of non-caloric tastants.

GI motility appears to be attenuated as one research group has consistently found gastric motility and the GI peptides motilin and ghrelin to be affected by post-oral 
delivery of non-caloric tastants. ${ }^{28,31-33}$ Moreover, this research group recently published a review that elaborated the role of motilin as a regulator of hunger and food intake in humans, ${ }^{69}$ which indicates motilin as a possible target in combating the obesity epidemic. These interesting data are awaiting replication by other research groups.

Four studies showed increased CCK and/or GLP-1 levels after post-oral delivery of non-caloric tastants. ${ }^{27,29,37,43}$ Other studies that investigated these traditional satiety peptides did not find any effect of post-oral delivery of non-caloric tastants. ${ }^{30,36,38,42}$ This raises the question whether the focus should shift from more traditional satiety peptides towards motilin and/or ghrelin. It must be noted that all studies reported on plasma levels of GI peptides, pointing to systemic effects. Up to now, it is still unclear what the effect of taste receptor activation is on local secretion of GI peptides. It is conceivable that GI peptides are elevated at a splanchnic level or that they exert a more local or paracrine effect.

Only one study investigated brain signalling after post-oral delivery of non-caloric tastants. These authors found an increase in activity in homeostatic and hedonic brain regions and a decrease of activity in the brain stem and medulla after intragastric delivery of quinine. 33 These are interesting findings, since these data suggest additional mechanisms of effect of post-oral delivery of non-caloric tastants on eating behaviour. It remains to be further elucidated whether these changes are mediated by orexigenic GI peptides.

\section{Implications of present data}

In this review and meta-analysis, we have summarised the current knowledge on the effects of non-caloric tastants on energy intake. Using non-caloric tastants to reduce energy intake could provide a useful tool to combat the obesity epidemic. Specifically, the use of bitter tastants appears to be promising. It is important to note that most studies described in this review have been performed in healthy adults with a normal BMI or in slightly overweight healthy adults. In several studies blunted postprandial levels of PYY70,71 and GLP-172-74 were observed in obese subjects, and reductions in plasma CCK after weight loss. ${ }^{75,76}$ This points to alterations in the sensitivity of various receptors to GI peptides and in the magnitude of peptide secretion in obesity. Non-caloric tastants, because of their modest reduction in caloric intake, appear to be more suitable as a weight control intervention in a population that is worried about, but has not yet gained excess weight. 
This review and meta-analysis clearly illustrates the potential of bitter tastants in reducing caloric intake. However, several weaknesses of the currently available data should be elucidated. First, data are lacking uniformity and most studies were underpowered: only small numbers of subjects have been included. Second, different study designs have been employed, making it difficult to compare results between various publications. An important variable with respect to energy intake reduction is the varying time interval between post-oral delivery of non-caloric tastants and meal intake. These intervals varied among studies between 30 mins - five hours but usually an interval around $60 \mathrm{~min}$ was chosen. The optimal interval between intervention and ad libitum meal is currently unknown, but standardisation is necessary.

Third, most of the studies included in this review described the acute effects of post-oral delivery of non-caloric tastants on eating behaviour. Only two studies described energy intake during the day ${ }^{37,39}$ and only one of those described an intervention period of two weeks. ${ }^{39}$ Therefore, data on the long-term effects of post-oral delivery of non-caloric tastants are lacking. Consequently, it is unknown whether adaptation to the effects occurs. A fourth limitation is the lack of knowledge on the effects of post-oral delivery of umami tastants on eating behaviour, as this was described in only one paper. ${ }^{42}$ Fifth, only one study investigated several target locations in the GI tract. ${ }^{34}$ Sixth, based on the present data it is unknown which bitter stimulus elicits the greatest effect on energy intake. Most studies described the use of either QHCl or DB.

\section{Future perspectives}

In order to evaluate the effects of gastrointestinal delivery of non-caloric tastants on eating behaviour, future studies should preferably standardise study design and doses of tastants. First, standardisation could be achieved by creating consensus from the lead experts in the field. Second, mechanisms of effect should be more thoroughly investigated. For this, more research on the effects of post-oral delivery of non-caloric tastants on GI motility and systemic and local GI peptides secretion is needed. Based on the current data, we propose to focus on motilin and gastric motility. Third, compared with other tastants, knowledge on the effects of umami tastants is lacking. Therefore, the effects of post-oral delivery of umami tastants should be further elucidated. Fourth, taste receptors are expressed throughout the entire GI-tract. ${ }^{19-22}$ The most appropriate location(s) for tastant delivery to modulate eating behaviour is unknown. More research investigating delivery of tastants in different locations in the GI-tract is needed. Fifth, the 
optimal dose of tastants to exert an effect on eating behaviour is unknown. Studies should focus on finding the balance between the maximum possible effect without occurrence of side effects. Sixth, it should be investigated which bitter stimulus elicits the largest effect on energy intake. For this, studies should compare different bitter stimuli. We propose to focus on $\mathrm{QHCl}$ and $\mathrm{DB}$, as most data are available on these bitter stimuli and both stimuli activate a wide range of bitter receptors. Lastly, when all the foundations are laid out, the field should move towards implementation of the successful interventions in battling the obesity epidemic. For this, the longer-term effects of post-oral delivery of noncaloric tastants on energy intake and ultimately body weight control should be investigated.

\section{Conclusion}

The current data show that, among tastants, bitter compounds are most effective in influencing eating behaviour. Energy intake, in the acute setting, decreased modestly after post-oral delivery of bitter tastants. This highlights the potential preventive role of bitter tastants in battling the obesity epidemic. However, there are still several gaps in knowledge, for which recommendations have been provided. Systematically addressing these issues is warranted and worldwide collaboration could provide a welcome solution. 


\section{References}

1. Besnard P, Passilly-Degrace P, Khan NA. Taste of Fat: A Sixth Taste Modality? Physiol Rev 2016; 96(1):151-76.

2. Lim J, Pullicin AJ. Oral carbohydrate sensing: Beyond sweet taste. Physiol Behav 2019;202:14-25.

3. I IJ, Renken RJ, Ter Horst GJ, Reyners AK. Metallic taste in cancer patients treated with chemotherapy. Cancer Treat Rev 2015;41(2):179-86.

4. Roper SD. TRPs in taste and chemesthesis. Handb Exp Pharmacol 2014;223:827-71.

5. Varghese S, Kubatka P, Rodrigo L, Gazdikova K, Caprnda M, Fedotova J, et al. Chili pepper as a body weight-loss food. Int J Food Sci Nutr 2017;68(4):392-401.

6. van Avesaat M, Troost FJ, Westerterp-Plantenga MS, Helyes Z, Le Roux CW, et al. Capsaicin-induced satiety is associated with gastrointestinal distress but not with the release of satiety hormones. Am J Clin Nutr 2016;103(2):305-13.

7. Depoortere I. Taste receptors of the gut: emerging roles in health and disease. Gut 2014;63(1):179-90.

8. Breslin PA, Spector AC. Mammalian taste perception. Curr Biol 2008;18(4):R148-55.

9. Cines BM, Rozin P. Some aspects of the liking for hot coffee and coffee flavor. Appetite 1982;3(1): 23-34.

10. Chambers L, Mobini S, Yeomans MR. Caffeine deprivation state modulates expression of acquired liking for caffeine-paired flavours. Q J Exp Psychol (Hove) 2007;60(10):1356-66.

11. Dotson CD, Geraedts MC, Munger SD. Peptide regulators of peripheral taste function. Semin Cell Dev Biol 2013;24(3):232-9.

12. Geraedts MC, Munger SD. Gustatory stimuli representing different perceptual qualities elicit distinct patterns of neuropeptide secretion from taste buds. J Neurosci 2013;33(17):7559-64.

13. Lieverse RJ, Jansen JB, van de Zwan A, Samson L, Masclee AA, Lamers CB. Effects of a physiological dose of cholecystokinin on food intake and postprandial satiation in man. Regul Pept 1993;43(1-2):83-9.

14. Lieverse RJ, Jansen JB, Masclee AA, Lamers CB. Satiety effects of a physiological dose of cholecystokinin in humans. Gut 1995;36(2):176-9.

15. Verdich C, Flint A, Gutzwiller JP, Naslund E, Beglinger C, Hellstrom PM, et al. A meta-analysis of the effect of glucagon-like peptide-1 (7-36) amide on ad libitum energy intake in humans. J Clin Endocrinol Metab 2001;86(9):4382-89.

16. Gutzwiller JP, Goke B, Drewe J, Hildebrand P, Ketterer S, Handschin D, et al. Glucagon-like peptide-1: a potent regulator of food intake in humans. Gut 1999;44(1):81-6.

17. Batterham RL, Cowley MA, Small CJ, Herzog H, Cohen MA, Dakin CL, et al. Gut hormone PYY(3-36) physiologically inhibits food intake. Nature 2002;418(6898):650-4.

18. Gutzwiller JP, Drewe J, Ketterer S, Hildebrand P, Krautheim A, Beglinger C. Interaction between CCK and a preload on reduction of food intake is mediated by CCK-A receptors in humans. Am J Physiol-Reg I 2000;279(1):R189-95

19. van der Wielen N, van Avesaat M, de Wit NJW, Vogels JTWE, Troost F, Masclee A, et al. Cross-Species Comparison of Genes Related to Nutrient Sensing Mechanisms Expressed along the Intestine. PloS One 2014;9 (9):e107531.

20. Young RL, Sutherland K, Pezos N, Brierley SM, Horowitz M, Rayner CK, et al. Expression of taste molecules in the upper gastrointestinal tract in humans with and without type 2 diabetes. Gut 2009;58(3):337-46.

21. Bezencon C, le Coutre J, Damak S. Taste-signaling proteins are coexpressed in solitary intestinal epithelial cells. Chemical Senses 2007;32(1):41-9.

22. Gu F, Liu X, Liang J, Chen JY, Chen FX, Li F. Bitter taste receptor mTas2r105 is expressed in small intestinal villus and crypts. Biochem Bioph Res Co 2015;463(4):934-41.

23. Sternini C, Anselmi L, Rozengurt E. Enteroendocrine cells: a site of 'taste' in gastrointestinal chemosensing. Curr Opin Endocrinol Diabetes Obes 2008;15(1):73-8.

24. Jang HJ, Kokrashvili Z, Theodorakis MJ, Carlson OD, Kim BJ, Zhou J, et al. Gut-expressed gustducin and taste receptors regulate secretion of glucagon-like peptide-1. Proc Natl Acad Sci U S A 2007;104(38): 15069-74. 
25. Rozengurt N, Wu SV, Chen MC, Huang C, Sternini C, Rozengurt E. Colocalization of the alpha-subunit of gustducin with PYY and GLP-1 in L cells of human colon. Am J Physiol Gastrointest Liver Physiol 2006;291(5):G792-802.

26. WHO. Obesity and Overweight. https://www.who.int/en/news-room/fact-sheets/detail/ obesity-andoverweight. Accessed 10 December 2019. 2018.

27. Andreozzi P, Sarnelli G, Pesce M, Zito FP, D'Alessandro A, Verlezza V, et al. The Bitter Taste Receptor Agonist Quinine Reduces Calorie Intake and Increases the Postprandial Release of Cholecystokinin in Healthy Subjects. Journal of Neurogastroenterology and Motility 2015;21(4):511-9.

28. Avau B, Rotondo A, Thijs T, Andrews CN, Janssen P, Tack J, et al. Targeting extra-oral bitter taste receptors modulates gastrointestinal motility with effects on satiation. Sci Rep 2015;5:15985.

29. Bitarafan V, Fitzgerald PCE, Little TJ, Meyerhof W, Jones KL, Wu T, et al. Intragastric administration of the bitter tastant quinine lowers the glycemic response to a nutrient drink without slowing gastric emptying in healthy men. Am J Physiol Regul Integr Comp Physiol 2020; 318(2):R263-73.

30. Bitarafan V, Fitzgerald PCE, Little TJ, Meyerhof W, Wu TZ, Horowitz M, et al. Effects of Intraduodenal Infusion of the Bitter Tastant, Quinine, on Antropyloroduodenal Motility, Plasma Cholecystokinin, and Energy Intake in Healthy Men. J Neurogastroenterol Motil 2019;25 (3):413-22.

31. Deloose E, Corsetti M, Van Oudenhove L, Depoortere I, Tack J. Intragastric infusion of the bitter tastant quinine suppresses hormone release and antral motility during the fasting state in healthy female volunteers. Neurogastroenterol Motil 2018;30(1).

32. Deloose E, Janssen P, Corsetti M, Biesiekierski J, Masuy I, Rotondo A, et al. Intragastric infusion of denatonium benzoate attenuates interdigestive gastric motility and hunger scores in healthy female volunteers. Am J Clin Nutr 2017;105(3):580-8.

33. Iven J, Biesiekierski JR, Zhao DX, Deloose E, O'Daly OG, Depoortere I, et al. Intragastric quinine administration decreases hedonic eating in healthy women through peptide-mediated gut-brain signaling mechanisms. Nutritional Neuroscience 2019;22(12):850-62.

34. Klaassen T, Alleleyn AME, van Avesaat M, Troost FJ, Keszthelyi D, Masclee AAM. Intraintestinal Delivery of Tastants Using a Naso-Duodenal-Ileal Catheter Does Not Influence Food Intake or Satiety. Nutrients 2019;11(2):472.

35. Little TJ, Gupta N, Case RM, Thompson DG, McLaughlin JT. Sweetness and bitterness taste of meals per se does not mediate gastric emptying in humans. Am J Physiol Regul Integr Comp Physiol 2009;297(3):R632-9.

36. Ma J, Bellon M, Wishart JM, Young R, Blackshaw LA, Jones KL, et al. Effect of the artificial sweetener, sucralose, on gastric emptying and incretin hormone release in healthy subjects. Am J Physiol Gastrointest Liver Physiol 2009;296(4):G735-9.

37. Mennella I, Fogliano V, Ferracane R, Arlorio M, Pattarino F, Vitaglione P. Microencapsulated bitter compounds (from Gentiana lutea) reduce daily energy intakes in humans. Br J Nutr 2016;1-10.

38. Meyer-Gerspach AC, Biesiekierski JR, Deloose E, Clevers E, Rotondo A, Rehfeld JF, et al. Effects of caloric and noncaloric sweeteners on antroduodenal motility, gastrointestinal hormone secretion and appetite-related sensations in healthy subjects. Am J Clin Nutr 2018;107(5):707-16.

39. Peters HPF, Koppenol W, Schuring EAH, Gouka R, Mela DJ, Blom WAM. The effect of two weeks ingestion of a bitter tastant mixture on energy intake in overweight females. Appetite 2016;107:268-73.

40. Rogers PJ, Pleming HC, Blundell JE. Aspartame Ingested without Tasting Inhibits Hunger and FoodIntake. Physiol Behav 1990;47(6):1239-43.

41. Steinert RE, Frey F, Topfer A, Drewe J, Beglinger C. Effects of carbohydrate sugars and artificial sweeteners on appetite and the secretion of gastrointestinal satiety peptides. Br J Nutr 2011;105(9):1320-8.

42. van Avesaat M, Troost FJ, Ripken D, Peters J, Hendriks HF, Masclee AA. Intraduodenal infusion of a combination of tastants decreases food intake in humans. Am J Clin Nutr 2015;102(4):729-35.

43. Wolnerhanssen BK, Cajacob L, Keller N, Doody A, Rehfeld JF, Drewe J, et al. Gut hormone secretion, gastric emptying, and glycemic responses to erythritol and xylitol in lean and obese subjects. Am J Physiol Endocrinol Metab 2016;310(11):E1053-61.

44. Black RM, Leiter LA, Anderson GH. Consuming aspartame with and without taste: differential effects on appetite and food intake of young adult males. Physiol Behav 1993;53(3):459-66. 
45. Walker E, Lo K, Tham S, Pahl M, Lomiwes D, Cooney J, et al. New Zealand Bitter Hops Extract Reduces Hunger During a 24 h Water Only Fast. Nutrients 2019;11(11):2754.

46. Moher D, Liberati A, Tetzlaff J, Altman DG, Group P. Preferred reporting items for systematic reviews and meta-analyses: the PRISMA statement. Int J Surg 2010;8(5):336-41.

47. Sterne JAC, Savovic J, Page MJ, Elbers RG, Blencowe NS, Boutron I, et al. RoB 2: a revised tool for assessing risk of bias in randomised trials. BMJ 2019;366:14898.

48. Viechtbauer W. Conducting Meta-Analyses in R with the metafor Package. J Stat Softw 2010;36(3): 1-48.

49. Dagan-Wiener A, Di Pizio A, Nissim I, Bahia MS, Dubovski N, Margulis E, et al. BitterDB: taste ligands and receptors database in 2019. Nucleic Acids Res 2019;47(D1):D1179-85.

50. Horne J, Lawless HT, Speirs W, Sposato D. Bitter taste of saccharin and acesulfame-K. Chem Senses 2002;27(1):31-8.

51. Tan VWK, Wee MSM, Tomic O, Forde CG. Temporal sweetness and side tastes profiles of 16 sweeteners using temporal check-all-that-apply (TCATA). Food Res Int 2019;121:39-47.

52. Tao R, Cho S. Consumer-Based Sensory Characterization of Steviol Glycosides (Rebaudioside A, D, and M). Foods 2010;9(8):1026.

53. Meyerhof W, Batram C, Kuhn C, Brockhoff A, Chudoba E, Bufe B, et al. The molecular receptive ranges of human TAS2R bitter taste receptors. Chem Senses 2010;35(2):157-70.

54. Jéquier E. Carbohydrates as a source of energy. Am J Clin Nutr 1994;59(3):682S-5S.

55. Lindemann B. Taste reception. Physiol Rev 1996;76(3):719-66.

56. Nelson G, Chandrashekar J, Hoon MA, Feng L, Zhao G, Ryba NJ, et al. An amino-acid taste receptor. Nature 2002;416(6877):199-202.

57. Zhao GQ, Zhang Y, Hoon MA, Chandrashekar J, Erlenbach I, Ryba NJ, et al. The receptors for mammalian sweet and umami taste. Cell 2003;115(3):255-66.

58. Hosaka H, Kusano M, Zai H, Kawada A, Kuribayashi S, Shimoyama Y, et al. Monosodium glutamate stimulates secretion of glucagon-like peptide-1 and reduces postprandial glucose after a lipid-containing meal. Aliment Pharmacol Ther 2012;36(9):895-903.

59. Luscombe-Marsh ND, Smeets AJ, Westerterp-Plantenga MS. The addition of monosodium glutamate and inosine monophosphate- 5 to high-protein meals: effects on satiety, and energy and macronutrient intakes. Br J Nutr 2009;102(6):929-37.

60. Prescott J. Effects of added glutamate on liking for novel food flavors. Appetite 2004;42(2):143-50.

61. Dermiki M, Prescott J, Sargent LJ, Willway J, Gosney MA, Methven L. Novel flavours paired with glutamate condition increased intake in older adults in the absence of changes in liking. Appetite 2015;90:108-13.

62. Steiner JE, Glaser D, Hawilo ME, Berridge KC. Comparative expression of hedonic impact: affective reactions to taste by human infants and other primates. Neurosci Biobehav Rev 2001;25 (1):53-74.

63. Yeomans MR, Durlach PJ, Tinley EM. Flavour liking and preference conditioned by caffeine in humans. Q J Exp Psychol B 2005;58(1):47-58.

64. Higgins MJ, Hayes JE. Regional Variation of Bitter Taste and Aftertaste in Humans. Chem Senses 2019;44(9):721-32.

65. Rogers PJ, Hogenkamp PS, de Graaf C, Higgs S, Lluch A, Ness AR, et al. Does low-energy sweetener consumption affect energy intake and body weight? A systematic review, including meta-analyses, of the evidence from human and animal studies. Int J Obes (Lond) 2016;40(3):381-94.

66. FDA US. CFR - Code of Federal Regulations Title 21. https://www.accessdata.fda.gov/scripts/cdrh/ cfdocs/cfCFR/CFRSearch.cfm?fr=172.575. Accessed 18 December 2019

67. El-Tawil S, Al Musa T, Valli H, Lunn MP, Brassington R, El-Tawil T, et al. Quinine for muscle cramps. Cochrane Database Syst Rev (4):CD005044.

68. Agency MaHpR (2017) Quinine: reminder of dose-dependent QT-prolonging effects; updated medicine interactions. https://www.gov.uk/drug-safety-update/quinine-reminder-of-dose-dependent-qt-prolongingeffects-updated-medicine-interactions. Accessed 27 May 2020

69. Deloose E, Verbeure W, Depoortere I, Tack J. Motilin: from gastric motility stimulation to hunger signalling. Nat Rev Endocrinol 2019;15(4):238-50. 
70. Zwirska-Korczala K, Konturek SJ, Sodowski M, Wylezol M, Kuka D, Sowa P, et al. Basal and postprandial plasma levels of PYY, ghrelin, cholecystokinin, gastrin and insulin in women with moderate and morbid obesity and metabolic syndrome. J Physiol Pharmacol 2007;58 Suppl 1:13-35

71. le Roux CW, Batterham RL, Aylwin SJ, Patterson M, Borg CM, Wynne KJ, et al. Attenuated peptide YY release in obese subjects is associated with reduced satiety. Endocrinology 2006;147(1):3-8.

72. Adam TC, Westerterp-Plantenga MS. Glucagon-like peptide-1 release and satiety after a nutrient challenge in normal-weight and obese subjects. Br J Nutr 2005;93(6):845-51.

73. Carroll JF, Kaiser KA, Franks SF, Deere C, Caffrey JL. Influence of BMI and gender on postprandial hormone responses. Obesity (Silver Spring) 2007;15(12):2974-83.

74. Verdich C, Toubro S, Buemann B, Lysgard Madsen J, Juul Holst J, Astrup A. The role of postprandial releases of insulin and incretin hormones in meal-induced satiety--effect of obesity and weight reduction. Int J Obes Relat Metab Disord 2001;25(8):1206-14.

75. Sumithran P, Prendergast LA, Delbridge E, Purcell K, Shulkes A, Kriketos A, Proietto J. Long-term persistence of hormonal adaptations to weight loss. N Engl J Med 2011;365(17):1597-604.

76. Chearskul S, Delbridge E, Shulkes A, Proietto J, Kriketos A. Effect of weight loss and ketosis on postprandial cholecystokinin and free fatty acid concentrations. Am J Clin Nutr 2008;87(5):1238-46. 
Supplemental material
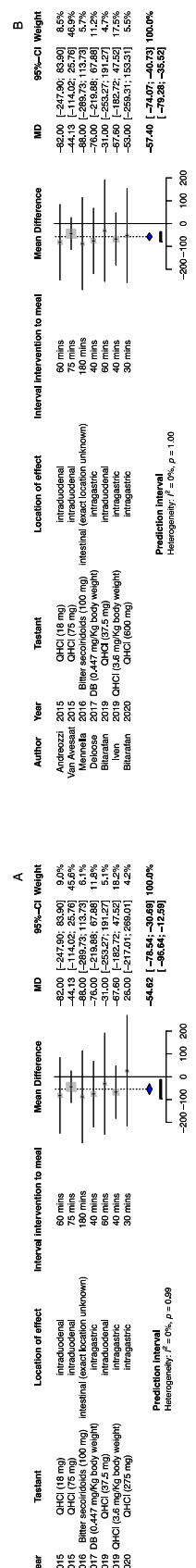

I||H!|
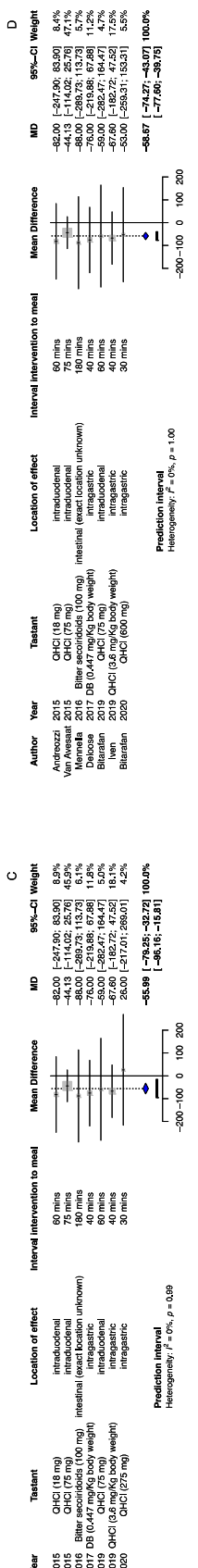

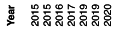

I|!!!
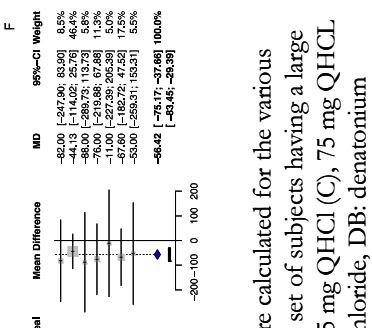

离.

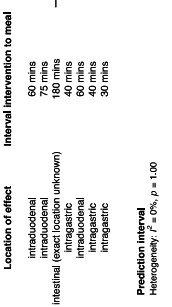

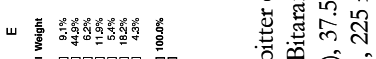

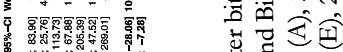

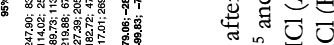

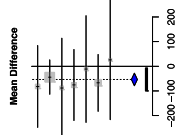

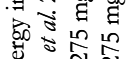

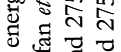

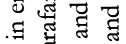

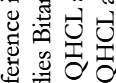

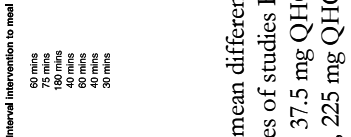

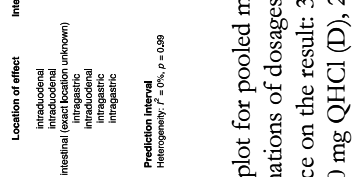

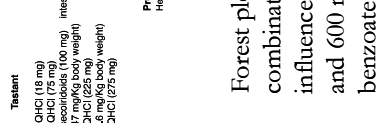

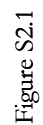




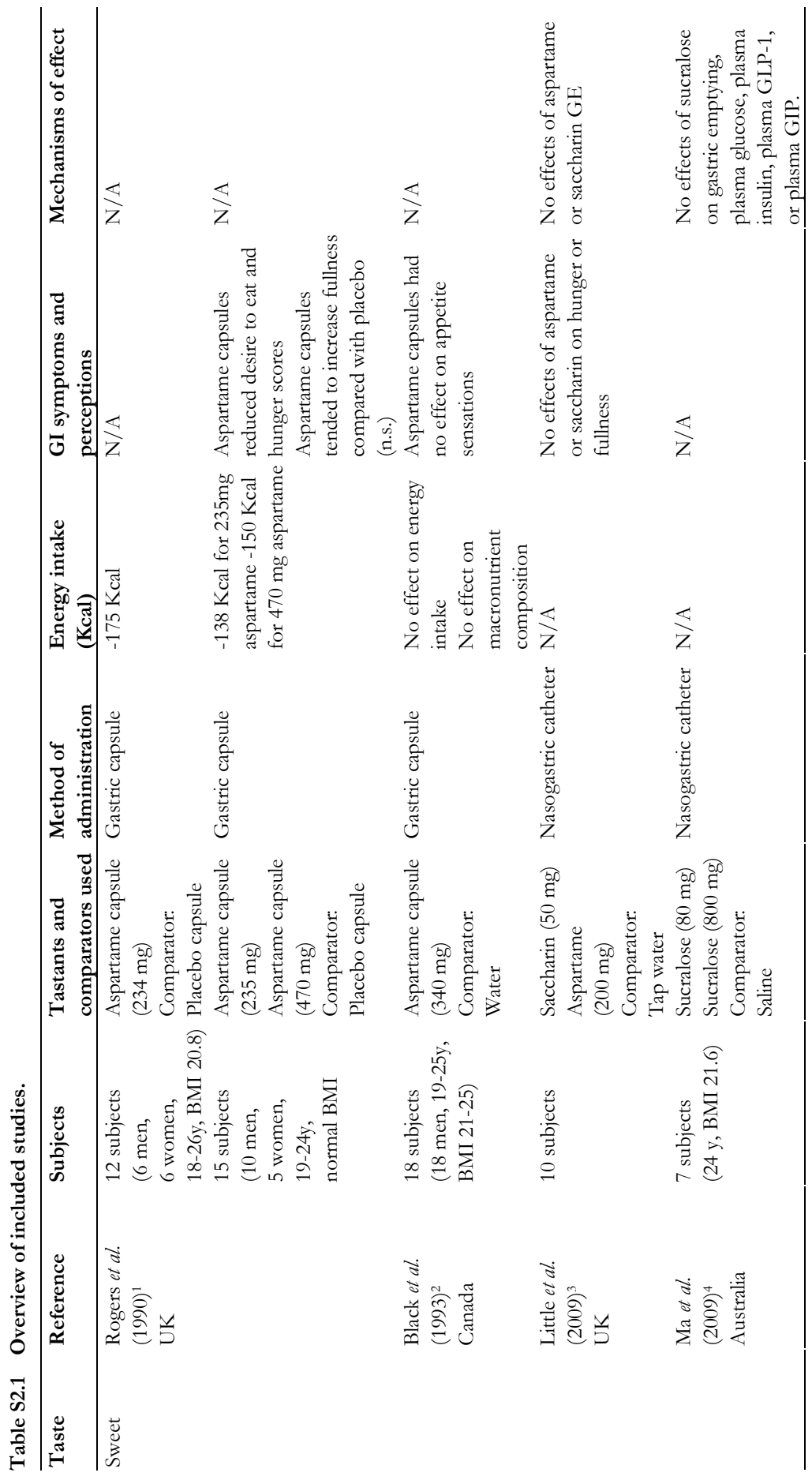




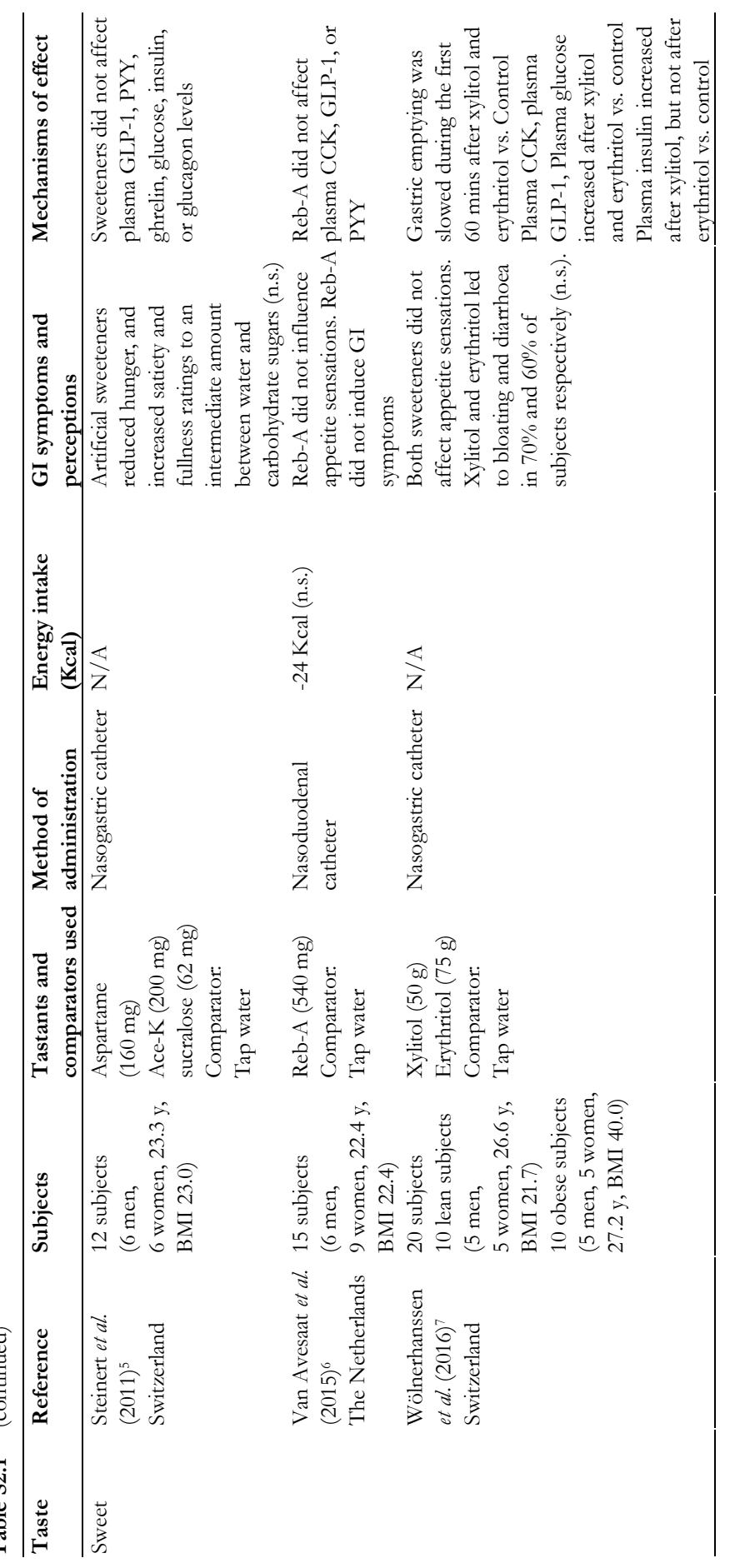




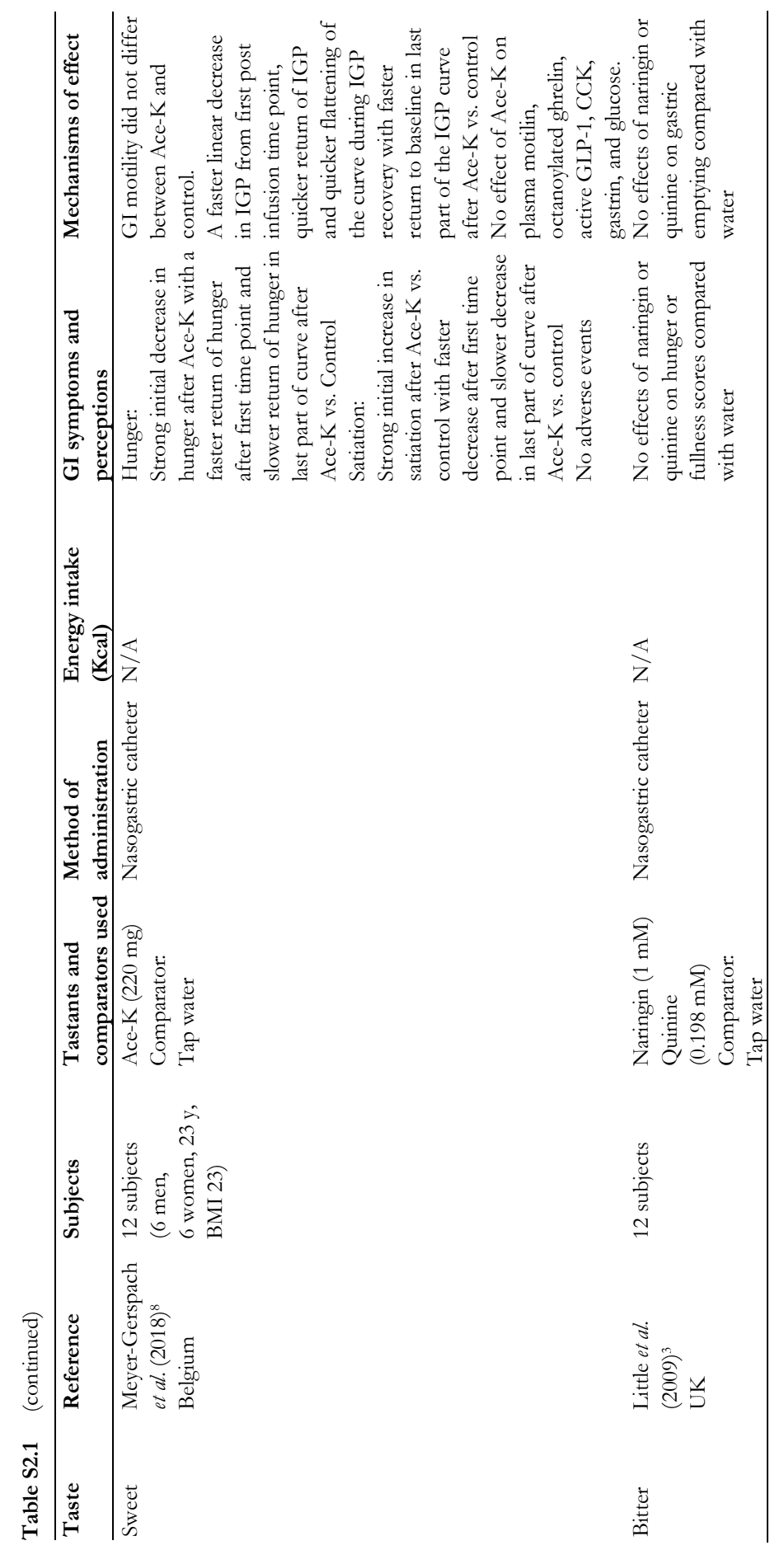




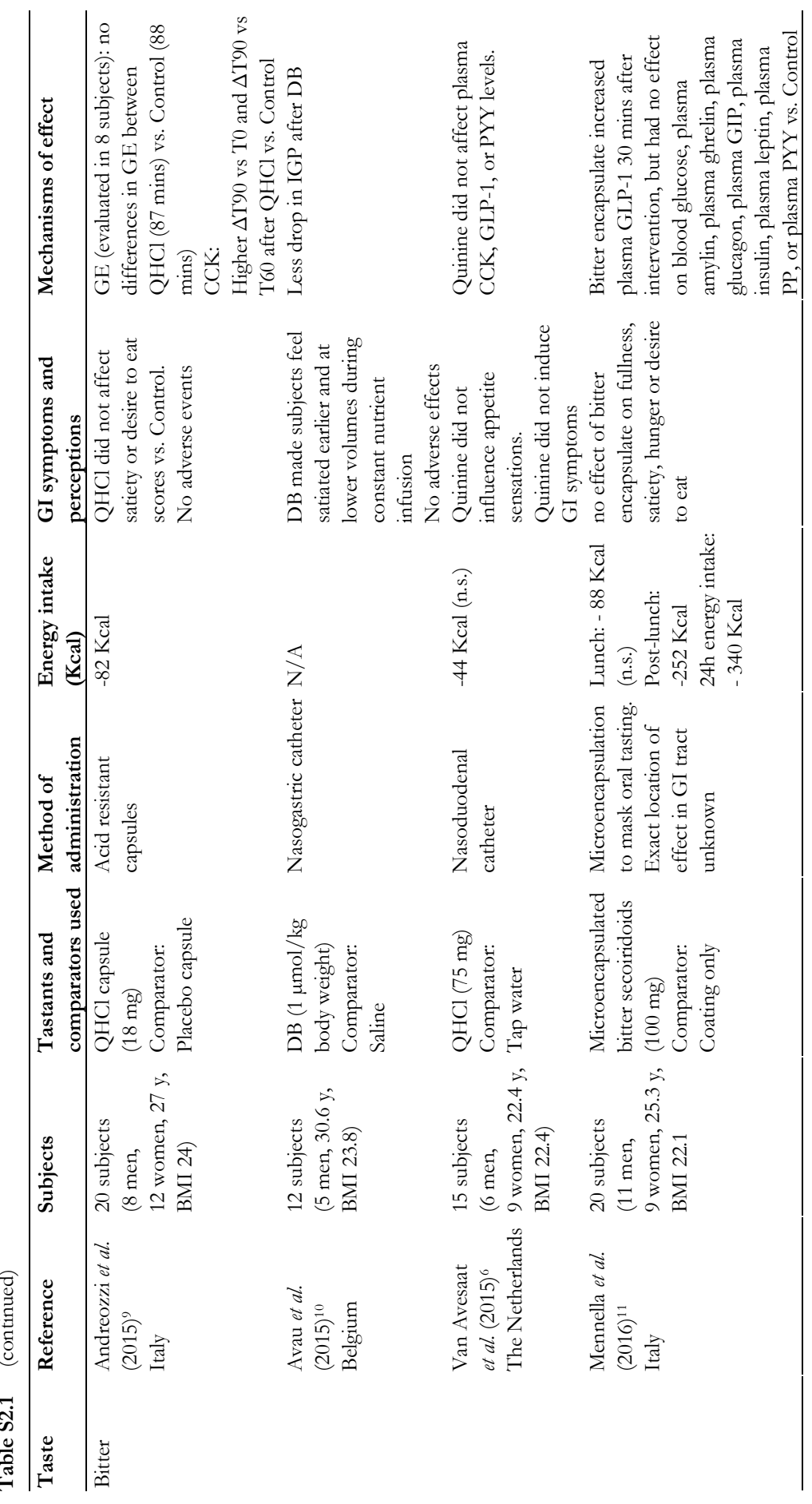




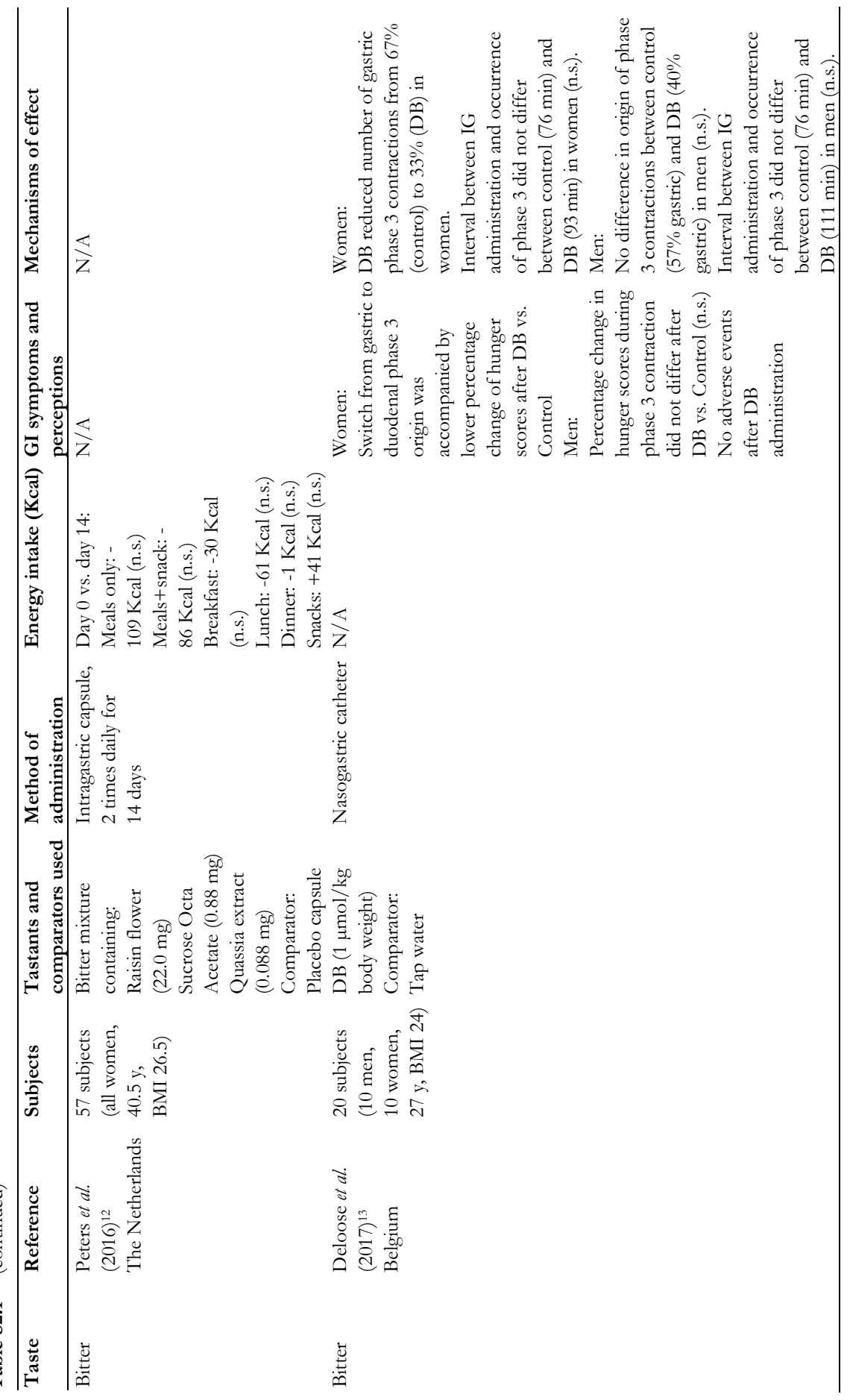




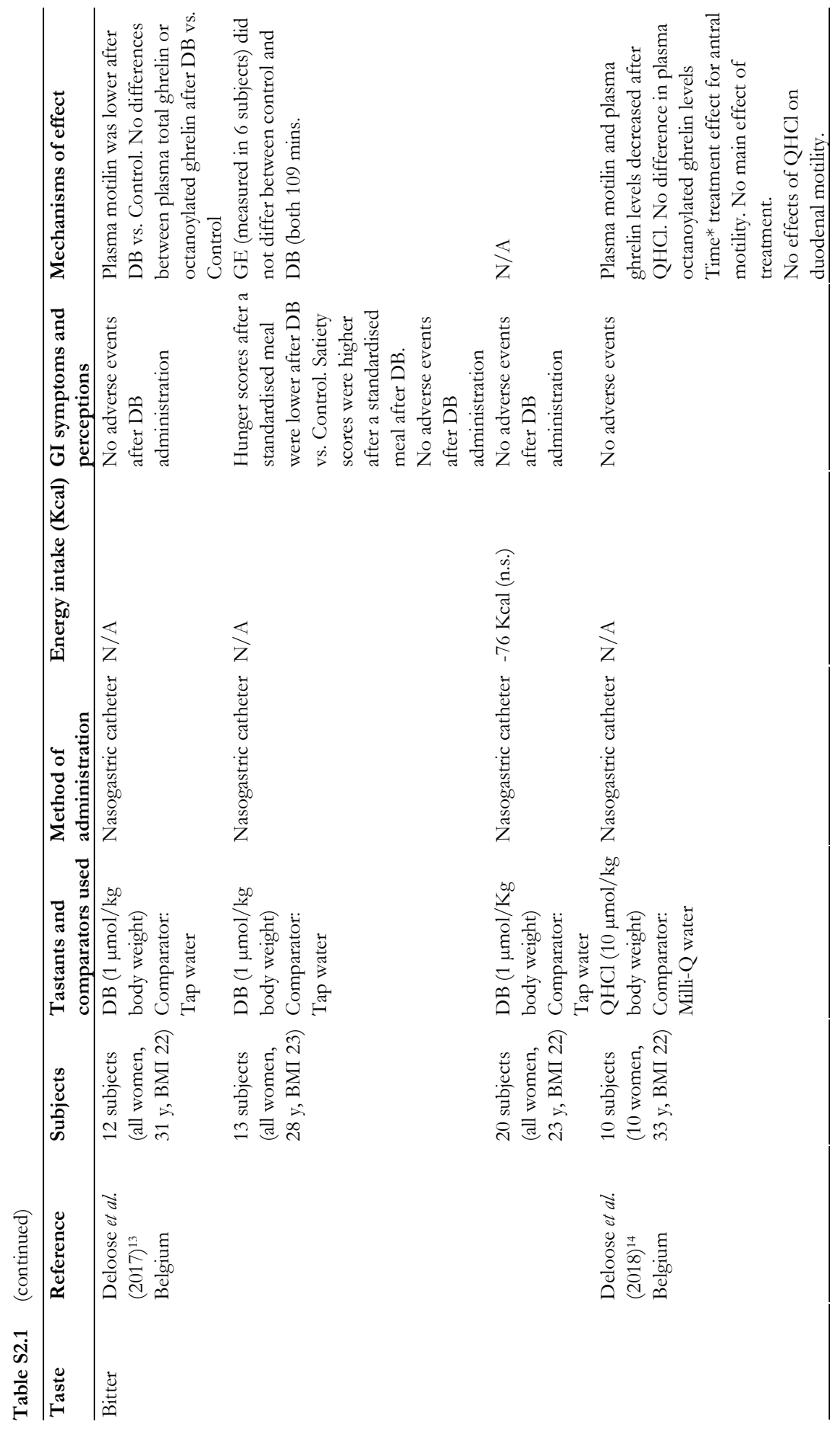




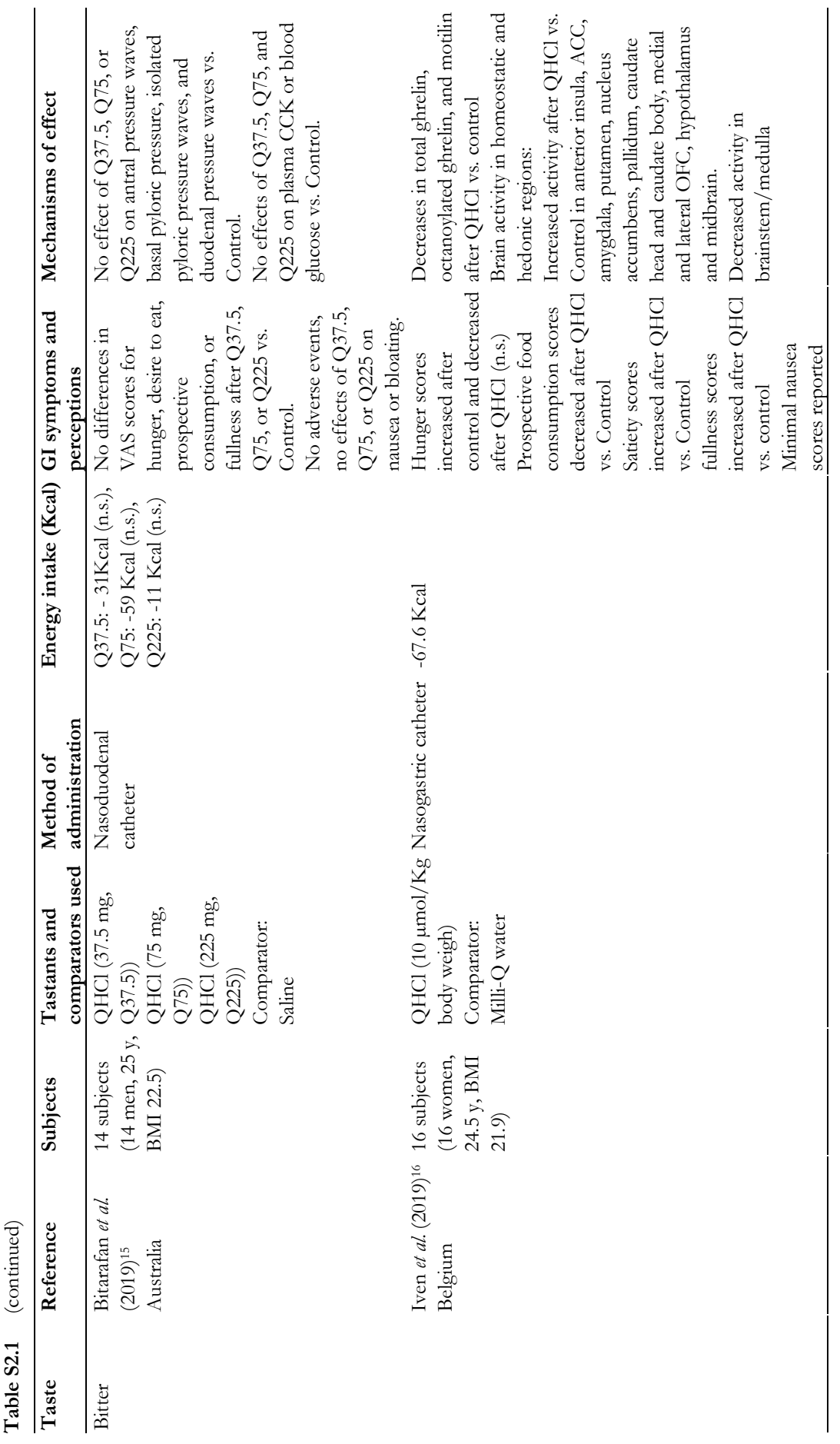




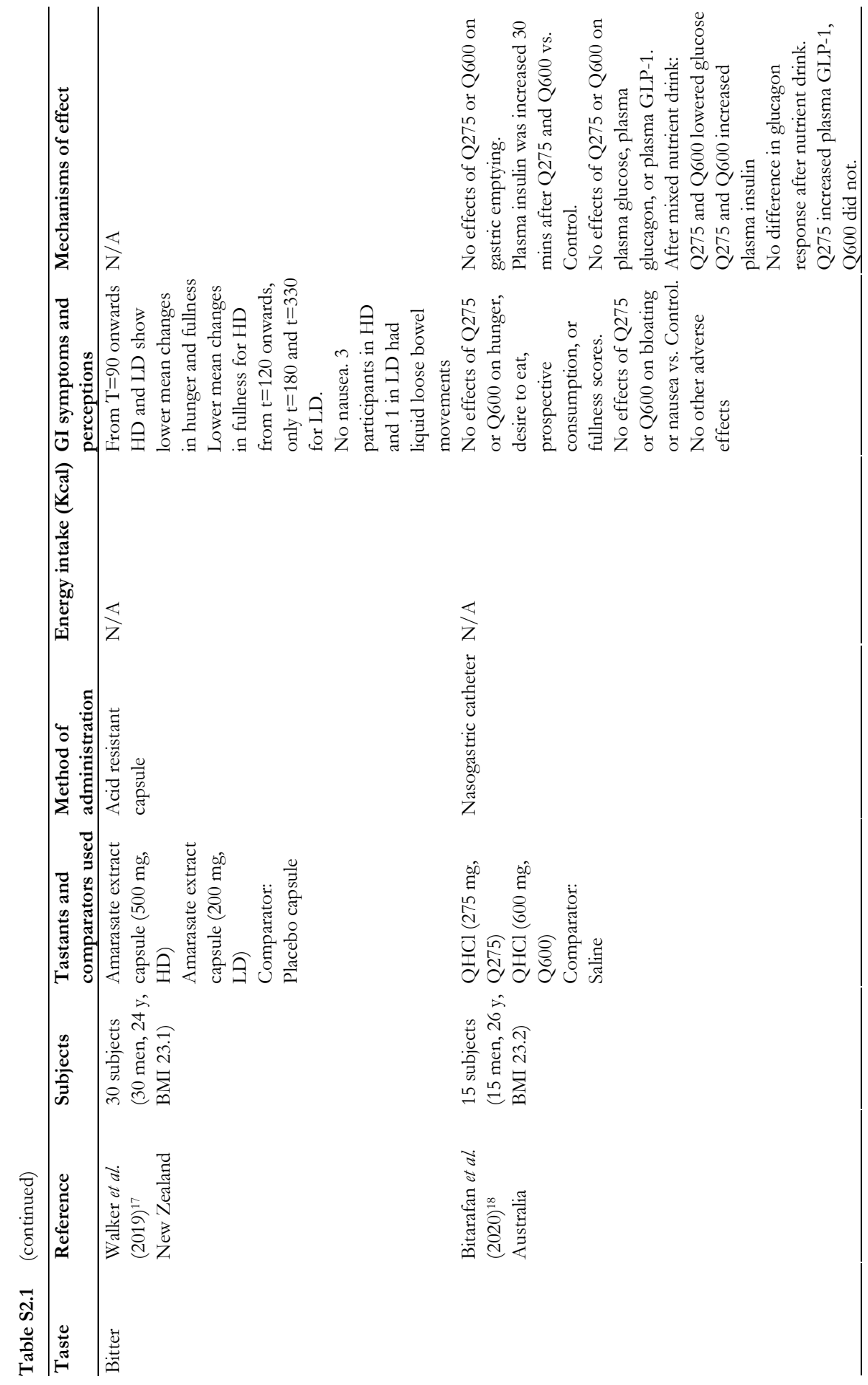




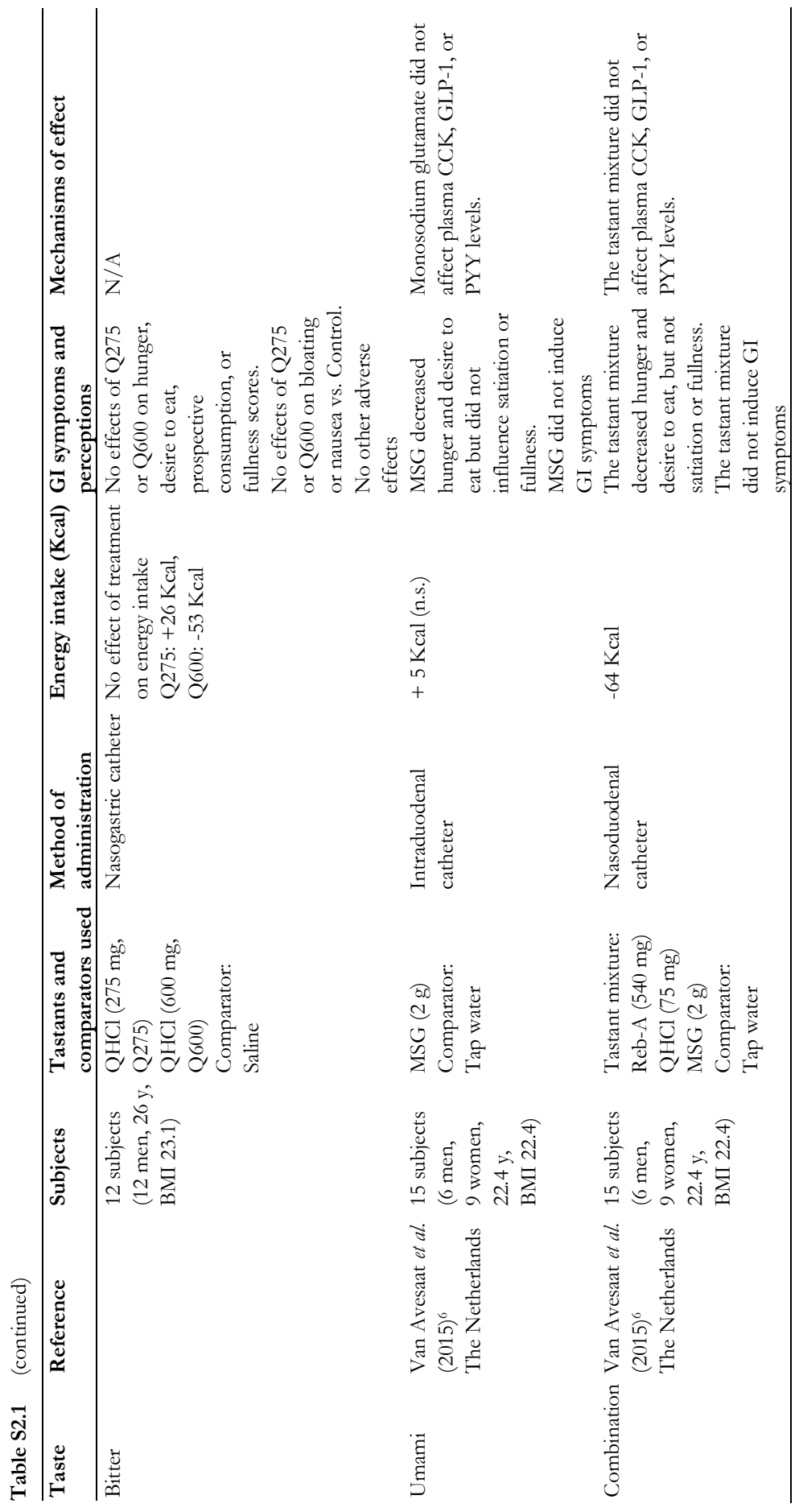


Effects of gastrointestinal delivery of non-caloric tastants on energy intake

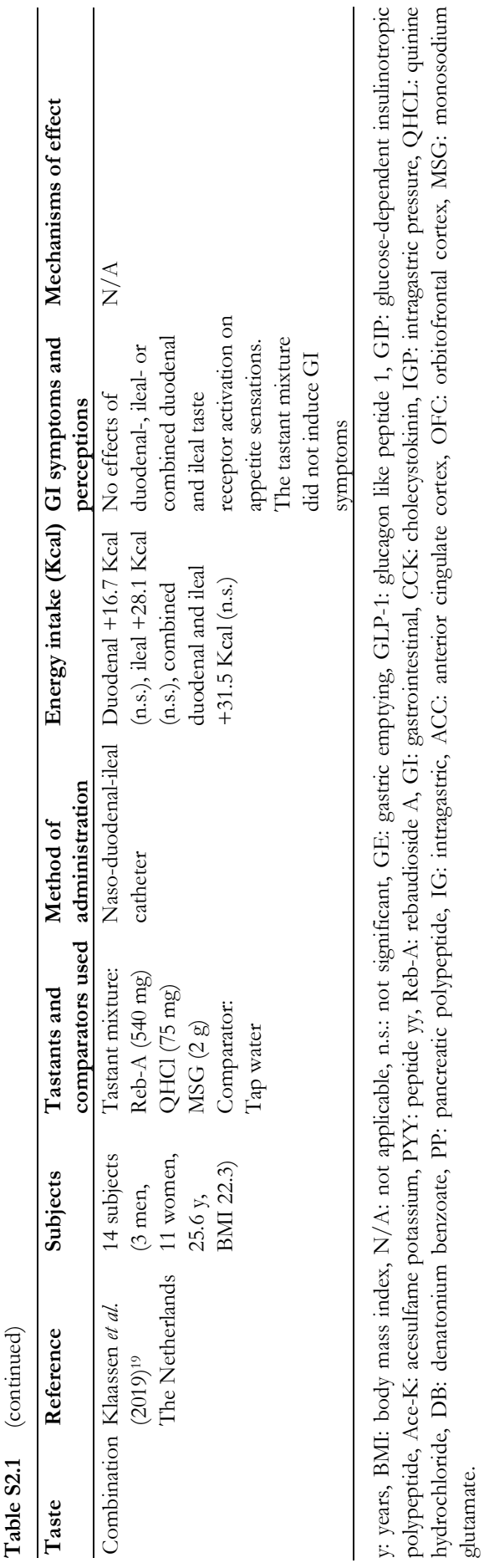




\section{References}

1. Rogers PJ, Pleming HC, Blundell JE. Aspartame Ingested without Tasting Inhibits Hunger and Food Intake. Physiol Behav 1990;47(6):1239-43.

2. Black RM, Leiter LA, Anderson GH. Consuming aspartame with and without taste: differential effects on appetite and food intake of young adult males. Physiol Behav 1993;53(3):459-66.

3. Little TJ, Gupta N, Case RM, Thompson DG, McLaughlin JT. Sweetness and bitterness taste of meals per se does not mediate gastric emptying in humans. Am J Physiol Regul Integr Comp Physiol 2009; 297(3):R632-9.

4. Ma J, Bellon M, Wishart JM, Young R, Blackshaw LA, Jones KL, et al. Effect of the artificial sweetener, sucralose, on gastric emptying and incretin hormone release in healthy subjects. Am J Physiol Gastrointest Liver Physiol 2009;296(4):G735-9.

5. Steinert RE, Frey F, Topfer A, Drewe J, Beglinger C. Effects of carbohydrate sugars and artificial sweeteners on appetite and the secretion of gastrointestinal satiety peptides. Br J Nutr 2011;105(9): 1320-8.

6. van Avesaat M, Troost FJ, Ripken D, Peters J, Hendriks HF, Masclee AA. Intraduodenal infusion of a combination of tastants decreases food intake in humans. Am J Clin Nutr 2015;102(4):729-35.

7. Wolnerhanssen BK, Cajacob L, Keller N, Doody A, Rehfeld JF, Drewe J, et al. Gut hormone secretion, gastric emptying, and glycemic responses to erythritol and xylitol in lean and obese subjects. Am J Physiol Endocrinol Metab 2016;310(11):E1053-61.

8. Meyer-Gerspach AC, Biesiekierski JR, Deloose E, Clevers E, Rotondo A, Rehfeld JF, et al. Effects of caloric and noncaloric sweeteners on antroduodenal motility, gastrointestinal hormone secretion and appetite-related sensations in healthy subjects. Am J Clin Nutr 2018;107(5):707-16.

9. Andreozzi P, Sarnelli G, Pesce M, Zito FP, D'Alessandro A, Verlezza V, et al. The Bitter Taste Receptor Agonist Quinine Reduces Calorie Intake and Increases the Postprandial Release of Cholecystokinin in Healthy Subjects. J Neurogastroenterol Motil 2015;21(4):511-9.

10. Avau B, Rotondo A, Thijs T, Andrews CN, Janssen P, Tack J, et al. Targeting extra-oral bitter taste receptors modulates gastrointestinal motility with effects on satiation. Sci Rep 2015;5:15985.

11. Mennella I, Fogliano V, Ferracane R, Arlorio M, Pattarino F, Vitaglione P. Microencapsulated bitter compounds (from Gentiana lutea) reduce daily energy intakes in humans. Br J Nutr 2016;1-10.

12. Peters HPF, Koppenol W, Schuring EAH, Gouka R, Mela DJ, Blom WAM. The effect of two weeks ingestion of a bitter tastant mixture on energy intake in overweight females. Appetite 2016;107: 268-73.

13. Deloose E, Janssen P, Corsetti M, Biesiekierski J, Masuy I, Rotondo A, et al. Intragastric infusion of denatonium benzoate attenuates interdigestive gastric motility and hunger scores in healthy female volunteers. Am J Clin Nutr 2017;105(3):580-8.

14. Deloose E, Corsetti M, Van Oudenhove L, Depoortere I, Tack J. Intragastric infusion of the bitter tastant quinine suppresses hormone release and antral motility during the fasting state in healthy female volunteers. Neurogastroenterol Motil 2018;30(1).

15. Bitarafan V, Fitzgerald PCE, Little TJ, Meyerhof W, Wu TZ, Horowitz M, et al. Effects of Intraduodenal Infusion of the Bitter Tastant, Quinine, on Antropyloroduodenal Motility, Plasma Cholecystokinin, and Energy Intake in Healthy Men. J Neurogastroenterol Motil 2019;25 (3):413-22.

16. Iven J, Biesiekierski JR, Zhao DX, Deloose E, O'Daly OG, Depoortere I, et al. Intragastric quinine administration decreases hedonic eating in healthy women through peptide-mediated gut-brain signaling mechanisms. Nutr Neurosci 2019;22(12):850-62.

17. Walker E, Lo K, Tham S, Pahl M, Lomiwes D, Cooney J, et al. New Zealand Bitter Hops Extract Reduces Hunger During a $24 \mathrm{~h}$ Water Only Fast. Nutrients 2019;11(11):2754.

18. Bitarafan V, Fitzgerald PCE, Little TJ, Meyerhof W, Jones KL, Wu T, et al. Intragastric administration of the bitter tastant quinine lowers the glycemic response to a nutrient drink without slowing gastric emptying in healthy men. Am J Physiol Regul Integr Comp Physiol 2020; 318(2):R263-73.

19. Klaassen T, Alleleyn AME, van Avesaat M, Troost FJ, Keszthelyi D, Masclee AAM. Intraintestinal Delivery of Tastants Using a Naso-Duodenal-Ileal Catheter Does Not Influence Food Intake or Satiety. Nutrients 2019;11(2). 



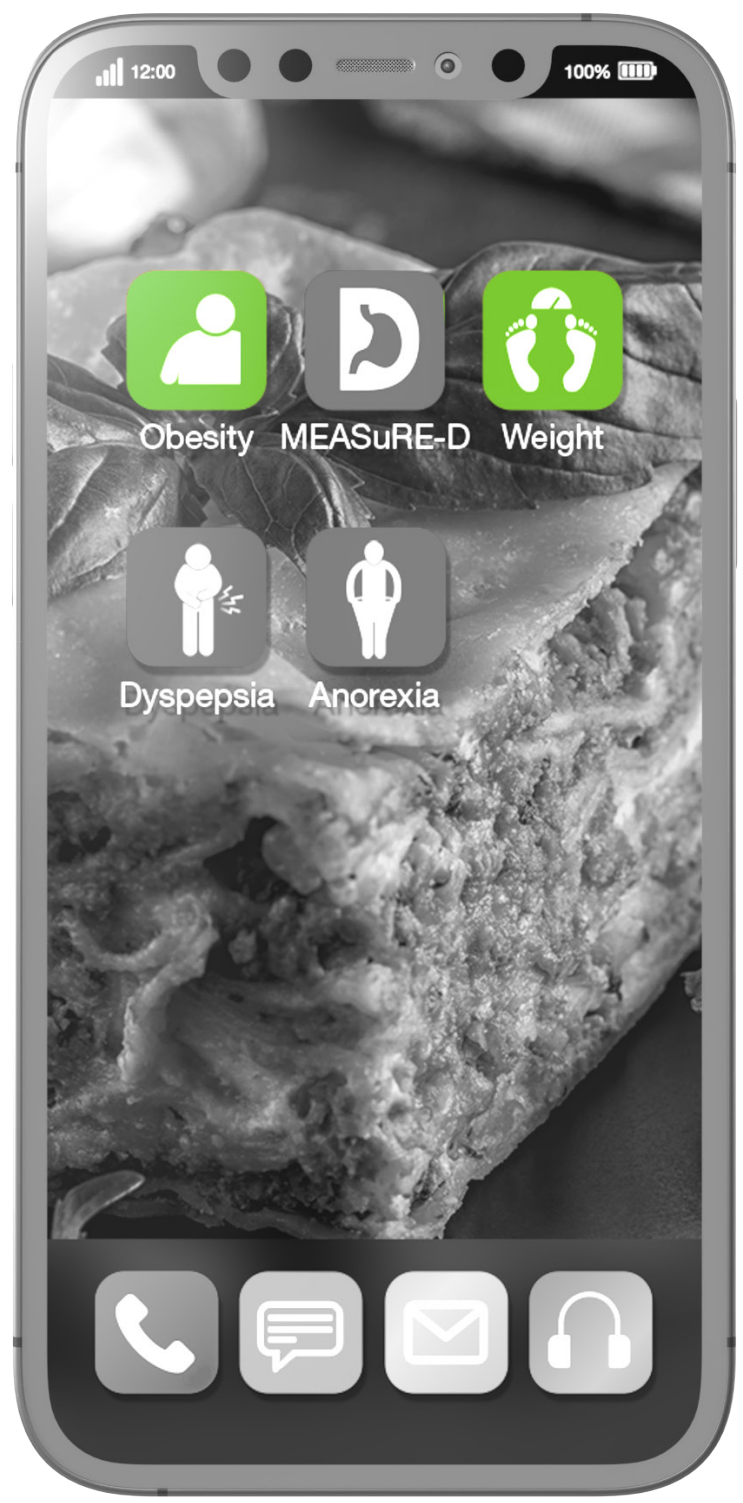




\section{Chapter 3}

Intraintestinal delivery of tastants using a nasoduodenal-ileal catheter does not influence food intake or satiation

Tim Klaassen Annick M.E. Alleleyn Mark van Avesaat Freddy J. Troost Daniel Keszthelyi

Ad A.M. Masclee

Nutrients 2019;11:472 


\begin{abstract}
Intraduodenal activity of taste receptors reduces food intake. Taste receptors are expressed throughout the entire gastrointestinal tract. Currently, there are no data available on the effects of distal taste receptor activation. In this study, we investigate the effect of intraduodenal and/or intraileal activation of taste receptors on food intake and satiation. In a single-blind randomised crossover trial, fourteen participants were intubated with a naso-duodenal-ileal catheter and received four infusion regimens: duodenal placebo and ileal placebo (DPIP), duodenal tastants and ileal placebo (DTIP), duodenal placebo and ileal tastants (DPIT), duodenal tastants and ileal tastants (DTIT). Fifteen minutes after cessation of infusion, subjects received an ad libitum meal to measure food intake. Visual analogue scale scores for appetite sensations were collected at regular intervals. No differences in food intake were observed between the various interventions (DPIP: $786.6 \pm 79.2 \mathrm{Kcal}$, DTIP: $803.3 \pm 69.0 \mathrm{Kcal}$, DPIT: $814.7 \pm$ $77.3 \mathrm{Kcal}$, DTIT: $834.8 \pm 59.2 \mathrm{Kcal}, \mathrm{p}=0.59)$. No differences in appetite sensations were observed. Intestinal infusion of tastants using a naso-duodenalileal catheter did not influence food intake or appetite sensations. Possibly, the burden of the four-day naso-duodenal-ileal intubation masked a small effect that tastants might have on food intake and satiation.
\end{abstract}




\section{Introduction}

Obesity is considered a major healthcare problem with worldwide obesity almost being tripled since $1975 .{ }^{1}$ Therefore, there is an increasing need for non-invasive therapies for weight management. Gastrointestinal (GI) hormones, such as cholecystokinin (CCK) and glucagon-like peptide-1 (GLP-1), have been shown to reduce food intake and hunger after intravenous administration. ${ }^{2-4}$ Therefore, the GI-tract is an interesting target for non-invasive therapies to reduce food intake and induce satiety/satiation.

Intestinal macronutrient infusion decreases food intake and induces the release of CCK, GLP-1, and peptide YY (PYY). 5 This mechanism is commonly referred to as intestinal- or ileal brake. ${ }^{6,7} \mathrm{~A}$ recent review proposed a proximal to the distal gradient in the small intestine, where a more profound effect on food intake can be found after distal compared to proximal macronutrient infusion. ${ }^{8}$ Previous studies have demonstrated that besides macronutrients, substances referred to as tastants are able to activate certain taste receptors in the GI-tract which are coupled to enteroendocrine cells (EEC) and can trigger the release of satiety hormones (i.e., CCK, GLP-1, and PYY).9-13 These taste receptors can be found throughout the entire GI-tract. Expression levels for the various taste receptor differ throughout the gut. Table 3.1 gives a simplified visual representation of the relative expression of taste receptors throughout the human gut based on current literature. ${ }^{14-17}$

In a recent study, van Avesaat et al. have shown that duodenal infusion of a combination of sweet, bitter, and umami tastants significantly decreased ad libitum meal intake, whilst increasing satiation and decreasing hunger. These effects were not accompanied by changes in systemic levels of GLP-1, PYY, and CCK. ${ }^{18} \mathrm{Up}$ to now, no data are available on the effect of activation of taste receptors in the more distal small intestine. Since one of the functions of taste receptors in the gut is to sense food being present in the lumen, it should be investigated whether the beforementioned proximal to distal gradient found for the intestinal brake is operative for taste receptor activation.

Therefore, in the present study, we compared the effects of intraduodenal infusion versus intraileal infusion of a combination of tastants (sweet, bitter, and umami) on ad libitum food intake, satiation, and GI-complaints in healthy subjects. Since sweet and umami taste are sensed by various subtypes of the taste receptor family 1 (TAS1R) taste receptor family and bitter taste is sensed by the taste receptor family 2 (TAS2R), the combination will activate a wide range of taste receptors. We hypothesised that infusing tastants at both infusion sites 
(duodenum and ileum) will decrease food intake and increase satiation to the greatest extent when compared with infusion of placebo or single port infusion. Infusing in solely the duodenum or the ileum will also decrease food intake and increase satiation when compared to placebo, albeit to a lesser degree than infusing at both infusion sites simultaneously. Furthermore, we expect intraileal delivery of tastants will decrease food intake and increase satiation to a greater extent when compared with intraduodenal delivery of tastants.

Table 3.1 A simplified visual representation of the relative expression of taste receptors and gustducin throughout the human GI-tract.

\begin{tabular}{|c|c|c|c|c|c|}
\hline & Stomach & Duodenum & Jejunum & Ileum & Colon \\
\hline $\begin{array}{l}\text { TAS1R1 } \\
\left(\text { Bezencon } \text { et al. }{ }^{14} \text { ) }\right.\end{array}$ & ++ & + & ++ & + & $+/-$ \\
\hline $\begin{array}{l}\text { TAS1R2 } \\
\text { (Bezencon } \text { et al. }{ }^{14} \text { ) }\end{array}$ & - & ++ & + & $+/-$ & + \\
\hline $\begin{array}{l}\text { TAS1R2 } \\
\left(\text { Young et al. }{ }^{15}\right)\end{array}$ & $--\$$ & + & $++\#$ & $\mathrm{~N} / \mathrm{A}$ & $\mathrm{N} / \mathrm{A}$ \\
\hline $\begin{array}{l}\text { TAS1R3 } \\
\left(\text { Bezencon } \text { et } a l .{ }^{14}\right)\end{array}$ & + & ++ & ++ & + & + \\
\hline $\begin{array}{l}\text { TAS1R3 } \\
\text { (van der Wielen } \text { et al. }{ }^{16} \text { ) }\end{array}$ & $\mathrm{N} / \mathrm{A}$ & + & + & + & + \\
\hline $\begin{array}{l}\text { TAS1R3 } \\
\left(\text { Young et al. }{ }^{15}\right)\end{array}$ & $+\$$ & ++ & $++^{\#}$ & $\mathrm{~N} / \mathrm{A}$ & $\mathrm{N} / \mathrm{A}$ \\
\hline $\begin{array}{l}\text { TAS2R102-TAS2R144 } \\
\left(\mathrm{Gu} \text { et al. }{ }^{17}\right)\end{array}$ & $\mathrm{N} / \mathrm{A}$ & + & + & + & $\mathrm{N} / \mathrm{A}$ \\
\hline $\begin{array}{l}\text { Gustducin } \\
\left(\text { Bezencon } e t a l .^{14} \text { ) }\right.\end{array}$ & -- & ++ & ++ & + & - \\
\hline $\begin{array}{l}\text { Gustducin } \\
\left(\text { Young et al. }{ }^{15}\right)\end{array}$ & $-\$$ & + & $++^{\#}$ & $\mathrm{~N} / \mathrm{A}$ & $\mathrm{N} / \mathrm{A}$ \\
\hline
\end{tabular}

Expression levels are relative to each other and a simplified visual representation with ++ indicating very high expression, + indicating high expression, +/ - indicating medium expression, - indicating low expression, and - indicating very low expression. \$ Young et al. displayed the stomach as fundus, body, and antrum. For details, please refer to Young et al. ${ }^{15}$ \# Young et al. displayed jejunum as proximal jejunum and distal jejunum. For details, please refer to Young et al. ${ }^{15} \mathrm{~N} / \mathrm{A}$ : not available. ${ }^{*} \mathrm{~T} 2 \mathrm{R}$ family is expressed throughout the entire small intestine in a comparable fashion with some subtypes more abundant proximally and some distally. For details, please refer to $\mathrm{Gu}$ et al..$^{17}$

\section{Materials and methods}

This study was approved by the Medical Ethics Committee of the Maastricht University Medical Centre+ (MUMC+), Maastricht, the Netherlands, and performed in full accordance with the Declaration of Helsinki (latest amendment by the World Medic Association in 2013) and Dutch Regulations on Medical Research Involving Human Subjects (WMO, 1998). This study was registered in 
the US National Library of Medicine (http://www.clinicaltrials.gov, ID NCT03140930). All subjects gave written informed consent before screening.

\section{Subjects}

Healthy men and women were recruited by local advertisements. Inclusion criteria were age between 18 and 65 years, a body mass index (BMI) between 18 and $25 \mathrm{~kg} / \mathrm{m}^{2}$, with a stable weight over the past six months $(<5 \%$ body weight change). Exclusion criteria were gastrointestinal complaints, history of chronic or severe disease, use of medication influencing endpoints within 14 days prior to testing, administration of investigational drugs which interfere with this study, major abdominal surgery, dieting, pregnancy or lactation, excessive alcohol consumption (>20 alcoholic consumptions per week), smoking, weight $<60 \mathrm{~kg}$, non-tasters of sweet, bitter or umami stimuli, evidence of monosodium glutamate (MSG)-hypersensitivity.

Prior to testing, screening was performed where abovementioned inclusion and exclusion criteria were checked, and a taste perception test was performed. Subjects tasted quinine $(0.5 \mathrm{mmol} / \mathrm{L})$, Reb A (50 mmol/L), MSG (50 mmol/L), and tap water blindly and had to indicate their sense of taste. Subjects had to identify each taste correctly in order to be eligible for the study. Furthermore, their length and weight were measured to calculate their BMI.

A sample size calculation was based on the difference in meal intake between duodenal infusion of a combination of tastants and duodenal infusion of placebo as reported by van Avesaat et al. ${ }^{18}$ Using a difference in means of $64 \mathrm{Kcal}$, a standard deviation of difference of 63 , a power of $80 \%$, and an alpha of $1.67 \%$, a total number of 13 subjects were needed. An alpha of $1.67 \%$ was used to correct for multiple testing.

\section{Study design}

In this single-blind randomised, placebo-controlled crossover study, subjects received the combination of tastants (sweet, bitter, and umami) and/or placebo (tap water) in the duodenum and/or the ileum for four consecutive test days. This results in four combinations which were infused on the various test days: duodenal placebo and ileal placebo (DPIP), duodenal tastants and ileal placebo (DTIP), duodenal placebo and ileal tastants (DPIT), duodenal tastants and ileal tastants (D'TIT). 


\section{Catheter positioning}

A $305 \mathrm{~cm}$ long silicon 9-lumen (8-lumen, 1 balloon inflation channel, the outer diameter of $3.5 \mathrm{~mm}$ ) custom-made naso-ileal reusable catheter (Dentsleeve International, Mui Scientific, Mississauga, Canada) was used for intubation.

One day prior to the first test day, subjects arrived at 7:40 AM at the Maastricht University Medical Centre+ (MUMC+) after an overnight fast. If preferred by the subject, local anaesthesia of nasal mucosa using xylocaine $(10 \%$ spray, AstraZeneca, Zoetermeer, the Netherlands) was applied. After placement of the catheter in the stomach, the catheter was guided through the pylorus and into the duodenum under intermittent fluoroscopic control. Progression of the catheter from duodenum to ileum was performed as described earlier. ${ }^{19}$ Fluoroscopy was used to check the positioning of the catheter on the first and the last test day. Radio-opaque markers were added to the infusion ports on the catheter, which accounted for the determination of the catheter position. On all test days, intestinal fluid was sampled from various infusion ports, and $\mathrm{pH}$ was measured using $\mathrm{pH}$ strips (MColorpHast ${ }^{\mathrm{TM}}$, Merck, Darmstadt, Germany) in order to estimate the catheter positioning.

\section{Preparation and infusion of tastants}

The combination of three tastants was infused in the duodenum, the ileum, or both the duodenum and the ileum. In order to prevent side effects from occurring, $75 \%$ of acceptable daily intake (ADI) of these tastants was infused. $540 \mathrm{mg}$ Rebaudioside A (Reb A, Stevija Natuurlijk, Drachten, the Netherlands), 75 mg Quinine (Arnold Suhr, Hilversum, the Netherlands), and $2 \mathrm{~g}$ Monosodium Glutamate (MSG, Ajinomoto, Hamburg, Germany) were dissolved in $120 \mathrm{~mL}$ tap water and was used as tastant mixture for infusion, as was done by van Avesaat $e t$ al.18 All tastants used were non-caloric and yielded no nutritional value. The placebo infusion consisted of $120 \mathrm{~mL}$ of tap water. A magnetic stirrer was used to dissolve the tastants. The mixture was infused over a $60-\mathrm{min}$ period with an infusion rate of $2 \mathrm{~mL} / \mathrm{min}$. This was consistent with the infusion rate of van Avesaat et al. mimicking the slow influx from the stomach to duodenum and slow transit through the gut in the ileum.

\section{Protocol}

On each test day, after an $8 \mathrm{~h}$ overnight fast, subjects arrived at 8:00 $\mathrm{AM}$ at the MUMC+. Subjects were instructed to consume the same habitual meal on the 
evening prior to testing. Hereafter, at $\mathrm{t}=0 \mathrm{~min}$, a standardised liquid breakfast meal (250 mL Goedemorgen drinkontbijt (Vifit); energy $145 \mathrm{Kcal}$ per portion, $20.25 \mathrm{~g}$ carbohydrates, $8.5 \mathrm{~g}$ protein, and $2 \mathrm{~g}$ fat) was consumed. One hundred and fifty $\min ($ at $t=150 \mathrm{~min}$ ) after breakfast consumption, a syringe containing the mixture for infusion was connected to the duodenal and ileal infusion port. The infusion was performed in $60 \mathrm{~min}$ at an infusion rate of $2 \mathrm{ml} / \mathrm{min}$. Subjects received a standardised ad libitum lunch meal (Lasagne Bolognese (Plus supermarket); energy density per $100 \mathrm{~g}: 152 \mathrm{Kcal}, 11 \mathrm{~g}$ carbohydrates, $7.1 \mathrm{~g}$ protein, and $8.6 \mathrm{~g}$ fat) fifteen $\min ($ at $\mathrm{t}=225 \mathrm{~min}$ ) after cessation of the infusion. The test meal was offered in excess and subjects were instructed to eat until they felt satiated.

\section{VAS for appetite sensations and GI-complaints}

Appetite sensations and GI-complaints (e.g., satiation, hunger, stomach pain, and nausea) were measured using visual analogue scales (VAS, 0-100 mm) scores at various time points $(t=-30,30,90,150,165,180,195,210$, and $240 \mathrm{~min})$ during the day. Subjects were asked to indicate on a line, anchored at the low end with the lowest intensity feelings, with opposing terms at the high end, which place on the scale best reflected their feeling at that moment. ${ }^{20}$

\section{Statistical analyses}

Data were analysed using IBM SPSS statistics 24 (IBM Corporation, Armonk, NY, USA). A visual check of the normality of the data was performed. The primary outcome of this study was the amount of food intake in Kcal during an ad libitum lunch meal. Secondary outcomes were VAS scores for appetite sensations and GI-symptoms.

Age, BMI, and gender were calculated by descriptive statistics. Food intake in Kcal and area under the curve (AUC) for VAS scores were compared using a linear mixed model with intervention (DTIP, DPIT, and DTIT, and DPIP), test day and the interaction of intervention $\times$ test day as fixed factors. When no significant interaction was found, the interaction was removed from the model to get the best model fit.

For VAS scores, a linear mixed model that included abovementioned fixed factors with the addition of fixed factors time and time $\times$ treatment interaction was also performed.

Data are presented as mean \pm standard error of the mean (SEM) (unless specified otherwise), and a $\mathrm{p}<0.05$ was considered statistically significant. 


\section{Results}

\section{Subjects}

In total, 19 subjects met the inclusion and exclusion criteria. Two subjects dropped out due to discomfort induced by the naso-ileal catheter, two subjects dropped out due to incorrect position of the catheter on the first test day, and one subject was excluded after not properly following the instructions for the ad libitum meal on the first test day. Therefore, 14 healthy volunteers (11 female, age $25.6 \pm$ 10.5 years, BMI $22.3 \pm 1.7 \mathrm{~kg} / \mathrm{m}^{2}$ ) completed the study protocol and were included in the analyses.

\section{Food intake}

No intervention $\times$ test day interaction was found. No differences in ad libitum food intake in Kcal were observed after intraduodenal, intraileal or combined infusion of tastants versus placebo infusion (DPIP: $786.6 \pm 79.2 \mathrm{Kcal}$, DTIP: $803.3 \pm 69.0 \mathrm{Kcal}$, DPIT: $814.7 \pm 77.3 \mathrm{Kcal}$, DTIT: $834.8 \pm 59.2 \mathrm{Kcal} ; \mathrm{p}=0.59)$ (Figure 3.1). Furthermore, as depicted in Figure 3.2, no trends in individual responses were found.

\section{Satiation/Satiety scores}

The mean VAS scores for the desire to eat, hunger, satiation, and fullness are depicted in Figure 3.3. No differences in area under the curve $\left(\mathrm{AUC}_{150-210}\right)$ for these VAS scores were observed between the various interventions. Furthermore, no intervention $\times$ timepoint interactions were found for these VAS scores.

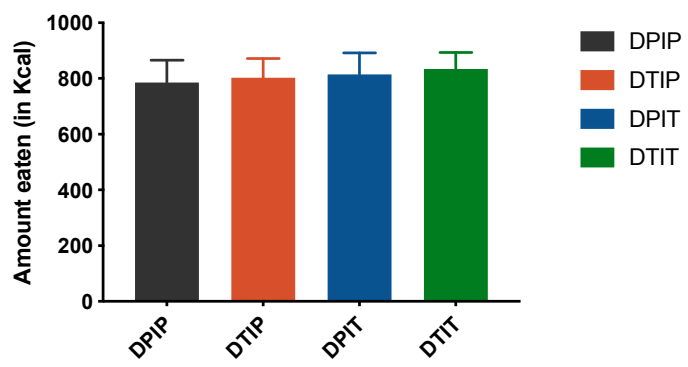

Figure 3.1 Food intake. The amount eaten in Kcal (mean + SEM) 15 min after cessation of the infusion of placebo both intraduodenal and intraileal (DPIP), tastants intraduodenal and placebo intraileal (DTIP), placebo intraduodenal and tastants intraileal (DPIT), and tastants both intraduodenal and intraileal (DTIT). Based on a linear mixed model, no difference in food intake was observed between the conditions $(\mathrm{p}=0.59)$. 


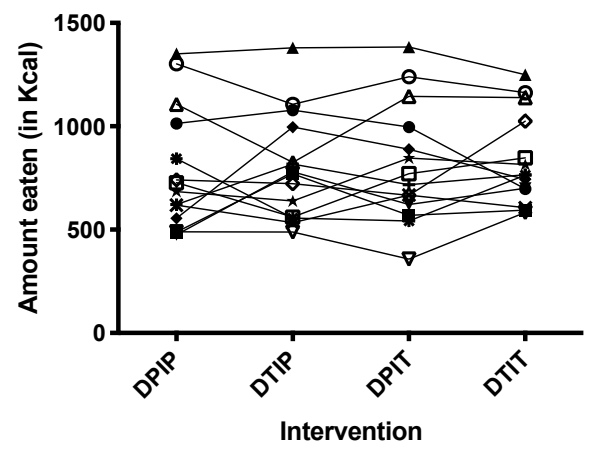

Figure 3.2 Individual food intake. An individual representation per subject of amount eaten in Kcal 15 min after cessation of the infusion of placebo both intraduodenal and intraileal (DPIP), tastants intraduodenal and placebo intraileal (DTIP), placebo intraduodenal and tastants intraileal (DPIT), and tastants both intraduodenal and intraileal (DTIT). Treatment order was randomised for each subject. Each line with a unique symbol represents an individual subject. Based on a linear mixed model, no difference in food intake was observed between the conditions $(p=0.59)$.

A

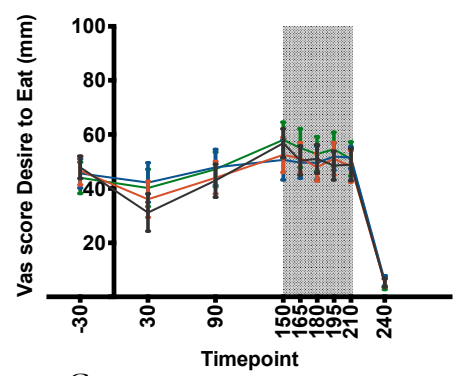

C

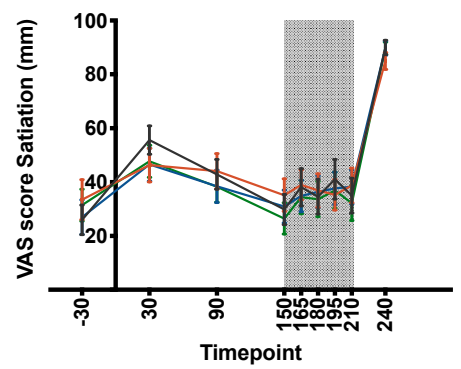

B

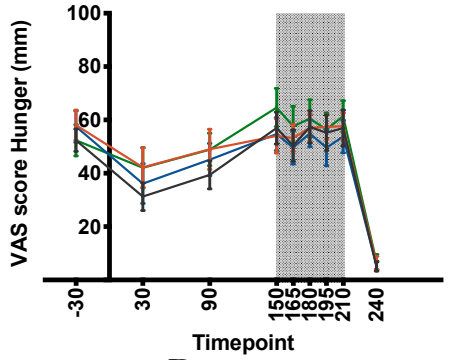

$\mathrm{D}$

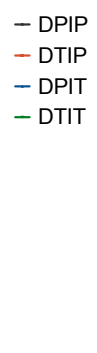

- DPIP

- DPIT

- DTIP

- DTIT

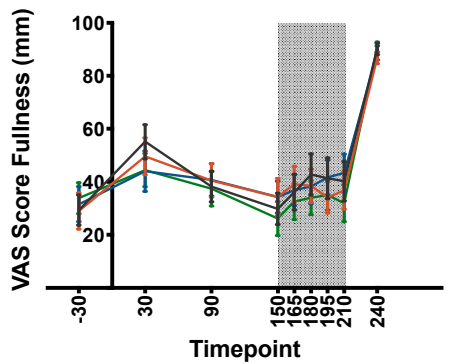

Figure 3.3 Appetite sensations. VAS scores for desire to eat $(\mathbf{A})$, hunger $(\mathbf{B})$, satiation $(\mathbf{C})$, and fullness $(\mathbf{D})$ (mean + SEM) before, during, and after the infusion of placebo both intraduodenal and intraileal (DPIP), tastants intraduodenal and placebo intraileal (DTIP), placebo intraduodenal and tastants intraileal (DPIT), and tastants both intraduodenal and intraileal (DTIT). VAS scores were measured at $\mathrm{t}=-30,30,90,150,165,180,195,210$, and $240 \mathrm{~min}$. No VAS scores were taken at $\mathrm{t}=225 \mathrm{~min}$. At $\mathrm{t}=0 \mathrm{~min}$, subjects received a standardised breakfast, infusion of mixtures was performed from $\mathrm{t}=150$ until $\mathrm{t}=210 \mathrm{~min}$, and ad libitum test meal was presented at $\mathrm{t}=225$. Based on a linear mixed model of mean scores and area under the curve (AUC150-210), no differences in desire to eat, hunger, satiation, and fullness were observed between the various conditions. 


\section{GI-complaints}

The mean VAS scores for stomach pain, bloating, and nausea are depicted in Figure 3.4. No differences in area under the curve $\left(\mathrm{AUC}_{150-210}\right)$ for these VAS scores were observed between the various interventions. Furthermore, no intervention $\times$ timepoint interactions were found for these VAS scores.

A

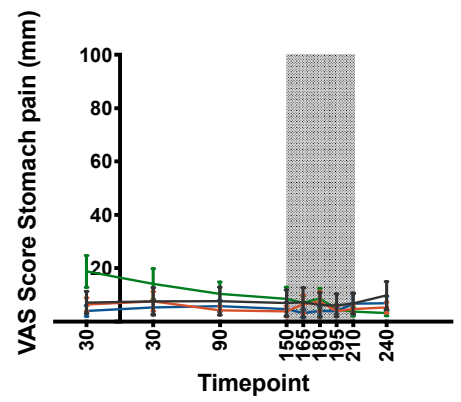

C

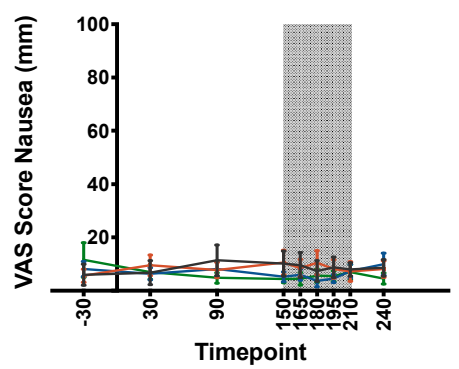

$\mathrm{B}$

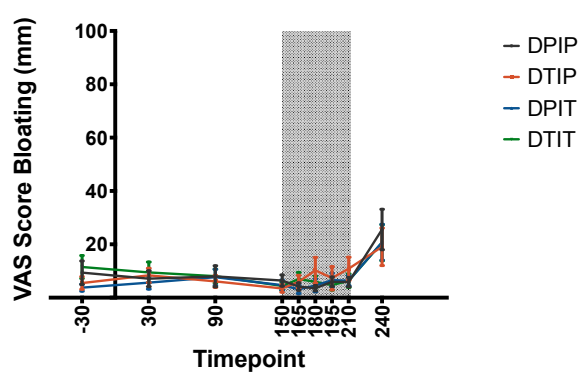

Figure 3.4 GI complaints. VAS scores for stomach pain (A), bloating (B), and nausea (C) (mean + SEM) before, during, and after the infusion of placebo both intraduodenal and intraileal (DPIP), tastants intraduodenal and placebo intraileal (DTIP), placebo intraduodenal and tastants intraileal (DPIT), and tastants both intraduodenal and intraileal (DTIT). $\mathrm{t}=-30,30,90,150,165,180,195,210$, and $240 \mathrm{~min}$. No VAS scores were taken at $\mathrm{t}=225 \mathrm{~min}$. At $\mathrm{t}=0 \mathrm{~min}$, subjects received a standardised breakfast, infusion of mixtures was performed from $\mathrm{t}=150$ until $\mathrm{t}=210 \mathrm{~min}$, and ad libitum test meal was presented at $\mathrm{t}=225 \mathrm{~min}$. Based on a linear mixed model of mean scores and area under the curve (AUC $150-210)$, no differences in stomach pain, bloating, and nausea were observed between the various conditions.

\section{Discussion}

Our results do not reveal any difference in appetite sensations or food intake between combined duodenal- and ileal administration of placebo, duodenal 
administration of a tastant mixture, ileal administration of a tastant mixture, or combined duodenal and ileal administration of a tastant mixture. Moreover, no GI-complaints were caused by infusing a tastant mixture or placebo into the duodenum and/or the ileum.

Van Avesaat et al. have investigated the effect of intraduodenal infusion of the same tastant mixture on food intake. ${ }^{18}$ In that study, intraduodenal infusion of this combination of tastants, in similar study design, using the same amount of tastants significantly reduced food intake by $64 \mathrm{Kcal}$ and was accompanied by increased satiation. However, it must be noted that this is a small difference, which on its own might not be clinically significant. Repeating this effect multiple times per day with each meal might result in a clinically significant decrease of caloric intake. This difference in results of food intake between the two studies may be related to differences in study design. In the study of van Avesaat et al., the subjects were intubated with a naso-duodenal catheter on every test day for the administration of tastants. The catheter was removed immediately thereafter before the subjects were presented with the ad libitum test meal. In the present study, subjects were intubated for several days with a naso-ileal catheter, and therefore this catheter was present while meals were offered and ingested. We hypothesise that having a naso-ileal catheter in situ for multiple days negatively influences meal ingestion to such a degree that this masks the smaller magnitude of effect that infusion of noncaloric tastants into the intestine has. On the other hand, mean caloric intake showed no major differences between the two studies.

Previous studies from our group investigating the 'intestinal brake' by infusing macronutrients in the ileum have repeatedly shown that infusion of even low doses of macronutrients results in a significant reduction of food intake, ranging between $64-188 \mathrm{Kcal}$, corresponding to a percentual decrease of $11.7 \%-32 \%$ of caloric intake during a single meal.,21 This indicates a negative feedback mechanism on food intake that arises from nutrient sensing. These data demonstrate that magnitude of the effect of macronutrient infusion on food intake is greater than the effects of infusing tastants.

Conclusively, studies investigating differences in food intake should be aware that naso-ileal intubation might mask a small effect. Therefore, other delivery options, such as encapsulation, should be considered in the future.

Results of studies investigating the effects of single tastants on food intake, satiation/satiety, and GI peptides are not consistent. An initial strong decrease of hunger with a steep increase thereafter has been observed after administration of a non-caloric sweetener. ${ }^{22}$ Ingestion of low caloric sweeteners did not influence energy intake compared with a control condition (intake of water). ${ }^{23}$ Adding an 
umami tastant to a meal did not affect appetite sensations but has been shown to result in an increase of subsequent food intake. ${ }^{24}$ Recently, increased attention has been given to the effects of bitter substances on satiation and food intake. Intake or infusion of bitter substances (quinine, denatonium benzoate) not only reduced antral motility 25,26 but also increased satiation/satiety scores and resulted in a significant decrease in food intake. ${ }^{27} \mathrm{~A}$ possible mechanism explaining the strong aversive effects of bitter tastants is that bitter taste is evolutionarily linked to toxic substances, as has been showed by presenting new-born infants with bitter substances. ${ }^{28}$

Alleleyn et al. have shown that the inhibition of food intake shows a proximal to the distal gradient, with higher effects observed after distal versus proximal administration of nutrients. ${ }^{8}$ Based on our data, such a gradient was not observed for intestinally administered tastants. Intestinal taste receptor expression varies for various taste receptors, where some taste receptors are more profound proximally in the GI-tract, while expression of other taste receptors is higher in the more distal intestine. ${ }^{14-17}$

We thought the proximal to distal gradient found for macronutrient infusion might be operable for taste receptor activation, which was clearly not the case. It is possible that taste receptors inhibit food intake in a different fashion than macronutrients. For instance, it has been speculated that taste receptors function by sensing the type of food (i.e., sweet for carbohydrates, umami for amino acids, and bitter for toxic substances). ${ }^{29}$ Since bitter tastants are linked to toxic substances, another working mechanism for bitter tastants could be through an aversive reaction of subsequent food intake.

From an evolutionary perspective, a more pronounced inhibitory or aversive effect for toxic substances could be expected to occur in the most proximal parts of the GI tract. However, there are no data available with respect to activation of oral (bitter) taste receptors on subsequent food intake. It is therefore unclear, whether activation of more proximal taste receptors will reveal more pronounced effects on food intake and satiation/satiety. Consequently, further studies are needed to investigate whether more proximal activation of taste receptors results in a stronger decrease in food intake.

Published data on the role of GI peptides in the regulation of food intake after administration of tastants are not in line. Van Avesaat et al. found a clear effect of intraduodenal administration of tastants on food intake that was not accompanied by changes in GLP-1- or PYY level. ${ }^{18}$ Other studies, however, did show a decrease in systemic ghrelin- and motilin levels ${ }^{25,26}$ and an increase in systemic CCK levels ${ }^{27}$ after administration of a bitter tastant. 
A limitation of our study is that the wash-out period consisted of only one day. Prolonging the wash-out period over one day would have resulted in a longer period of naso-ileal catheter intubation increasing the discomfort to our volunteers. No interaction effect between intervention and test day was found on food intake, satiation scores or GI-complaints, indicating that no carry-over effect was present.

Another limitation of the present study was the absence of systemic GI hormone measurements. This would have provided a complete analysis of the effects of intestinal tastant administration on eating behaviour. However, van Avesaat et al. showed a decrease in food intake and an increase in satiation scores, which was not accompanied by changes in systemic GI hormone levels. ${ }^{18}$ Therefore, no systemic GI hormone measurement was conducted in the present study.

It has to be noted that the ideal duration of administration of the intervention and of the timing between intervention and serving the ad libitum meal is unknown. We employed a design similar to that of van Avesaat et al. based on their positive results. ${ }^{18}$ Future research protocols should consider these factors.

Studies investigating the effects of tastants on food intake up to now focus on only acute effects in a single ad libitum meal. It is not known whether repetitive or chronic administration of tastants will lead to other results. More data are needed on the long-term effects of tastants, especially on daily energy intake. 


\section{References}

1. WHO. Obesity and Overweight 2018. Available online: http://www.who.int/en/news-room/fact-sheets/ detail/obesity-and-overweight (accessed on 3 August 2018).

2. Lieverse RJ, Jansen JB, Masclee AA, Lamers CB. Satiety effects of a physiological dose of cholecystokinin in humans. Gut 1995;36:176-9.

3. Lieverse RJ, Jansen JB, van de Zwan A, Samson L, Masclee AA, Lamers CB. Effects of a physiological dose of cholecystokinin on food intake and postprandial satiation in man. Regul Pept 1993;43:83-9.

4. Verdich C, Flint A, Gutzwiller JP, Naslund E, Beglinger C, Hellstrom PM, et al. A meta-analysis of the effect of glucagon-like peptide-1 (7-36) amide on ad libitum energy intake in humans. J Clin Endocrinol Metab 2001;86:4382-9.

5. van Avesaat M, Troost FJ, Ripken D, Hendriks HF, Masclee AA. Ileal brake activation: Macronutrientspecific effects on eating behavior? Int J Obes 2015;39:235-43.

6. Maljaars PW, Peters HP, Mela DJ, Masclee AA. Ileal brake: A sensible food target for appetite control. A review. Physiol Behav 2008;95:271-81.

7. Shin HS, Ingram JR, McGill AT, Poppitt S. Lipids, CHOs, proteins: Can all macronutrients put a 'brake' on eating? Physiol Behav 2013;120:114-23.

8. Alleleyn AM, van Avesaat M, Troost FJ, Masclee AA. Gastrointestinal Nutrient Infusion Site and Eating Behavior: Evidence for A Proximal to Distal Gradient within the Small Intestine? Nutrients 2016;8:117.

9. Sternini C, Anselmi L, Rozengurt E. Enteroendocrine cells: A site of 'taste' in gastrointestinal chemosensing. Curr Opin Endocrinol Diabetes Obes 2008;15:73-8.

10. Jang HJ, Kokrashvili Z, Theodorakis MJ, Carlson OD, Kim BJ, Zhou J, et al. Gut-expressed gustducin and taste receptors regulate secretion of glucagon-like peptide-1. Proc Natl Acad Sci USA 2007;104:15069-74.

11. Rozengurt N, Wu SV, Chen MC, Huang C, Sternini C, Rozengurt E. Colocalization of the alpha-subunit of gustducin with PYY and GLP-1 in L cells of human colon. Am J Physiol Gastrointest Liver Physiol 2006;291:G792-G802.

12. Sutherland K, Young RL, Cooper NJ, Horowitz M, Blackshaw LA. Phenotypic characterization of taste cells of the mouse small intestine. Am J Physiol Gastrointest Liver Physiol 2007;292:G1420-8.

13. Wu SV, Rozengurt N, Yang M, Young SH, Sinnett-Smith J, Rozengurt E. Expression of bitter taste receptors of the T2R family in the gastrointestinal tract and enteroendocrine STC-1 cells. Proc Natl Acad Sci USA 2002;99:2392-7.

14. Bezencon C, le Coutre J, Damak S. Taste-signaling proteins are coexpressed in solitary intestinal epithelial cells. Chem Senses 2007;32:41-9.

15. Young RL, Sutherland K, Pezos N, Brierley SM, Horowitz M, Rayner CK, et al. Expression of taste molecules in the upper gastrointestinal tract in humans with and without type 2 diabetes. Gut 2009;58:337-46.

16. van der Wielen N, van Avesaat M, de Wit NJ, Vogels JT, Troost F, Masclee A, et al. Cross-species comparison of genes related to nutrient sensing mechanisms expressed along the intestine. PLoS One 201419: e107531.

17. Gu F, Liu X, Liang J, Chen JY, Chen FX, Li F. Bitter taste receptor mTas2r105 is expressed in small intestinal villus and crypts. Biochem Biophys Res Commun 2015; 463: 934-41.

18. van Avesaat M, Troost FJ, Ripken D, Peters J, Hendriks HF, Masclee AA. Intraduodenal infusion of a combination of tastants decreases food intake in humans. Am J Clin Nutr 2015;102:729-35.

19. Maljaars PW, Symersky T, Kee BC, Haddeman E, Peters HP, Masclee AA. Effect of ileal fat perfusion on satiety and hormone release in healthy volunteers. Int J Obes 2008; 32:1633-9.

20. Parker BA, Sturm K, MacIntosh CG, Feinle C, Horowitz M, Chapman IM. Relation between food intake and visual analogue scale ratings of appetite and other sensations in healthy older and young subjects. Eur $\mathrm{J}$ Clin Nutr 2004;58:212-8.

21. van Avesaat M, Ripken D, Hendriks HF, Masclee AA, Troost FJ. Small intestinal protein infusion in humans: Evidence for a location-specific gradient in intestinal feedback on food intake and GI peptide release. Int J Obes 2017;41:217-24. 
22. Meyer-Gerspach AC, Biesiekierski JR, Deloose E, Clevers E, Rotondo A, Rehfeld JF, et al. Effects of caloric and noncaloric sweeteners on antroduodenal motility, gastrointestinal hormone secretion and appetite-related sensations in healthy subjects. Am J Clin Nutr 2018;107:707-16.

23. Fantino M, Fantino A, Matray M, Mistretta F. Beverages containing low energy sweeteners do not differ from water in their effects on appetite, energy intake and food choices in healthy, non-obese French adults. Appetite 2018;125:557-65.

24. Luscombe-Marsh ND, Smeets AJ, Westerterp-Plantenga MS. The addition of monosodium glutamate and inosine monophosphate-5 to high-protein meals: Effects on satiety, and energy and macronutrient intakes. Br J Nutr 2009;102:929-37.

25. Deloose E, Corsetti M, Van Oudenhove L, Depoortere I, Tack J. Intragastric infusion of the bitter tastant quinine suppresses hormone release and antral motility during the fasting state in healthy female volunteers. Neurogastroent. Motil. 2018;30(1).

26. Deloose E, Janssen P, Corsetti M, Biesiekierski J, Masuy I, Rotondo A, et al. Intragastric infusion of denatonium benzoate attenuates interdigestive gastric motility and hunger scores in healthy female volunteers. Am J Clin Nutr 2017;105:580-8.

27. Andreozzi P, Sarnelli G, Pesce M, Zito FP, Alessandro AD, Verlezza V, et al. The Bitter Taste Receptor Agonist Quinine Reduces Calorie Intake and Increases the Postprandial Release of Cholecystokinin in Healthy Subjects. J Neurogastroenterol Motil 2015;21:511-9.

28. Steiner JE, Glaser D, Hawilo ME, Berridge KC. Comparative expression of hedonic impact: Affective reactions to taste by human infants and other primates. Neurosci Biobehav Rev 2001;25:53-74.

29. Breslin PA, Spector AC. Mammalian taste perception. Curr Biol 2008;18:R148-55. 


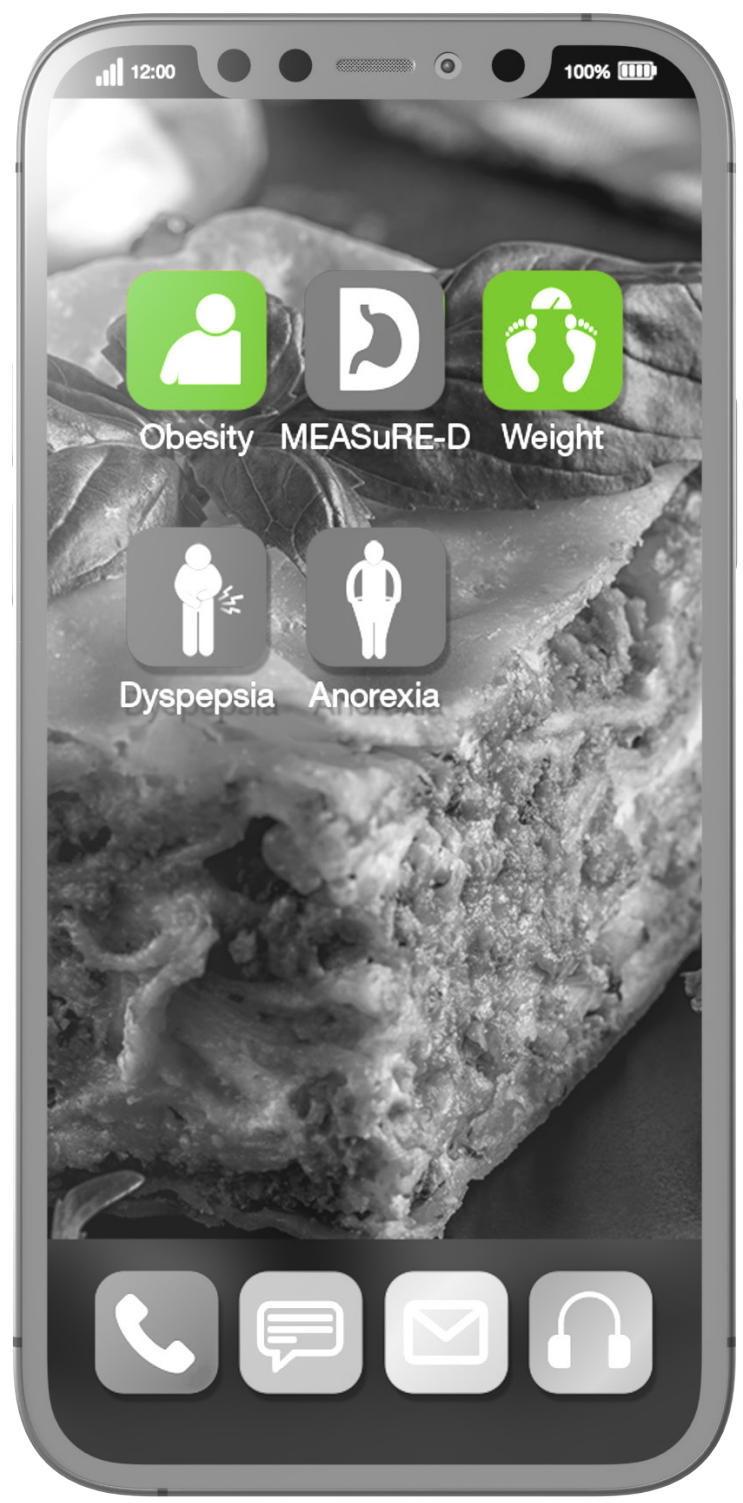




\section{Chapter 4}

Effect of oral or intragastric delivery of the bitter tastant quinine on food intake and appetite sensations: a randomised crossover trial

Tim Klaassen

Daniel Keszthelyi Annick M.E. Alleleyn

Ellen Wilms

Aalt Bast

Ad A.M. Masclee

Freddy J. Troost 


\begin{abstract}
Stimulation of gastrointestinal taste receptors affects eating behaviour. Intraduodenal infusion of tastants leads to increased satiation and reduced food intake, whereas intraileal infusion of tastants does not affect eating behaviour. Currently, it is unknown whether oral- or intragastric administration of tastants induces a larger effect on eating behaviour. This study investigated the effects of oral- and/or intragastric administration of quinine on food intake, appetite sensations, and heart rate variability (HRV). In a blinded randomised crossover trial, 32 healthy volunteers participated in four interventions with a one-week washout: oral placebo/intragastric placebo (OPGP), oral quinine/intragastric placebo (OQGP), oral placebo/intragastric quinine (OPGQ), and oral quinine/intragastric quinine (OQGQ). On test days, 150 minutes after a standardised breakfast, subjects ingested a capsule containing quinine or placebo and were sham-fed a mixture of quinine or placebo orally. Fifty min after intervention, subjects received an ad libitum meal to measure food intake. Visual analogue scales for appetite sensations were collected and HRV measurements were performed at regular intervals. Oral- and/or intragastric delivery of the bitter tastant quinine did not affect food intake OPGP: 3273.6 (SEM 131.8) KJ, OQGP: 3072.7 (SEM 132.2) KJ, OPGQ: 3289.0 (SEM 132.6) KJ, OQGQ: 3204.1 (SEM 133.1) KJ, $\mathrm{p}=0.069)$. Desire to eat and hunger decreased after OQGP and OPGQ compared with OPGP ( $\mathrm{p}<0.001$ and $\mathrm{p}<0.05$, respectively), whereas satiation, fullness and HRV did not differ between interventions. In conclusion, sole oral sham feeding with- and sole intragastric delivery of quinine decreased desire to eat and hunger, without affecting food intake, satiation, fullness, or HRV.
\end{abstract}




\section{Introduction}

Since 1975, the prevalence of obesity has nearly tripled, being a major healthcare problem worldwide ${ }^{1}$ urging the need for non-invasive treatment strategies. The gastrointestinal (GI) tract plays a crucial role in the regulation of eating behaviour via its ability to produce and secrete GI peptides upon food-derived triggers. ${ }^{2-4}$ In order for the GI tract to modulate eating behaviour, food constituents need to be sensed in the gut. It has been shown that intestinal infusion of macronutrients reduces food intake that is accompanied by the release of GI peptides, generally called the intestinal brake, ${ }^{5-7}$ which is operable in a proximal to distal intestinal gradient. ${ }^{8}$

Another way to perceive food constituents in the gut is via taste receptors, which are expressed throughout the entire GI tract.9-11 and have been shown to trigger the release of GI peptides in vitro. ${ }^{12-15}$ Duodenal delivery of a tastant mixture containing non-caloric sweet, bitter and umami tastants, resulted in significant decrease in food intake, without affecting systemic GI peptide levels. ${ }^{16}$ However, the proximal to distal gradient operable for macronutrients was not applicable to tastants. ${ }^{17}$

Inhibition of food intake via taste receptors may occur via pathways different from those via nutrient receptors. It has been hypothesised that taste predicts the type of food that is ingested (i.e., bitter for toxic substances, umami for amino acids, and sweet for carbohydrates). ${ }^{18}$ Since bitter taste is linked to toxic substances, subsequent food intake could be limited via an aversive reaction to bitter tastants. Currently, data on sole oral effects of (bitter) tastant delivery (i.e., without ingesting) on eating behaviour is lacking.

Besides endocrine signalling, the autonomic nervous system (ANS) plays a role in appetite signalling. Changes in the balance of ANS can occur prior to changes in GI peptide levels in presence of a shift from hunger to satiety. ${ }^{19,20}$ Increased sympathetic tone is suggested to indicate satiation in humans. ${ }^{21}$ In addition to aversive responses in reaction to bitter substances, bitter taste also exerts a strong sympathetic activation. ${ }^{22}$ A simple, non-invasive method to measure ANS is heart rate variability (HRV), a physiological variation in time interval between consecutive heartbeats. ${ }^{23}$

This study investigated the effects of oral- versus intragastric versus synchronous oral- and intragastric delivery of the bitter tastant quinine on eating behaviour in healthy subjects, with ad libitum food intake as primary outcome and HRV, appetite sensations, and GI-complaints as secondary outcomes. We hypothesised that synchronous oral and intragastric delivery of quinine decreases food intake 
compared with placebo or delivery of quinine solely oral- or intragastric. Moreover, we expected that solely oral- or intragastric delivery of quinine would decrease food intake compared with placebo, albeit to a lesser extent than synchronous oral- and intragastric delivery of quinine. Finally, we expect oral delivery of quinine to decrease food intake to a greater extent than intragastric delivery of quinine.

\section{Methods}

This study was approved by the Medical Ethics Committee of the Maastricht University Medical Centre+ (MUMC+), Maastricht, the Netherlands (ID METC163047), and performed in full accordance with the Declaration of Helsinki (latest amendment by the World Medic Association in 2013) and Dutch Regulations on Medical Research involving Human Subjects (WMO, 1998). The study was performed at the Maastricht University Campus Venlo from August 17th 2018 until August 15th 2019. This study was registered in the US National Library of Medicine (http://www.clinicaltrials.gov, ID NCT 03565133). All subjects gave written informed consent before screening.

\section{Subjects}

Healthy men and women were recruited by local advertisements. Inclusion criteria were age between 18 and 65 years, a body mass index (BMI) between 18 and $25 \mathrm{~kg} / \mathrm{m}^{2}$, with a stable weight over the past six months $(<5 \%$ bodyweight change). Exclusion criteria were GI complaints, history of chronic or severe disease, use of medication influencing study endpoints within 14 days prior to testing, administration of investigational drugs which interfere with this study, major abdominal surgery, dieting, pregnancy or lactation, excessive alcohol consumption ( $>20$ alcoholic consumptions per week), smoking, and non-tasters of the bitter stimulus quinine.

Prior to testing, a screening was performed where abovementioned in- and exclusion criteria were checked and a taste perception test with quinine was performed. Subjects tasted quinine $(0.5 \mathrm{mmol} / \mathrm{L})$ and tap water blindly and had to indicate their sense of taste. Subjects had to correctly identify the bitter taste of the quinine sample in order to be eligible for the study. Furthermore, length and weight were measured to calculate BMI. 


\section{Study design}

In this blinded randomised, placebo-controlled crossover study, subjects received a capsule containing quinine or placebo (cellulose, which is tasteless and odourless in itself 22,24 and subjects performed oral sham-feeding with quinine dissolved in tap water or placebo (tap water) on four test days separated by at least one-week wash-out. An independent researcher not involved in execution of the study generated the randomisation list using www.sealedenvelope.com. On each test day, participants received one of the following interventions in random order: oral placebo and intragastric placebo (OPGP), oral quinine and intragastric placebo (OQGP), oral placebo and intragastric quinine (OPGQ), and oral quinine and intragastric quinine (OQGQ). Subjects and researchers were blinded for the containments of the capsule, but not for the substance used for oral sham feeding as subjects cannot be blinded for the taste of oral sham feeding intervention. Moreover, due to an evolutionary aversive reaction to tasting a bitter substance, ${ }^{25}$ subjects would involuntarily show whether oral sham feeding with tap water or with quinine dissolved in tap water is being performed. Therefore, the researcher could not be blinded for the oral sham condition.

\section{Oral sham feeding}

For oral sham feeding $75 \mathrm{mg}$ of quinine-hydrochloride (QHCl) (Arnold Suhr, Hilversum, the Netherlands) was dissolved in $120 \mathrm{ml}$ tap water. A magnetic stirrer was used to dissolve the quinine. As placebo condition, $120 \mathrm{ml}$ tap water was used. Sham feeding was performed by letting subjects take several sips (habitual size as if they would take a sip of a drink) out of one cup and letting them swish the contents around with closed mouth for 20-30 seconds before expectorating it in a different cup according to previously described protocols. ${ }^{26,27}$ This induced two to three minutes of sensory stimulation.

\section{Intragastric capsule}

Capsules were manufactured by 'Verenigde Apotheken Limburg (VAL) Bereidingsapotheek', Maastricht, the Netherlands. Gelatine capsules were filled with $75 \mathrm{mg}$ QHCl and cellulose. As placebo, capsules were filled with cellulose only. The capsules were indistinguishable in terms of appearance and weight. According to the VAL capsule breakup time was $<$ nine minutes (unpublished results). A dosage of $75 \mathrm{mg} \mathrm{QHCl}$ was used, as this aligns with previous research from our group. ${ }^{16,17}$ 


\section{Protocol}

On each test day, after an $8 \mathrm{~h}$ overnight fast, subjects arrived at 8:30 AM at the Maastricht University Campus Venlo. Subjects were instructed to consume the same habitual meal on the evening prior to testing. At $\mathrm{t}=-150 \mathrm{~min}$ subjects consumed a standardised liquid breakfast meal $(250 \mathrm{ml}$ Goedemorgen drinkontbijt (Vifit, Friesland Campina, Amersfoort, the Netherlands); energy $648.5 \mathrm{KJ}$ (155 Kcal) per portion, $22 \mathrm{~g}$ carbohydrates, $8.5 \mathrm{~g}$ protein, and $2 \mathrm{~g}$ fat). One hundred and fifty $\min$ (at $\mathrm{t}=0 \mathrm{~min}$ ) after breakfast consumption, subjects ingested the capsule with $120 \mathrm{ml}$ tap water and directly thereafter performed the oral sham feeding. Participants were not allowed to rinse their mouths after the sham feeding. Participants reported a persistent bitter taste in their mouth, although this was not quantified. Fifty min after the intervention (at $\mathrm{t}=50$ ), subjects received a standardised ad libitum lunch meal. During the test day, heart rate variability (HRV) measurements (at $\mathrm{t}=-150 \mathrm{~min}, \mathrm{t}=-15 \mathrm{~min}, \mathrm{t}=5 \mathrm{~min}$, and $\mathrm{t}=35 \mathrm{~min}$ ) were performed and VAS scores for appetite sensations $(t=-20 \mathrm{~min}, t=-10 \mathrm{~min}$, $\mathrm{t}=0 \mathrm{~min}, \mathrm{t}=10 \mathrm{~min}, \mathrm{t}=20 \mathrm{~min}, \mathrm{t}=30 \mathrm{~min}, \mathrm{t}=40 \mathrm{~min}, \mathrm{t}=50 \mathrm{~min}$, and $\mathrm{t}=\mathrm{END})$ were collected. An overview of the timeline of the test days can be found in Figure 4.1.

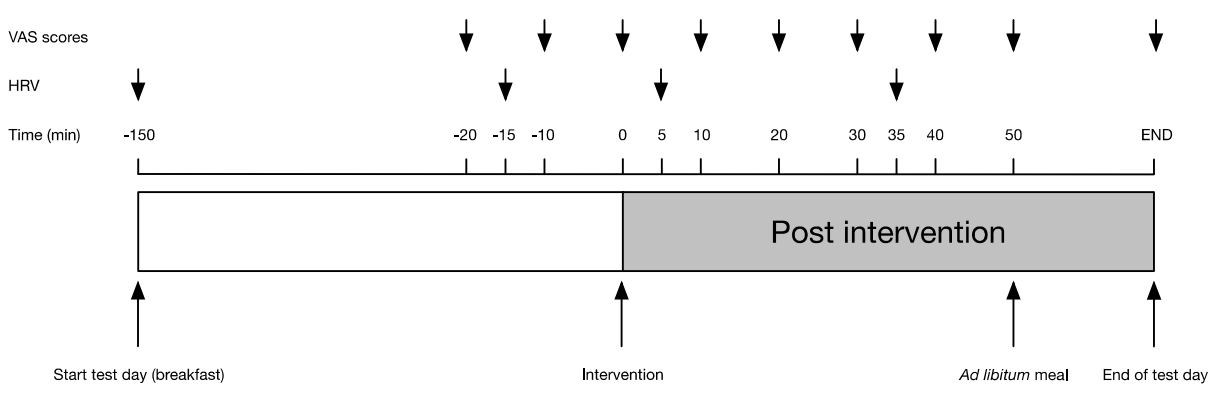

Figure 4.1 Timeline of test day. A standardised breakfast was consumed at $t=-150 \mathrm{~min}$. At $\mathrm{t}=0 \mathrm{~min}$ participants ingested a capsule containing quinine or placebo and performed oral sham feeding with quinine dissolved in tap water or solely tap water. Fifty mins after the intervention an ad libitum test meal was offered. Heart rate variability (HRV) measurements were performed and VAS scores for appetite sensations and GI complaints were collected over the course of the test day. Endpoint of the study and last VAS scores varied per subject, depending on duration of test meal intake.

\section{Ad libitum test meal}

Subjects received a standardised ad libitum lunch meal (Lasagne Bolognese (Plus supermarket, Utrecht, the Netherlands); energy density per 100 g: $581.6 \mathrm{KJ}$ 
(139 Kcal); food constituents: $10.6 \mathrm{~g}$ carbohydrates, $8.1 \mathrm{~g}$ protein, and $6.7 \mathrm{~g}$ fat) fifty $\mathrm{min}$ (at $\mathrm{t}=50 \mathrm{~min}$ ) after the intervention. The test meal was offered in excess (a portion of $1 \mathrm{~kg}(5815.7 \mathrm{KJ}(1390 \mathrm{Kcal}))$, which is more than half of the recommended daily intake. No participant finished the entire portion) and subjects were instructed to eat until they felt satiated.

VAS for appetite sensations and gastrointestinal complaints

Appetite sensations and GI-complaints (e.g., satiety, hunger, stomach pain, and nausea) were measured using visual analogue scales (VAS, 0-100 $\mathrm{mm}$ ) over the course of the test day. Subjects were asked to indicate on a line, anchored at the low end with the lowest intensity feelings, with opposing terms at the high end, which place on the scale best reflected their feeling at that moment. ${ }^{28}$

\section{Heart rate variability}

Utilising only standard and uni-polar leads, short time electrocardiogram (ECG) records were obtained using computer electrocardiograph "Poly-Spectrum-8/E" (Neurosoft ${ }^{\circledR}$, version 5.3.1.0, Ivanovo, Russia). Five minutes recordings were performed after a resting period of at least 5 minutes. Measurements were performed in a semi-recumbent position in order to minimise ectopic activity. With a sampling frequency of $2 \mathrm{kHz}$, successive heartbeats or inter-beat intervals were determined and analysed according to HRV standards using "PolySpectrum-8" (Neurosoft $\AA$, version 5.3.1.0, Ivanovo, Russia) software. ${ }^{23}$ The power spectral analysis was performed with a fast Fourier transformation. Total power (TP, 0.01 to $0.40 \mathrm{~Hz}$ ), high frequency power ( $\mathrm{HF}, .15$ to $0.40 \mathrm{~Hz}$ ), low frequency power (LF, 0.04 to $0.15 \mathrm{~Hz}$ ), and very low frequency power (VLF, 0.01 to $0.04 \mathrm{~Hz}$ ) were calculated. For this study heart rate and $\mathrm{LF} / \mathrm{HF}$ ratio were investigated.

\section{Statistical analyses}

A sample size calculation was based on the difference in food intake after duodenal infusion of the bitter tastant quinine in comparison to food intake after duodenal infusion of placebo as reported by van Avesaat et al. ${ }^{16} \mathrm{We}$ anticipated the same magnitude for change comparing the combined oral and gastric administration vs. placebo. Using a difference in means of $184.1 \mathrm{KJ}$ (44 Kcal), a standard deviation of difference of $355.6 \mathrm{KJ}$ (85 Kcal), a power of $80 \%$, and an alpha of $5 \%$, a total number of 32 subjects was needed. 
Data was analysed using IBM SPSS statistics 25 (IBM Corporation, Armonk, NY, USA). Kolmogorov-Smirnov tests as well as a visual check of normality of the data were performed. The primary outcome of this study was food intake during an ad libitum lunch meal. Secondary outcomes were VAS scores for appetite sensations and GI-complaints, and HRV measurements. Data are presented as mean \pm standard error of mean (SEM) (unless specified otherwise).

Age, BMI and sex were calculated by descriptive statistics.

Food intake measurements were compared using an autoregressive (1) linear mixed model with intervention, test day and the interaction of intervention $\times$ test day as fixed factors. In case no intervention $\times$ test day interaction was found, this factor was removed from the model to get the best model fit.

VAS scores for appetite sensations and GI complaints were compared using an autoregressive (1) linear mixed model with intervention, test day, time and the interactions of intervention $\times$ test day and time $\times$ intervention as fixed factors. In case no intervention $\times$ test day interaction was found, this factor was removed from the model to get the best model fit.

HRV measurements were compared using an autoregressive (1) linear mixed model with intervention, test day, time and the interactions of intervention $\times$ test day and time $x$ intervention as fixed factors. In case no intervention $\times$ test day interaction was found, this factor was removed from the model to get the best model fit.

For all analyses a $\mathrm{p}<0.05$ was considered statistically significant. Whenever a main effect was found, Bonferroni correction for multiple testing was performed per outcome parameter.

\section{Results}

\section{Subjects}

In total 34 subjects met the in- and exclusion criteria. Two subjects dropped out after the first test day due to personal circumstances. Therefore, 32 healthy volunteers (22 female, age $25.3 \pm$ SD 3.8 years, BMI $22.5 \pm$ SD $1.9 \mathrm{~kg} / \mathrm{m}^{2}$ ) completed the study protocol and were included in the analyses. No other adverse events were reported and all subjects tolerated the interventions well. 


\section{Food intake}

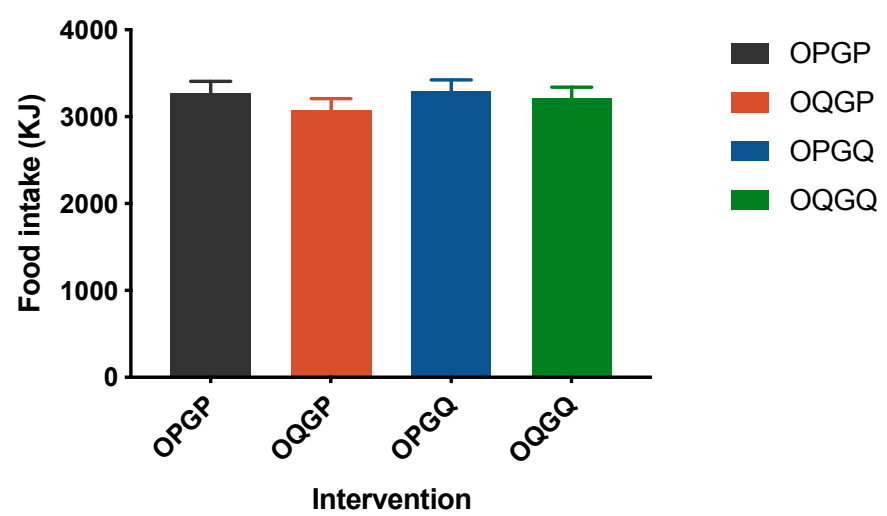

Figure 4.2 Food intake. Amount eaten in KJ (mean + SEM) 50 minutes after oral placebo and intragastric placebo (OPGP), oral quinine and intragastric placebo (OQGP), oral placebo and intragastric quinine (OPGQ), and quinine both oral and intragastric (OQGQ). Based on an autoregressive (1) linear mixed model, no difference in food intake was observed between the conditions $(p=0.069)$.

\section{Food intake}

Based on estimated means, no differences in ad libitum food intake were observed after oral sham feeding with quinine, intragastric delivery of quinine or combined oral sham feeding with- and intragastric delivery of quinine versus placebo (Placebo: 3273.6 (SEM 131.8) KJ, oral sham feeding with quinine: 3072.7 (SEM 132.2) KJ, intragastric delivery of quinine: 3289.0 (SEM 132.6) KJ, oral sham feeding with- and intragastric delivery of quinine: 3204.1 (SEM 133.1) KJ, $\mathrm{p}=0.069$ ) (Figure 4.2). Furthermore, no trends in individual responses were found (Figure 4.3). 


\section{Food intake individual}

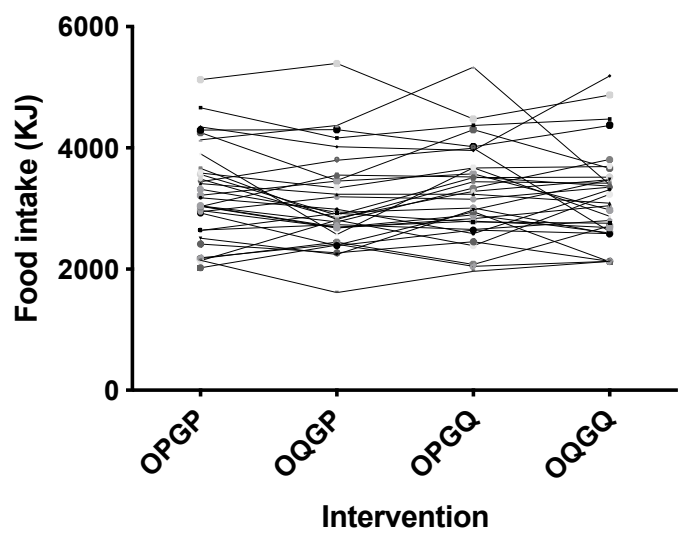

Figure 4.3 Individual food intake. Individual representation per subject of amount eaten in KJ (mean + SEM) 50 minutes after oral placebo and intragastric placebo (OPGP), oral quinine and intragastric placebo (OQGP), oral placebo and intragastric quinine (OPGQ), and quinine both oral and intragastric (OQGQ). Based on an autoregressive (1) linear mixed model, no difference in food intake was observed between the conditions $(\mathrm{p}=0.069)$.

\section{Appetite sensations}

The mean VAS scores for desire to eat, hunger, satiation, and fullness are depicted in Figure 4.4. Based on a linear mixed model, significant main effects of intervention were found for desire to eat and hunger scores, indicating an overall intervention effect on these scores. Post hoc pairwise comparisons showed a significant reduction in desire to eat and hunger scores for oral sham feeding with quinine vs. placebo (both $\mathrm{p}<0.001$ ), intragastric delivery of quinine vs. placebo (both $\mathrm{p}<0.05$ ), and oral sham feeding with quinine vs. oral sham feeding with- and intragastric delivery of quinine (both $\mathrm{p}<0.01$ ). No main effects of intervention were found for satiation and fullness scores. No intervention $\times$ time interactions were found for any of the VAS scores, thus intervention effects did not differ on specific timepoints. 

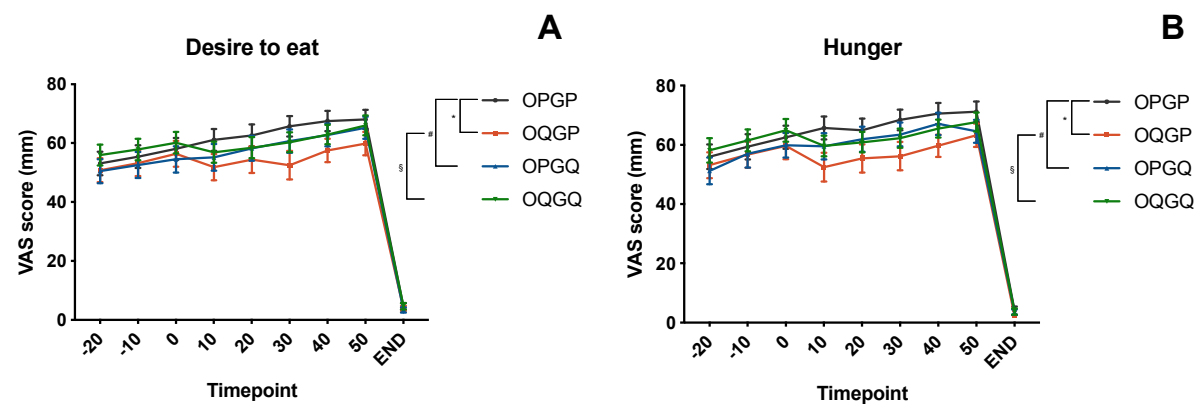

B

C
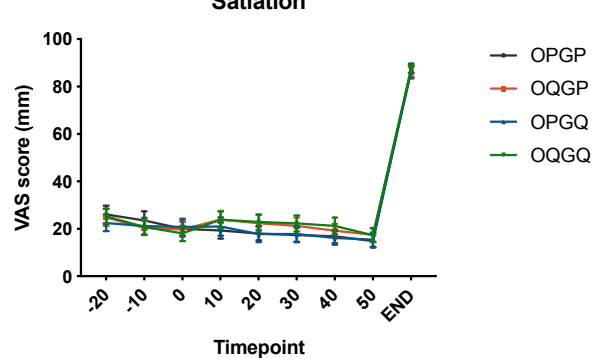

Fullness

D

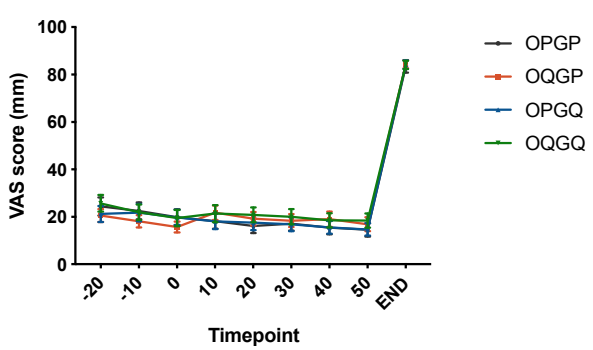

Figure 4.4 Appetite sensations. VAS scores for desire to eat $(\mathbf{A})$, hunger $(\mathbf{B})$, satiation $(\mathbf{C})$, and fullness $(\mathbf{D})$ $($ mean + SEM) before and after oral placebo and intragastric placebo (OPGP), oral quinine and intragastric placebo (OQGP), oral placebo and intragastric quinine (OPGQ), and quinine both oral and intragastric (OQGQ). Based on an autoregressive (1) linear mixed model, intervention effects were found for desire to eat and hunger scores $(\mathrm{p}<0.001)$. Bonferroni correction was applied for post-hoc pairwise comparisons. $*<0.001, \#<0.05, \mathbb{\Omega}<0.01$.

\section{Gastrointestinal complaints}

The mean VAS scores for stomach pain, bloating, and nausea are depicted in Figure 4.5. No intervention effects for these VAS scores were found. Moreover, no intervention $\times$ timepoint interactions were found for these VAS scores. 

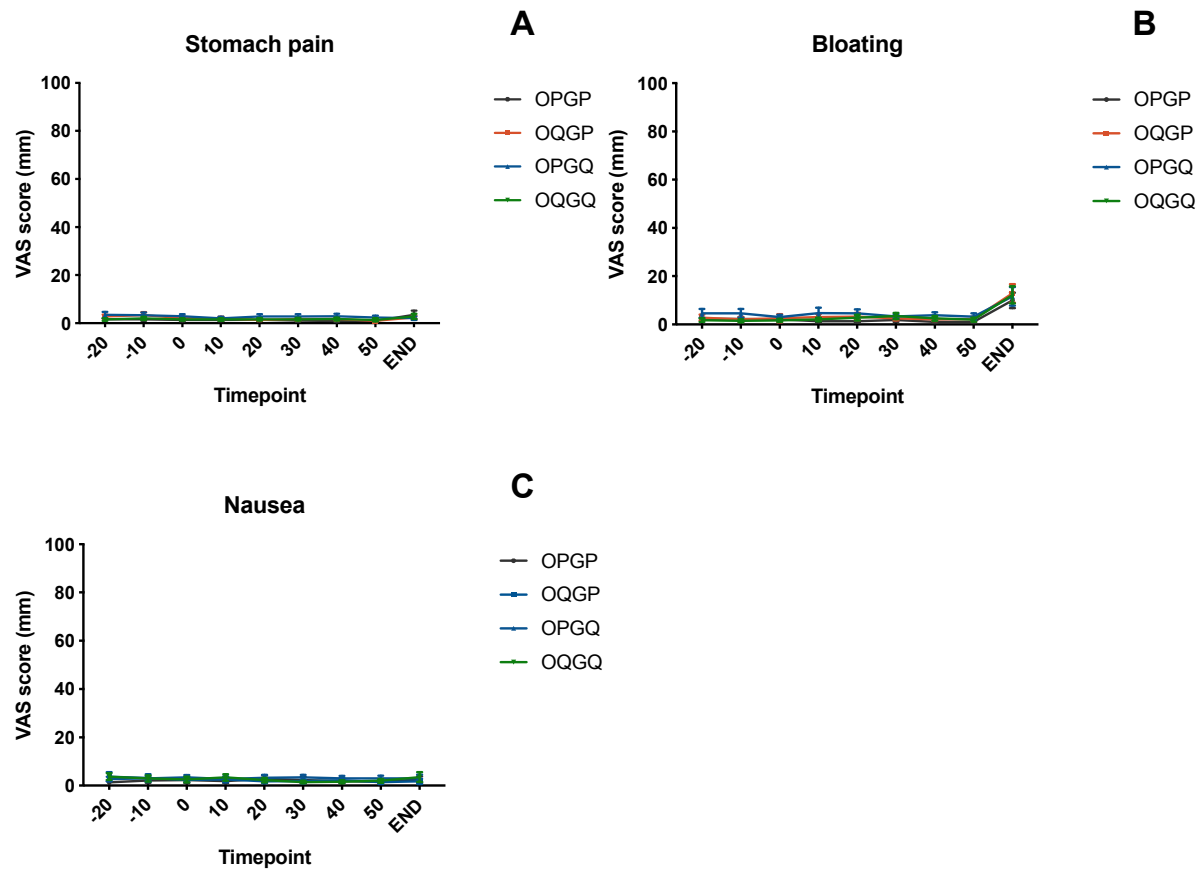

C

$$
\begin{aligned}
& \text { - OPGP } \\
& \text { - OQGP } \\
& \text { - OPGQ } \\
& \text { - OQGQ }
\end{aligned}
$$

Figure 4.5 GI complaints. VAS scores for stomach pain (A), bloating (B), and nausea (C) (mean + SEM) before and after oral placebo and intragastric placebo (OPGP), oral quinine and intragastric placebo (OQGP), oral placebo and intragastric quinine (OPGQ), and quinine both oral and intragastric (OQGQ). Based on an autoregressive (1) linear mixed model, no differences were observed between conditions.

Heart rate variability

Heart rate and LF/HF ratio are depicted in Figure 4.6. No intervention effects for these HRV measurements were found. Moreover, no intervention $\times$ timepoint interactions were found for these HRV measurements. 

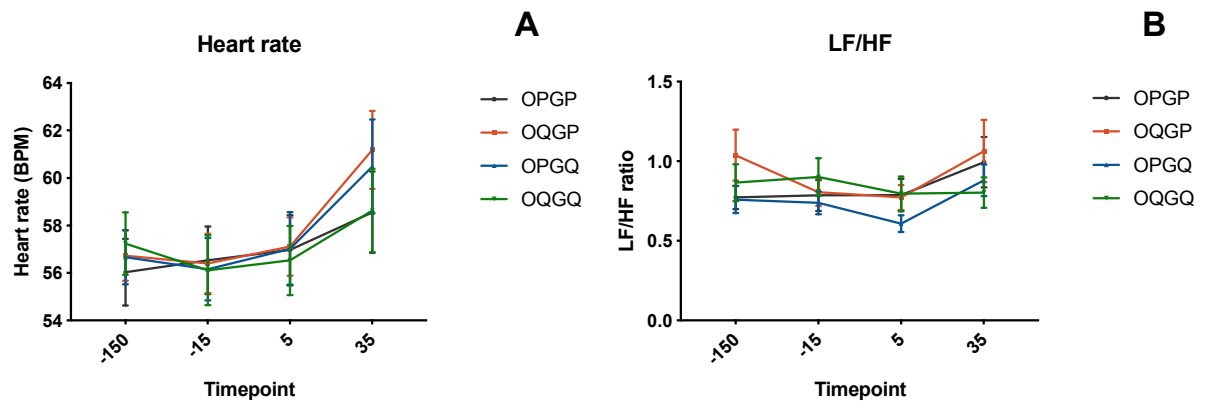

Figure 4.6 Heart rate variability (HRV). HRV depicted by heartrate (A) and low frequency (LF)/high frequency (HF) ratio (B) before and after oral placebo and intragastric placebo (OPGP), oral quinine and intragastric placebo (OQGP), oral placebo and intragastric quinine (OPGQ), and quinine both oral and intragastric (OQGQ). Based on an autoregressive (1) linear mixed model, no differences were observed between conditions.

\section{Discussion}

Our results show that food intake is affected neither by oral sham feeding of quinine, nor intragastric delivery of quinine, nor synchronous oral sham feeding and intragastric delivery of quinine compared with placebo. Moreover, no differences have been found in VAS scores for satiation or fullness and HRV measurements. However, VAS scores for desire to eat and hunger decreased significantly after oral sham feeding and intragastric delivery of quinine.

To the best of our knowledge, the effects of oral sham feeding with (bitter) tastants have not been described in literature previously. Moreover, the effects of bitter tastants on eating behaviour have been conducted only in small-sized studies. This is the first study to investigate the acute effects of a bitter tastant on eating behaviour in an adequately sized study.

The results of studies on the effects of bitter tastants on food intake, appetite sensations, and GI peptides are not conclusive. Most studies reported only a trend towards a decrease in food intake after intragastric or intraduodenal delivery of bitter tastants. ${ }^{16,29-32}$ Some studies, however, reported a statistically significant reduction in food intake. ${ }^{33,34}$ In one study, no initial effect of encapsulated bitter compounds on food intake was observed, while over the day a significant decrease in food intake was found. ${ }^{35}$ Deloose $e t$ al. showed a longer sustained satiety effect after a standardised meal when the meal was preceded by intragastric administration of denatonium benzoate (DB). ${ }^{29}$ Taken together, these results 
indicate that delivery of bitter tastants in the presence of- or followed by a caloric content, exerts a more pronounced effect on eating behaviour. With respect to our study, it is possible that a more marked decrease in food intake could have been found if food intake was measured over the course of the day. However, our aim was to explore in detail the acute effects of oral sham feeding and/or intragastric delivery of the bitter tastants quinine on caloric intake during the next meal and not over a longer period.

Intragastric administration of bitter compounds (quinine and DB) has been shown to reduce antral motility 29,36 and to decrease systemic motilin and ghrelin levels, ${ }^{29,34,36}$ whereas effects of bitter compounds on overall gastric emptying rate, have not been demonstrated in most studies. ${ }^{29,32,33,37}$ A recent study did show slowed gastric emptying after both intragastric and intraduodenal administration of quinine. ${ }^{38}$ These recent findings are in line with pre-clinical trials in rodents. ${ }^{39,40}$ Therefore, the effects of gastrointestinal delivery of tastants on circulating GI peptide levels have not been fully elucidated. Several studies did not observe any changes in glucagon like peptide-1 (GLP-1), polypeptide YY (PYY), and/or cholecystokinin (CCK). ${ }^{16,30,32}$ In one study an increase in plasma CCK was observed after intraduodenal delivery of the bitter tastant quinine, but systemic ghrelin levels were not affected. ${ }^{33}$

Where systemic GI peptide levels are considered to be an objective parameter to predict prospective food intake, VAS scores for appetite sensations can give insight in subjective feelings relating to prospective food intake. In the present study, oral sham feeding or intragastric delivery of quinine decreased the desire to eat and hunger sensations compared with placebo. Interestingly, there seems to be an overall trend of an upward slope for appetite throughout the test day. In this study, subjects were provided with the test meal around noon. Therefore, this might reflect the natural tendency to get an increased appetite towards habitual time of meal intake, due to conditioned hunger. ${ }^{41}$ Important to note is that synchronous oral sham feeding with- and intragastric delivery of quinine did not alter desire to eat and hunger scores compared with placebo. This rather unexpected finding could be explained by the higher starting point for this intervention, influencing a possible overall intervention effect.

Contrary to desire to eat and hunger sensations, satiation and fullness sensations were not affected. Since there was no intervention effect on actual food intake, this raises the question whether actual food intake might be more dependent on satiation and fullness rather than desire to eat and hunger. In addition, caloric intake might be influenced by a large array of different sensations and factors that are not necessarily captured by a single VAS score. Various studies that did find a 
significant decrease in food intake after gastrointestinal delivery of tastants showed mixed results on VAS scores for appetite sensations. Iven et al. showed a decrease in hunger and an increase in satiety and fullness. ${ }^{34}$ Van Avesaat et al. found a decrease in desire to eat and hunger and an increase in satiety, but no effects on fullness. ${ }^{16}$ Andreozzi et al. found no differences in satiation or desire to eat scores. ${ }^{33}$ It must be noted that in the present study no intervention $\times$ time interaction was found and therefore conclusions on timing of the effect of oral sham feeding with- and/or intragastric delivery of quinine on appetite sensations cannot be drawn. Moreover, interpretation of VAS scores for appetite sensations should always be done with care, since this usually is a secondary outcome parameter in studies on food intake and most studies might not have been adequately powered for such outcomes - as is the case for our study.

A strength of the design of the present study is the large sample size when compared to other research in the field. Moreover, possible inter-subject confounding factors (i.e., habitual meal size, daily energy requirements) were countered by the cross-over design. However, this study also has several limitations. A limitation of this study is generalisability to daily life. In this study, subjects consumed their test meal without external stimuli (i.e., phone use, watching television) and were asked to stop eating when comfortably full. In daily life people might not be focussed on their appetite sensations and be distracted by said external stimuli, which are known to have an increasing effect on eating behaviour. ${ }^{42,43}$ However, before implementing interventions in daily life, their effects should first be investigated under controlled conditions, as was done in the present study. Another important limitation of this study is that systemic GI peptide levels were not assessed. Measurement of GI peptides could have provided a more complete overview of the effect of oral sham feeding withand/or intragastric delivery of quinine on eating behaviour. However, a previous study from our group showed a decrease in food intake and increase in satiation without marked changes in systemic GI peptide levels. ${ }^{16}$ Although in vitro stimulation of intestinal cell lines with tastants results in markedly increased levels of GI peptides, these results have not always been reproduced in vivo, as stated above. It should be noted that all studies measured plasma levels of GI peptides, in search for systemic effects. It remains to be determined what the effect of gastrointestinal delivery of tastants is on local splanchnic excretion of GI peptides or on possible paracrine effects. Measurement of local levels of GI peptides requires complex invasive techniques. We focussed on other, non-invasive, markers that can indicate a shift in hunger/satiation, such as the balance in ANS, 
which can occur before systemic GI peptide changes can be detected ${ }^{19,20}$ and used HRV measurements. ${ }^{23}$

In the present study, no differences in HRV measurements were observed between the various interventions, which is in line with the fact that there was no shift in hunger/satiation, as indicated by the VAS scores for fullness and satiation. Moreover, food intake was not influenced by the various interventions. A recent meta-analysis showed that HRV is sensitive to changes in the autonomic nervous system as a response to stress. ${ }^{44}$ Although two studies showed meal intake to influence $\mathrm{HRV}, 45,46$ it is uncertain whether $\mathrm{HRV}$ measurements are sensitive enough to detect satiation responses. Therefore, future studies should ascertain whether the application of HRV measurements in detecting satiation responses has an added value.

Furthermore, it has to be noted that the ideal interval between tastant delivery and the timing of the ad libitum test meal is unknown. In the present study, we employed a timing identical to that of studies from other groups investigating the effects of bitter compounds on food intake. ${ }^{29,30,33}$ However, these studies investigated only intragastric or intraduodenal effects of bitter tastants. It is possible that effects of oral sham feeding with quinine could have been found if the test meal was offered sooner after the intervention, since tasting a substance orally might have more acute effects. Moreover, our results suggest a fast response on desire to eat and hunger scores after intervention which could have driven the overall effect that was found. It is possible that earlier presentation of the test meal would have resulted in a reduction in energy intake after administration of quinine. On the other hand, the possibility of an increase in energy intake, due to the need to quell their symptoms (i.e., get rid of the bad taste of quinine), cannot be excluded. Future research protocols should consider timing as a factor to be investigated.

Another important aspect to mention is the dosage of quinine. According to the code of federal regulations stated by the United States Food and Drug Administration (U.S. FDA), soft drinks such as tonic water are allowed to contain 83 parts per million quinine. ${ }^{47}$ In this protocol we chose to administer $75 \mathrm{mg}$ of $\mathrm{QHCl}$ which is lower than this amount and aligns with previous studies conducted by our group. ${ }^{16,17}$ Due to this relatively low dosage of quinine, should we have found significant effects on eating behaviour, this dosage of quinine could have been easily implemented for daily intake. Other studies employ various dosages of quinine administration ranging from $18 \mathrm{mg}$ to $600 \mathrm{mg} \cdot{ }^{29,30,32-34,36}$. The higher dosages may give rise to medical problems when implemented for daily intake. A systematic review on the usage of quinine as treatment for muscle cramps showed 
an increase in minor adverse events such as GI complaints, headache, and tinnitus after daily intake of $200 \mathrm{mg}$ to $500 \mathrm{mg}$ for three days up to several weeks. ${ }^{48}$ This aspect should also be considered when investigating the effects on eating behaviour of higher dosages of quinine.

Up to now, most studies investigating the effects of tastants on food intake focussed on acute effects in single test meals. Repetitive or chronic administration of tastants has not been investigated, warranting studies to be conducted on longterm effects of tastants on energy intake.

In conclusion, we have shown that oral sham feeding with- or intragastric delivery of the bitter tastant quinine decreased desire to eat and hunger feelings, without affecting food intake, feelings of satiation and fullness, and HRV when compared with placebo. 


\section{References}

1. WHO. Obesity and Overweight. https://www.who.int/en/news-room/fact-sheets/detail/obesity-andoverweight (accessed December 2019) 2018.

2. Verdich C, Flint A, Gutzwiller JP, Naslund E, Beglinger C, Hellstrom PM, et al. A meta-analysis of the effect of glucagon-like peptide-1 (7-36) amide on ad libitum energy intake in humans. J Clin Endocrinol Metab 2001;86:4382-9.

3. Lieverse RJ, Jansen JB, Masclee AA, Lamers CB. Satiety effects of a physiological dose of cholecystokinin in humans. Gut 1995;36:176-9.

4. Lieverse RJ, Jansen JB, van de Zwan A, Samson L, Masclee AA, Lamers CB. Effects of a physiological dose of cholecystokinin on food intake and postprandial satiation in man. Regul Pept 1993;43:83-9.

5. van Avesaat M, Troost FJ, Ripken D, Hendriks HF, Masclee AA. Ileal brake activation: macronutrientspecific effects on eating behavior? Int J Obes 2015;39:235-43.

6. Maljaars PW, Peters HP, Mela DJ, Masclee AA. Ileal brake: a sensible food target for appetite control. A review. Physiol Behav 2008;95:271-81.

7. Shin HS, Ingram JR, McGill AT, Poppitt SD. Lipids, CHOs, proteins: can all macronutrients put a 'brake' on eating? Physiol Behav. 2013;120:114-123.

8. Alleleyn AM, van Avesaat M, Troost FJ, Masclee AA. Gastrointestinal Nutrient Infusion Site and Eating Behavior: Evidence for A Proximal to Distal Gradient within the Small Intestine? Nutrients 2016;8:117.

9. van der Wielen N, van Avesaat M, de Wit NJ, Vogels JT, Troost F, Masclee A, et al. Cross-species comparison of genes related to nutrient sensing mechanisms expressed along the intestine. PLoS One 2014;9:e107531.

10. Young RL, Sutherland K, Pezos N, Brierley SM, Horowitz M, Rayner CK, et al. Expression of taste molecules in the upper gastrointestinal tract in humans with and without type 2 diabetes. Gut 2009;58: 337-46.

11. Bezencon C, le Coutre J, Damak S. Taste-signaling proteins are coexpressed in solitary intestinal epithelial cells. Chem Senses 2007;32:41-9.

12. Sternini C, Anselmi L, Rozengurt E. Enteroendocrine cells: a site of 'taste' in gastrointestinal chemosensing. Curr Opin Endocrinol 2008;15:73-8.

13. Jang HJ, Kokrashvili Z, Theodorakis MJ, Carlson OD, Kim BJ, Zhou J, et al. Gut-expressed gustducin and taste receptors regulate secretion of glucagon-like peptide-1. Proc Natl Acad Sci U S A 2007;104: 15069-74.

14. Rozengurt N, Wu SV, Chen MC, Huang C, Sternini C, Rozengurt E. Colocalization of the alpha-subunit of gustducin with PYY and GLP-1 in L cells of human colon. Am J Physiol Gastrointest Liver Physiol 2006;291:G792-802.

15. Geraedts MC, Troost FJ, Saris WH. Different tastants and low-caloric sweeteners induce differential effects on the release of satiety hormones. Food Chem 2011;129:731-8.

16. van Avesaat M, Troost FJ, Ripken D, Peters J, Hendriks HF, Masclee AA. Intraduodenal infusion of a combination of tastants decreases food intake in humans. Am J Clin Nutr 2015;102:729-35.

17. Klaassen T, Alleleyn AME, van Avesaat M, Troost FJ, Keszthelyi D, Masclee AAM. Intraintestinal Delivery of Tastants Using a Naso-Duodenal-Ileal Catheter Does Not Influence Food Intake or Satiety. Nutrients 2019;11:472.

18. Breslin PA, Spector AC. Mammalian taste perception. Curr Biol 2008;18:R148-55.

19. Nederkoorn C, Smulders FT, Jansen A. Cephalic phase responses, craving and food intake in normal subjects. Appetite 2000;35:45-55.

20. Mattes RD. Physiologic responses to sensory stimulation by food: nutritional implications. J Am Diet Assoc 1997;97:406-13.

21. Harthoorn LF, Dransfield E. Periprandial changes of the sympathetic-parasympathetic balance related to perceived satiety in humans. Eur J Appl Physiol 2008;102:601-8.

22. Pavli F, Tassou C, Nychas GE, Chorianopoulos N. Probiotic Incorporation in Edible Films and Coatings: Bioactive Solution for Functional Foods. Int J Mol Sci 2018;19:150. 
23. Anonymous. Heart rate variability. Standards of measurement, physiological interpretation, and clinical use. Task Force of the European Society of Cardiology and the North American Society of Pacing and Electrophysiology. Eur Heart J 1996;17:354-81.

24. Burdock GA. Safety assessment of hydroxypropyl methylcellulose as a food ingredient. Food Chem Toxicol 2007;45:2341-51.

25. Steiner JE, Glaser D, Hawilo ME, Berridge KC. Comparative expression of hedonic impact: affective reactions to taste by human infants and other primates. Neurosci Biobehav Rev 2001;25:53-74.

26. Just T, Pau HW, Engel U, Hummel T. Cephalic phase insulin release in healthy humans after taste stimulation? Appetite 2008;51:622-7.

27. Teff KL, Devine J, Engelman K. Sweet taste: effect on cephalic phase insulin release in men. Physiol Behav 1995;57:1089-95.

28. Parker BA, Sturm K, MacIntosh C, Feinle C, Horowitz M, Chapman IM. Relation between food intake and visual analogue scale ratings of appetite and other sensations in healthy older and young subjects. Eur J Clin Nutr 2004;58:212-8.

29. Deloose E, Janssen P, Corsetti M, Biesiekierski J, Masuy I, Rotondo A, et al. Intragastric infusion of denatonium benzoate attenuates interdigestive gastric motility and hunger scores in healthy female volunteers. Am J Clin Nutr 2017;105:580-8.

30. Bitarafan V, Fitzgerald PCE, Little TJ, Meyerhof W, Wu T, Horowitz M, et al. Effects of Intraduodenal Infusion of the Bitter Tastant, Quinine, on Antropyloroduodenal Motility, Plasma Cholecystokinin, and Energy Intake in Healthy Men. J Neurogastroenterol Motil 2019;25:413-22.

31. Peters HPF, Koppenol W, Schuring EAH, Gouka R, Mela DJ, Blom WAM. The effect of two weeks ingestion of a bitter tastant mixture on energy intake in overweight females. Appetite 2016;107:268-73.

32. Bitarafan V, Fitzgerald PCE, Little TJ, Meyerhof W, Jones KL, Wu T, et al. Intragastric administration of the bitter tastant quinine lowers the glycemic response to a nutrient drink without slowing gastric emptying in healthy men. Am J Physiol Regul Integr Comp Physiol 2020;318:R263-73.

33. Andreozzi P, Sarnelli G, Pesce M, Zito FP, Alessandro AD, Verlezza V, et al. The Bitter Taste Receptor Agonist Quinine Reduces Calorie Intake and Increases the Postprandial Release of Cholecystokinin in Healthy Subjects. J Neurogastroenterol Motil 2015;21:511-9.

34. Iven J, Biesiekierski JR, Zhao D, Deloose E, O'Daly OG, Depoortere I, et al. Intragastric quinine administration decreases hedonic eating in healthy women through peptide-mediated gut-brain signaling mechanisms. Nutr Neurosci 2019;22:850-62.

35. Mennella I, Fogliano V, Ferracane R, Arlorio M, Pattarino F, Vitaglione P. Microencapsulated bitter compounds (from Gentiana lutea) reduce daily energy intakes in humans. Br J Nutr 2016;116:1841-50.

36. Deloose E, Corsetti M, Van Oudenhove L, Depoortere I, Tack J. Intragastric infusion of the bitter tastant quinine suppresses hormone release and antral motility during the fasting state in healthy female volunteers. Neurogastroenterol Motil 2018;30:e13171.

37. Little TJ, Gupta N, Case RM, Thompson DG, McLaughlin JT. Sweetness and bitterness taste of meals per se does not mediate gastric emptying in humans. Am J Physiol Regul Integr Comp Physiol 2009;297:R632-9

38. Rose BD, Bitarafan V, Rezaie P, Fitzgerald PCE, Horowitz M, Feinle-Bisset C. Comparative Effects of Intragastric and Intraduodenal Administration of Quinine on the Plasma Glucose Response to a MixedNutrient Drink in Healthy Men: Relations with Glucoregulatory Hormones and Gastric Emptying. J Nutr 2021; Epub ahead of print.

39. Janssen S, Laermans J, Verhulst PJ, Thijs T, Tack J, Depoortere I. Bitter taste receptors and $\alpha$-gustducin regulate the secretion of ghrelin with functional effects on food intake and gastric emptying. Proc Natl Acad Sci U S A 2011;108:2094-9.

40. Glendinning JI, Yiin YM, Ackroff K, Sclafani A. Intragastric infusion of denatonium conditions flavor aversions and delays gastric emptying in rodents. Physiol Behav 2008;93:757-65.

41. van den Akker K, Havermans RC, Jansen A. Appetitive conditioning to specific times of day. Appetite 2017;116:232-8.

42. Boulos R, Vikre EK, Oppenheimer S, Chang H, Kanarek RB. ObesiTV: How television is influencing the obesity epidemic. Physiol Behav 2012;107:146-53. 
43. Ogden J, Coop N, Cousins C, Crump R, Field L, Hughes S, et al. Distraction, the desire to eat and food intake. Towards an expanded model of mindless eating. Appetite 2013;62:119-26.

44. Kim HG, Cheon EJ, Bai DS, Lee YH, Koo BH. Stress and Heart Rate Variability: A Meta-Analysis and Review of the Literature. Psychiatry Investig 2018;15:235-45.

45. Harthoorn LF, DransWeld E. Periprandial changes of the sympathetic-parasympathetic balance related to perceived satiety in humans. Eur J Appl Physiol 2008;102:601-8.

46. Sauder KA, Johnston ER, Skulas-Ray AC, Campbell TS, West SG. Effect of meal content on heart rate variability and cardiovascular reactivity to mental stress. Psychophysiology 2012;49:470-7.

47. US Food and Drug Administration. CFR - Code of Federal Regulations Title 21. https://www.accessdata.fda.gov/scripts/cdrh/cfdocs/cfCFR/CFRSearch.cfm?fr=172.575 (accessed December 2019) 2019

48. El-Tawil S, Al Musa T, Valli H, Lunn MP, Brassington R, El-Tawil T, et al. Quinine for muscle cramps. Cochrane Database Syst Rev 2015;(4):CD005044. 



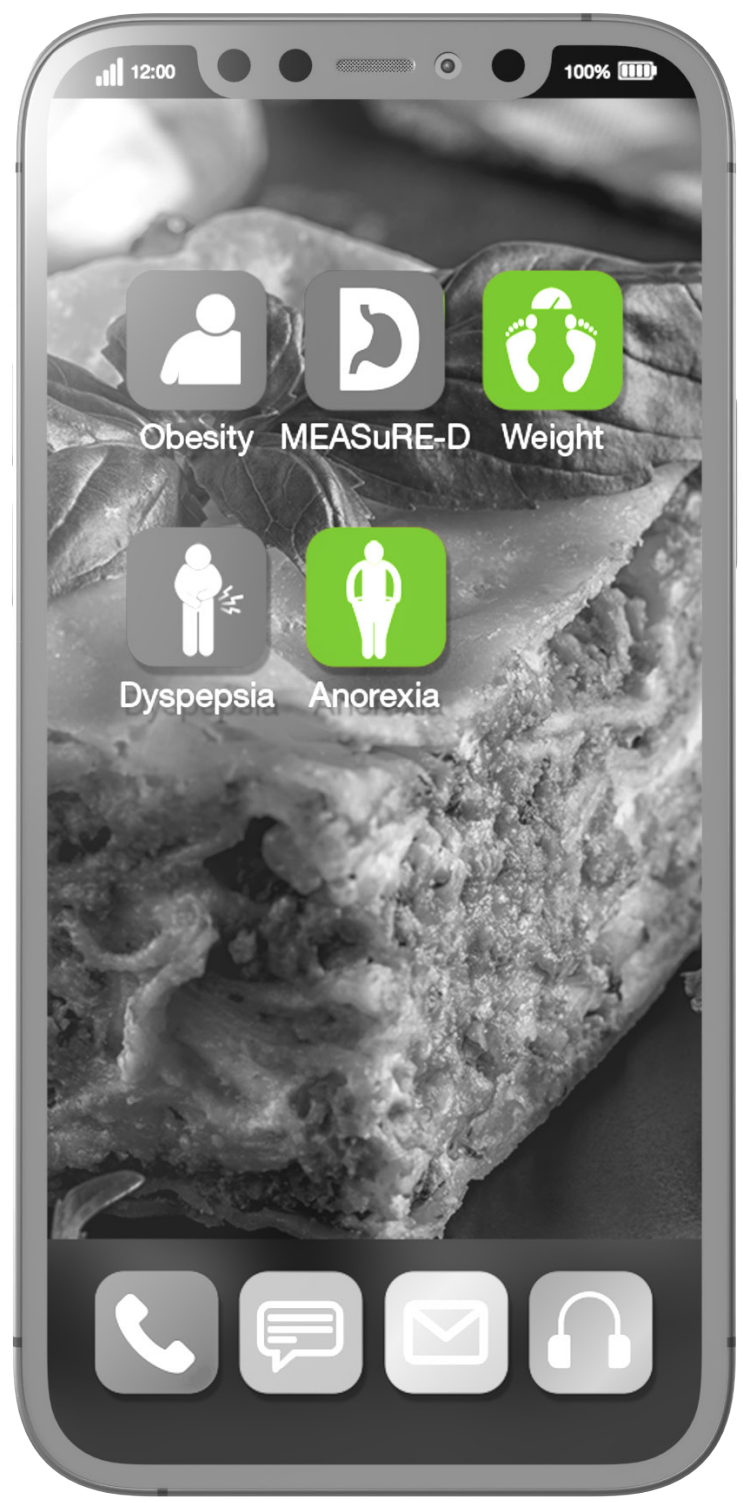




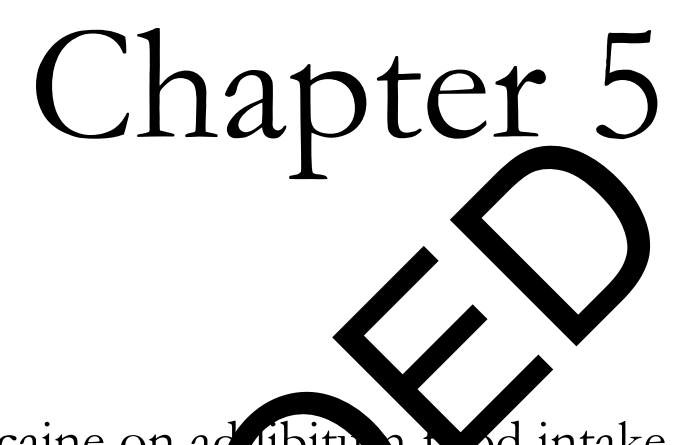

Effect of intragastric lidocaine on ac libitu Mad intake and satiation in healthy male volun ers: double-blind

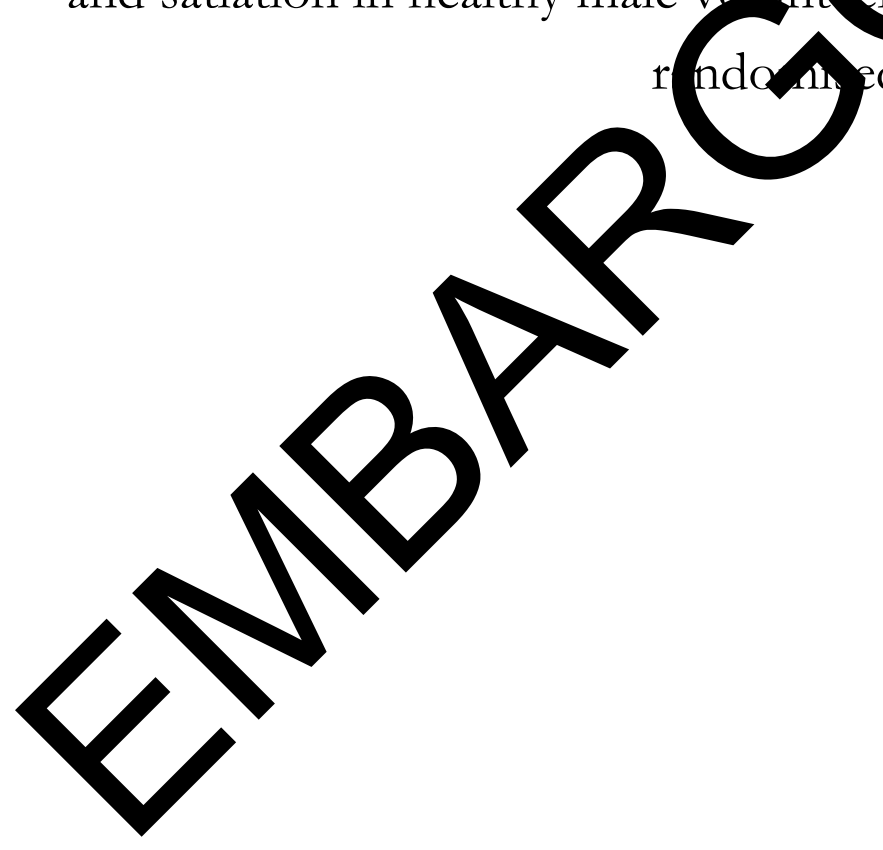

Annick M.E. Alleleyn

Tim Klaassen

Mark van Avesaat

Bjorn Winkens

Bernardus W.M.M. Peeters

Christophorus L.E. Broekkamp

Daniel Keszthelyi

Ad A.M. Masclee

To be submitted 


\section{Chapter 6}

\section{Psychometric evaluation of an experience sampling method-based patient-reported outcome measure in functional dyspepsia}

Tim Klaassen Fabienne G.M. Smeets* Lisa Vork* Jan Tack

Nicholas J. Talley Magnus Simren Qasim Aziz Alexander C. Ford Joanna W. Kruimel José M. Conchillo Carsten Leue Ad A.M. Masclee Daniel Keszthelyi

* Shared second authorship Neurogastroenterology and motility, 2021; Epub ahead of print 


\section{Abstract}

\section{Background}

Due to important biases, conventional end-of-day and end-of-week assessment methods of gastrointestinal symptoms in functional dyspepsia (FD) are considered suboptimal. Real-time symptom assessment based on the experience sampling method (ESM) could be a more accurate measurement method. The present study aimed to evaluate validity and reliability of an ESM-based patient-reported outcome measure (PROM) for symptom assessment in FD.

\section{Methods}

Thirty-five patients with FD (25 female, mean age 44.7 years) completed the ESM-based PROM (a maximum of 10 random moments per day) and an end-of-day symptom diary for 7 consecutive days. On day 7, end-of-week questionnaires were completed including the Nepean Dyspepsia Index (NDI) and Patient Assessment of Gastrointestinal Symptom Severity Index (PAGI-SYM).

\section{Key results}

ESM- and corresponding end-of-day scores for gastrointestinal symptoms were significantly associated (ICCs ranging from 0.770-0.917). However, end-of-day scores were significantly higher $(\Delta 0.329-1.031)$ than mean ESM scores $(p<0.05)$. Comparing ESM with NDI and PAGI-SYM scores, correlations were weaker (Pearson's $r$ ranging from 0.4670.846). Cronbach's $\alpha$ coefficient was good for upper gastrointestinal symptoms $(\alpha=0.842)$. First half-week and second half-week scores showed very good consistency (ICCs ranging from 0.913-0.975).

\section{Conclusion \& inferences}

The present results demonstrate good validity and reliability of a novel ESM-based PROM for assessing gastrointestinal symptoms in patients with FD. Moreover, this novel PROM allows to evaluate individual symptom patterns and can evaluate interactions between symptoms and environmental/contextual factors. ESM has the potential to increase patients' disease insight, provide tools for self-management, and improve shared decisionmaking. Hence, this novel tool may aid in the transition towards personalised healthcare for patients with FD. 


\section{Introduction}

Functional dyspepsia (FD) is one of the most common functional gastrointestinal disorders, recently renamed in disorders of gut-brain interaction, with an estimated prevalence of $10-15 \%$ in the general population. ${ }^{1}$ According to the Rome IV criteria for functional gastroduodenal disorders, it is defined by the presence of various symptoms in the absence of organic, systemic, or metabolic diseases that could explain complaints. ${ }^{2}$ Among the heterogeneous presentation of patients with FD, four core symptoms have been defined: early satiation, postprandial fullness, epigastric burning, and epigastric pain. ${ }^{2,3}$ Quality of life and work productivity are impaired in patients with FD. ${ }^{4}$ Moreover, up to $40 \%$ of patients will consult a physician, having substantial financial implications. ${ }^{5}$ The diagnosis of FD largely relies on symptoms, since underlying pathophysiologic mechanisms remain unclear and specific biological markers are currently lacking. Hence, symptom assessment is warranted to evaluate treatment efficacy. The Food and Drug Administration (FDA) recommends the use of well-defined patient-reported outcome measures (PROMs) for evaluation of treatment outcomes in clinical trials. ${ }^{6}$ A recent systematic review identified 20 PROMs for assessment of dyspeptic symptoms. However, no single instrument has undergone all the development steps recommended by the FDA. Therefore, no consensus has yet been reached with regard to the most relevant outcome measure in patients with FD. ${ }^{7}$

The currently used assessment methods to evaluate dyspeptic symptoms and response to treatment are mainly retrospective, self-reported questionnaires, based on daily or weekly monitoring. This has important limitations. Firstly, retrospective questionnaires are prone to recall bias. ${ }^{8}$ Secondly, symptom variability in functional disorders can occur due to external triggers, such as intake of food or psychological factors, ${ }^{9-11}$ which cannot be accurately captured by retrospective assessments, thereby resulting in ecological bias. Thirdly, lack of patient adherence or fake adherence are common problems that arise with the use of paper questionnaires. ${ }^{12}$ These limitations underline the need for a reliable method for symptom assessment to evaluate treatment efficacy in patients with FD.

The experience sampling method (ESM) might overcome these limitations. ESM is characterised by random, repeated assessments in a patient's current state and environment. Assessment has to be completed within a short time after an auditory signal and questions always relate to current symptoms, contextual factors, and psychological factors. Therefore, ESM might be able to reduce the risk of recall and ecological bias and capture symptom variability over time. ${ }^{13,14}$ Current use of ESM in gastrointestinal disorders is limited. Several studies evaluated the use of ESM in patients with irritable 
bowel syndrome (IBS) and found good correlation between symptom scores on ESM and retrospective questionnaires. However, abdominal pain scores were significantly higher in retrospective questionnaires compared with mean scores derived from ESM. Interestingly, the scores for abdominal pain on retrospective questionnaires seemed to represent the peak scores measured by ESM. ${ }^{15-17}$ Currently, there are no data available on the use of ESM in patients with FD. Recently an ESM-based PROM was developed for patients with FD. ${ }^{18}$ Therefore, the present study aimed to assess the validity and reliability of this novel FD-specific ESM-based PROM.

\section{Methods}

The study protocol was approved by the Medical Ethics Committee of the Maastricht University Medical Centre+ (MUMC+), Maastricht, the Netherlands (ID METC19-077), and performed in full accordance with the Declaration of Helsinki (latest amendment by the World Medic Association in 2013) and Dutch Regulations of Medical Research involving Human Subjects (WMO, 1998). This prospective observational study was performed at the MUMC+ from 29th May 2020 until 1 $1^{\text {st }}$ October 2020. This study was registered in the US National Library of Medicine (http://www.clinicaltrials.gov, ID NCT04204421).

\section{Subjects}

Recruitment of patients with FD, aged between 18 and 75 years, took place at the outpatient clinic of Gastroenterology and Hepatology of the MUMC+, a secondary/tertiary academic hospital. Additionally, patients with FD that participated in other studies of the MUMC+ were contacted to participate in the current study (NCT02522000, NCT03652571). Functional dyspepsia, including subtype assessment, was diagnosed according to the Rome IV criteria, which were evaluated by a trained clinical researcher in a face-to-face interview. For all subgroups of FD, subjects needed to have symptoms for at least 6 months. As per Rome IV definitions, in order to fulfil criteria for postprandial distress syndrome (PDS), subjects needed to experience either 1) an uncomfortably full feeling after meal of a normal portion size for at least 3 days or more per week in the past 3 months that restricted their normal activities, or 2) have an uncomfortable feeling of early satiation that resulted in inability to finish a normal sized meal for at least 3 days or more per week in the past 3 months. In order to fulfil criteria for epigastric pain syndrome (EPS), subjects needed to experience either 1) epigastric pain or 2) burning for at least 1-2 days per week that restricted their normal activities. In order 
to fulfil criteria for overlap syndrome (OS), subjects needed to fulfil both PDS and EPS criteria. Apart from the Rome IV criteria, no specific minimum symptom frequency/intensity on a weekly basis was used as an entry criterion. Exclusion criteria were the initiation of regularly used medication from 1 month before inclusion until the end of the study period, a history of upper gastrointestinal surgery, history of radiation therapy to the abdomen, and pregnancy. Subjects could only participate if they understood the Dutch language and were able to use the smartphone application. Moreover, as studies in the general population show patients fulfilling criteria for both FD and IBS are common, ${ }^{19-23}$ fulfilling criteria for IBS was not deemed an exclusion criterion, as to adequately reflect FD patients in the general population.

\section{Data collection}

ESM and an end-of-day symptom diary were collected during seven consecutive days. On day 7 , subjects completed validated symptom questionnaires using an electronic case report form (eCRF) system (CastorEDC).

\section{ESM}

The MEASuRE-D application was developed for the use of ESM in patients with FD.18 Figure 6.1 displays the home screen of the application. The subjects downloaded this app on their smartphones. During their regular daily life, subjects completed ESM for seven consecutive days. In order to complete the real-time questionnaires as often as possible, subjects were instructed to carry their smartphone with them during the week. The MEASuRE-D app sent out a haptic, auditory, and written signal 10 times per day between 07:00 and 22:00 at randomly chosen moments, with a time-interval of at least 15 minutes between consecutive signals. Following a signal, the ESM-questionnaire (called "Beep vragenlijst", Figure 6.1) was available for 10 minutes. On all measurement moments, the questions were repeated in the same order, and scored on an 11-point numeric rating scale (NRS) $(0=$ not at all to $10=$ very severely). The development of this ESM-based questionnaire has been described previously. ${ }^{18}$ 


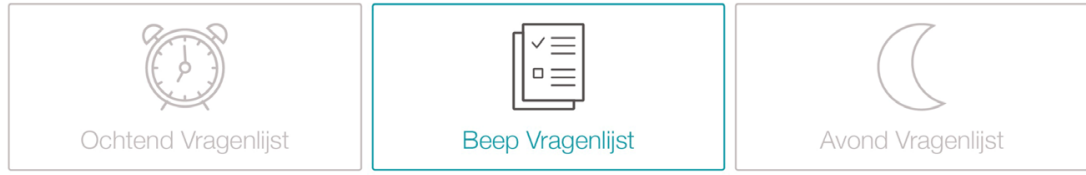

Figure 6.1 Home screen of the MEASuRE-D smartphone application.

\section{End-of-day diary}

A 7-day end-of-day symptom diary was used to evaluate symptom severity on a daily basis. Gastrointestinal symptoms (i.e., upper abdominal fullness, upper abdominal heaviness, bloating, upper abdominal pain, upper abdominal burning sensation, lower abdominal pain, nausea, belching, heartburn, regurgitation, ability to eat normal portion sizes, vomiting, as well as urge to defecate) were scored using an 11-point NRS ( $0=$ not at all to $10=$ very severely) at the end of each test day. This symptom diary was built into the MEASuRE-D app and made available between 19:00 and 0:00. Subjects were instructed to manually open the application to fulfil this diary, as no signal was sent to the smartphone to indicate availability of this questionnaire. In the app this list was called “Avondvragenlijst” (Figure 6.1).

\section{End-of-week questionnaires}

At the end of the study period, validated questionnaires were completed using an eCRF, assessing upper gastrointestinal symptoms and mental health status. Regarding upper gastrointestinal symptom severity, the Nepean Dyspepsia Index (NDI; 0-4 scale for occurrence of core complaints, 0-5 scale for severity of core complaints, $0-4$ scale for hinderance due to core complaints, recall period 14 days) ${ }^{24-26}$ and Patient Assessment of Gastrointestinal Symptom Severity Index (PAGI-SYM; 1-6 scale; composes sub scores for postprandial fullness, nausea/vomiting, bloating, upper abdominal pain, lower abdominal pain, heartburn/regurgitation, recall period 14 days) ${ }^{27}$ were completed. 
The Generalised Anxiety Disorder-7 (GAD-7; 0-3 scale; total composite score for severity of anxiety symptoms; recall period of 14 days), ${ }^{28}$ the Hospital Anxiety and Depression Scale (HADS; 0-3 scale, total composite scores for severity of anxiety and depression, recall period one week), ${ }^{29}$ and the Patient Health Questionnaire-9 (PHQ-9; 0-3 scale; total composite score for severity of depressive symptoms, recall period 14 days) ${ }^{30}$ were collected regarding anxiety and depression.

\section{Statistical analyses}

Sample size was based on previous studies using ESM-data that have shown sample sizes between 20 and 30 subjects to be sufficient for analyses. ${ }^{31,32}$ Moreover, in IBS patients sample sizes of 26-37 were used to evaluate a novel ESM-based PROM. 16,33,34 The present study was an exploratory study on the use of an ESM-based PROM in patients with FD. Therefore, we aimed to include at least 30 valid cases with a maximum of 36 . Subjects were included in the analyses only when at least $1 / 3$ of the total number of ESMassessments (i.e., 23 out of 70 ) were completed. ${ }^{35,36}$

All analyses were performed using $\mathrm{R}$ version 3.6.3. Continuous outcomes are presented as mean \pm standard deviation (SD), and tested using paired or independent samples t-test. Proportions for categorical variables were tested using the $\chi^{2}$-test. For all analyses, $\mathrm{p}<0.05$ was considered statistically significant.

ESM scores were compared with end-of-day diary scores and with end-of-week questionnaire scores to assess concurrent validity. In order to compare ESM scores with end-of-day diary scores, mean and maximum scores for ESM were calculated for each of the 7 days. Associations between ESM scores and end-of-day scores were tested using a linear mixed-effects model with end-of-day score as the dependent and ESM score as the independent variable, a random intercept, and correcting for repeated measures by using an autoregression (AR1) correlation structure. The level of agreement between these scores was assessed by calculating intra-class correlation coefficients (ICC), based on a single-rating, consistency, two-way model. Additionally, intercept-only linear mixed-effects models with the delta scores (i.e., difference between ESM and end-of-day diary) as the dependent variable were used to assess differences between assessment methods.

In order to compare ESM scores with end-of-week questionnaire scores, average ESM scores were calculated per subject. Paired samples t-test and Pearson correlations were calculated to assess the differences between measurement methods. A Pearson $r$ above 0.7 reflects a strong correlation, a Pearson r of 0.50-0.70 reflects a good correlation, a Pearson 
r between 0.3 and 0.5 reflects a moderate correlation, and a Pearson $\mathrm{r}$ below 0.30 reflects a poor correlation. ${ }^{37}$ For the PAGI-SYM questionnaire the sub scores for postprandial fullness, nausea/vomiting, bloating, upper abdominal pain, lower abdominal pain, and heartburn/regurgitation were used. Corresponding ESM scores that were used were fullness, nausea, bloating, upper abdominal pain, lower abdominal pain, and heartburn, respectively. For comparison between ESM scores and NDI or PAGI-SYM, end-of-week scores were rescaled to an 11-point scale by multiplying the NDI and PAGI-SYM scores by $\frac{11}{6}$.

Reliability was assessed with the internal consistency and test-retest reliability. For assessment of internal consistency with the Cronbach's alpha coefficient, the ESM-PROM items were divided into five domains (i.e., upper gastrointestinal symptoms, lower gastrointestinal symptoms, physical non-GI symptoms, mental positive affect, and mental negative affect). Good internal consistency is reflected by a Cronbach's alpha of 0.7-0.9.38

For assessment of test-retest reliability, we assumed that ESM scores during the first half of the study period (i.e., days 1, 2, and 3) would show moderate to good consistency with ESM scores during the second half of the study period (i.e., day 5, 6, and 7). For each symptom, mean scores were calculated per subject for these two time periods. A paired samples t-test was performed to test the differences between these study periods in order to exclude a time effect. Agreement was assessed by calculating an ICC between the time periods. For this, a two-way model based on average-measures and absolute agreement was used. ICC values above 0.75 are considered good, whereas ICC values between 0.5 and 0.75 are considered moderate. ${ }^{39}$

\section{Results}

\section{Subjects}

In total, 36 patients with FD met the inclusion criteria. One patient did not complete at least $1 / 3$ of the total number of ESM-assessments. Therefore, 35 patients (25 female (71.4\%), age 44.7 (SD 15.7) years, GAD-7 4.8 (SD 4.5), HADS-Anxiety 5.3 (SD 4.5), HADS-Depression 4.9 (SD 4.3)) were included in the analyses. Ten patients fulfilled the criteria for EPS (28.6\%), seven for PDS (20\%), and 18 for OS (51.4\%). Of the 35 included patients, 13 had comorbid IBS (37\%, one in the EPS group, three in the PDS group, and nine in the overlap group). During the study, no adverse events were reported by the subjects. 


\section{Compliance}

The completion rate of ESM assessments was $62.2 \%$. Over the 7-day period, a mean number of 43.5 measurements was completed per individual (range: 23-68). The majority of subjects completed between 31 and 60 assessments during the study period (Figure 6.2).

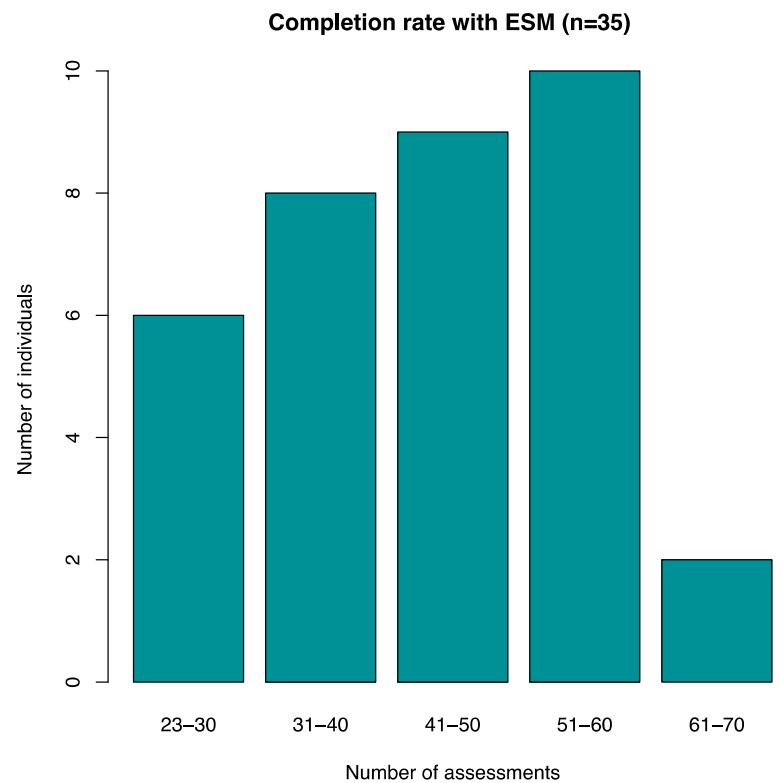

Figure 6.2 Number of individuals (y-axis) per category of completed number of assessments (x-axis).

\section{Concurrent validity}

\section{ESM scores compared with end-of-day diary scores}

Both ESM and the end-of-day diary scored the following gastrointestinal symptoms: upper abdominal fullness, upper abdominal heaviness, bloating, upper abdominal pain, upper abdominal burning sensation, lower abdominal pain, nausea, belching, heartburn, and regurgitation.

Mean scores on ESM and end-of-day scores were all significantly associated, which indicates that both assessment methods measure the same construct (Table 6.1). Furthermore, ICCs between ESM scores and end-of-day diary scores were all above 0.75 , indicating good agreement between these assessment methods (Table 6.1). However, symptom scores were all significantly higher in end-of-day diaries compared with mean ESM-scores (Table 6.2). Furthermore, symptom scores were all significantly lower in end- 
of-day diaries compared with maximum ESM-scores. Therefore, end-of-day diary scores were placed in between the mean and maximum ESM scores for all gastrointestinal symptoms. This concept is illustrated in Figure 6.3 for fullness scores.

These differences between end-of-day scores and both mean and maximum ESM scores can be made insightful for individual patients. Figure 6.4 depicts the fullness scores on the end-of-day diary and the ESM for one individual patient. A highly fluctuating pattern for fullness is observed during the 7-day study period with ESM: the patient reported multiple time-points without fullness (i.e., score 0 ) or with low feelings of fullness (i.e., scores below 5 ) and only a few time-points with higher symptom scores (i.e., above 5). Instead of realtime symptom assessment, end-of-day diary scores reflect scores of the entire day. For this individual, this resulted in end-of-day fullness scores higher than 5 for 6 out of 7 days. Figure 6.4 highlights the discrepancy between assessment methods.

Table 6.1 Associations and intraclass correlation coefficients between mean ESM scores and end-ofday diary scores.

\begin{tabular}{lcccc}
\hline \multirow{2}{*}{ Symptom } & \multicolumn{2}{c}{ Associations } & \multicolumn{2}{c}{ Intraclass correlations } \\
\cline { 2 - 5 } & Estimate & SE & ICC & $\mathbf{9 5 \% - C I ~}$ \\
\hline Fullness & $0.952^{* * *}$ & 0.084 & 0.790 & $0.729-0.839$ \\
Heaviness & $1.025^{* * *}$ & 0.060 & 0.803 & $0.745-0.849$ \\
Bloating & $1.092^{* * *}$ & 0.054 & 0.865 & $0.824-0.898$ \\
Upper abdominal pain & $0.953 * * *$ & 0.062 & 0.833 & $0.783-0.873$ \\
Upper abdominal burning & $0.735^{* * *}$ & 0.069 & 0.885 & $0.849-0.913$ \\
Lower abdominal pain & $1.103^{* * *}$ & 0.078 & 0.770 & $0.703-0.823$ \\
Nausea & $1.147^{* * *}$ & 0.052 & 0.872 & $0.832-0.903$ \\
Belching & $1.045^{* * *}$ & 0.061 & 0.861 & $0.818-0.894$ \\
Heartburn & $1.107^{* * *}$ & 0.043 & 0.917 & $0.891-0.938$ \\
Regurgitation & $1.154 * * *$ & 0.078 & 0.771 & $0.704-0.824$ \\
\hline
\end{tabular}

Mixed linear models with end-of-day diary score as dependent variable and ESM mean scores as independent variable, corrected for repeated measures (AR1 covariate structure) were used to test significance. Strength and direction of the association is depicted by estimate. SE: Standard Error; ICC Intraclass Correlation Coefficient. $* * * \mathrm{p}<0.001$. 
Table 6.2 Difference between ESM mean and maximum scores and end-of-day diary scores.

\begin{tabular}{|c|c|c|c|c|}
\hline \multirow[t]{2}{*}{ Symptom } & \multicolumn{2}{|c|}{ ESM mean vs. end-of-day } & \multicolumn{2}{|c|}{ ESM maximum vs. end-of day } \\
\hline & Difference & SE & Difference & SE \\
\hline Fullness & $1.031 * * *$ & 0.191 & $-1.001 * * *$ & 0.233 \\
\hline Heaviness & $0.875 * * *$ & 0.127 & $-1.133 * * *$ & 0.164 \\
\hline Bloating & $0.793 * * *$ & 0.133 & $-0.991 * * *$ & 0.101 \\
\hline Upper abdominal pain & $0.563 * * *$ & 0.148 & $-0.712 * * *$ & 0.132 \\
\hline Upper abdominal burning & $0.426 * *$ & 0.144 & $-0.484 * * *$ & 0.124 \\
\hline Lower abdominal pain & $0.562 * * *$ & 0.151 & $-0.459 * * *$ & 0.120 \\
\hline Nausea & $0.524 * * *$ & 0.128 & $-0.597 * * *$ & 0.113 \\
\hline Belching & $0.677 * * *$ & 0.150 & $-0.387 * * *$ & 0.115 \\
\hline Heartburn & $0.459 * * *$ & 0.125 & $-0.398 * * *$ & 0.103 \\
\hline Regurgitation & $0.329 *$ & 0.131 & $-0.359 * * *$ & 0.080 \\
\hline
\end{tabular}

A positive difference indicates a higher score, and a negative difference indicates a lower score in end-of-day diary compared with ESM. Mixed linear models with the delta score (i.e., difference between ESM mean/max score and end-of-day diary score) as the dependent variable, corrected for repeated measures (AR1 covariate structure) were used to test significance. Strength and direction of the association is depicted by estimate. SE: Standard Error; ICC Intraclass Correlation Coefficient. ${ }^{*} \mathrm{p}<0.05 ;{ }^{*} \mathrm{p}<0.01 ;{ }^{* * *} \mathrm{p}<0.001$.

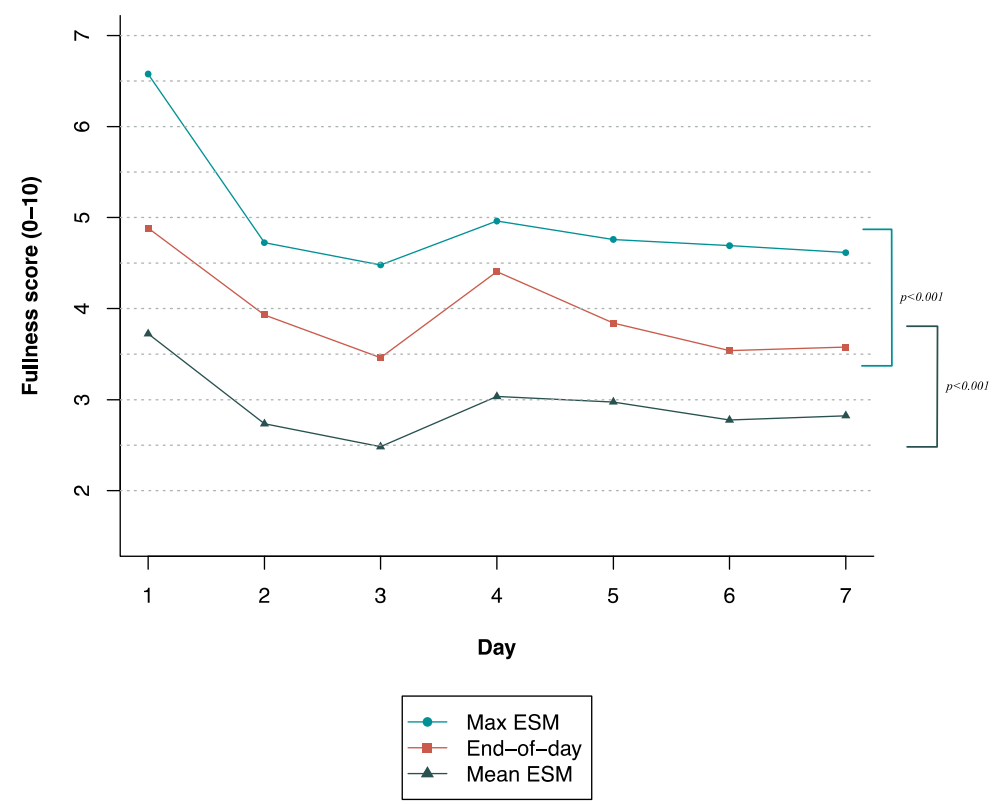

Figure 6.3 Fullness scores. Daily fullness scores based on end-of-day diary scores and mean and maximum ESM scores (11-points NRS). Mixed linear models with the delta score (i.e., difference between ESM mean/max score and end-of-day diary score) as the dependent variable, corrected for repeated measures (AR1 covariate structure) were used to test significance. 

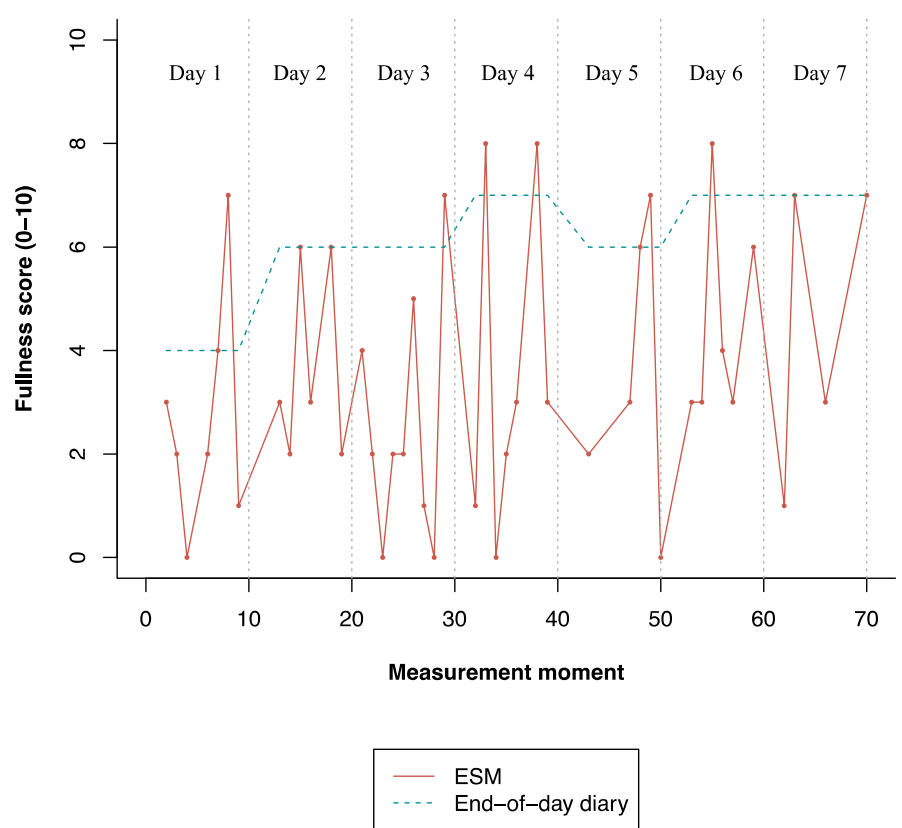

Figure 6.4 Individual fullness scores. Fullness scores (on an 11-point NRS) for one FD patient on ESM and end-of-day diary over the seven-day study period. Each day, at maximum 10 assessments were available for ESM. One assessment was completed electronically at the end of each day.

\section{ESM scores compared with end-of-week scores}

The comparison and correlation between ESM scores and end-of-week scores are depicted in Table 6.3. ESM scores for postprandial fullness, nausea, bloating, upper abdominal pain, lower abdominal pain, heartburn, upper abdominal burning, and belching were all lower compared with end-of-week scores on the NDI and PAGI-SYM. Scores for upper abdominal burning, heartburn, bloating, and belching on the NDI were strongly correlated with ESM scores. Scores for upper abdominal pain, fullness, and nausea on the NDI showed good correlation with ESM scores. Reflux scores on the NDI showed a moderate correlation with ESM scores. Bloating, upper abdominal pain, and heartburn/regurgitation sub scores on the PAGI-SYM were strongly correlated with ESM scores. All other PAGI-SYM sub scores showed good correlation with ESM scores.

In addition to gastrointestinal symptoms, psychological factors were assessed with ESM. Several psychological factors corresponded with the PHQ-9 or GAD-7, namely "feeling down", "feeling anxious", "feeling worried", "feeling irritated", and "feeling relaxed". Answering scales were substantially different and, therefore, did not allow for 
harmonisation of the scores. Hence, no mean scores could be compared between assessment methods. However, correlations between the two assessment methods could be calculated. Strong correlations between ESM and end-of week scores were found for "feeling down", "feeling worried", "feeling irritated", and "feeling relaxed". Good correlations were found for "feeling anxious".

Table 6.3 ESM scores compared with end-of-week scores. Mean scores based on subject-level.

\begin{tabular}{lccc}
\hline NDI vs. ESM & $\begin{array}{c}\text { ESM score } \\
\text { mean } \pm \text { SD }\end{array}$ & $\begin{array}{c}\text { NDI score } \\
\text { mean } \pm \text { SD }\end{array}$ & $\begin{array}{c}\text { Pearson } \\
\text { correlation }\end{array}$ \\
\hline Upper abdominal pain & $1.88 \pm 2.05$ & $3.72 \pm 2.29 * * *$ & 0.617 \\
Upper abdominal burning & $1.37 \pm 2.01$ & $2.10 \pm 2.56 * *$ & 0.846 \\
Heartburn & $1.35 \pm 1.96$ & $2.51 \pm 2.71 * * *$ & 0.737 \\
Reflux & $0.58 \pm 1.05$ & $1.94 \pm 2.39 * * *$ & 0.465 \\
Fullness & $2.88 \pm 1.98$ & $4.66 \pm 2.24 * * *$ & 0.574 \\
Bloating & $2.86 \pm 1.95$ & $4.03 \pm 2.84 * * *$ & 0.838 \\
Nausea & $1.35 \pm 1.91$ & $3.25 \pm 2.85 * * *$ & 0.556 \\
Belching & $1.23 \pm 1.63$ & $2.67 \pm 2.79 * * *$ & 0.779 \\
\hline PAGI-SYM vs. ESM & & PAGI-SYM subscale score & \\
& & mean \pm SD & 0.636 \\
Postprandial fullness & $2.88 \pm 1.98$ & $3.89 \pm 2.06 * *$ & 0.556 \\
Nausea/vomiting & $1.35 \pm 1.91$ & $1.64 \pm 2.05$ & 0.728 \\
Bloating & $2.86 \pm 1.95$ & $4.64 \pm 2.89 * * *$ & 0.804 \\
Upper abdominal pain & $1.81 \pm 2.05$ & $3.75 \pm 2.44 * * *$ & 0.680 \\
Lower abdominal pain & $1.16 \pm 1.56$ & $2.20 \pm 2.29 * * *$ & 0.802 \\
Heartburn/regurgitation & $1.35 \pm 1.96$ & $1.92 \pm 1.87 * *$ & 0.828 \\
\hline PHQ-9/GAD-7 vs. ESM & & & 0.586 \\
Down & & & 0.865 \\
Anxious & & & 0.724 \\
Worried & & & 0.836 \\
Irritated & & & \\
Relaxed & & & \\
\hline NDI & & & \\
\hline
\end{tabular}

NDI vs. ESM: NDI scores transformed from 6-point scale to 11-point scale by multiplying with $\frac{11}{6}$. PAGI-SYM sub scores vs. ESM: PAGI-SYM scores transformed from 6-point scale to 11-point scale by multiplying with $\frac{11}{6}$. Corresponding ESM scores tested with PAGI-SYM scores: Early satiety and Fullness, Nausea/vomiting and Nausea, Bloating and Bloating, Upper abdominal pain and Upper abdominal pain, Lower abdominal pain and Lower abdominal pain, Heartburn/regurgitation and Heartburn. PHQ-9/GAD-7 vs. ESM: answering scales do not allow comparison between mean scores. Paired samples t-test was used to test for differences. ${ }^{* *} \mathrm{p}<0.01$; $* * * \mathrm{p}<0.001$.

\section{Internal consistency}

Internal consistency of the ESM-PROM for FD was determined by categorising the items in five constructs, namely upper gastrointestinal symptoms, lower gastrointestinal symptoms, physical non-gastrointestinal symptoms, positive affect, and negative affect. Table 6.4 lists the Cronbach's $\alpha$ coefficients for these constructs. Very good internal consistency was found for upper gastrointestinal symptoms and negative affect. Good 
internal consistency was found for physical non-gastrointestinal symptoms. An acceptable internal consistency was found for positive affect. Consistency was relatively low for lower gastrointestinal symptoms, indicating that these two symptoms might not perfectly reflect the same construct for lower gastrointestinal symptoms.

Table 6.4 Internal consistency of five ESM-PROM symptom domains, reflected by Cronbach's $\alpha$ coefficient.

\begin{tabular}{lc}
\hline Symptoms & Cronbach's $\alpha$ \\
\hline Upper gastrointestinal symptoms & 0.842 \\
Fullness & \\
Upper abdominal heaviness & \\
Upper abdominal pain & \\
Upper abdominal burning & \\
Nausea & \\
Vomiting & \\
Belching & 0.483 \\
Heartburn & \\
Regurgitation & \\
Lower gastrointestinal symptoms & 0.786 \\
Bloating & \\
Lower abdominal pain & \\
Physical - non-gastrointestinal & \\
Palpitations & \\
Sweating & \\
Dyspnoea & \\
Dizziness & \\
Mental - Positive affect & \\
Good & \\
Relaxed & \\
Mental - Negative affect & \\
Down & \\
Anxious & \\
Irritated & \\
Stressed & \\
Worried & \\
\hline
\end{tabular}

\section{Test-retest reliability}

Mean ESM scores for the first (i.e., day 1, 2, and 3) and second (i.e., day 5, 6, and 7) half week of the study period are depicted in Table 6.5. Only the scores for "feeling down", "feeling anxious", "feeling irritated", "feeling stressed", and "feeling worried" differed, with all scores lower in the second half-week. All other scores did not differ between the first half-week and the second half-week. All symptoms showed good consistency between the measurements, as reflected by the ICCs. These findings suggest sufficient test-retest reliability. 
Table 6.5 Mean scores for ESM-reported gastrointestinal symptoms, non-gastrointestinal physical symptoms, and mental status in the first half-week and second-half week of the study period. Agreement between first and second half-week is reflected by the ICC.

\begin{tabular}{lccc}
\hline & $\begin{array}{c}\text { First half-week } \\
\text { Mean score } \pm \text { SD }\end{array}$ & $\begin{array}{c}\text { Second half-week } \\
\text { Mean score } \pm \text { SD }\end{array}$ & $\begin{array}{c}\text { ICC } \\
{[\mathbf{9 5 \% - C I ]}}\end{array}$ \\
\hline Gastrointestinal symptoms & & & \\
Fullness & $2.94 \pm 1.93$ & $2.79 \pm 2.08$ & $0.913[0.828-0.956]$ \\
Upper abdominal heaviness & $2.58 \pm 1.72$ & $2.48 \pm 1.91$ & $0.935[0.871-0.967]$ \\
Bloating & $2.99 \pm 1.86$ & $2.74 \pm 2.13$ & $0.934[0.869-0.966]$ \\
Upper abdominal pain & $1.74 \pm 1.89$ & $1.86 \pm 2.22$ & $0.956[0.913-0.978]$ \\
Upper abdominal burning & $1.40 \pm 1.90$ & $1.36 \pm 2.11$ & $0.957[0.915-0.978]$ \\
Lower abdominal pain & $1.24 \pm 1.57$ & $1.13 \pm 1.65$ & $0.947[0.896-0.973]$ \\
Nausea & $1.43 \pm 2.00$ & $1.28 \pm 1.82$ & $0.970[0.940-0.985]$ \\
Belching & $1.27 \pm 1.67$ & $1.24 \pm 1.77$ & $0.942[0.884-0.971]$ \\
Heartburn & $1.30 \pm 1.82$ & $1.41 \pm 2.16$ & $0.915[0.832-0.957]$ \\
Non-gastrointestinal physical symptoms & & & \\
Palpitations & $0.68 \pm 1.33$ & $0.67 \pm 1.52$ & $0.953[0.907-0.976]$ \\
Sweating & $1.50 \pm 2.19$ & $1.37 \pm 2.27$ & $0.958[0.918-0.979]$ \\
Dyspnoea & $1.20 \pm 1.96$ & $1.35 \pm 2.12$ & $0.975[0.950-0.987]$ \\
Dizziness & $0.65 \pm 1.34$ & $0.67 \pm 1.47$ & $0.955[0.910-0.977]$ \\
Pressure on chest & $0.89 \pm 1.62$ & $1.06 \pm 1.95$ & $0.955[0.910-0.977]$ \\
Tired & $4.77 \pm 2.36$ & $5.03 \pm 2.35$ & $0.966[0.930-0.983]$ \\
Mental status & & & \\
Good & $6.11 \pm 1.62$ & $6.32 \pm 1.50$ & $0.931[0.862-0.965]$ \\
Down & $1.41 \pm 1.85$ & $0.98 \pm 1.67 * *$ & $0.929[0.822-0.968]$ \\
Anxious & $0.85 \pm 1.58$ & $0.48 \pm 1.44 * *$ & $0.914[0.804-0.959]$ \\
Irritated & $1.32 \pm 1.90$ & $1.02 \pm 1.80 *$ & $0.963[0.914-0.982]$ \\
Stressed & $2.26 \pm 2.27$ & $1.79 \pm 2.33 *$ & $0.938[0.858-0.971]$ \\
Relaxed & $6.15 \pm 1.80$ & $6.22 \pm 1.83$ & $0.929[0.859-0.964]$ \\
Worried & $2.07 \pm 2.61$ & $1.66 \pm 2.54 *$ & $0.941[0.878-0.971]$ \\
\hline
\end{tabular}

First half-week reflects day 1, 2, and 3. Second half-week reflects day 5, 6, and 7. Paired samples t-test was used to test for significance. SD: standard deviation, ICC: intraclass correlation coefficient. ${ }^{*} \mathrm{p}<0.05,{ }^{*} \mathrm{p}<0.01$.

\section{Discussion}

The present study evaluated the validity and reliability of an ESM-based PROM for symptom assessment in patients with FD. The development of this tool has been previously described. ${ }^{18}$ This study demonstrated significant associations between ESM scores for gastrointestinal symptoms and end-of-day scores, as well as moderate to strong correlations between ESM scores and end-of-week scores, confirming concurrent validity. Besides validity, reliability was considered adequate based on moderate-to-good internal consistency and excellent test-retest reliability.

Prior to the implementation of a novel PROM in patient care or clinical trials, adequate validity and reliability have to be demonstrated. Throughout the years, a plethora of 
statistical methods to test psychometric properties of novel PROMs have been described. $6,38,40$ In this study, measures of validity and reliability that are most applicable to the novel ESM-based PROM are used. Regarding concurrent validity, significant associations for all mean ESM and end-of-day scores for gastrointestinal symptoms were found. Given the good agreement between these assessment methods, it can be stated that the ESM-PROM and end-of-day diary measure similar constructs regarding gastrointestinal symptoms. Interestingly, in this study, no peak symptom score in end-ofday reporting was shown, contrary to studies performed in IBS patients. ${ }^{15,16}$ End-of-day diary symptom scores tended to be in between the mean and maximum ESM scores. This points towards over-reporting of gastrointestinal complaints when subjects need to provide one score over the entire day. The difference between mean ESM scores and endof-week scores was even more pronounced. This indicates that subjects tend to remember the moments that they were aware of complaints and neglect the moments without complaints when providing scores over a longer period of time, emphasising the usefulness of ESM in generating accurate individual symptom patterns.

This study demonstrated very good internal consistency for upper gastrointestinal symptoms, whereas a poor consistency was found for lower gastrointestinal symptoms. This suggests that the two items chosen to represent lower gastrointestinal symptoms (i.e., bloating and lower abdominal pain) should possibly be considered to reflect different constructs. It should be noted that the items were selected based on focus group interviews with FD patients. A previous study developed an ESM-based PROM for IBS patients that included more items reflecting lower gastrointestinal symptoms. ${ }^{33}$ It could have been possible to combine both PROMs. However, this would have increased the number of total symptom items substantially and, therefore, the patient's burden. Instead, we decided to focus on the symptoms deemed essential by patients with FD, as reflected by the item selection in the focus groups. However, internal consistency might have been improved by expanding this domain with lower gastrointestinal symptoms that are deemed more appropriate.

In the present study, continuous repeated measurements were performed for 1 week. The strength and purpose of ESM is real-time assessment. Test-retest reliability of ESM was investigated by comparing and correlating mean scores of the first half-week with those of the second half-week. We hypothesised that test-retest reliability of the ESM would not be perfect due to the fluctuating nature of FD symptoms and the influence of subjects' daily life on (gastrointestinal) symptoms. The probability that within-subject differences are smaller than between-subject differences is plausible. Therefore, it is possible that a subjects' own symptom pattern can be identified by using ESM. For all upper- and lower 
gastrointestinal symptoms, as well as non-gastrointestinal symptoms and positive affect, no significant differences in mean scores were found, when the first half of the week was compared with the second half. Symptoms reflecting negative affect tended to be significantly lower during the second half-week. For all scores, high correlations between the first half-week and second half-week were demonstrated. Most subjects started the test period in the beginning of the week. Consequently, many of the second half-week assessments were scheduled on one or more weekend days. It is possible that feelings of negative affect were lower in the second half-week, due to less daily life hassles (i.e., no work pressure).

The regulatory authorities recommend the use of end-of-day reporting in FD. ${ }^{41}$ ESM represents a higher burden for patients than end-of-day reporting, as multiple assessments during the day are likely to be more time-consuming than most conventional assessment methods. The accuracy of the assessment method would be at stake if this had resulted in low adherence. A completion rate of $33 \%$ for ESM-based PROMS is conventionally accepted. ${ }^{35,36}$ In the present study, $62.2 \%$ of the total assessments was completed. Reported completion rates are reliable and accurate, since ESM assessments were only available for a set period of time and electronic date- and time-stamps were registered for each assessment.

A particular strength of the present study is the validation of this novel tool according to the recommendations of de FDA. ${ }^{6}$ An important addition is that conventionally static measures of health status at specific time-points are used for comparison. In contrast to end-of-day or end-of-week health questionnaires, ESM, is able to detect short-term fluctuations in symptoms by its dynamic assessment of symptomatology. Therefore, ESM has the ability to provide a more detailed and individual assessment of symptom patterns. Moreover, this study demonstrated the suitability of ESM to provide an overview of patients' symptoms over the 7-day period as well as a detailed insight into within-day fluctuations of symptoms. Furthermore, by assessing other symptoms at the exact same moments, ESM offers the opportunity to investigate associations between concurrent symptoms, environmental factors, and psychological symptoms. ${ }^{13,42}$ This means that ESM is capable of investigating symptom formation, in other words, how symptoms impact on symptoms. More insight in symptom dynamics may reveal a better understanding of the underlying pathophysiology in FD and a more customised treatment trajectory. A recent study in psychiatry even demonstrated the capability of ESM-based self-monitoring combined with positive emotion enhancement to enhance treatment effects in patients treated for depression. ${ }^{43}$ This emphasises the capability of ESM to aid in disease insight, self-management, and improved shared decision making. 
Moreover, FD is characterised as a heterogeneous disorder often accompanied by general somatic complaints and/or psychological disturbances. This is reflected by a considerable number of studies describing lower levels of physical and mental quality of life.44-48 Therefore, items reflecting frequently reported physical complaints and mental state were included in addition to gastrointestinal symptoms. Previous studies have described the assessment of patients' mental state by using ESM-based PROMs. ${ }^{32,49,50}$ However, the main focus of the current study was the gastrointestinal complaints as reflected in this PROM.

A potential shortcoming of the present study is the relatively small sample size. For the evaluation of validity and reliability of outcome measures, it has been recommended to include at least 50 subjects. ${ }^{51}$ However, the large number of repeated measures per subject provides a significant increase in power, which is a substantial strength of ESM concerning required sample sizes in clinical trials. Moreover, in this small sample size, adherence was reasonable. However, adherence should be evaluated in a larger pragmatic trial in order to adequately evaluate compliance to the present smartphone app. Furthermore, potential user bias should be considered, as this study required subjects to own a smartphone and to be able to adequately operate the smartphone app requiring sufficient digital skills. Additionally, intensive recording using this smartphone app was mandatory. Another important aspect in quality testing of PROMs is assessment of responsiveness (i.e., the sensitivity to detect change over time). ${ }^{38,40,52}$ In the present study, responsiveness was not evaluated, and this has to be performed before the use of this novel ESM-based PROM as a tool to evaluate treatment efficacy in patients with FD. In addition, cross-cultural validation remains to be performed.

In conclusion, adequate concurrent validity, moderate-to-good internal consistency, and very good test-retest reliability were demonstrated for the novel ESM-based PROM for patients with FD. Moreover, the ESM-based PROM has the advantage of evaluating individual symptom patterns, providing the opportunity to evaluate interactions between symptoms and environmental factors. It must be noted that this was not evaluated in the present study as the goal of the present study was merely the validation of the used smartphone app. Future studies should evaluate the potential of this tool to evaluate these interactions, as this may lead to increased insight into their illness and tools for selfmanagement, as well as improved shared decision-making. Thus, this novel tool has the ability to aid in the transition towards more personalised healthcare for patients with FD. Future research for assessment of responsiveness of this novel ESM-based PROM is warranted, in order to determine its place in the evaluation of treatment efficacy. 


\section{References}

1. Aziz I, Palsson OS, Tornblom H, Sperber AD, Whitehead WE, Simren M. Epidemiology, clinical characteristics, and associations for symptom-based Rome IV functional dyspepsia in adults in the USA, Canada, and the UK: a cross-sectional population-based study. Lancet Gastroenterol Hepatol. 2018; 3(4):252-62.

2. Stanghellini V, Chan FK, Hasler WL, Malagelada JR, Suzuki H, Tack J, et al. Gastroduodenal Disorders. Gastroenterology. 2016;150(6):1380-92.

3. Taylor F, Reasner DS, Carson RT, Deal LS, Foley C, Iovin R, et al. Development of a Symptom-Based Patient-Reported Outcome Instrument for Functional Dyspepsia: A Preliminary Conceptual Model and an Evaluation of the Adequacy of Existing Instruments. Patient. 2016;9(5):409-18.

4. Sander GB, Mazzoleni LE, Francesconi CF, Balbinotto G, Mazzoleni F, Wortmann AC, et al. Influence of organic and functional dyspepsia on work productivity: the HEROES-DIP study. Value Health. 2011;14(5 Suppl 1):S126-9.

5. Ford AC, Forman D, Bailey AG, Cook MB, Axon AT, Moayyedi P. Who consults with dyspepsia? Results from a longitudinal 10-yr follow-up study. Am J Gastroenterol. 2007;102(5):957-65.

6. U.S. Department of Health and Human Services FaDA, Center for Drug Evaluation and Research (CDER), Center for Biologics Evaluation and Research (CBER), Center for Devices and Radiological Health (CDRH). Guidance for Industry Patient-Reported Outcome Measures: Use in Medical Product Development to Support Labeling Claims. 2009.

7. Smeets FGM, Masclee AAM, Conchillo JM, Keszthelyi D. Systematic review: Disease-specific instruments to assess gastrointestinal symptoms in functional dyspepsia. Neurogastroenterol Motil. 2018.

8. Bradburn NM, Rips LJ, Shevell SK. Answering autobiographical questions: the impact of memory and inference on surveys. Science. 1987;236(4798):157-61.

9. Feinle-Bisset C, Azpiroz F. Dietary and lifestyle factors in functional dyspepsia. Nat Rev Gastroenterol Hepatol. 2013;10(3):150-7.

10. Feinle-Bisset C, Horowitz M. Dietary factors in functional dyspepsia. Neurogastroenterol Motil. 2006;18(8):608-18.

11. Aro P, Talley NJ, Johansson SE, Agreus L, Ronkainen J. Anxiety Is Linked to New-Onset Dyspepsia in the Swedish Population: A 10-Year Follow-up Study. Gastroenterology. 2015;148(5):928-37.

12. Stone AA, Shiffman S, Schwartz JE, Broderick JE, Hufford MR. Patient compliance with paper and electronic diaries. Control Clin Trials. 2003;24(2):182-99.

13. Myin-Germeys I, Oorschot M, Collip D, Lataster J, Delespaul P, van Os J. Experience sampling research in psychopathology: opening the black box of daily life. Psychol Med. 2009;39(9):1533-47.

14. Shiffman S, Stone AA, Hufford MR. Ecological momentary assessment. Annu Rev Clin Psychol. 2008;4: 132.

15. Weinland SR, Morris CB, Hu Y, Leserman J, Bangdiwala SI, Drossman DA. Characterization of episodes of irritable bowel syndrome using ecological momentary assessment. Am J Gastroenterol. 2011;106(10): 1813-20.

16. Mujagic Z, Leue C, Vork L, Lousberg R, Jonkers DM, Keszthelyi D, et al. The Experience Sampling Method--a new digital tool for momentary symptom assessment in IBS: an exploratory study. Neurogastroenterol Motil. 2015;27(9):1295-302.

17. Chan Y, So SH, Mak ADP, Siah KTH, Chan W, Wu JCY. The temporal relationship of daily life stress, emotions, and bowel symptoms in irritable bowel syndrome-Diarrhea subtype: A smartphone-based experience sampling study. Neurogastroenterol Motil. 2019;31(3):e13514.

18. Smeets FGM, Keszthelyi D, Vork L, Tack J, Talley NJ, Simren M, et al. Development of a real-time patient-reported outcome measure for symptom assessment in patients with functional dyspepsia using the experience sampling method. Neurogastroenterol Motil. 2019;31(2):e13496.

19. Wang AJ, Liao XH, Xiong LS, Peng S, Xiao YL, Liu SC, et al. The clinical overlap between functional dyspepsia and irritable bowel syndrome based on Rome III criteria. BMC Gastroenterol. 2008;8.

20. Agreus L, Svardsudd K, Nyren O, Tibblin G. Irritable-Bowel-Syndrome and Dyspepsia in the GeneralPopulation - Overlap and Lack of Stability over Time. Gastroenterology. 1995;109(3):671-80. 
21. Park JM, Choi MG, Cho YK, Lee IS, Kim JI, Kim SW, et al. Functional Gastrointestinal Disorders Diagnosed by Rome III Questionnaire in Korea. Journal of Neurogastroenterol Motil. 2011;17(3):279-86.

22. Outlaw WM, Koch KL. Dyspepsia and its overlap with irritable bowel syndrome. Curr Gastroenterol Rep. 2006;8(4):266-72.

23. Choi YJ, Kim N, Yoon H, Shin CM, Park YS, Kim JW, et al. Overlap between irritable bowel syndrome and functional dyspepsia including subtype analyses. J Gastroen Hepatol. 2017;32(9):1553-61.

24. Talley NJ, Haque M, Wyeth JW, Stace NH, Tytgat GN, Stanghellini V, et al. Development of a new dyspepsia impact scale: the Nepean Dyspepsia Index. Aliment Pharmacol Ther. 1999;13(2):225-35.

25. Jones MP, Sato YA, Talley NJ. The Nepean Dyspepsia Index is a valid instrument for measuring quality-oflife in functional dyspepsia. Eur J Gastroenterol Hepatol. 2019;31(3):329-33.

26. Talley NJ, Verlinden M, Jones M. Validity of a new quality of life scale for functional dyspepsia: a United States multicenter trial of the Nepean Dyspepsia Index. Am J Gastroenterol. 1999;94(9):2390-7.

27. Rentz AM, Kahrilas P, Stanghellini V, Tack J, Talley NJ, de la Loge C, et al. Development and psychometric evaluation of the patient assessment of upper gastrointestinal symptom severity index (PAGI-SYM) in patients with upper gastrointestinal disorders. Qual Life Res. 2004;13(10):1737-49.

28. Spitzer RL, Kroenke K, Williams JB, Lowe B. A brief measure for assessing generalized anxiety disorder: the GAD-7. Arch Intern Med. 2006;166(10):1092-7.

29. Zigmond AS, Snaith RP. The hospital anxiety and depression scale. Acta Psychiatr Scand. 1983;67(6): 361-70.

30. Kroenke K, Spitzer RL, Williams JB. The PHQ-9: validity of a brief depression severity measure. J Gen Intern Med. 2001;16(9):606-13.

31. Kimhy D, Delespaul P, Corcoran C, Ahn H, Yale S, Malaspina D. Computerized experience sampling method (ESMc): assessing feasibility and validity among individuals with schizophrenia. J Psychiatr Res. 2006;40(3):221-30.

32. Myin-Germeys I, Peeters F, Havermans R, Nicolson NA, deVries MW, Delespaul P, et al. Emotional reactivity to daily life stress in psychosis and affective disorder: an experience sampling study. Acta Psychiat Scand. 2003;107(2):124-31.

33. Vork L, Keszthelyi D, Mujagic Z, Kruimel JW, Leue C, Ponten I, et al. Development, content validity, and cross-cultural adaptation of a patient-reported outcome measure for real-time symptom assessment in irritable bowel syndrome. Neurogastroenterol Motil. 2018;30(3).

34. Vork L, Keszthelyi D, van Kuijk SMJ, Quetglas EG, Tornblom H, Simren M, et al. Patient-Specific StressAbdominal Pain Interaction in Irritable Bowel Syndrome: An Exploratory Experience Sampling Method Study. Clin Transl Gastroenterol. 2020;11(7):e00209.

35. Delespaul P. Assessing schizophrenia in daily life the experience sampling method.: UPM, Universitaire Pers Maastricht, Maastricht University; 1995.

36. Palmier-Claus JE, Myin-Germeys I, Barkus E, Bentley L, Udachina A, Delespaul PA, et al. Experience sampling research in individuals with mental illness: reflections and guidance. Acta Psychiatr Scand. 2011; 123(1):12-20.

37. Hazra A, Gogtay N. Biostatistics Series Module 6: Correlation and Linear Regression. Indian J Dermatol. 2016;61(6):593-601.

38. Alrubaiy L, Hutchings HA, Williams JG. Assessing patient reported outcome measures: A practical guide for gastroenterologists. United European Gastroenterol J. 2014;2(6):463-70.

39. Koo TK, Li MY. A Guideline of Selecting and Reporting Intraclass Correlation Coefficients for Reliability Research. J Chiropr Med. 2016;15(2):155-63.

40. Verhagen SJW, Berben JA, Leue C, Marsman A, Delespaul P, van Os J, et al. Demonstrating the reliability of transdiagnostic mHealth Routine Outcome Monitoring in mental health services using experience sampling technology. PLoS One. 2017;12(10):e0186294.

41. Clinical Outcome Assessments (COA) Qualification Program DDTCOA: Functional Dyspepsia Symptom Diary (FDSD) 2017 [updated 27 October 2017. Available from: https://www.fda.gov/media/ 125024/download.

42. Verhagen SJW, Hasmi L, Drukker M, van Os J, Delespaul PAEG. Use of the experience sampling method in the context of clinical trials. Evid-Based Ment Heal. 2016;19(3):86-9. 
43. Kramer I, Simons CJ, Hartmann JA, Menne-Lothmann C, Viechtbauer W, Peeters F, et al. A therapeutic application of the experience sampling method in the treatment of depression: a randomized controlled trial. World Psychiatry. 2014;13(1):68-77.

44. Aro P, Talley NJ, Agreus L, Johansson SE, Bolling-Sternevald E, Storskrubb T, et al. Functional dyspepsia impairs quality of life in the adult population. Aliment Pharmacol Ther. 2011;33(11):1215-24.

45. Van Oudenhove L, Vandenberghe J, Vos R, Holvoet L, Demyttenaere K, Tack J. Risk factors for impaired health-related quality of life in functional dyspepsia. Aliment Pharmacol Ther. 2011;33(2):261-74.

46. Lee HJ, Lee SY, Kim JH, Sung IK, Park HS, Jin CJ, et al. Depressive mood and quality of life in functional gastrointestinal disorders: differences between functional dyspepsia, irritable bowel syndrome and overlap syndrome. Gen Hosp Psychiatry. 2010;32(5):499-502.

47. Mahadeva S, Goh KL. Anxiety, depression and quality of life differences between functional and organic dyspepsia. J Gastroen Hepatol. 2011;26:49-52.

48. Talley NJ, Locke GR, Lahr BD, Zinsmeister AR, Tougas G, Ligozio G, et al. Functional dyspepsia, delayed gastric emptying, and impaired quality of life. Gut. 2006;55(7):933-9.

49. van Os J, Verhagen S, Marsman A, Peeters F, Bak M, Marcelis M, et al. The experience sampling method as an mHealth tool to support self-monitoring, self-insight, and personalized health care in clinical practice. Depress Anxiety. 2017;34(6):481-93.

50. van Winkel M, Nicolson NA, Wichers M, Viechtbauer W, Myin-Germeys I, Peeters F. Daily life stress reactivity in remitted versus non-remitted depressed individuals. Eur Psychiatry. 2015;30(4):441-7.

51. Arrindell WA, van der Ende J. An empirical test of the utility of the observations-to-variables ratio in factor and components analysis. Applied Psychological Measurement. 1985;9:165-78.

52. Terwee CB, Bot SD, de Boer MR, van der Windt DA, Knol DL, Dekker J, et al. Quality criteria were proposed for measurement properties of health status questionnaires. J Clin Epidemiol. 2007;60(1): 34-42. 


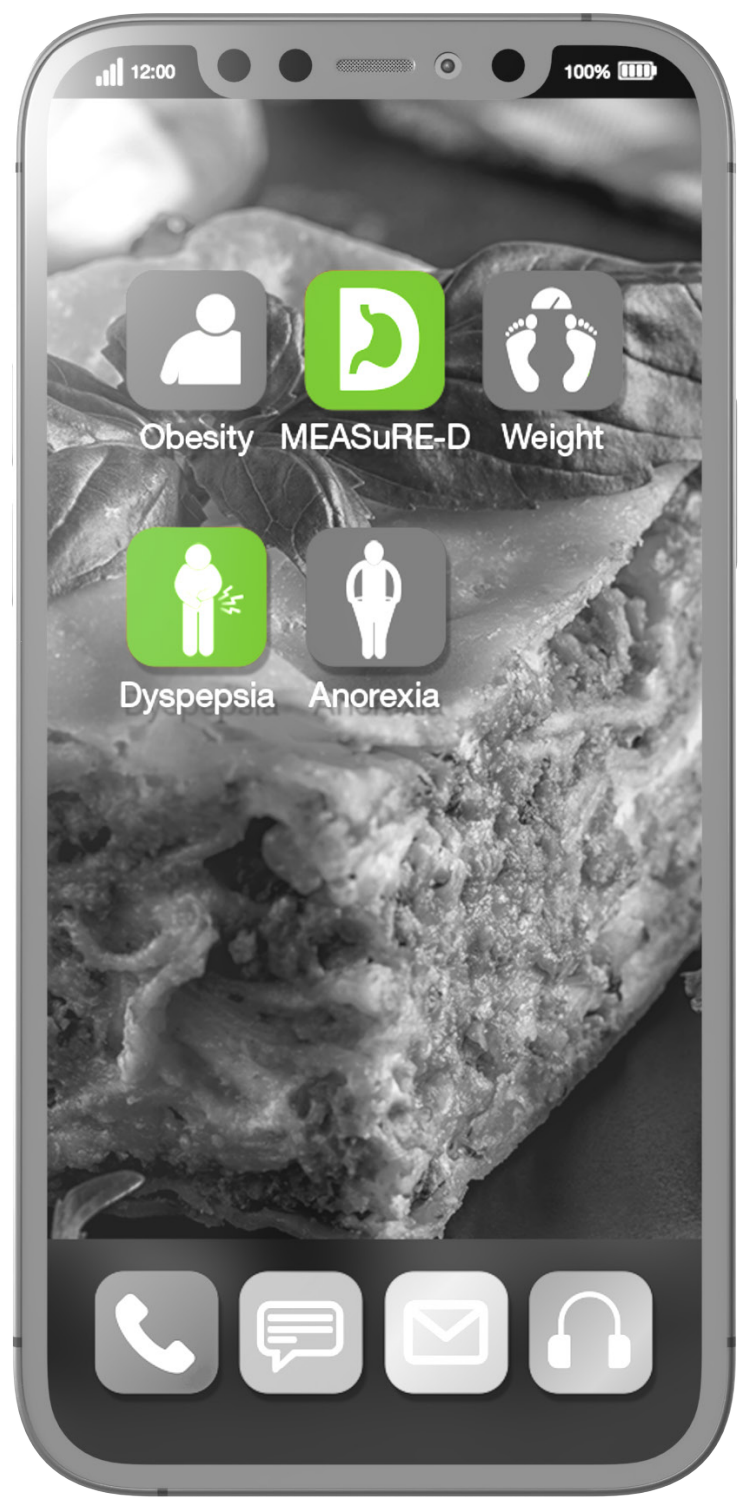




\section{Chapter 7}

The interplay between stress and fullness in functional dyspepsia and healthy controls: an exploratory experience sampling method study

Tim Klaassen

Lisa Vork*

Fabienne G.M. Smeets*

Freddy J. Troost Joanna W. Kruimel

Carsten Leue

Ad A.M. Masclee

Daniel Keszthelyi

* Shared second authorship 


\section{Abstract}

\section{Background and aims}

Fullness is a cardinal symptom in functional dyspepsia (FD). The use of real-time symptom assessment might provide more insight in factors, such as stress, that can influence fullness. Furthermore, it is unknown whether real-time assessment of fullness is able to capture the construct of early satiation. Therefore, this study aimed to use a realtime, repeated measurement method (Experience Sampling Method, ESM) to primarily assess the association between stress and fullness in FD patients and healthy controls (HC). Additionally, this study aimed to evaluate whether real-time assessment of fullness can capture the construct of early satiation.

\section{Methods}

Thirty-five FD patients (25 female, mean age 44.7 years) and 34 HC (24 females, mean age 44.1 years) completed ESM (a maximum of 10 random moments per day) for seven consecutive days. Stress, fullness, and ability to finish meal scores were rated on an 11-point Numeric Rating Scale.

\section{Results}

FD patients scored 2.24 points higher on fullness $(\mathrm{p}<0.001), 1.37$ points higher on stress $(p<0.01)$, and 1.94 points lower on ability to finish meals $(p<0.001)$ compared with HC. In $\mathrm{FD}$, fullness scores increased with 0.14 for every 1-point increase in concurrent stress scores $(\mathrm{p}=0.01)$ and increased with 0.20 for every 1 -point decrease in ability to finish meal $(p<0.001)$. Fullness scores at $t=0$ increased with 0.09 for every 1 -point increase in stress scores at $t=-1 \quad(p=0.02)$. No associations between stress scores or ability to finish meals and fullness scores were found for HC.

\section{Conclusion}

Concurrent and preceding stress scores are positively associated with fullness scores in FD patients, but not in HC, indicating a difference in response to stress. Moreover, real-time assessment of the symptom fullness is able to capture the construct of early satiation. 


\section{Introduction}

Functional dyspepsia (FD) is one of the most common functional gastrointestinal (GI) disorders, with an estimated prevalence of $10-15 \%$ in the general population. ${ }^{1}$ According to the Rome IV criteria, FD is defined by the presence of various symptoms in the absence of evident organic, systemic or metabolic diseases that could explain the complaints. ${ }^{2}$ Among the heterogeneous presentation of FD patients, four core symptoms have been defined: early satiation, postprandial fullness, epigastric burning, and epigastric pain. ${ }^{2,3}$ Based on the occurrence of these core-symptoms, three subtypes of FD can be distinguished: postprandial distress syndrome (PDS), epigastric pain syndrome (EPS), and overlap syndrome (OS). ${ }^{2}$ Among FD patients, $60 \%$ can be diagnosed with the PDS subtype and herewith, PDS appears to be the predominant subtype. ${ }^{4}$ In that regard, symptom generation is part of a complex interaction between the gastroduodenal region and the brain, and is triggered by factors including food, stress, and psychosocial events. ${ }^{5}$ Given that PDS is the predominant subtype among FD patients, specific triggers that can generate fullness complaints should be thoroughly investigated, including its core symptom of early satiation.

FD is known to be associated with anxiety and depression, daily stress and life hassles. ${ }^{6,7}$ Ly et al. demonstrated that acute anxiety, induced by a stressor, results in a disturbance of gastric sensory and motor function, manifested by an impairment of the gastric accommodation reflex. ${ }^{8}$ Moreover, it has been shown that even the anticipation of a stressor already elicits alterations in brain activity in FD patients. ${ }^{9}$ These findings point towards the capability of acute stress to interfere with gastrointestinal sensory-motor responses resulting in abnormal sensations of early satiation/fullness, which are both defining characteristics of the PDS subtype of FD. However, it is still unclear whether GI symptoms are more a cause or a consequence of psychological characteristics. ${ }^{10-12}$

Currently, most studies assessing psychological symptoms and GI symptoms are crosssectional or assess these symptoms in retrospect over a longer period of time and are therefore prone to recall bias. ${ }^{712-14}$ Unfortunately, these methods of evaluation are not able to take symptom fluctuation over time into account. Symptoms of functional GI disorders are known to vary over time $e^{15,16}$ and stress is also characterised by daily fluctuations. ${ }^{17,18}$ Therefore, daily life symptom variability should be taken into account when evaluating triggers for early satiation/fullness complaints in FD patients.

For this purpose, an electronic patient-reported outcome measure (PROM) based on the experience sampling methodology (ESM) for patients with FD was developed. ${ }^{19}$ ESM is characterised by collection of repeated measurements on random moments during the day. Due to the repeated and momentary nature, ESM might be able to capture fullness complaints and possible influencing factors, such as stress, over the course of the day. 
Therefore, ESM offers the opportunity to provide insight in the interplay between daily life stress and fullness complaints. Moreover, using ESM, it could be investigated whether real-time assessment of fullness can capture the construct of early satiation.

Primary aim of this study was to evaluate the association between stress and fullness complaints, using concurrent and time-lagged assessments, by using ESM in FD patients and healthy controls (HC). Our secondary aim was to evaluate whether real-time assessment of the symptom fullness is able to capture the construct of early satiation. We hypothesised that stress levels and fullness levels will be associated in FD patients, but not in HC. Moreover, we hypothesised that fullness scores, provided a meal had been consumed, is able to capture the construct of early satiation.

\section{Methods}

The study protocol was approved by the Medical Ethics Committee of the Maastricht University Medical Centre+ (MUMC +), Maastricht, the Netherlands (ID METC19-077), and performed in full accordance with the Declaration of Helsinki (latest amendment by the World Medic Association in 2013) and Dutch Regulations of Medical Research involving Human Subjects (WMO, 1998). This prospective observational study was performed at the MUMC+ from 29 May 2020 until 1 October 2020. This study was registered in the US National Library of Medicine (http:///www.clinicaltrials.gov, ID NCT04204421).

\section{Subjects}

Recruitment of FD patients, aged between 18 and 75 years, took place at the outpatient clinic of Gastroenterology and Hepatology of the MUMC+, a secondary/tertiary hospital. Additionally, FD patients that participated in other studies of the MUMC+ were contacted to participate in the current study (NCT02522000, NCT03652571). FD and FD subtypes were diagnosed according to the Rome IV criteria, which were evaluated by a trained clinical researcher in a face-to-face interview.

Healthy controls, aged between 18 and 75 years, were recruited through local advertisements. Healthy controls were eligible if they did not fulfil Rome IV criteria for FD and did not have a past or present diagnosis of any organic or functional GI disorder. Exclusion criteria for all subjects were initiation of regularly used medication from one month before inclusion until the end of the study period, a history of upper digestive surgery influencing end points, history of radiation therapy of the abdomen, and 
pregnancy. Subjects could only participate if they understood the Dutch language and were able to use the smartphone application.

\section{Data collection}

ESM was collected during seven consecutive days. On day seven, subjects completed validated symptom questionnaires using an electronic CRF (eCRF) system (CastorEDC).

\section{ESM}

The MEASuRE-D application was developed for the use of ESM in FD patients, ${ }^{19}$ and was downloaded on the subjects' smartphones for the purpose of the current study. During their regular daily life, subjects completed ESM for seven consecutive days. In order to complete the real-time questionnaires as often as possible, subjects were instructed to carry their smartphone with them during the week. The MEASuRE-D app sent out a haptic, auditory and written signal ten times per day between 07:00 and 22:00 at randomly chosen moments, with a time-interval of at least 15 minutes between consecutive signals. Following a signal, the ESM-questionnaire was available for 10 minutes. On all measurement moments, the questions were repeated in the same order and questions were scored on an 11-point Numeric Rating Scale (0: not at all to 10: very severely). Questions were asked in Dutch and translate as follows. Fullness was defined as "I am having full feeling in my upper abdomen" (0: not at all, 10: very severely). Early satiation was defined as "I am able to finish a normal sized meal" (0: not at all, 10: very much). Question for early satiation was only prompted when a preceding question "I have eaten ... since the last beep" (breakfast, lunch, dinner, a snack, none of these) was not answered "none of these". This question was not analysed when participants answered with "a snack". Stress was defined as "I am feeling stressed" (0: not at all, 10: very severely). Contrary to fullness and stress constructs, early satiation was not momentary, as this feeling is always in relation to eating a meal. The development of this ESM-based questionnaire was previously described. ${ }^{19}$

\section{Questionnaires}

At the end of the seven-day study period the Generalised Anxiety Disorder (GAD-7; 0-3 scale, total composite score for severity of anxiety, recall period of two weeks ${ }^{20}$ and the Hospital Anxiety and Depression Scale (HADS; 0-3, total composite scores for severity of anxiety and depression, recall period of one week) ${ }^{21,22}$ were completed. 


\section{Statistical analyses}

Sample size was based on several previous studies using ESM-data that have shown sample sizes between 20-30 subjects to be sufficient for analyses. ${ }^{23,24}$ Moreover, in IBS patients sample sizes of 26-37 were used to evaluate a novel ESM-based PROM. ${ }^{25-27}$ The present study was an exploratory study on the usage of an ESM-based PROM in FD patients. To date, no data on the use of ESM in FD are available. FD is a functional GI disorder, as is IBS, in which abovementioned trials were performed. Therefore, we aimed to include at least 30 valid cases with a maximum of 36 . Subjects were included in the analyses only when at least $1 / 3$ of the total number of assessments (i.e., 23 out of 70 ) were completed. ${ }^{28,29}$

All analyses were performed using $\mathrm{R}$ version 3.6.3. Continuous outcomes are presented as mean \pm standard deviation (SD), and tested using paired or independent samples t-test. Proportions for categorical variables were tested using the $\chi^{2}$-test. For all analyses, $\mathrm{p}<0.05$ was considered statistically significant.

A linear mixed-effects model was used with repeated measures (level 1) nested within subjects (level 2) to compare levels of fullness, levels of stress, and early satiation between FD patients and HC. ESM scores were indicated as dependent variable and group (i.e., FD, HC) was used as predictor variable. An autoregressive covariate (AR1) was used to correct for repeated measures and autocorrelation.

Similar analyses were performed to evaluate associations between fullness and stress and between fullness and early satiation.

First, fullness scores were used as dependent and stress or early satiation scores were used as independent variables to investigate concurrent fullness and stress and concurrent fullness and early satiation.

Second, assessing whether fullness scores could be predicted by stress scores preceding the measurement of fullness, lagged scores (i.e., $\mathrm{t}=-1$ ) were used as the predictor variable. Similarly, association between stress scores and preceding fullness scores were investigated by using lagged scores for fullness as predictor variables with stress scores as dependent variables. The association between lagged scores for early satiation and fullness was not investigated, as the measurement of early satiation was dependent on meal intake prior to the assessment and was, therefore, in itself not momentary. Random slopes for predictor variables were tested in all models. Best model fit was reported based on Akaike Information Criterion.

Linear mixed model analyses were not performed to evaluate associations between early satiation and stress, since the perception of early satiation is unsuitable for momentary assessment, as it is dependent on consumption of a meal, which does not occur at random. 
In patients with FD, individual regression coefficients were calculated for the associations between fullness and stress and the associations between fullness and early satiation. In both cases, FD patients were selected that showed a positive association, a negative association, and a very weak association in order to visually represent inter-individual differences.

\section{Results}

\section{Subjects}

In total, $36 \mathrm{FD}$ patients and $36 \mathrm{HC}$ met the inclusion criteria and not the exclusion criteria. One FD patient and two HC completed less than $1 / 3$ of the total number of ESM assessments. Therefore, $35 \mathrm{FD}$ patients and $34 \mathrm{HC}$ were included in the analyses. Baseline characteristics are summarised in Table 7.1.

In the FD patients, ten patients fulfilled the criteria for EPS (28.6\%), seven for PDS (20\%) and 18 for OS (51.4\%). Of the 35 included patients, 13 had comorbid IBS (37\%, one in the EPS group, three in the PDS group, and nine in the OS group). During the study, no adverse events were reported by the subjects.

Table 7.1 Demographics of included subjects.

\begin{tabular}{lcc}
\hline & $\begin{array}{c}\text { FD patients } \\
(\mathbf{n}=\mathbf{3 5})\end{array}$ & $\begin{array}{c}\text { Healthy controls } \\
(\mathbf{n}=\mathbf{3 4})\end{array}$ \\
\hline Age & $44.7( \pm 15.7)$ & $44.1( \pm 13.9)$ \\
Gender female (\%) & $25(71.4 \%)$ & $24(70.6 \%)$ \\
GAD-7 & $4.8( \pm 4.5)^{* *}$ & $1.5( \pm 1.9)^{* *}$ \\
HADS-Anxiety & $5.3( \pm 4.5)^{*}$ & $2.9( \pm 2.2)^{*}$ \\
HADS-Depression & $4.9( \pm 4.3)^{* *}$ & $0.9( \pm 1.0)^{* *}$ \\
\hline
\end{tabular}

Demographics of FD patients and healthy controls. Means and standard deviations (SD) are depicted. $*_{\mathrm{p}}<0.01$, ${ }^{* *} \mathrm{p}<0.001$

\section{Compliance ESM}

Figure 7.1 depicts the compliance rate for FD patients and HC. For FD patients, completion rate of ESM assessments was $62.2 \%$. Over the seven-day period, a mean number of 43.5 measurements were completed per individual (range:23-68). The majority of subjects completed between 31 and 60 assessments during the study period.

For HC, completion rate of ESM assessments was $69,7 \%$. Over the seven-day period, a mean number of 48.8 measurements were completed per individual (range: 24-69). The majority of subjects completed between 41 and 60 assessments during the study period. 
It should be noted that feedback in general revealed that the question "I have eaten ... since the last beep" was difficul to answer, as subjects could not always remember whether they already reported the meal with the last beep. Therefore, some meals might be overreported by subjects.

\section{Completion rate with ESM}

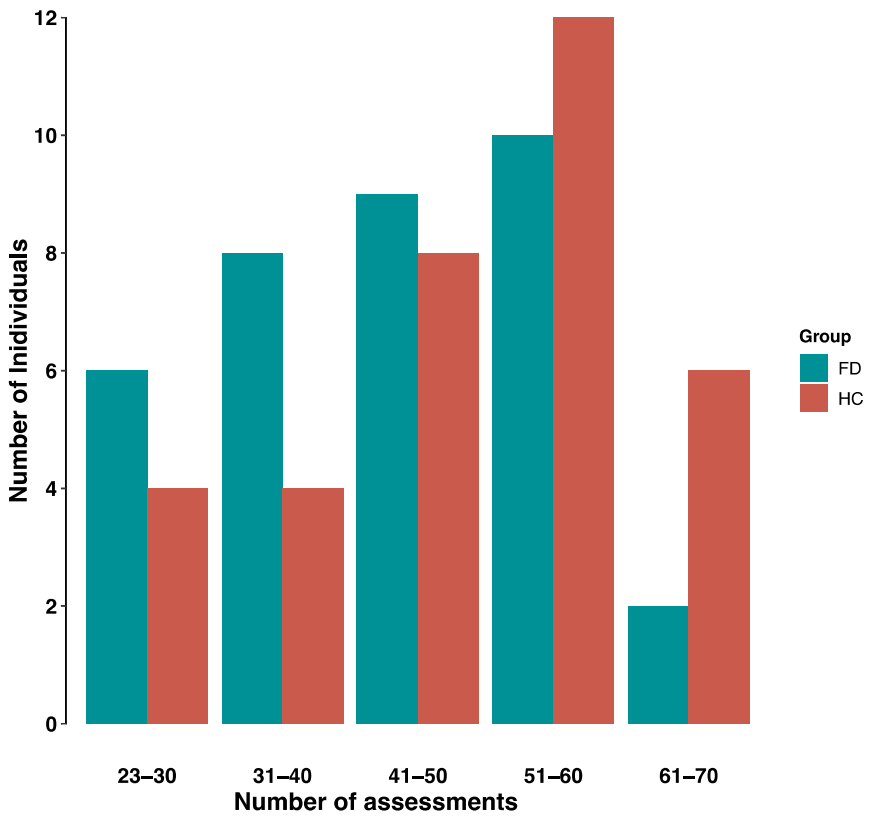

Figure 7.1 Number of individuals (y-axis) per category of completed number of assessments (x-axis) for FD patients $(n=35)$ and HC $(n=34)$.

\section{Fullness, stress and ability to finish meal}

Mean scores for fullness, stress, and ability to finish meals for FD patients and HC are depicted in Figure 7.2. Fullness scores were, on average, 2.23 (SE 0.37, p<0.001) points higher in FD patients compared with HC (2.88 (SE 0.33) vs. 0.66 (SE 0.16)). FD patients also reported higher mean stress scores. Stress scores were, on average, 1.37 (SE 0.30, $\mathrm{p}<0.01)$ points higher in FD patients compared with HC (1.99 (SE 0.29) vs. 0.62 (SE $0.30)$ ).

Ability to finish meal scores were, on average, 1.94 (SE 0.46, p<0.001) points lower in FD patients compared with HC (6.27 (SE 0.32) vs. 8.21 (SE 0.33)). 
Fullness, stress and ability to finish meals over 7 days
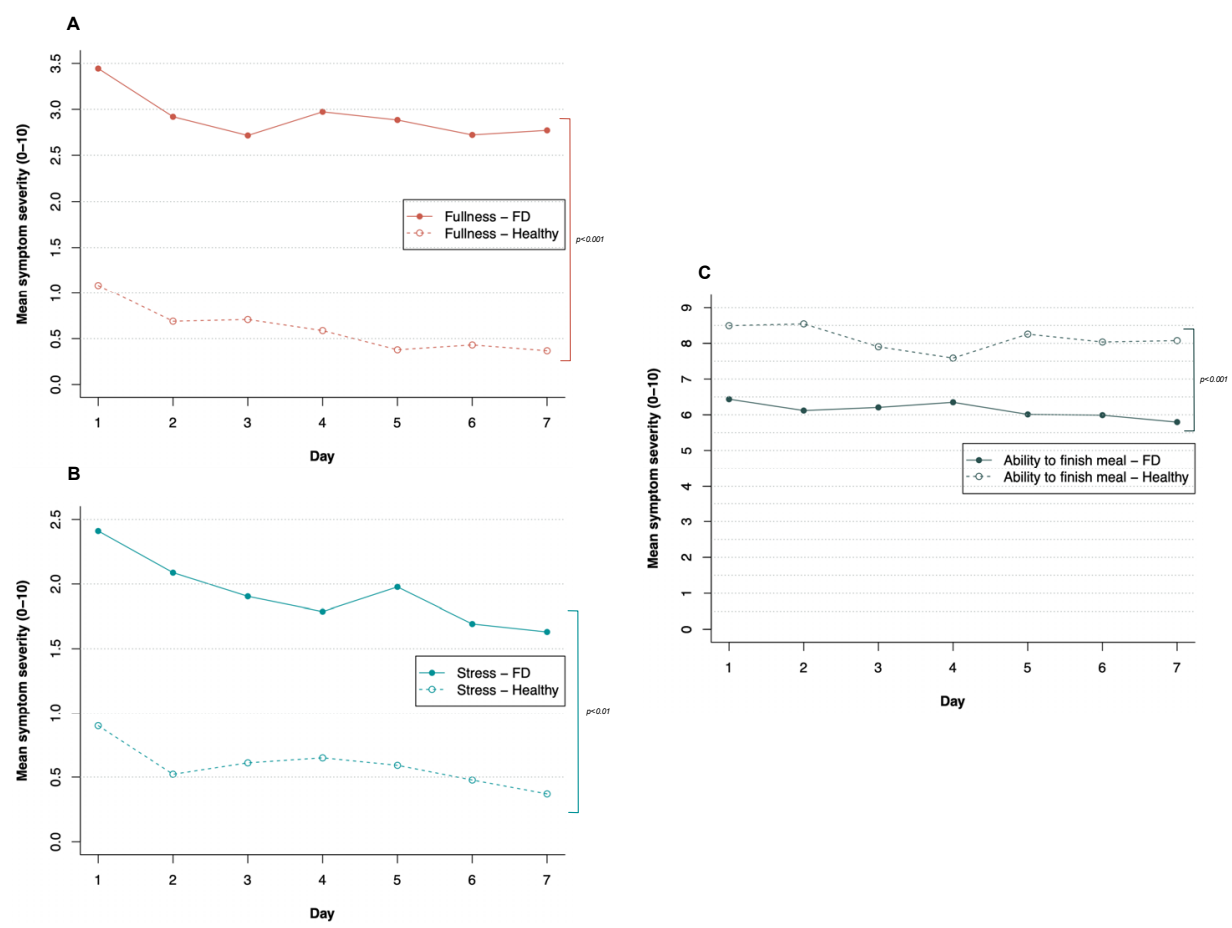

Figure 7.2 Symptom severity. Symptom severity for fullness $(\mathbf{A})$ and stress $(\mathbf{B})$ and ability to finish meals $(\mathbf{C})$ over the 7-day study period, separately for functional dyspepsia patients and healthy controls. Mean scores per day as recorded using experience sampling method over 7 days.

\section{Associations between concurrent fullness and stress scores}

In FD patients a 1-point increase in stress scores was associated with an increase in fullness of 0.138 (SE 0.05, $\mathrm{p}=0.01$ ). On the other hand, stress and fullness scores were not associated in HC $(p=0.97)$. In Figure 7.3 , repeated measures for stress and fullness for three FD patients are depicted. Between-subject differences in the association between fullness and stress are clearly seen here, as the plots show varying relationships between fullness and stress for these three patients. These inter-individual differences are confirmed when performing the linear mixed-effects model for each FD patient separately. The coefficients for the association between fullness and stress range from 0.62 to 1.59 . This indicates that, in a particular patient, a 1 -point increase in stress corresponds with a decrease in fullness of 0.62 points, while another patient has an increase of 1.59 points on fullness for every 1-point increase in stress. Figure 7.3 depicts the distribution of the individual coefficients for fullness and stress among FD patients. Three 
patients, selected based on varying individual regression coefficients $(-0.17,0.03$, and 0.32$)$, were depicted to demonstrate inter-individual differences.

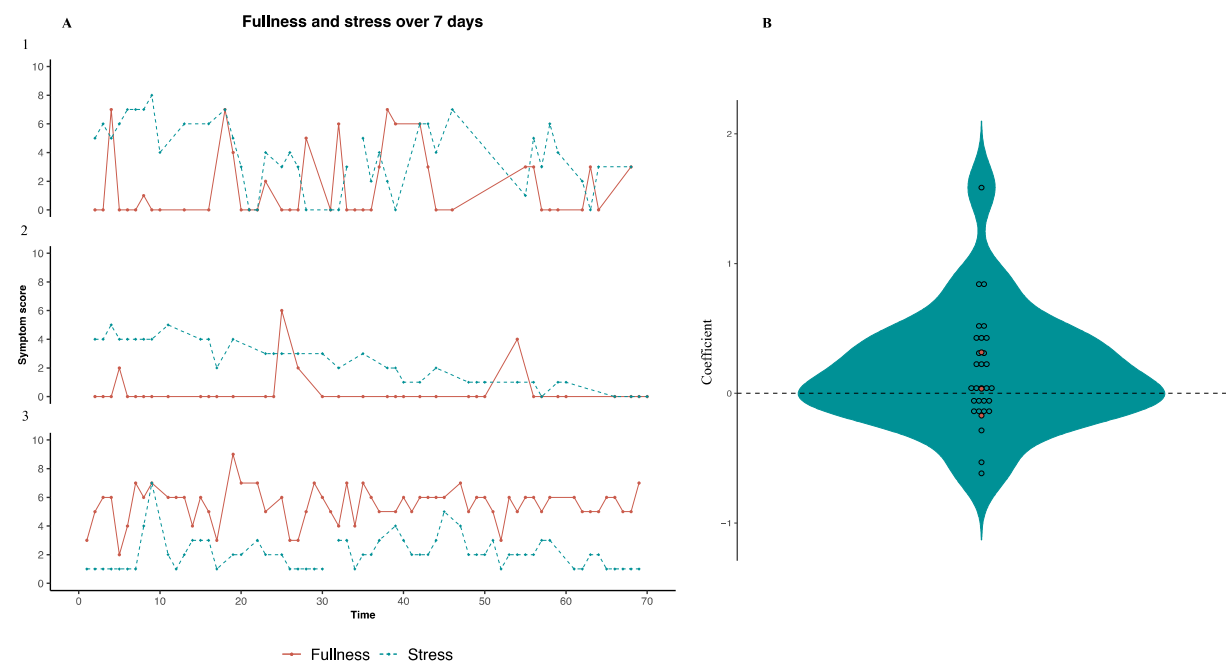

Figure 7.3 Individual representation of fullness and stress scores. A: Individual representation of symptom severity scores for fullness and stress for 3 functional dyspepsia patients on 70 random time points over 7 consecutive days. On the $\mathrm{x}$ axis: 70 consecutive assessments, each within a 90 minute timeframe between 07:00 AM and 22:00 (day 1: 1-10; day 2:11-20; day 3: 21-30; day 4: 3140; day 5: 41-50; day 6:51-60; day 7: 61-70. Different patterns of stress and fullness indicate the heterogeneity between FD patients. This is also reflected by differences in the corresponding regression coefficients for (1) -0.17 , (2) 0.03 , and (3) 0.32. B: Distribution of individual coefficients for fullness and stress, based on linear mixed effects model per individual, among FD patients. Selected patients in panel A are highlighted in orange.

\section{Associations between fullness and lagged stress scores}

For FD patients a 1-point increase in lagged-stress scores was associated with an increase in fullness scores of 0.09 (SE 0.04, $\mathrm{p}=0.02$ ). On the other hand, fullness and lagged stress scores were not associated for $\mathrm{HC}(\mathrm{p}=0.65)$.

\section{Associations between stress and lagged fullness scores}

Fullness scores at $\mathrm{t}=-1$ were not a significant predictor for stress at $\mathrm{t}=0$ in $\mathrm{FD}$ patients $(\mathrm{p}=0.42)$ nor in $\mathrm{HC}(\mathrm{p}=0.73)$.

\section{Associations between fullness and early satiation}

In FD patients, a 1-point decrease in ability to finish meal was associated with an increase in fullness scores of 0.20 (SE $0.08, \mathrm{p}<0.001$ ). Whereas ability to finish meal and fullness 
scores were not associated in HC $(\mathrm{p}=0.08)$. In Figure 7.4, repeated measures for fullness and ability to finish meals (if a meal was consumed since the last beep) are depicted for three FD patients. Between-subject differences in the association between fullness and early satiation are clearly shown in these three patients. The plots show varying relationships between fullness and early satiation between the three patients. These interindividual differences are confirmed when performing the linear mixed-effects model for each FD patient separately. The coefficients for the association between fullness and ability to finish meal range from -1.34 to 1.31 . This indicates that, in a particular patient, a 1 -point increase in ability to finish the meal corresponds with a decrease in fullness of 1.34 points, while another patient has an increase of 1.31 points on fullness for every 1-point increase in ability to finish meal. Figure 7.4 depicts the distribution of the individual coefficients for fullness and early satiation among FD patients. Three patients, selected based on varying individual regression coefficients $(-0.34,0.01$, and 0.42$)$, were depicted to demonstrate inter-individual differences.

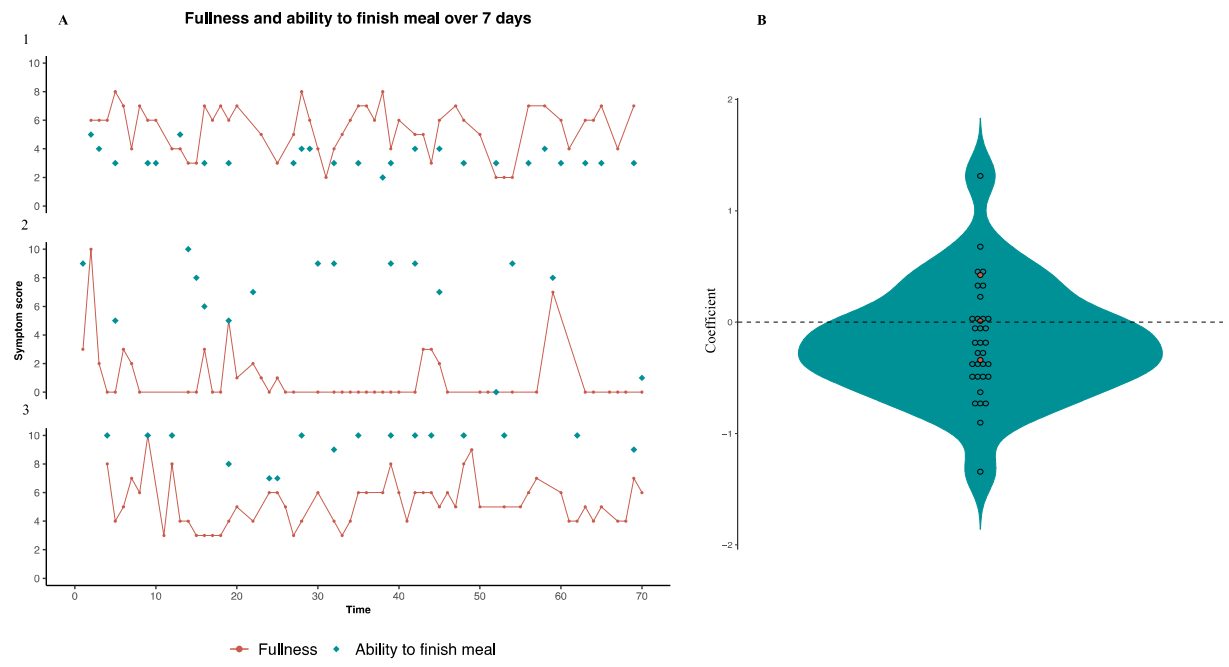

Figure 7.4 Individual representation of fullness and ability to finish meal scores. A: Individual representation of fullness and ability to finish meal scores for 3 functional dyspepsia patients on 70 random time points over 7 consecutive days. Ability to finish meal is based on self-reported meal intake (breakfast, lunch or dinner) preceding the assessment. A high score on ability to finish meal indicates good ability to finish said meal. On the x axis: 70 consecutive assessments, each within a 90-minute timeframe between 07:00 AM and 22:00 (day 1: 1-10; day 2:11-20; day 3: 21-30; day 4: 31-40; day 5: 41-50; day 6:51-60; day 7: 61-70. Different patterns of ability to finish meals and fullness indicate the heterogeneity between FD patients. This is also reflected by differences in the corresponding regression coefficients for (1) -0.34 , (2) 0.01 , and (3) 0.42. B: Distribution of individual coefficients for fullness and early satiation, based on linear mixed effects model per individual, among FD patients. Selected patients in panel A are highlighted in orange. 


\section{Discussion}

To our knowledge, the current study is the first to examine a real-time association between stress and fullness in FD patients compared with HC using momentary assessment. Our results provide more detailed information on the associations between daily life stress and sensations such as fullness and early satiation that are both defining characteristics in FD. Indeed, concurrent fullness and daily stress levels were significantly associated in FD patients, but not in HC. In HC, stress levels were substantially lower compared with FD patients. Furthermore, the ability to finish meals was associated with fullness scores in FD patients, but not in HC.

Both average fullness levels and average stress levels were significantly higher in FD patients compared with HC. This was also true for the scores on GAD-7, and HADS questionnaires completed at the end of the week. In contrast to our findings in FD patients, previous ESM studies in IBS patients showed daily stress levels in IBS patients to be comparable to $\mathrm{HC}$, whereas abdominal pain scores were significantly higher in IBS patients compared to HC. 27,30 We compared the results of the present study with data from the ESM study in IBS patients (data not shown). ${ }^{27}$ Stress scores were higher in FD patients compared with IBS patients (1.94 vs. 1.26, p<0.001). It should be noted, that in the present study, only subjects from a secondary/tertiary referral centre were included, whereas in the study with IBS patients subjects were also included from primary practice. Interestingly, mean stress scores of $\mathrm{HC}$ in our study appeared to be lower when compared with mean stress scores of HC in the previously performed ESM study by our group (0.59 vs. $1.06, \mathrm{p}<0.001)$. . It should be taken into account that the present study was performed for a large part during the summer holiday season in the Netherlands. This could have resulted in lesser daily-life hassles and stress, as previous studies demonstrated lower daily life stress during vacation periods. ${ }^{31}-33$ This may point towards other factors (i.e., not workrelated) resulting in daily life stress or a more chronic state of daily life stress in FD patients compared with HC.

The association found between stress and functional GI complaints does not reveal whether stress and FD symptoms are cause or consequence. The association between fullness and stress in FD patients, which could not be confirmed in healthy subjects, at least points towards a susceptibility in FD patients for the effects of daily life stress. We have described similar findings using ESM in IBS patients. ${ }^{27}$ Other studies have also demonstrated that patients with functional GI disorders are also susceptible to a different form of stress, namely early life stress events. ${ }^{34,35}$ On the other hand, the presence of invalidating FD symptoms may also lead to stress. ${ }^{6}$ The higher stress levels found in FD 
patients compared with $\mathrm{HC}$ in this study may reflect, thus, a cause-effect relationship. However, this study showed an association between lagged daily stress scores and fullness, which indicates that stress scores were able to predict fullness scores for the subsequent questionnaire. These findings lead us to assume that stress triggers the onset or worsening of fullness complaints in FD patients, rather than the other way around. Possibly, this could be related to the effects of stress on gastric accommodation or neurohormonal processing which affects gastrointestinal sensing and signalling. This is in line with findings by Ly et al. who demonstrated disturbed gastric sensory and motor function after inducing acute anxiety in FD patients. ${ }^{8}$ Moreover, stress induces an inhibition of propulsive gastric motor activity in FD patients. ${ }^{36}$ Other studies showed modified gastroduodenal motility after either a physical stressor or mental stress in healthy volunteers. ${ }^{37,38}$ On the other hand, Lunding et al. previously showed that gastric accommodation was not influenced by induction of acute emotional stress in FD patients or healthy volunteers. ${ }^{39}$ Furthermore, in healthy volunteers, corticotropin-releasing hormone was not able to modulate gastric accommodation. ${ }^{40}$ Based on our results, no definite conclusions with respect to the direction of the interplay between stress and fullness can be made, as our ESM analyses indicate associations rather than causality. However, the association between fullness and lagged stress scores demonstrated by the present study are in favour of stress as a predictor of fullness, in terms of symptom formation, in FD patients.

Overall, this study demonstrates a high heterogeneity between FD patients in the magnitude of the stress-fullness association. The inter-individual heterogeneity in the interplay between stress and fullness points towards variations in stress-sensitivity in FD patients. It is known that each individual has different coping mechanisms for stress. ${ }^{41}$ This study demonstrates the usefulness of ESM in characterising individualised symptom patterns, including influencing factors.

The association between fullness scores and ability to finish meals in FD patients points towards the ability of fullness to capture the construct of early satiation, as this sensation only occurs in conjunction with meal consumption and is therefore unsuitable for momentary assessment. In that regard, a major advantage of ESM in comparison to conventional questionnaires is the repeated measure moments over the day. This allows for fullness scores on ESM to reflect both satiation and satiety. Although commonly used as synonyms, satiation and satiety are known to be separate entities. Satiation refers to feelings of fullness during ingestion of a meal, acting as terminating factor of meal intake, whereas satiety reflects feelings of fullness in between meals, determining the length of the inter-meal interval. ${ }^{42}$ Subjects informed us about their difficulties in answering the question "I have eaten ... since the last beep". It was difficult for them to recall whether a 
meal has previously been reported during the preceding beep. This may have resulted in over-reporting of the same meals and it underlines the impact of recall bias in questionnaires that are not based on momentary reporting. Our momentary assessment method does not systematically capture meal intakes over the day. This should be improved in future versions, perhaps by asking subjects to manually indicate the onset, end, and content of a meal.

\section{Strengths and limitations}

Here, we provided an in-depth analysis of the relation between stress and fullness complaints in FD patients and HC. These in depth-analyses can be performed for a variety of factors that can influence eating behaviour. Since sample size was small, this study only focused on the interplay between stress and fullness. In the present study, we demonstrated the potential of ESM to investigate the role of specific triggers that can influence eating behaviour and satiety signalling in healthy and diseased. A strength of this study was the inclusion of healthy controls. Therefore, conclusions on this interplay in FD patients could accurately be drawn. Moreover, including all tree subtypes of FD patients led to generalisable results reflecting the entire FD patient group. Collection of data was performed with an FD-specific ESM tool developed according to FDA guidelines for the development of PROMs. ${ }^{19}$ Furthermore, correction for autocorrelation was performed in all statistical models. ${ }^{43}$

Using ESM also poses several limitations. The occurrence of missing data is inevitable. This study accounted for missing data to the greatest possible extent by correcting for repeated measures and within-subject autocorrelation using advanced statistical modelling. Moreover, subjects who failed to complete at least one-third of the total numbers of assessments were excluded from the analyses. Furthermore, ESM might be experienced as burdensome, which can result in selection bias. Despite of multiple measurements, results should be interpreted with care, as this study's sample size still is relatively small. Moreover, the present study focused on merely two aspects, namely stress and fullness/early satiation, while probably more factors playing a role in the interplay are involved. Furthermore, due to the small sample size, groups for each subtype were rather small (i.e., 10 EPS and 7 PDS). Therefore, analyses on subtypes were not performed. Future studies should aim to expand sample size, allowing a) analyses of and correction for additional factors that might influence fullness complaints in FD patients and b) comparison between FD subgroups. 
In conclusion, using ESM for real-time symptom assessment, a positive association between stress levels and fullness scores was observed in FD patients. Moreover, the momentary assessment of fullness scores was able to capture the concept of early satiation.

Additionally, fullness scores were predicted by preceding stress levels, but not the other way around. This suggests the presence of a longitudinal relation between stress and fullness, existing next to the in-the-moment association. Moreover, ESM can depict within-day changes in stress-perception, abdominal symptoms, psychosocial aspects, and food intake, providing healthcare professionals with the tools to evaluate patient-specific symptom patterns. By knowing these symptom patterns, healthcare professionals can be enabled to offer tailor-made treatment options to the individual patients. This study, therefore, emphasises the importance of assessing individual symptom patterns in FD patients and supports the use of real-time measurement methodologies. 


\section{References}

1. Aziz I, Palsson OS, Tornblom H, Sperber AD, Whitehead WE, Simren M. Epidemiology, clinical characteristics, and associations for symptom-based Rome IV functional dyspepsia in adults in the USA, Canada, and the UK: a cross-sectional population-based study. Lancet Gastroenterol Hepatol. 2018;3(4): 252-62.

2. Stanghellini V, Chan FK, Hasler WL, Malagelada JR, Suzuki H, Tack J, et al. Gastroduodenal Disorders. Gastroenterology. 2016;150(6):1380-92.

3. Taylor F, Reasner DS, Carson RT, Deal LS, Foley C, Iovin R, et al. Development of a Symptom-Based Patient-Reported Outcome Instrument for Functional Dyspepsia: A Preliminary Conceptual Model and an Evaluation of the Adequacy of Existing Instruments. Patient. 2016;9(5):409-18.

4. Aziz I, Palsson OS, Tornblom H, Sperber AD, Whitehead WE, Simren M. Epidemiology, clinical characteristics, and associations for symptom-based Rome IV functional dyspepsia in adults in the USA, Canada, and the UK: a cross-sectional population-based study. Lancet Gastroenterol. 2018;3(4):252-62.

5. Ford AC, Mahadeva S, Carbone MF, Lacy BE, Talley NJ. Functional dyspepsia. Lancet. 2020.

6. Van Oudenhove L, Crowell MD, Drossman DA, Halpert AD, Keefer L, Lackner JM, et al. Biopsychosocial Aspects of Functional Gastrointestinal Disorders. Gastroenterology. 2016.

7. Aro P, Talley NJ, Johansson SE, Agreus L, Ronkainen J. Anxiety Is Linked to New-Onset Dyspepsia in the Swedish Population: A 10-Year Follow-up Study. Gastroenterology. 2015;148(5):928-37.

8. Ly HG, Weltens N, Tack J, Van Oudenhove L. Acute Anxiety and Anxiety Disorders Are Associated With Impaired Gastric Accommodation in Patients With Functional Dyspepsia. Clin Gastroenterol Hepatol. 2015;13(9):1584-+.

9. Van Oudenhove L, Vandenberghe J, Dupont P, Geeraerts B, Vos R, Dirix S, et al. Abnormal regional brain activity during rest and (anticipated) gastric distension in functional dyspepsia and the role of anxiety: a H(2)(15)O-PET study. Am J Gastroenterol. 2010;105(4):913-24.

10. Jones MP, Tack J, Van Oudenhove L, Walker MM, Holtmann G, Koloski NA, et al. Mood and Anxiety Disorders Precede Development of Functional Gastrointestinal Disorders in Patients but Not in the Population. Clin Gastroenterol Hepatol. 2017;15(7):1014-+.

11. Koloski N, Holtmann G, Talley NJ. Is there a causal link between psychological disorders and functional gastrointestinal disorders? Expert Rev Gastroent. 2020;14(11):1047-59.

12. Koloski NA, Jones M, Kalantar J, Weltman M, Zaguirre J, Talley NJ. The brain-gut pathway in functional gastrointestinal disorders is bidirectional: a 12-year prospective population-based study. Gut. 2012; 61(9):1284-90.

13. Huang ZP, Wang K, Duan YH, Yang G. Correlation between lifestyle and social factors in functional dyspepsia among college freshmen. J Int Med Res. 2020;48(8).

14. Bradburn NM, Rips LJ, Shevell SK. Answering autobiographical questions: the impact of memory and inference on surveys. Science. 1987;236(4798):157-61.

15. Tack J, Lee KJ. Pathophysiology and treatment of functional dyspepsia. J Clin Gastroenterol. 2005;39(5 Suppl 3):S211-6.

16. Mearin F, Baro E, Roset M, Badia X, Zarate N, Perez I. Clinical patterns over time in irritable bowel syndrome: symptom instability and severity variability. Am J Gastroenterol. 2004;99(1):113-21.

17. DeLongis A, Folkman S, Lazarus RS. The impact of daily stress on health and mood: psychological and social resources as mediators. J Pers Soc Psychol. 1988;54(3):486-95.

18. Havermans R, Nicolson NA, Devries MW. Daily hassles, uplifts, and time use in individuals with bipolar disorder in remission. J Nerv Ment Dis. 2007;195(9):745-51.

19. Smeets FGM, Keszthelyi D, Vork L, Tack J, Talley NJ, Simren M, et al. Development of a real-time patient-reported outcome measure for symptom assessment in patients with functional dyspepsia using the experience sampling method. Neurogastroenterol Motil. 2019;31(2):e13496.

20. Spitzer RL, Kroenke K, Williams JB, Lowe B. A brief measure for assessing generalized anxiety disorder: the GAD-7. Arch Intern Med. 2006;166(10):1092-7.

21. Zigmond AS, Snaith RP. The hospital anxiety and depression scale. Acta Psychiatr Scand. 1983;67(6): 361-70. 
22. Bjelland I, Dahl AA, Haug TT, Neckelmann D. The validity of the Hospital Anxiety and Depression Scale. An updated literature review. J Psychosom Res. 2002;52(2):69-77.

23. Kimhy D, Delespaul P, Corcoran C, Ahn H, Yale S, Malaspina D. Computerized experience sampling method (ESMc): assessing feasibility and validity among individuals with schizophrenia. J Psychiatr Res. 2006;40(3):221-30.

24. Myin-Germeys I, Peeters F, Havermans R, Nicolson NA, deVries MW, Delespaul P, et al. Emotional reactivity to daily life stress in psychosis and affective disorder: an experience sampling study. Acta Psychiat Scand. 2003;107(2):124-31.

25. Mujagic Z, Leue C, Vork L, Lousberg R, Jonkers DM, Keszthelyi D, et al. The Experience Sampling Method--a new digital tool for momentary symptom assessment in IBS: an exploratory study. Neurogastroenterol Motil. 2015;27(9):1295-302.

26. Vork L, Keszthelyi D, Mujagic Z, Kruimel JW, Leue C, Ponten I, et al. Development, content validity, and cross-cultural adaptation of a patient-reported outcome measure for real-time symptom assessment in irritable bowel syndrome. Neurogastroenterol Motil. 2018;30(3).

27. Vork L, Keszthelyi D, van Kuijk SMJ, Quetglas EG, Tornblom H, Simren M, et al. Patient-Specific StressAbdominal Pain Interaction in Irritable Bowel Syndrome: An Exploratory Experience Sampling Method Study. Clin Transl Gastroenterol. 2020;11(7):e00209.

28. Delespaul P. Assessing schizophrenia in daily life the experience sampling method.: UPM, Universitaire Pers Maastricht, Maastricht University; 1995.

29. Palmier-Claus JE, Myin-Germeys I, Barkus E, Bentley L, Udachina A, Delespaul PA, et al. Experience sampling research in individuals with mental illness: reflections and guidance. Acta Psychiatr Scand. 2011;123(1):12-20.

30. Chan Y, So SH, Mak ADP, Siah KTH, Chan W, Wu JCY. The temporal relationship of daily life stress, emotions, and bowel symptoms in irritable bowel syndrome-Diarrhea subtype: A smartphone-based experience sampling study. Neurogastroenterol Motil. 2019;31(3):e13514.

31. Blank C, Gatterer K, Leichtfried V, Pollhammer D, Mair-Raggautz M, Duschek S, et al. Short Vacation Improves Stress-Level and Well-Being in German-Speaking Middle-Managers-A Randomized Controlled Trial. Int J Environ Res Public Health. 2018;15(1).

32. Westman M, Etzion D. The impact of vacation and job stress on burnout and absenteeism. Psychol Health. 2001;16(5):595-606.

33. de Bloom J, Radstaak M, Geurts S. Vacation effects on behaviour, cognition and emotions of compulsive and non-compulsive workers: do obsessive workers go 'cold turkey'? Stress Health. 2014;30(3):232-43.

34. Mayer EA, Craske M, Naliboff BD. Depression, anxiety, and the gastrointestinal system. J Clin Psychiatry. 2001;62 Suppl 8:28-36; discussion 7.

35. Locke GR, 3rd, Weaver AL, Melton LJ, 3rd, Talley NJ. Psychosocial factors are linked to functional gastrointestinal disorders: a population based nested case-control study. Am J Gastroenterol. 2004;99(2): $350-7$.

36. Camilleri M, Malagelada JR, Kao PC, Zinsmeister AR. Gastric and autonomic responses to stress in functional dyspepsia. Dig Dis Sci. 1986;31(11):1169-77.

37. Fone DR, Horowitz M, Maddox A, Akkermans LM, Read NW, Dent J. Gastroduodenal motility during the delayed gastric emptying induced by cold stress. Gastroenterology. 1990;98(5 Pt 1):1155-61.

38. Holtmann G, Singer MV, Kriebel R, Stacker KH, Goebell H. Differential effects of acute mental stress on interdigestive secretion of gastric acid, pancreatic enzymes, and gastroduodenal motility. Dig Dis Sci. 1989;34(11):1701-7.

39. Lunding JA, Gilja OH, Hausken T, Bayati A, Mattsson H, Berstad A. Distension-induced gastric accommodation in functional dyspepsia: effect of autonomic manipulation. Neurogastroenterol Motil. 2007;19(5):365-75.

40. van den Elzen BD, van den Wijngaard RM, Tytgat GN, Boeckxstaens GEE. Influence of corticotropinreleasing hormone on gastric sensitivity and motor function in healthy volunteers. Eur J Gastroenterol Hepatol. 2007;19(5):401-7.

41. Lazarus RS, Folkman S. Stress, appraisal, and coping. New York: Springer Pub. Co.; 1984. xiii, 445 p. p.

42. Camilleri M. Peripheral mechanisms in appetite regulation. Gastroenterology. 2015;148(6):1219-33. 
Chapter 7

43. Blanchard EB, Lackner JM, Jaccard J, Rowell D, Carosella AM, Powell C, et al. The role of stress in symptom exacerbation among IBS patients. J Psychosom Res. 2008;64(2):119-28. 



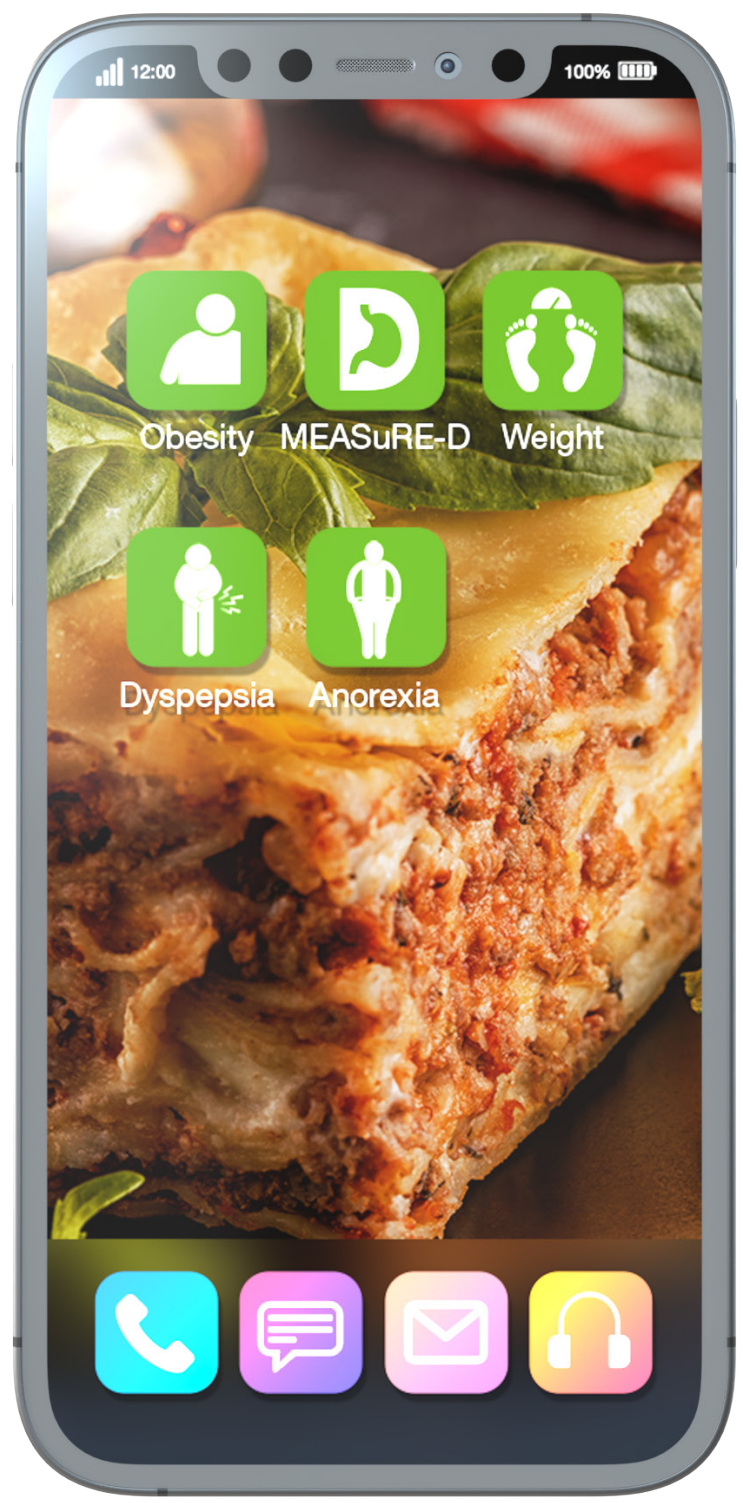




\section{Chapter 8}

General discussion 



\section{Main findings}

The gastrointestinal tract plays a pivotal role in the regulation of satiety and food intake. Several clinical scenarios can disrupt the sensing and signalling of satiety resulting in increased or decreased food intake behaviour. Disordered food intake can result in disease conditions at both ends of the spectrum: obesity can be the result of an increase in food intake, ${ }^{1,2}$ whereas the aging population shows decreased food intake, mainly due to decreased appetite, resulting in weight loss. ${ }^{3,4}$ Proof of concept studies investigating treatment and/or preventive treatment strategies are described in chapter 2, chapter 3, chapter 4 , and chapter 5 .

Satiety signalling can also be disrupted by abnormal sensations such recurring abdominal pain, resulting in abdominal complaints such as functional dyspepsia and food intake disorders such as avoidant/restrictive food intake disorder (ARFID), which can also result in weight loss, albeit through a different mechanism. ${ }^{5-7}$ In chapter 6 a new monitoring tool for functional dyspepsia was described and was validated. Chapter 7 elucidated the interplay between stress and fullness complaints in FD patients and healthy controls.

Previous studies have shown that gastrointestinal delivery of non-caloric tastants can result in a reduction of food intake. ${ }^{8-10}$ In chapter 2 of this thesis, we showed that, among noncaloric tastants, bitter tastants are the most potent to reduce food intake. The optimal location in the GI tract for tastants to exert their effect on food intake is unknown. Therefore, chapter 3 and chapter 4 aimed to assess the optimal location of respectively a tastants mixture and the bitter tastant quinine. No effect was found on food intake or appetite sensations after intraduodenal, intraileal or synchronous intraduodenal and intraileal delivery of a tastant mixture (chapter 3). Moreover, oral, intragastric, or synchronous oral and intragastric delivery of the bitter tastant quinine did not result in a reduction of food intake. However, desire to eat and hunger scores did decrease in the quinine interventions, whereas satiation and fullness scores were not affected (chapter 4).

Although the optimal location for tastants to sufficiently influence eating behaviour was not found in the set of studies we performed, the results from various studies analysed in more detail in the systematic review and meta-analysis described in chapter 2 are promising with respect to bitter agents, but standardisation of protocols and of interventions, as well as collaboration in this research field is a pre-requisite.

Mechanoreceptors in the stomach are the first step in the satiation cascade. An increase in sensitivity of these mechanoreceptors could result in a decrease in food intake. In chapter 
5, we showed that acute intragastric administration of lidocaine in order to blunt the mechanoreceptor signalling did not result in an increase in food intake or appetite sensations in healthy volunteers. However, results were promising and no safety issues occurred. As next step a chronic intervention study in subjects suffering from early satiation, reduced food intake or cachexia is warranted.

Negative signals such as pain can result in avoidant food intake behaviour as a conditioned adaptive mechanism aimed at decreasing symptoms (i.e., avoiding food intake altogether or avoiding specific food products that trigger complaints). Chapter 6 showed an adequate concurrent validity, moderate-to-good internal consistency, and very good test-retest reliability for the novel experience sampling method (ESM) based questionnaire on symptoms of functional dyspepsia (FD). Chapter 7 additionally showed that fullness complaints were associated with stress levels in FD patients but not in healthy controls.

\section{Effects of non-caloric tastants on food intake behaviour}

Nutritive triggers in the intestine are known to elicit satiety signalling. ${ }^{11}$ One way for the gut to perceive food intraluminally is via taste receptors found throughout the entire GI tract. ${ }^{12-15}$ In the GI tract, these taste receptors are localised on enteroendocrine cells (EECs). Activation of these taste receptors in vitro results in GI peptide release, indicating their possible role in the satiation cascade. ${ }^{16-18}$ Interestingly, in chapter 3 and chapter 4 we found no effect of duodenal, ileal or intragastric delivery of tastants on energy intake. This was in line with some previous findings. ${ }^{19-22}$ However, several other studies did show reduced energy intake after gastrointestinal delivery of non-caloric tastants. ${ }^{8-10,23,24}$ It should be taken into account that among most studies that showed no significant decrease in energy intake, a non-significant decrease was found. Therefore, we conducted a systematic review and meta-analysis to investigate the effect of gastrointestinal delivery of tastants on eating behaviour (chapter 2). This review and meta-analysis clearly showed that among the various tastants, bitter agents are the most potent to influence eating behaviour. Overall, a significant reduction in food intake was found after gastrointestinal delivery of bitter tastants. The effects of gastrointestinal delivery of tastants on GI peptide release were inconclusive. Most recently, the role of motilin as opposed to the more conventional GI peptides was elaborated to be a regulator of hunger and food intake in humans. ${ }^{25}$ It must be noted, however, that generally plasma levels of GI peptides are measured, indicating systemic instead of local effects. The effects of taste receptor activation on local secretion of GI peptides in vivo are entirely unknown. Since elevated GI peptides are consistently found after taste receptor activation in vitro, ${ }^{16-18}$ it is conceivable 
that, at local and splanchnic level, GI peptides levels are elevated. However, both splanchnic blood collection and using catheters to investigate local intestinal tissue levels of GI peptides are invasive and complex procedures. Interestingly, recent studies consistently show attenuated gastric motility and serum motilin as possible mediators of the effect of bitter tastants on eating behaviour. ${ }^{21,23,26}$ Therefore, future research projects in this field should focus on motility and motilin as outcome measures to investigate underlying mechanisms of action.

Although GI delivery of bitter tastants seems promising with respect to influencing eating behaviour, it must be noted that the reduction in energy intake that was found is small. Several studies showed blunted postprandial levels of GI peptides PYY 27,28 and GLP-1 in obese subjects. ${ }^{29-31}$ Moreover, a reduction in plasma CCK levels has been shown after weight loss. ${ }^{32,33}$ These observations point to alterations in the sensitivity of various receptors to GI peptides in obesity. Due to the modest caloric reduction in energy intake, bitter tastants appear to be more suitable to prevent obesity rather than treat (morbid) obesity. Further research is needed to elucidate the long-term efficacy and safety of gastrointestinal bitter tastant delivery before it can be made available for consumers. At first, repetitive stimulation should be investigated to examine whether desensitisation of taste receptors occurs or not. Thereafter, a long-term intervention study should be conducted to evaluate the effects of bitter tastant administration on eating behaviour, actual weight loss. Moreover, safety issues should be addressed. We propose such a first long-term intervention study to last at least 3-6 months, as most pilot studies investigating initial weight loss employ an intervention period of 3-6 months. ${ }^{34-36}$

It must be noted that the currently available data is highly heterogenic with different modes and sites of delivery of tastants, different dosages of tastants. The field should move towards uniformity in study designs, preferably by meeting each other and discussing further steps.

One specific aspect should also be taken into account: differences in response between subjects classified as 'tasters' or 'non-tasters'. Up to now only one study addressed this issue and found a difference in response between 'tasters' and 'non-tasters', with a higher reduction in energy intake in 'tasters' ${ }^{8}$ Classifying 'tasters' and 'non-tasters' in that study was performed based on the ability to recognise phenylthiocarbamide (PTC) and 6-N propylthiouracil (PROP). ${ }^{37}$ Bitter taste is sensed by the taste receptor family 2 (TAS2R). Currently, there are 25 known subtypes of TAS2Rs in humans, with different compounds activating various (combinations of) subtypes. Both PTC and PROP are recognised only by TAS2R38. ${ }^{38}$ Chapter 2 showed that denatonium benzoate (DB) and quinine are most 
commonly used in studies investigating the effects of bitter compounds on eating behaviour. DB is known to activate 8 TAS2R subtypes (TAS2R 4, 8, 10, 13, 39, 43, 46, and 47), whereas quinine is known to activate 9 subtypes of TAS2R (TAS2R 4, 7, 10, 14, 39, 40, 43, 44, and 46). ${ }^{38}$ Therefore, it essential to characterise 'tasters' and 'non-tasters' based on the tastant that is being used in the study. This challenge can be met by using a gustometer, a taste delivery system able to deliver a precise amount of taste. ${ }^{39-41}$ The gustometer could also be used to predict interventional success based on tastant responders when applied in the screening setting.

Furthermore, studies should focus on feasible, and in daily life implementable methodology such as capsules rather than using naso-gastric or naso-intestinal catheters, as effect sizes of gastrointestinal tastant delivery are small. The potentially negative and aversive effects of catheters may mask or override the subtle effects that tastants exert on eating behaviour. Regarding bitter agents, studies in new-born infants showed bitter taste to be evolutionarily linked to toxic substances. ${ }^{42}$ Therefore, one should realise that oral ingestion of bitter tastants is not pleasant and may even be aversive. Such effects could result in loss of compliance over time. Taken together, we consider the stomach as best target location for bitter tastants to exert their effect and we advise to focus on the effects of intragastrically delivered bitter tastants on eating behaviour.

\section{Effects of lidocaine on food intake behaviour}

Directly after ingestion of a meal, the initial satiating effect occurs due to distension of the stomach wall. Along the stomach wall are mechanoreceptors that sense an increase in stomach volume, which in turn triggers neural circuits that inhibit food intake behaviour. ${ }^{11,43}$ A recent study applicated a local topical anaesthetic to rats' stomachs and found a significant increase in energy intake during a subsequent meal. ${ }^{44}$

In chapter 5, we described the first in-human study to investigate safety and acute effects on eating behaviour of lidocaine infusion into the stomach. Lidocaine infusion resulted in a modest, non-significant, increase in energy intake. Interestingly, this increase in energy intake was found on treatment day 2 compared with treatment day 1 . It is known that stressors can influence energy intake in both directions, dependent on strength, type, and impact of the stressor. ${ }^{45-47}$ As a nasogastric catheter was used to administer the lidocaine, we believe this treatment day effect to arise from the subjects not being familiar with the procedures of catheter placement and removal. Based on this knowledge, the option of 
using a mock test day to familiarise subjects to study protocols should be considered for future studies involving invasive procedures.

Moreover, in this study we employed a rather low dosage of lidocaine when compared with the dosage of topical anaesthetics used in the beforementioned animal study. It is likely that a higher dosage of lidocaine could have resulted in a more pronounced, statistically significant increase in energy intake. However, it should be taken into account that applying higher dosages of lidocaine may increase the risk of hazardous side-effects, such as cardiac arrythmias. ${ }^{48,49}$ These aspects should be taken into account when designing future studies.

In this study we did not exclude subjects based on their capability to eat large meals. One could speculate that subjects with the ability to consume large volume meals are able to eat until maximum distension of the stomach. If this holds true, desensitising the stomach mechanoreceptors using local topical anaesthetics would not result in an additional increase in energy intake in these individuals. Therefore, we expect lidocaine to have a certain window of efficacy. We anticipate no effects to occur in response to lidocaine on an empty stomach, as there is no stretch or distension of the stomach wall. On the other hand, in a fully distended stomach it is physiologically impossible to further increase the volume.

Another aspect that should be noted is the fact that this study was performed in healthy, young individuals. The aging population, on the other hand, is known to have alterations in the signalling of their sensory pathways in the gastrointestinal tract. ${ }^{50-52}$ Moreover, impaired gastric accommodation is found in patients suffering from functional dyspepsia (FD) and is associated with hypersensitivity of mechano-receptors. As these populations of elderly and dyspeptics show signs of oversensitivity of mechanoreceptors, interventions directed towards desensitisation of mechano-receptors may represent new and viable treatment options to improve nutrient intake and reverse the observed weight loss. Therefore, effects of gastric anaesthetics on eating behaviour should be investigated in individuals suffering from anorexia of aging and FD patients with predominant postprandial distress syndrome. As gastric anaesthetics have been shown to be safe in healthy individuals, future research should address the balance between treatment efficacy and potentially hazardous side-effects in the abovementioned patient groups.

Besides the selection of the patient groups, one should consider applying gastric anaesthetics using a capsule rather than via a naso-gastric catheter, as we have indicated possible negative effects of catheter usage and intubation on eating behaviour. Moreover, in patients with FD nutrient drink tests are often used to estimate gastric sensation and accommodation. ${ }^{53-55}$ It could be interesting to use nutrient drink test as an outcome rather than an ad libitum meal, as this possibly reflects gastric stretch more accurately. Therefore, we would propose to investigate the effect of gastric anaesthetics without using naso- 
gastric catheters and the nutrient drink test as primary outcome measure in patients with postprandial distress syndrome.

\section{Real time assessment to indicate triggers for postprandial distress}

According to the Rome IV criteria, functional dyspepsia is a symptom-based diagnosis. ${ }^{56}$ Use of patient reported outcome measures (PROMs) is recommended in both clinical and research settings, as objective outcome measures such as biological markers are lacking. Experience Sampling Method (ESM) is an attractive method to overcome limitations posed by retrospective questionnaires. This novel technique has proven to be reliable and valid in psychiatric patients. ${ }^{57} \mathrm{ESM}$ is not only able to assess symptoms and evaluate treatment efficacy. ESM has the ability to provide detailed feedback to patients in order to enhance insight in their complaints. Therefore, ESM has the potential to increase patient compliance, facilitate self-management, and improve shared decision making. ${ }^{58,59}$

The use of ESM in patients with gastrointestinal disorders is limited compared with the use of ESM in patients with psychiatric disorders. Several studies from our group that evaluated ESM in patients with irritable bowel syndrome (IBS) found correlations between commonly used questionnaires and symptom scores on ESM. However, peak abdominal pain scores found using ESM were reported as mean abdominal pain scores on retrospective questionnaires. ${ }^{60,61}$ Moreover, ESM was also able to demonstrate interactions between stress and abdominal complaints. ${ }^{62,63}$

In chapter 6 and Chapter 7, we described the first use of an ESM-based PROM used for patients with FD. We found good concurrent validity, internal consistency and test-retest reliability. One important aspect of quality testing of this new PROM that is yet to be investigated, is the responsiveness of this PROM. The responsiveness of a PROM refers to its ability to detect change. ${ }^{64,65}$ This is an important aspect to evaluate prior to evaluating treatment efficacy in FD patients by using this novel ESM-based PROM.

In Chapter 7, we showed the ability of ESM to evaluate the construct early satiation in FD patients. Moreover, both concurrent and preceding stress levels were associated with fullness levels in FD patients, but not in healthy controls. These findings lead us to assume that stress triggers the onset or worsening of fullness complaints in FD patients, rather than the other way around. Other studies have also shown the relationship between functional dyspepsia and psychological factors. ${ }^{66,67}$ Another study demonstrated disturbed gastric sensory-motor function, that was manifested in an impaired gastric accommodation 
reflex after acute anxiety, using a stressor. ${ }^{68}$ Moreover, another study has shown altered brain activity in FD patients that were in anticipation of a stressor. ${ }^{69}$

We demonstrated that the novel ESM-based PROM can distinguish individual symptom patterns as well as interplays between concurrent and preceding symptoms.

Based on these results, we postulate that this novel ESM-based PROM has the potential to aid us in obtaining more insight into the disorder FD, in underlying mechanisms and symptom triggers, to improve shared-decision making, and self-management of patients with functional dyspepsia.

\section{Conclusions and future directions}

In this section of the discussion, we present suggestions for further research focusing on gastrointestinal delivery of tastants and blunting mechanoreceptors on food intake. Moreover, recommendations for further studies investigating PROMs in diagnosing and the management of functional dyspepsia are presented.

As demonstrated in chapter 2, the use of non-caloric tastants to reduce food intake could provide a useful tool to combat the obesity epidemic. However, data are in consistent and study procedures lack uniformity. Studies generally employ small sample sizes, different study designs, and different doses of tastants. Moreover, data on the long-term effects of gastrointestinal delivery of non-caloric tastants on eating behaviour are lacking. However, we believe this to be a field that should be further explored using more standardised and uniform protocols.

In order to standardise the study designs, we suggest several steps to be taken. First, it is unclear whether potential effects of tastant administration on eating behaviour diminish over time. Therefore, effects of repetitive administration of tastants on eating behaviour should be investigated. Second, underlying mechanisms on effect of gastrointestinal tastant administration should be more thoroughly investigated. As recent results show attenuated gastric motility and serum motilin, we propose to focus on these aspects. ${ }^{21,23,26}$ Third, taste receptors are expressed throughout the entire GI tract. ${ }^{12-15}$ Chapter 3 and Chapter 4 are the first studies to assess the effects of tastant administration on food intake in different locations in the GI tract. The optimal location of administration is yet to be elucidated. More research investigating delivery of tastants in different locations in the GI-tract is therefore needed. Fourth, the optimal dose of tastants to influence eating behaviour is unknown. Future studies should focus on finding the balance between the maximal possible effect without inducing side effects. A last and crucial step relates to the 
implementation of successful interventions. Crucial is that longer-term effects of gastrointestinal delivery of tastants on eating behaviour are shown that ultimately result in body weight reduction.

In chapter 5, we showed that intragastric lidocaine infusion did not result in a significant increase in energy intake in this first in-human explorative study. However, we observed a significant increase in energy intake in treatment day 2 compared with treatment day 1. Future protocols should consider other delivery methods such as capsules. Moreover, the dose of lidocaine used was only $2.6 \mathrm{mg} / \mathrm{kg}$ body weight. As this dose proved to be safe and did not result in (cardiac) side effects, studies exploring the optimal dose of gastric lidocaine administration on energy intake should be conducted.

Furthermore, as local administration of anaesthetics in the stomach proved to be safe in healthy volunteers, the effects of gastric lidocaine administration on eating behaviour should be investigated in a population that show impaired energy intake. Moreover, outcome measures such as the nutrient drink test should be considered in these populations.

In chapter 6 and chapter 7, we showed a novel tool to address symptoms of FD patients. Moreover, we indicated that concurrent stress and fullness levels are associated in FD patients. Future studies should evaluate the responsiveness (i.e., the ability to detect change) of this novel ESM tool. Thereafter, researchers should make use of the ESM method to investigate patient-specific intervention methods in managing functional dyspepsia. Subsequently, this novel ESM tool should be optimised before implementation in patient care.

\section{Concluding remarks}

The studies presented in this thesis help to expand our understanding of potential novel treatment-, preventive-, and monitoring options in disrupted sensing and signalling of satiety. We focused on the potential of (bitter) tastants to reduce food intake and assessed the possibility of blunting the effects of mechanoreceptors in order to increase food intake. Moreover, we investigated the potential of real time assessment of PROMs in order to monitor FD and to search for specific triggers that can lead to fullness complaints. 


\section{References}

1. Jensen MD, Ryan DH, Apovian CM, Ard JD, Comuzzie AG, Donato KA, et al. 2013 AHA/ACC/TOS guideline for the management of overweight and obesity in adults: a report of the American College of Cardiology/American Heart Association Task Force on Practice Guidelines and The Obesity Society. J Am Coll Cardiol. 2014;63(25 Pt B):2985-3023.

2. Schwartz MW, Seeley RJ, Zeltser LM, Drewnowski A, Ravussin E, Redman LM, et al. Obesity Pathogenesis: An Endocrine Society Scientific Statement. Endocr Rev. 2017;38(4):267-96.

3. Sturm K, Parker B, Wishart J, Feinle-Bisset C, Jones KL, Chapman I, et al. Energy intake and appetite are related to antral area in healthy young and older subjects. Am J Clin Nutr. 2004;80(3):656-67.

4. Wysokinski A, Sobow T, Kloszewska I, Kostka T. Mechanisms of the anorexia of aging-a review. Age (Dordr). 2015;37(4):9821.

5. Fisher MM, Rosen DS, Ornstein RM, Mammel KA, Katzman DK, Rome ES, et al. Characteristics of Avoidant/Restrictive Food Intake Disorder in Children and Adolescents: A "New Disorder" in DSM-5. Journal of Adolescent Health. 2014;55(1):49-52.

6. Norris ML, Robinson A, Obeid N, Harrison M, Spettigue W, Henderson K. Exploring Avoidant/Restrictive Food Intake Disorder in Eating Disordered Patients: A Descriptive Study. International Journal of Eating Disorders. 2014;47(5):495-9.

7. Zimmerman J, Fisher M. Avoidant/Restrictive Food Intake Disorder (ARFID). Curr Probl Pediatr Adolesc Health Care. 2017;47(4):95-103.

8. Andreozzi P, Sarnelli G, Pesce M, Zito FP, D'Alessandro A, Verlezza V, et al. The Bitter Taste Receptor Agonist Quinine Reduces Calorie Intake and Increases the Postprandial Release of Cholecystokinin in Healthy Subjects. J Neurogastroenterol Motil. 2015;21(4):511-9.

9. Mennella I, Fogliano V, Ferracane R, Arlorio M, Pattarino F, Vitaglione P. Microencapsulated bitter compounds (from Gentiana lutea) reduce daily energy intakes in humans. Br J Nutr. 2016:1-10.

10. van Avesaat M, Troost FJ, Ripken D, Peters J, Hendriks HF, Masclee AA. Intraduodenal infusion of a combination of tastants decreases food intake in humans. Am J Clin Nutr. 2015;102(4):729-35.

11. Powley TL, Phillips RJ. Gastric satiation is volumetric, intestinal satiation is nutritive. Physiol Behav. 2004;82(1):69-74.

12. Bezencon C, le Coutre J, Damak S. Taste-signaling proteins are coexpressed in solitary intestinal epithelial cells. Chemical Senses. 2007;32(1):41-9.

13. Gu F, Liu X, Liang J, Chen JY, Chen FX, Li F. Bitter taste receptor mTas2r105 is expressed in small intestinal villus and crypts. Biochem Bioph Res Co. 2015;463(4):934-41.

14. van der Wielen N, van Avesaat M, de Wit NJW, Vogels JTWE, Troost F, Masclee A, et al. Cross-Species Comparison of Genes Related to Nutrient Sensing Mechanisms Expressed along the Intestine. Plos One. 2014;9(9).

15. Young RL, Sutherland K, Pezos N, Brierley SM, Horowitz M, Rayner CK, et al. Expression of taste molecules in the upper gastrointestinal tract in humans with and without type 2 diabetes. Gut. 2009;58(3):337-46.

16. Jang HJ, Kokrashvili Z, Theodorakis MJ, Carlson OD, Kim BJ, Zhou J, et al. Gut-expressed gustducin and taste receptors regulate secretion of glucagon-like peptide-1. Proc Natl Acad Sci U S A. 2007;104(38): 15069-74.

17. Sternini C, Anselmi L, Rozengurt E. Enteroendocrine cells: a site of 'taste' in gastrointestinal chemosensing. Curr Opin Endocrinol Diabetes Obes. 2008;15(1):73-8.

18. Rozengurt N, Wu SV, Chen MC, Huang C, Sternini C, Rozengurt E. Colocalization of the alpha-subunit of gustducin with PYY and GLP-1 in L cells of human colon. Am J Physiol Gastrointest Liver Physiol. 2006;291(5):G792-802.

19. Bitarafan V, Fitzgerald PCE, Little TJ, Meyerhof W, Jones KL, Wu T, et al. Intragastric administration of the bitter tastant quinine lowers the glycemic response to a nutrient drink without slowing gastric emptying in healthy men. Am J Physiol Regul Integr Comp Physiol. 2020;318(2):R263-R73. 
20. Bitarafan V, Fitzgerald PCE, Little TJ, Meyerhof W, Wu TZ, Horowitz M, et al. Effects of Intraduodenal Infusion of the Bitter Tastant, Quinine, on Antropyloroduodenal Motility, Plasma Cholecystokinin, and Energy Intake in Healthy Men. J Neurogastroenterol Motil. 2019;25(3):413-22.

21. Deloose E, Janssen P, Corsetti M, Biesiekierski J, Masuy I, Rotondo A, et al. Intragastric infusion of denatonium benzoate attenuates interdigestive gastric motility and hunger scores in healthy female volunteers. Am J Clin Nutr. 2017;105(3):580-8.

22. Black RM, Leiter LA, Anderson GH. Consuming aspartame with and without taste: differential effects on appetite and food intake of young adult males. Physiol Behav. 1993;53(3):459-66.

23. Iven J, Biesiekierski JR, Zhao D, Deloose E, O'Daly OG, Depoortere I, et al. Intragastric quinine administration decreases hedonic eating in healthy women through peptide-mediated gut-brain signaling mechanisms. Nutr Neurosci. 2018:1-13.

24. Rogers PJ, Pleming HC, Blundell JE. Aspartame Ingested without Tasting Inhibits Hunger and FoodIntake. Physiology \& Behavior. 1990;47(6):1239-43.

25. Deloose E, Verbeure W, Depoortere I, Tack J. Motilin: from gastric motility stimulation to hunger signalling. Nat Rev Endocrinol. 2019;15(4):238-50.

26. Deloose E, Corsetti M, Van Oudenhove L, Depoortere I, Tack J. Intragastric infusion of the bitter tastant quinine suppresses hormone release and antral motility during the fasting state in healthy female volunteers. Neurogastroenterol Motil. 2018;30(1).

27. le Roux CW, Batterham RL, Aylwin SJ, Patterson M, Borg CM, Wynne KJ, et al. Attenuated peptide YY release in obese subjects is associated with reduced satiety. Endocrinology. 2006;147(1):3-8.

28. Zwirska-Korczala K, Konturek SJ, Sodowski M, Wylezol M, Kuka D, Sowa P, et al. Basal and postprandial plasma levels of PYY, ghrelin, cholecystokinin, gastrin and insulin in women with moderate and morbid obesity and metabolic syndrome. J Physiol Pharmacol. 2007;58 Suppl 1:13-35.

29. Adam TC, Westerterp-Plantenga MS. Glucagon-like peptide-1 release and satiety after a nutrient challenge in normal-weight and obese subjects. Br J Nutr. 2005;93(6):845-51.

30. Carroll JF, Kaiser KA, Franks SF, Deere C, Caffrey JL. Influence of BMI and gender on postprandial hormone responses. Obesity (Silver Spring). 2007;15(12):2974-83.

31. Verdich C, Toubro S, Buemann B, Lysgard Madsen J, Juul Holst J, Astrup A. The role of postprandial releases of insulin and incretin hormones in meal-induced satiety--effect of obesity and weight reduction. Int J Obes Relat Metab Disord. 2001;25(8):1206-14.

32. Chearskul S, Delbridge E, Shulkes A, Proietto J, Kriketos A. Effect of weight loss and ketosis on postprandial cholecystokinin and free fatty acid concentrations. Am J Clin Nutr. 2008;87(5):1238-46.

33. Sumithran P, Prendergast LA, Delbridge E, Purcell K, Shulkes A, Kriketos A, et al. Long-term persistence of hormonal adaptations to weight loss. N Engl J Med. 2011;365(17):1597-604.

34. Newlands RSN, Ntessalen M, Clark J, Fielding S, Hoddinott P, Heys SD, et al. Pilot randomised controlled trial of Weight Watchers(R) referral with or without dietitian-led group support for weight loss in women treated for breast cancer: the BRIGHT (BReast cancer weIGHT loss) trial. Pilot Feasibility Stud. 2019;5:24.

35. Kapoor E, Faubion S, Hurt RT, Fischer K, Schroeder D, Fokken S, et al. A selective serotonin receptor agonist for weight loss and management of menopausal vasomotor symptoms in overweight midlife women: a pilot study. Menopause. 2020.

36. Tate DF, Quesnel DA, Lutes L, Hatley KE, Nezami BT, Wojtanowski AC, et al. Examination of a partial dietary self-monitoring approach for behavioral weight management. Obes Sci Pract. 2020;6(4): 353-64.

37. Kim UK, Drayna D. Genetics of individual differences in bitter taste perception: lessons from the PTC gene. Clin Genet. 2005;67(4):275-80.

38. Meyerhof W, Batram C, Kuhn C, Brockhoff A, Chudoba E, Bufe B, et al. The molecular receptive ranges of human TAS2R bitter taste receptors. Chem Senses. 2010;35(2):157-70.

39. Andersen CA, Alfine L, Ohla K, Hochenberger R. A new gustometer: Template for the construction of a portable and modular stimulator for taste and lingual touch. Behav Res Methods. 2019;51(6): 2733-47.

40. Iannilli E, Beger M, Furer R, Hummel T. A gustatory stimulator. J Neurosci Methods. 2015;255:12-6.

41. Canna A, Prinster A, Fratello M, Puglia L, Magliulo M, Cantone E, et al. A low-cost open-architecture taste delivery system for gustatory fMRI and BCI experiments. J Neurosci Methods. 2019;311:1-12. 
42. Steiner JE, Glaser D, Hawilo ME, Berridge KC. Comparative expression of hedonic impact: affective reactions to taste by human infants and other primates. Neurosci Biobehav Rev. 2001;25(1):53-74.

43. Phillips RJ, Powley TL. Tension and stretch receptors in gastrointestinal smooth muscle: re-evaluating vagal mechanoreceptor electrophysiology. Brain Res Brain Res Rev. 2000;34(1-2):1-26.

44. Broekkamp CLE, Peeters BWMM. Means to facilitate food intake and food retention. Patent application WO2013/171252.

45. Greeno CG, Wing RR. Stress-induced eating. Psychol Bull. 1994;115(3):444-64.

46. Kistenmacher A, Goetsch J, Ullmann D, Wardzinski EK, Melchert UH, Jauch-Chara K, et al. Psychosocial stress promotes food intake and enhances the neuroenergetic level in men. Stress. 2018:1-10.

47. Ulrich-Lai YM, Fulton S, Wilson M, Petrovich G, Rinaman L. Stress exposure, food intake and emotional state. Stress. 2015;18(4):381-99.

48. Man RY, Dresel PE. Effect of lidocaine and methyl lidocaine on cardiac conduction. J Pharmacol Exp Ther. 1977;201(1):184-91.

49. Rosen MR, Hoffman BF, Wit AL. Electrophysiology and pharmacology of cardiac arrhythmias. V. Cardiac antiarrhythmic effects of lidocaine. Am Heart J. 1975;89(4):526-36.

50. Gabella G. Fall in the number of myenteric neurons in aging guinea pigs. Gastroenterology. 1989;96(6):1487-93.

51. Meciano Filho J, Carvalho VC, de Souza RR. Nerve cell loss in the myenteric plexus of the human esophagus in relation to age: a preliminary investigation. Gerontology. 1995;41(1):18-21.

52. Rayner CK, MacIntosh CG, Chapman IM, Morley JE, Horowitz M. Effects of age on proximal gastric motor and sensory function. Scand J Gastroenterol. 2000;35(10):1041-7.

53. Boeckxstaens GE, Hirsch DP, van den Elzen BD, Heisterkamp SH, Tytgat GN. Impaired drinking capacity in patients with functional dyspepsia: relationship with proximal stomach function. Gastroenterology. 2001;121(5):1054-63.

54. Gonenne J, Castillo EJ, Camilleri M, Burton D, Thomforde GM, Baxter KL, et al. Does the nutrient drink test accurately predict postprandial gastric volume in health and community dyspepsia? Neurogastroenterol Motil. 2005;17(1):44-50.

55. Tack J, Caenepeel P, Piessevaux H, Cuomo R, Janssens J. Assessment of meal induced gastric accommodation by a satiety drinking test in health and in severe functional dyspepsia. Gut. 2003;52(9):1271-7.

56. Stanghellini V, Chan FK, Hasler WL, Malagelada JR, Suzuki H, Tack J, et al. Gastroduodenal Disorders. Gastroenterology. 2016;150(6):1380-92.

57. Verhagen SJW, Berben JA, Leue C, Marsman A, Delespaul P, van Os J, et al. Demonstrating the reliability of transdiagnostic mHealth Routine Outcome Monitoring in mental health services using experience sampling technology. PLoS One. 2017;12(10):e0186294.

58. van Os J, Verhagen S, Marsman A, Peeters F, Bak M, Marcelis M, et al. The experience sampling method as an mHealth tool to support self-monitoring, self-insight, and personalized health care in clinical practice. Depress Anxiety. 2017;34(6):481-93.

59. Verhagen SJ, Hasmi L, Drukker M, van Os J, Delespaul PA. Use of the experience sampling method in the context of clinical trials. Evid Based Ment Health. 2016;19(3):86-9.

60. Mujagic Z, Leue C, Vork L, Lousberg R, Jonkers DM, Keszthelyi D, et al. The Experience Sampling Method--a new digital tool for momentary symptom assessment in IBS: an exploratory study. Neurogastroenterol Motil. 2015;27(9):1295-302.

61. Weinland SR, Morris CB, Hu Y, Leserman J, Bangdiwala SI, Drossman DA. Characterization of episodes of irritable bowel syndrome using ecological momentary assessment. Am J Gastroenterol. 2011;106(10):1813-20.

62. Vork L, Keszthelyi D, van Kuijk SMJ, Quetglas EG, Tornblom H, Simren M, et al. Patient-Specific StressAbdominal Pain Interaction in Irritable Bowel Syndrome: An Exploratory Experience Sampling Method Study. Clin Transl Gastroenterol. 2020;11(7):e00209.

63. Chan Y, So SH, Mak ADP, Siah KTH, Chan W, Wu JCY. The temporal relationship of daily life stress, emotions, and bowel symptoms in irritable bowel syndrome-Diarrhea subtype: A smartphone-based experience sampling study. Neurogastroenterol Motil. 2019;31(3):e13514. 
64. Alrubaiy L, Hutchings HA, Williams JG. Assessing patient reported outcome measures: A practical guide for gastroenterologists. United European Gastroenterol J. 2014;2(6):463-70.

65. Terwee CB, Bot SD, de Boer MR, van der Windt DA, Knol DL, Dekker J, et al. Quality criteria were proposed for measurement properties of health status questionnaires. J Clin Epidemiol. 2007;60(1):34-42.

66. Aro P, Talley NJ, Johansson SE, Agreus L, Ronkainen J. Anxiety Is Linked to New-Onset Dyspepsia in the Swedish Population: A 10-Year Follow-up Study. Gastroenterology. 2015;148(5):928-37.

67. Van Oudenhove L, Crowell MD, Drossman DA, Halpert AD, Keefer L, Lackner JM, et al. Biopsychosocial Aspects of Functional Gastrointestinal Disorders. Gastroenterology. 2016.

68. Ly HG, Weltens N, Tack J, Van Oudenhove L. Acute Anxiety and Anxiety Disorders Are Associated With Impaired Gastric Accommodation in Patients With Functional Dyspepsia. Clin Gastroenterol H. 2015;13(9):1584-+.

69. Van Oudenhove L, Vandenberghe J, Dupont P, Geeraerts B, Vos R, Dirix S, et al. Abnormal regional brain activity during rest and (anticipated) gastric distension in functional dyspepsia and the role of anxiety: a H(2)(15)O-PET study. Am J Gastroenterol. 2010;105(4):913-24. 



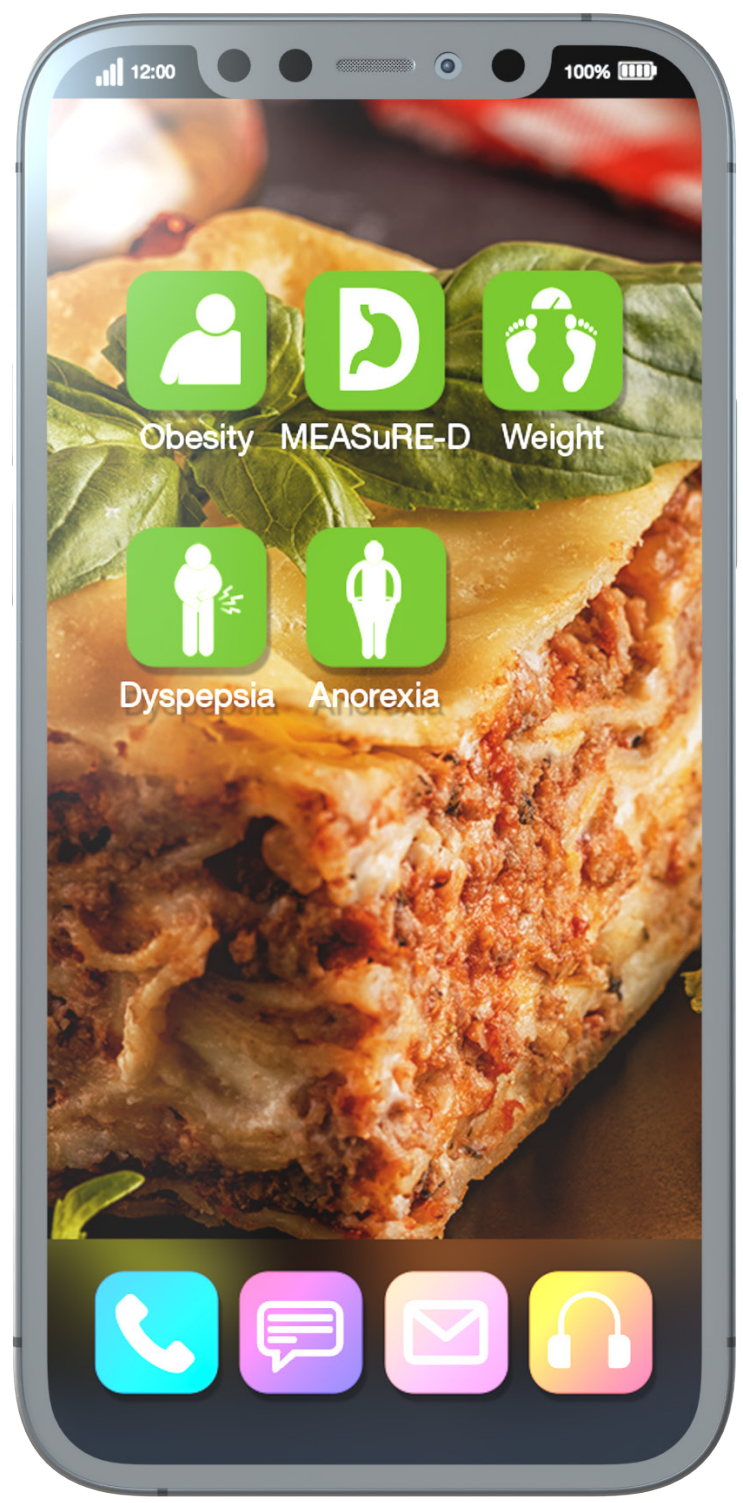




\section{Addendum}

Summary

Samenvatting

Impact

List of publications

Dankwoord

Curriculum Vitae 



\section{Summary}

Various clinical situations can influence energy intake and sensing and signaling of satiety. Increased energy intake and diminished satiety signaling can be seen in the case of overweight and obesity. On the other hand, decreased energy intake and increased satiety can be seen in the aging population, also known as anorexia of aging. Furthermore, abnormal sensations such as recurring pain, stress, and anxiety can influence energy intake and satiety signaling. This in turn can result in food intake disorders such as avoidant/restrictive food intake disorder (ARFID). This thesis contains studies that provide an in-depth understanding of food-gut interactions in order to develop and optimize therapeutic strategies aiming at correcting conditions with disturbed (being too high or too low) energy intake. Furthermore, a novel tool to provide more insight into disturbed sensing and signaling of satiety as seen in functional dyspepsia was investigated.

\section{Effects of non-caloric tastants on food intake behavior}

Humans are able to detect five basic tastes: sweet, bitter, umami and salty. Interestingly, taste receptors are not only found on the tongue. Taste receptors can be found throughout the entire GI tract. A function of these taste receptors is to sense the presence of food in the gut. The systematic review and meta-analysis described in Chapter 2 provides an overview of the effects of gastrointestinal delivery of non-caloric tastants on eating behavior. This review and meta-analysis showed that among non-caloric tastants, bitter tastants are the most potent to reduce food intake. However, further research and international collaboration is needed to move forward in this field.

One aspect that was not thoroughly investigated was the optimal location of effect of tastants on eating behavior. Chapter 3 of this thesis describes a study investigating the effects of a tastant mixture (consisting of a sweet, bitter, and umami tastant) on ad libitum food intake and appetite sensations. Fourteen healthy volunteers were intubated with a naso-duodenal-ileal catheter with infusion ports in the duodenum and the ileum for four days. Hereafter, four test days with the following infusion combinations followed: duodenal placebo and ileal placebo, duodenal tastant mixture with ileal placebo, duodenal placebo with ileal tastant mixture, duodenal tastant mixture with ileal tastant mixture. We found no differences in food intake or appetite sensations between these four interventions. Herewith, we showed that a more distal infusion of tastants does not result in a stronger decrease in food intake compared with proximal infusion of tastants. 
The findings of chapter 2 indicated that among tastants, the bitter agents seem most potent in affecting eating behavior. As bitter is taste is evolutionarily linked to toxic substances, a more proximal delivery of bitter tastants might exert a larger inhibitory effect on food intake. In chapter 4 of this thesis, we therefore investigated the effect of oral and/or intragastric delivery of the bitter tastant quinine on ad libitum food intake and appetite sensations. Thirty-two healthy volunteers underwent four regimens: both mouth wash and intragastric capsule with placebo, mouth wash with quinine and intragastric capsule with placebo, mouth wash with placebo and intragastric capsule with quinine, both mouth wash and intragastric capsule with quinine. We found no differences in food intake between the interventions. However, significant reductions in hunger and desire to eat scores were found for the quinine conditions compared with placebo. Herewith, we demonstrate the ability of a bitter tastant to influence appetite sensations that did not result in a reduction of food intake in this study.

\section{Effects of lidocaine on food intake behavior}

After ingestion of a meal, distension of the stomach wall is responsible for the initial satiating effect of a meal. Mechanoreceptors along the stomach wall sense the increase in stomach volume, in turn triggering neural circuits to inhibit food intake. In chapter 5, we described the first in-human study that investigated the effects of lidocaine infusion into the stomach on ad libitum food intake and appetite sensations. Moreover, safety of intragastric lidocaine infusion was assessed. Twenty-six healthy volunteers underwent two regimens: lidocaine and placebo infusion into the stomach. We found a modest, nonsignificant, increase in food intake after lidocaine infusion. Moreover, lidocaine infusion in the stomach was safe and no (cardiac) side effects were reported. Herewith, we demonstrated, in healthy volunteers, the potential of intragastric delivery of lidocaine to influence food intake behavior. Further studies need to clarify the role of intragastric lidocaine administration in patients suffering from postprandial distress syndrome.

\section{Real time assessment to indicate triggers for postprandial distress}

Functional dyspepsia (FD) is a symptom-based diagnosis. Objective outcome measures, such as biological markers are lacking. Therefore, the use of patient reported outcome measures (PROMs) is recommended in both research and clinical settings. Retrospective questionnaires pose several limitations that might be overcome by using the experience sampling method (ESM). ESM is an electronic structured questioning method that is characterized by random, repeated assessments in a patient's current state and environment. ESM has the ability to provide detailed feedback to patients in order to enhance insight in their complaints. Therefore, ESM has the potential to increase patient 
compliance, facilitate self-management, and improve shared decision making. In chapter 6, we described the validation of an ESM-based PROM used for patients with FD. In this study, 35 patients with FD completed the previously developed ESM-based PROM for seven consecutive days. Moreover, the subjects completed end-of-day and end-of-week questionnaires that are currently being used in both clinical and research settings. We found good concurrent validity, internal consistency, and test-retest reliability of our novel PROM. Moreover, individual symptom patterns could be investigated using this PROM.

The ESM-based PROM provides us with the opportunity to investigate associations between concurring symptoms. Daily life stress is known to be able to influence a disturbance in gastric sensory and motor function. In chapter 7, we investigated the associations between fullness complaints and stress in patients with FD and healthy volunteers. Moreover, we evaluated whether real-time assessment of fullness is able to capture the construct early satiation, a cardinal symptom seen in patients with FD. Thirtyfive patients with FD and 34 healthy volunteers completed the previously developed ESMbased PROM for seven consecutive days. We found that in patients with FD, but not in healthy volunteers, fullness showed significant associations with both concurrent and preceding stress scores. This indicates that stress induces fullness complaints in patients with FD. Moreover, we found that the construct of early satiation could be captured by the real-time measurement of fullness. Furthermore, we found high heterogeneity in symptom patterns between patients with FD. This once more emphasizes the need for a more individualistic approach in healthcare for patients with FD. We are convinced that this novel ESM-based PROM has the potential to aid in the transition towards personalized healthcare for patients with FD.

In chapter 8, we summarized and integrated the main findings of this thesis and discussed new insights and future directions. 


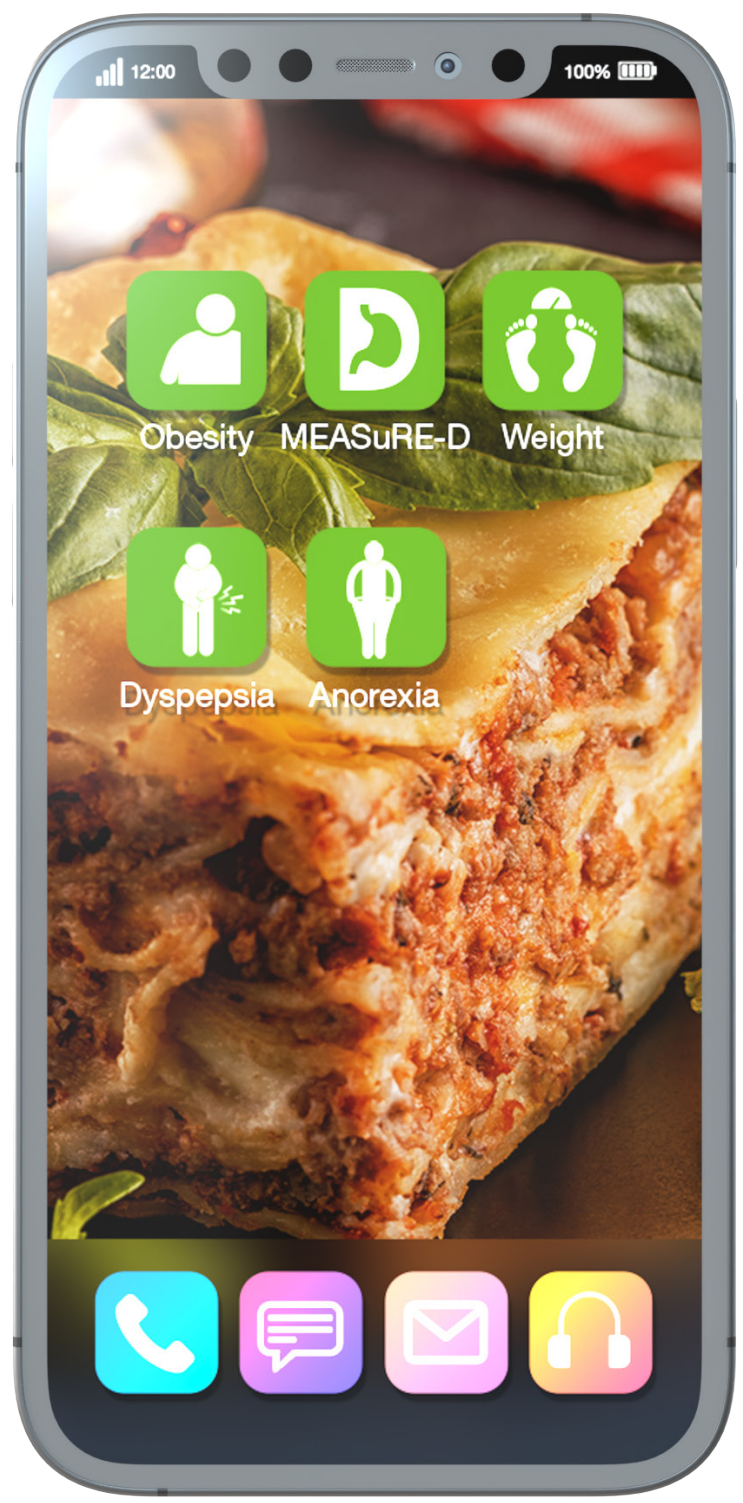




\section{Addendum}

Summary

Samenvatting

Impact

List of publications

Dankwoord

Curriculum Vitae 



\section{Samenvatting}

Er zijn diverse klinische situaties die voedselinname en het waarnemen en signaleren van verzadiging kunnen beïnvloeden. Een verhoogde voedselinname en verzwakt verzadigingssignaal wordt gezien in het geval van overgewicht en obesitas. Aan de andere kant kan men verminderde voedselinname en een verhoogde verzadiging zien in bijvoorbeeld de oudere populatie. Dit wordt anorexia van het ouder worden genoemd. Hiernaast kunnen abnormale gevoelens in de buik, zoals terugkerende buikpijn, maar ook stress en angst voedselinname en verzadiging beïnvloeden. Dit kan leiden tot eetstoornissen zoals vermijdende/restrictieve voedselinname stoornis. Dit proefschrift bevat studies die zorgen voor een betere kennis over voedsel-darm interacties om zo therapeutische en preventieve strategieën te ontwikkelen en optimaliseren voor condities met verstoorde (zijnde te hoge of te lage) voedselinname. Ook is er een nieuw instrument ontwikkeld dat meer inzicht kan geven in de verstoorde waarneming en signalering van verzadiging gezien bij de ziekte functionele dyspepsie.

\section{Effecten van niet-calorische smaakstoffen op voedselinname}

De mens is in staat om vijf basissmaken te onderscheiden: zoet, bitter, umami, zuur en zout.

Smaakreceptoren worden niet alleen op de tong gevonden, maar komen voor in het gehele maagdarmstelsel. Een van de functies van deze smaakreceptoren is het waarnemen dat er voedsel aanwezig is in de darm. Het overzichtsartikel met meta-analyse beschreven in Hoofstuk 2 geeft een actueel overzicht over de effecten van het toedienen van nietcalorische smaakstoffen in het maag-darmkanaal op eetgedrag. Uit dit overzichtsartikel komt naar voren dat van de niet-calorische smaakstoffen, bittere smaakstoffen het meest potent zijn in het reduceren van voedselinname. Echter, verder onderzoek en internationale samenwerking is nodig om de volgende stappen in dit onderzoeksveld te maken.

Een aspect dat onvoldoende onderzocht was is de optimale locatie van toediening van smaakstoffen voor het grootste effect op eetgedrag. Hoofdstuk 3 van dit proefschrift beschrijft een studie waarin de effecten van een smaakstofmengsel (bestaande uit een zoete, een bittere en een umami smaakstof) op voedselinname en verzadigingsgevoelens zijn onderzocht. Voor dit onderzoek hebben we 14 gezonde vrijwilligers geïntubeerd met een neus-ileum sonde met infusieplaatsen in het duodenum (het eerste deel van de dunne darm, ook wel de twaalfvingerige darm genoemd) en het ileum (het laatste deel van de dunne darm, ook wel de kronkeldarm genoemd). Hierna kregen zij op vier verschillende 
dagen de volgende infusiecombinaties: duodenaal en ileaal placebo, duodenaal het smaakstofmengsel en ileaal placebo, duodenaal placebo en ileaal het smaakstofmengsel, duodenaal en ilaal het smaakstofmengsel. In deze studie vonden we geen verschillen in voedselinname of verzadigingsgevoelens. Hiermee hebben we aangetoond dat het meer distaal, dus verderop in de darm, toedienden van smaakstoffen niet zorgt voor een sterkere rem op voedselinname vergeleken met meer proximale, dus meer aan het begin van de darm, toediening van smaakstoffen.

Een belangrijke bevinding uit Hoofdstuk 2 was dat van de niet-calorische smaakstoffen, bittere smaakstoffen het meest potent bleken in het beïnvloeden van eetgedrag. Gezien bittere smaak evolutionair gekoppeld is aan giftige stoffen, zou het kunnen zijn dat het meer proximaal, dus hogerop in het maagdarmkanaal, toedienen van bittere smaakstoffen een sterker remmend effect op voedselinname heeft. In Hoofdstuk 4 van dit proefschrift hebben we daarom de effecten van orale en/of intragastrische toediening van de bittere smaakstof kinine op voedselinname en verzadigingsgevoelens onderzocht. Voor dit onderzoek hebben 32 gezonde vrijwilligers vier testdagen ondergaan, waarbij zij de volgende interventiecombinaties kregen: mondspoeling en maagcapsule met placebo, mondspoeling met een kinine en maagcapsule met placebo, mondspoeling met placebo en maagcapsule met kinine, mondspoeling en maagcapsule met kinine. Uit dit onderzoek kwam naar voren dat er geen verschil was in voedselinname tussen de interventies. Echter, een significante afname in honger en de wens om te eten werd gevonden voor de kinine interventies vergeleken met placebo. Hierbij lieten wij zien dat kinine in staat is om verzadigingsgevoelens te beïnvloeden zonder dat dit leidde tot een verminderde voedselinname.

\section{Effecten van lidocaïne op voedselinname}

Het uitzetten van de maagwand zorgt voor het initiële verzadigingsgevoel na het innemen van een maaltijd. Er zijn zogeheten mechanoreceptoren te vinden op de maagwand die de rek van de maagwand en daarmee toename van het maagvolume waarnemen. Deze receptoren zorgen er vervolgens via neurale circuits voor dat voedselinname gestaakt wordt. Lidocaïne is een lokaal verdovingsmiddel, bekend van het gebruik door de tandarts bij het trekken van een kies. Mogelijk kan lidocaïne ook de bovengenoemde mechanoreceptoren verdoven. In Hoofstuk $\mathbf{5}$ beschreven we de eerste humane studie die de effecten van toediening van lidocaïne in de maag op voedselinname en verzadigingsgevoelens onderzocht. Daarnaast hebben we in deze studie gekeken naar de veiligheid van het toedienen van lidocaïne in de maag. Voor dit onderzoek kregen 26 gezonde vrijwilligers op 2 dagen een neus-maagsonde waarmee op de ene dag lidocaïne en 
de andere dag placebo werd ingespoten in de maag. We toonden een gematigde, nietsignificante, toename in voedselinname. Daarnaast lieten we zien dat het toedienen van lidocaïne in de maag veilig was en niet leidde tot (cardiale) bijwerkingen. Hierbij hebben we het potentiële effect van lidocaïne toediening in de maag op voedselinname laten zien in gezonde vrijwilligers. Verder onderzoek is nodig om de rol van deze interventie bij patiënten die lijden aan een syndroom van vroege verzadiging, ook wel postprandiale nood genoemd, vast te stellen.

\section{Real-time beoordeling van symptomen om triggers voor postprandiale nood te onderzoeken}

Functionele dyspepsie (FD) is een symptoom-gebaseerde diagnose. Er zijn geen objectieve uitkomstmaten zoals biologische markers. Daarom wordt geadviseerd om patiënt gerapporteerde uitkomstmaten (PROMs) te gebruiken in zowel de onderzoeks- als de klinische setting. Retrospectieve vragenlijsten zorgen echter voor belangrijke tekortkomingen die mogelijk ondervangen worden door gebruik te maken van de experience sampling methode (ESM). ESM is een elektronisch gestructureerde manier van vragen stellen die gekarakteriseerd wordt door willekeurige, herhaalde metingen in de huidige status en omgeving van een patiënt. ESM heeft de mogelijkheid om gedetailleerde feedback te geven aan patiënten om zo inzicht in hun klachten te verschaffen. Daarom biedt ESM de mogelijkheid om therapietrouw van patiënten te verbeteren, zelfmanagement van symptomen te faciliteren en gedeelde besluitvorming te verbeteren. In Hoofdstuk 6 hebben we de validatie van een op ESM gebaseerde PROM te gebruiken voor patiënten met FD beschreven. Voor deze studie hebben 35 patiënten met FD een eerder ontwikkelde op ESM gebaseerde PROM gedurende 7 dagen ingevuld. Ook vulden zijn einde-van-de-dag en einde-van-de-week vragenlijsten in die conventioneel worden gebruikt in zowel onderzoeks- als klinische setting. In deze studie vonden we goede validiteit ten opzichte van de conventionele vragenlijsten, goede interne consistentie en goede test-hertest betrouwbaarheid van dit nieuwe instrument. Daarnaast biedt deze nieuwe PROM de mogelijkheid om individuele symptoompatronen te onderzoeken.

Deze nieuwe op ESM gebaseerde PROM biedt ons de mogelijkheid om associaties tussen symptomen op hetzelfde moment te onderzoeken. Dagelijkse stress is een factor waarvan we weten dat deze in staat is om een verstoring in zowel de sensorische als motorische functie van de maag te bewerkstelligen. In Hoofdstuk 7 hebben we de associatie tussen 'een vol gevoel' en stress onderzocht in patiënten met FD en gezonde vrijwilligers. Daarnaast hebben we bekeken of het real-time meten van 'een vol gevoel' in staat is om het construct vroege verzadiging, een belangrijk symptoom dat gezien wordt in patiënten 
met FD, te vangen. Voor deze studie hebben 35 patiënten met FD en 34 vrijwilligers gedurende 7 dagen een op ESM gebaseerde PROM ingevuld. Hieruit kwam naar voren dat 'een vol gevoel' significant geassocieerd was met zowel gelijktijdige als voorafgaande stress scores in patiënten met FD, maar niet in gezonde vrijwilligers. Daarnaast hebben we aangetoond dat het construct vroege verzadiging gevangen kan worden door het real-time meten van 'een vol gevoel'. Ook zagen wij dat er een hoge heterogeniteit was in symptoompatronen tussen patiënten met FD. Dit onderstreept eens te meer dat er een meer individualistische aanpak nodig is in de zorg voor patiënten met FD. Wij zijn ervan overtuigd dat deze nieuwe op ESM gebaseerde PROM de mogelijkheid biedt om een rol te spelen in de transitie richting gepersonaliseerde gezondheidszorg voor patiënten met FD.

In Hoofdstuk $\mathbf{8}$ hebben we de resultaten van dit proefschrift samengevat en geïntegreerd. Daarnaast hebben we nieuwe inzichten en vervolgstappen bediscussieerd. 



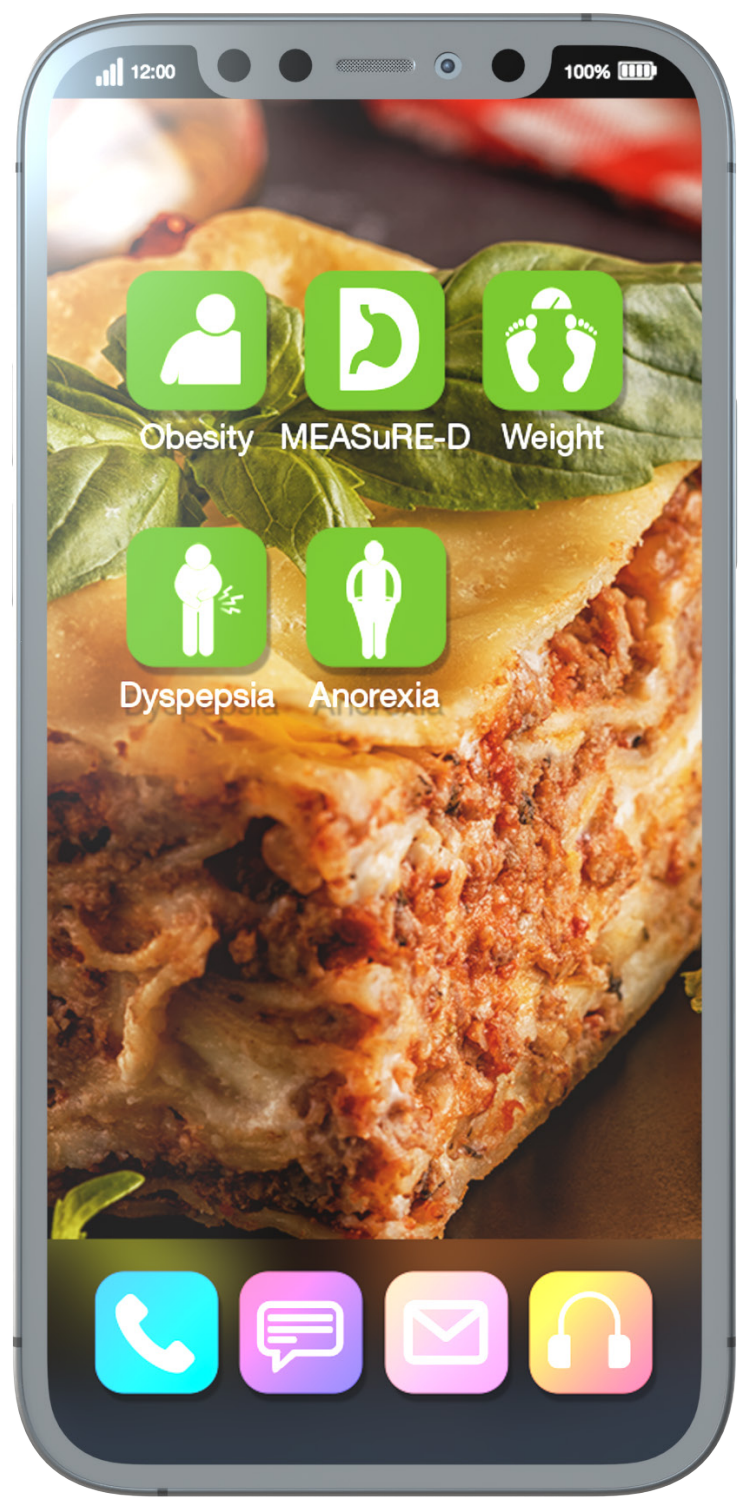




\section{Addendum}

Summary

Samenvatting

Impact

List of publications

Dankwoord

Curriculum Vitae 



\section{Impact}

Since 1975 , the prevalence of obesity in the population has nearly tripled. Obesity and overweight pose an evident burden and are linked to the occurrence of several diseases such as diabetes mellitus and cardiovascular diseases. Currently, only surgical options are an effective strategy for long-term weight loss. However, surgical treatment is invasive and only available for a selected group of morbidly obese subjects. Therefore, novel noninvasive treatment and preventive strategies are needed to battle the obesity epidemic. On the other hand, decreased food intake and increased satiety feelings are frequently seen in the aging population. A possible explanation could be altered sensitivity of pressure and nutrient and taste sensors in the stomach and small bowel. The gastrointestinal tract plays an important role in regulating food intake behaviour via release of gut peptides. Therefore, food-gut interactions could provide us with a strategy to influence and manipulate food intake behaviour.

The signalling of appetite can also be disrupted by abnormal sensations such as stress, anxiety, and recurrent pain. This can result in avoidance of food intake. Functional dyspepsia is a disorder in which patients experience symptoms such as bothersome early satiation, postprandial fullness, epigastric pain, and/or epigastric burning. However, no evidence for systemic, metabolic, or organic diseases can be found that is able to explain these symptoms. The presence of these symptoms is already sufficient to result in avoiding further food intake.

The aim of this thesis was to provide an in-depth understanding of interactions between food and the gastrointestinal tract related to satiety and eating behaviour. Hereby, we aimed to provide leads and thereafter develop and optimise therapeutic and preventive strategies that can correct disturbed (i.e., too high or too low) energy intake. Moreover, this thesis described the validation and application of a novel tool that will provide more insight into the disturbed sensing and signalling of appetite as observed in patients with functional dyspepsia.

This thesis highlighted the potential role of non-caloric bitter substances in decreasing food intake. However, this decrease in food intake is rather modest. Appetite signalling in obese individuals is substantially dysregulated. Therefore, the place of bitter substances in battling the obesity epidemic should be more as a preventive strategy, rather than a treatment strategy. This is also in line with the current concept of shifting the focus in healthcare from therapeutic care and cure towards prevention. In this thesis the scientific steps that need to be undertaken before implementing this preventive strategy were 
provided. The most important step is harmonising the designs of studies conducted by different research groups in order to generate more consistent data.

An intriguing observation in this thesis was that that local application of lidocaine, a local anaesthetic, in the stomach in humans was able to modify food intake although the overall effect was not statistically significant. However, in order to apply lidocaine a rather invasive method was used. We cannot exclude that the intubation negatively influenced the study results. Therefore, we advise future studies to consider other methods of administration of lidocaine in the stomach in order to further substantiate this concept.

Additional studies in this thesis investigated the usefulness of a novel assessment method for patients with functional dyspepsia. In these studies, we demonstrated the ability of this assessment method to capture the same constructs as conventional questionnaires. Moreover, we demonstrated the ability of the new assessment method to characterise individual symptom patterns. This provides us with a tool that can help move towards a more personalised approach in treating this functional symptom-based disorder. Using this novel tool, patients will be able to develop disease insight, shared-decision making can be improved, and patients can be provided with tools for self-management of their disease.

In summary, the first part of this thesis focused on generating knowledge on a strategy that has the potential to prevent the expansion of the obesity epidemic. Second, the first in-human experiment investigating a novel treatment tool for individuals with reduced food intake has been described. This paves the way for research to further elucidate the concept of modifying gastrointestinal responses to specific luminal triggers to influence satiety signalling and eating behaviour. Third, a novel tool that can aid functional dyspepsia patients in the transition towards personalised health care has been evaluated and was validated. Overall, this thesis, therefore, provided novel strategies to address disrupted sensing and signalling of satiety and eating behaviour. 



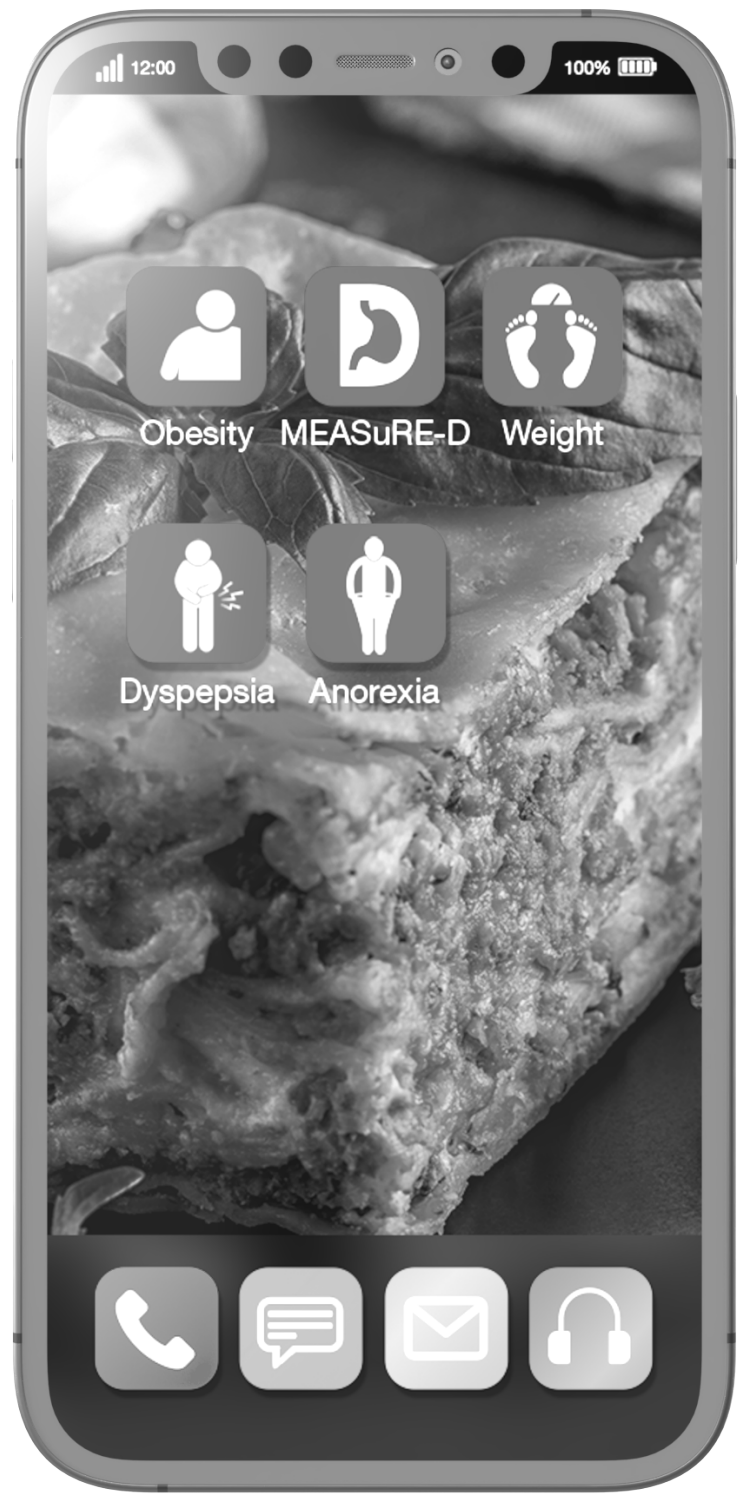




\section{Addendum}

Summary

Samenvatting

Impact

List of publications

Dankwoord

Curriculum Vitae 



\section{List of publications}

Wilbrink J, Masclee GMC, Klaassen T, van Avesaat M, Keszthelyi D, Masclee AAM. Review on the regional effects of gastrointestinal luminal stimulation on appetite and energy intake: (pre)clinical observations. Nutrients. 2021;13 (1601).

Klaassen T, Smeets FGM, Vork L, Tack J, Talley NJ, Simrén M, Aziz Q, Ford AC, Kruimel JW, Conchillo JM, Leue C, Masclee AAM, Keszthelyi D. Psychometric evaluation of an experience sampling method-based patient-reported outcome measure in functional dyspepsia. Neurogastroenterol Motil. 2021; Epub ahead of print.

Klaassen T, Keszthelyi D. Satiation or Satiety? More than mere semantics. Lancet; 397(10279):1060-1061.

Klaassen T, Keszthelyi D, Troost FJ, Bast A, Masclee AAM. Effects of gastrointestinal delivery of non-caloric tastants on energy intake: a systematic review and meta-analysis. Eur J Nutr. 2021; Epub ahead of print.

Klaassen T, Keszthelyi D, Alleleyn AME, Wilms E, Bast A, Masclee AAM, Troost FJ. Effect of oral or intragastric delivery of the bitter tastant quinine on food intake and appetite sensations: a randomised crossover trial. Br J Nutr. 2021;125:92-100.

Wilbrink J, Bernards N, Mujagic Z, van Avesaat M, Pijls K, Klaassen T, van Eijk H, Nienhuijs S, Stronkhorst A, Wilms E, Troost FJ, Masclee AAM. Intestinal barrier function in morbid obesity: results of a prospective study on the effect of sleeve gastrectomy. Int J Obes. 2020; 44;368-376.

Corstens MN, Troost FJ, Alleleyn AME, Klaassen T, Berton-Carabin CCB, Schroën K, Masclee AAM. Encapsulation of lipids as emulsion-alginate beads reduces food intake: a randomized placebo-controlled cross-over human trial in overweight adults. Nutrition Research. 2019;63:86-94.

Klaassen T, Alleleyn AME, van Avesaat M, Troost FJ, Keszthelyi D, Masclee AAM Intraintestinal Delivery of Tastants Using a Naso-Duodenal-Ileal Catheter Does Not Influence Food Intake or Satiety. Nutrients. 2019;11:472. 


\section{Submitted}

Klaassen T, Vork L, Smeets FGM, Troost FJ, Kruimel JW, Leue C, Masclee AAM, Keszthelyi D. The interplay between stress and fullness in functional dyspepsia and healthy controls: an exploratory experience sampling method study.

\section{To be submitted}

Alleleyn AME, Klaassen T, van Avesaat M, Winkens B, Peeters BWMM, Broekkamp CLE, Keszthelyi D, Masclee AAM. Effect of intragastric lidocaine on ad libitum food intake and satiation in healthy male volunteers: a double-blind randomised crossover study.

Beckers AB, Snijkers JTW, Weerts ZZRM, Vork L, Klaassen T, Smeets FGM, Masclee AAM, Keszthelyi D. Digital instruments for reporting of gastrointestinal symptoms in clinical trials: comparison of end-of-day diaries versus experience sampling method.

\section{Oral presentations}

Digestive Disease Days, spring 2021, Veldhoven, the Netherlands - The interplay between stress and fullness in functional dyspepsia and healthy controls: an exploratory experience sampling method study.

Digestive Disease Days, autumn 2020, Veldhoven, the Netherlands - Oral or intragastric delivery of the bitter tastant quinine does not influence food intake.

NUTRIM symposium 2019, Maastricht the Netherlands - Oral or intragastric delivery of the bitter tastant quinine does not influence food intake.

\section{Poster presentations}

Digestive Disease Days, spring 2021, Veldhoven, the Netherlands - Psychometric evaluation of an experience sampling method-based Patient-Reported Outcome Measure in Functional Dyspepsia.

NUTRIM symposium 2019, Maastricht the Netherlands - Oral or intragastric delivery of the bitter tastant quinine does not influence food intake. 
Neurogastro 2019, Lisboa, Portugal - Intraintestinal delivery of tastants using a nasoduodenal-ileal catheter does not influence food intake or satiety.

Wetenschapsdag MUMC+ 2019, Maastricht, the Netherlands - Intraintestinal delivery of tastants using a naso-duodenal-ileal catheter does not influence food intake or satiety.

NUTRIM symposium 2018, Maastricht, the Netherlands - Intraintestinal delivery of tastants using a naso-duodenal-ileal catheter does not influence food intake or satiety. 


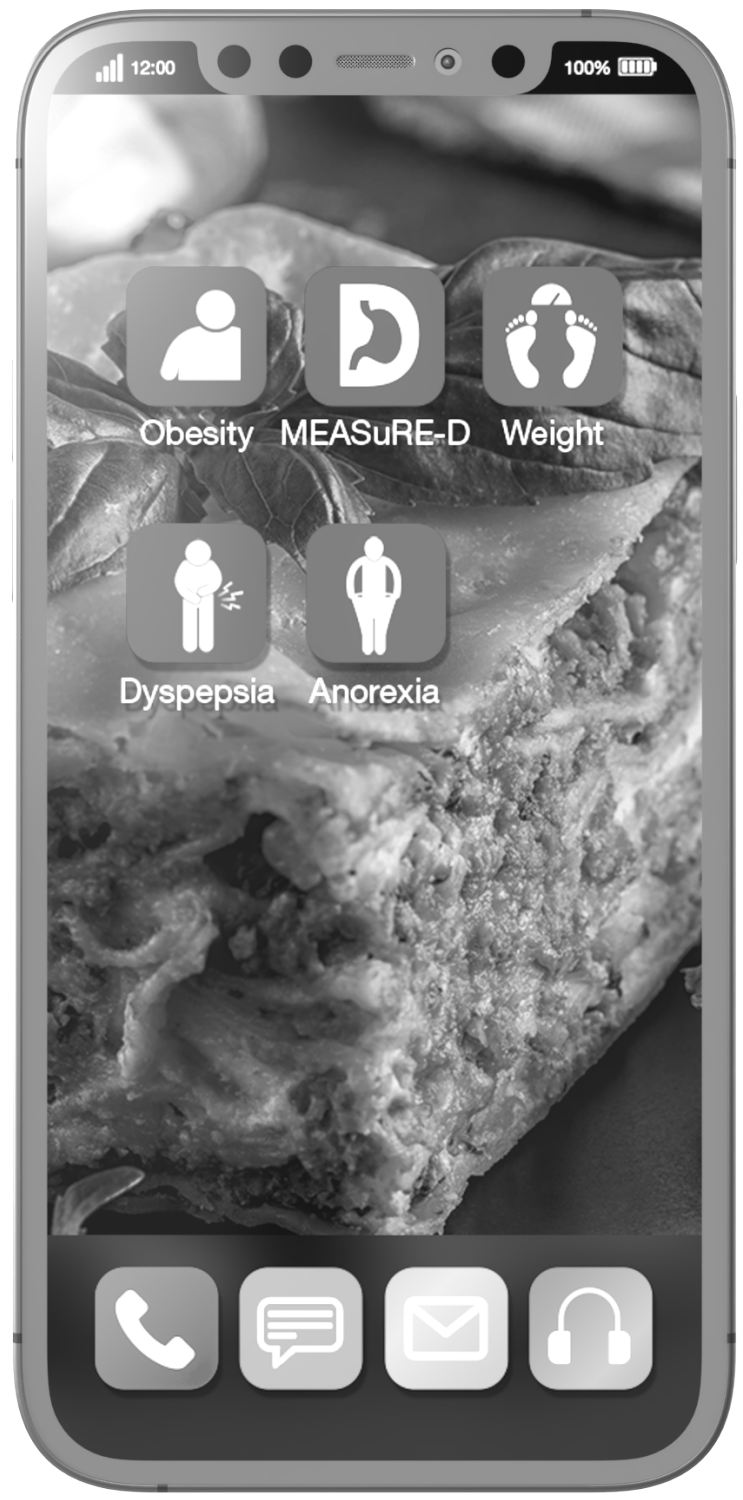




\section{Addendum}

Summary

Samenvatting

Impact

List of publications

Dankwoord

Curriculum Vitae 



\section{Dankwoord}

Wat een fijn gevoel om mijn woorden van dank neer te mogen schrijven. Er zijn veel mensen direct of indirect betrokken geweest bij het tot stand komen van dit proefschrift. Daarvoor mijn onuitputtelijke dank.

Prof. Masclee, beste Ad, toen ik semi-arts was bij de MDL sprak ik u na de ochtendoverdracht aan om mijn interesse in de MDL kenbaar te maken. U gaf aan dat ik een afspraak mocht maken om dit te bespreken. In dit gesprek bespraken we meteen de mogelijkheid tot een promotieonderzoek voorafgaand aan de opleiding. Daarna begon al snel onze samenwerking. $U$ heef op onmiskenbare wijze bijgedragen aan de totstandkoming van dit proefschrift. Manuscripten werden doorgaans het weekend nadat ik ze had opgestuurd al gecorrigeerd geretourneerd. Na onze gezamenlijke overleggen ging ik altijd met goede moed en hernieuwde motivatie weer aan de slag. Uw enthousiasme, gedrevenheid en creativiteit sloegen altijd weer op me over. Graag dank ik u voor de kans die ik heb gekregen om mijn promotieonderzoek te doen.

Dr. Keszthelyi, beste Daniel, al snel na de eerste gesprekken met prof. Masclee kwam jij in beeld als begeleider bij dit promotietraject. Jouw brede kennis en interesse, inzicht, creativiteit en motivatie maken dat je voor mij een voorbeeld bent in de medische- en de onderzoekswereld. Het feit dat je daarnaast altijd interesse hebt in de mensen om je heen makt dat je voor mij ook een voorbeeld bent als mens. Mede door jouw tomeloze inzet en snelle respons op protocollen en manuscripten is dit proefschrift tot stand gekomen. Uitspraken als "ik had je binnen een uur mijn correcties gestuurd he!" en "Eigenlijk zou ik nog niet naar het manuscript kijken, maar ik was zo benieuwd dus ik heb toch direct 's avonds gekeken." zal ik nooit vergeten. Daarnaast waren jouw commentaren altijd precies wat ik nodig had om zelf die denkstap verder te maken, dank daarvoor. Ook ons gezamenlijke congresbezoek in Lissabon is memorabel. Dat er nog veel gezamenlijke congresbezoeken mogen komen! Daniel, ik mag met recht zeggen dat je mij een betere onderzoeker hebt gemaakt en ik ben er trots op dat ik jou 'mijn baas' heb mogen noemen.

Dr. Troost, beste Freddy, ook al vroeg in het promotietraject maakten wij kennis. Na een jaar samenwerking zorgde je ervoor dat ik als pionier met humaan onderzoek in Venlo aan de slag kon, waarvoor dank! Ik wil je ook bedanken voor de vrijheid die je me liet tijdens het bedenken en uitvoeren van studies. Hierbij kon ik wel op je rekenen op de momenten dat het nodig was. Ik heb het altijd gewaardeerd dat onze overleggen altijd begonnen met je oprechte vraag hoe het met me persoonlijk ging. Jouw jarenlange ervaring in de onderzoekswereld maken dat je onderzoeken en ideeën heel goed kunt pitchen bij 
geldschieters. Daar heb ik veel bewondering voor. Ook zal ik onze uitstapjes naar Parijs nooit meer vergeten. Bedankt voor je begeleiding, hulp en gezelligheid!

Prof. Bast, beste Aalt, ondanks dat u officieel geen deel uitmaakt van het promotieteam wil ik u bedanken voor de kans die ik kreeg om als pionier in Venlo met humaan onderzoek aan de slag te gaan. Ook uw enthousiasme werkt aanstekelijk. Het is jammer dat met het ingaan van uw pensioen niet meer promovendi hiervan kunnen profiteren.

Graag bedank ik de leden van de beoordelingscommissie, te weten prof. dr. ir. Blaak (voorzitster), prof. dr. Havermans, prof. dr. Westerterp-Plantenga, prof. dr. Vanuytsel en dr. Corsetti voor de kritische beoordeling van dit proefschrift

Mietsie, Elly, Nienke en Nicole, jullie hielden je hart vast als er weer een meeting gepland moest worden met het hele team (Maastricht + Venlo). Toch is dit jullie altijd gelukt. Dank jullie wel voor jullie oprechte interesse, vriendelijkheid en ondersteuning!

Tiny en Tim, bedankt voor jullie hulp bij lay-out en het coverdesign. We hebben er samen een mooi boekje van gemaakt!

Dank aan alle MDL-collega's van het MUMC+ bestaande uit MDL-artsen, artsassistenten, (arts-)onderzoekers, medewerkers van de endoscopieafdeling en de functiekamer.

Het MDL-onderzoeksteam Maastricht heeft mijn promotietijd fantastisch gemaakt. Naast dat iedereen gedreven was, was er ook genoeg tijd voor lol, koffiemomentjes, fietsen, nawerkse activiteiten, congressen en andersoortig plezier. Ellen, Yala, Roel, Haoran, Wiesje, Vince, Annick, Evelien, Dion, Bas, Steven, Roy, Tim 1.0, Zlatan, Mark, Zsa Zsa, Lisa, Montserrat, Marin, Pan, Heike Anke, Bram, Marlijne, Gonny, Toon, Lonne, Corinne, Wenke, Quirine, Laura, Rob, Greetje, Benedict, Ashkan en Michelle, bedankt voor de koffiemomentjes, gezelligheid, samenwerking en adviezen! Jullie hebben van mijn promotietijd een prachtige tijd gemaakt.

Ook mijn collega's uit Venlo wil ik graag bedanken voor de gezelligheid, lunches en nawerkse activiteiten. Door jullie kwam ik op Villa Flora in een warm bad terecht. Remco, Koen, Anouk, Ardi, Sanne, Jessica, Cheng, Gizem, Karin, Alvaro, Britt, Evy, Miriam, Rob, Mônica, Paulina, Alicia, Hidde, Timme, bedankt voor alles!

Een paar collega's wil ik graag nog apart benoemen. Allereerst mijn kamergenoten in Maastricht: Yala en Ellen. Bij jullie op de kamer 'wonen' was een feest. We konden altijd 
bij elkaar terecht voor een gezellig praatje en een snelle lach, maar konden ook goed bij elkaar terecht om even te sparren over een protocol of statistische analyse. Ook bij persoonlijk moeilijkere tijden konden we altijd bij elkaar terecht. Veel dank daarvoor! Annick, heel veel dank voor de prettige samenwerking. We hebben veel meegemaakt samen, van tripjes naar Parijs tot stomavloeistof ophalen door het land met de stomamobiel! Ook wij konden in goede en minder goede tijden bij elkaar terecht. Dank je wel daarvoor. Fabienne en Lisa, ook jullie wil ik bedanken voor de fijne samenwerking. Ondanks dat jullie drukke baan in de kliniek wisten jullie tijd te maken om te helpen met de opzet en analyse van het MEASuRE-D onderzoek! Dion, Toon, Bram, Anke, Marlijne, Gonny, Benedict, dank voor de mooie momenten aan de tafelvoetbaltafel. Tim 1.0, Zlatan, Brecht, dank voor de mooie momenten op het zaalvoetbalveld. Deze woensdagavonden heb ik erg gewaardeerd. Helaas heeft mijn enkel dit voortijdig een halt toegeroepen. Mark, het was een eer jouw onderzoek te mogen voortzetten en later samen te tennissen.

Naast vrienden op het werk ben ik gezegend deel uit te maken van veel vriendengroepen. Aan iedereen die ik mijn vriend(in) mag noemen: veel dank, jullie hebben mij gevormd als mens.

Niels, Rob W., Rob van K., Tom, Jeroen, Etienne, Joep, Jasper, Alexander, Yvo, Dennis, Annouk, Janneke, Kirsten, Maartje, ik ben blij dat we samen de A-KO hebben gestudeerd en elkaar nog steeds regelmatig zien! Bedankt voor de leuke weekendjes weg, de fietstochtjes en de spellenavonden en -middagen. Jullie hebben mij gevormd als mens. Niels, bedankt voor de koffie op het MRUM. Jeroen, ik ben trots dat ik getuige mag zijn op je huwelijk!

Heren van O.H.D. Bonobo, dank dat ik een deel van mijn studententijd met jullie heb mogen doorbrengen. Ook jullie hebben mij deels gemaakt tot wie ik ben, al hadden we natuurlijk geen keurslijf. Robert, Philippe, Rogier, Thijs, Jasper, dank voor de koffiemomenten op de uni en de gameavondjes. Robert, ik heb veel met je over het onderzoek en andere zaken kunnen sparren. Helaas uit het zuiden vertrokken, maar uit het oog is niet uit het hart.

Dan mijn paranimfen Rob en Toon.

Toon, jij kwam bij ons binnen als een keurige WESP student. Nadat je was begonnen aan je promotieonderzoek bleef je nog ongeveer 2 maanden netjes en keurig. "Daarna kent iedereen me en dan kan ik echt mezelf zijn.” Mijn tip: wees ook jezelf. Je bent grappig en ad rem en zoekt graag de grenzen op waar je dan af en toe overheen gaat. Maar bovenal 
ben je een mooi mens met het hart op de goede plek. En ja, jij bent het beste in tafelvoetbal. Ik ben blij dat je naast me wilt staan tijdens mijn verdediging en kijk uit naar de gezamenlijke onderwijsmomenten tijdens de opleiding!

Rob, wij leerden elkaar kennen als kamergenoot op wintersport en het klikte direct. Ik vind het mooi dat je zo'n positieve instelling hebt en altijd vrolijk bent. Je bent grappig en ik kan me niet herinneren dat wij ooit een gesprek hebben gehad waarbij we niet hebben moeten lachen. Dat waardeer ik heel erg. Ook ben ik blij dat we je hebben kunnen overtuigen om bij ons te komen tennissen. Daardoor is ook op de tennisbaan de lach nooit ver weg. Ik ben er trots op dat je naast mij wilt staan tijdens mijn verdediging en hoop dat we samen nog vele mooie momenten mogen meemaken!

In mijn dankwoord kan mijn familie natuurlijk niet ontbreken, te beginnen met de 'koude kant'. Ria en Piet, met de kachel (letterlijk en figuurlijk) aan bij jullie was de 'koude kant' altijd een relatief begrip. Bedankt voor de open ontvangst en jullie warmte! Niels, Arjan en Anniek, met jullie is het altijd gezellig en kan ik altijd lachen. Dank ook voor de, zeker voor herhaling vatbare, wintersport!

Lieve Irma, Bertie, Sanne, Lotte en Merel, als zussen hebben jullie me altijd gesteund. Ik vind het waardevol dat we de broer-zussen dag weer nieuw leven in hebben geblazen. Onder andere een uitgelezen gelegenheid om het even níet over het onderzoek te hebben. Irma en Daan, Bertie, bedankt voor de open gesprekken over het leven. Sanne en Paul dank jullie wel voor de leuke vakanties, maar ook voor de discussies omtrent het onderzoek. Merel en Duncan, dank jullie wel voor het logeren in Amsterdam als ik weer eens vroeg in het vliegtuig moest zitten voor een congres. Lotte, ik ben trots dat je onlangs bent afgestudeerd als arts en je eerste stappen hebt gezet in de medische wereld.

Lieve pap en mam, dank jullie wel voor alle onvoorwaardelijke steun tijdens mijn promotie, daarvoor en daarna. Dankzij jullie heb ik kunnen worden wat ik wilde worden. Jullie grenzeloze vertrouwen heeft ervoor gezorgd dat ik alles heb kunnen bereiken dat ik wilde. Ook wil ik jullie bedanken voor de open en zorgeloze opvoeding die ik genoten heb. Hierdoor ben ik ook als mens geworden wie ik wil zijn. Jullie hebben meer dan jullie denken bijgedragen aan dit proefschrift.

Allerliefste Pauline, we leerden elkaar kennen tijdens ons promotieonderzoek. Dat maakte dat we ons bij baalmomenten goed in elkaar in konden leven. Jouw ambitie, enthousiasme, doorzettingsvermogen, rust en openheid heb ik altijd erg gewaardeerd. Sterker nog, hier heb ik altijd tegenop gekeken. Ondanks dat je naast je baan in de kliniek nog met je promotieonderzoek bezig was, heb ik nooit het gevoel gehad dat ik aandacht van je te kort kwam, veel dank daarvoor! 
Met het afsluiten van onze promotieonderzoeken komt een van onze gedeelde tijdpaden ten einde. Ik wil niets liever dan met jou nog veel tijdpaden delen en samen nieuwe tijdpaden starten. Ik kijk uit naar de rest van ons leven samen! 


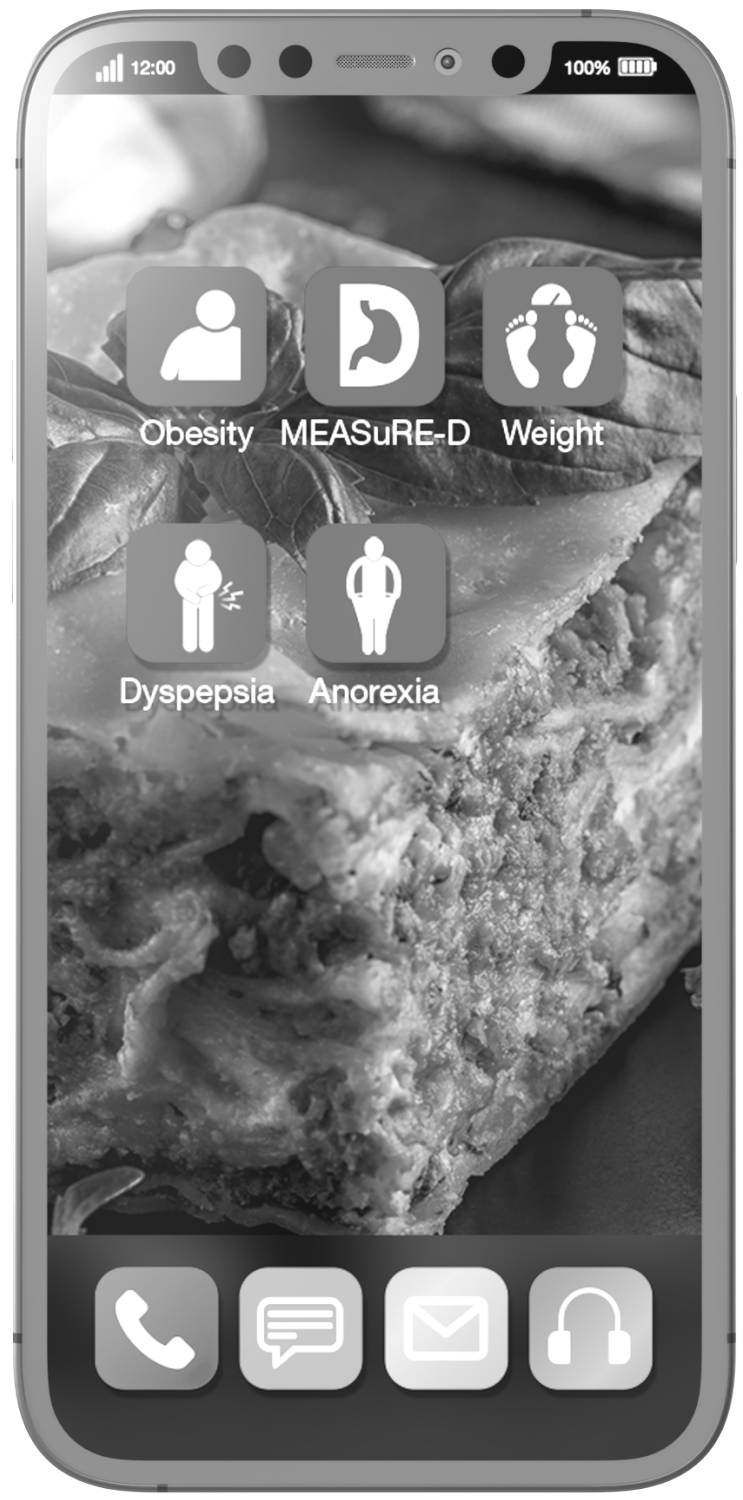




\section{Addendum}

Summary

Samenvatting

Impact

List of publications

Dankwoord

Curriculum Vitae 



\section{Curriculum Vitae}

Tim Klaassen was born on the $5^{\text {th }}$ of September 1990 in Helmond, the Netherlands. After finishing secondary school at the Udens College in 2008, he studied Biomedical sciences at the University of Amsterdam and obtained his BSc degree in 2011. Hereafter, he studied Psychology at the University of Amsterdam and obtained his propaedeutic diploma with merit in 2012. Hereafter, he studied the master Physician - Clinical investigator at Maastricht University and obtained his MSc in 2016. During this master, he did his internship 'mother and child' at Academical Hospital Paramaribo in Paramaribo,

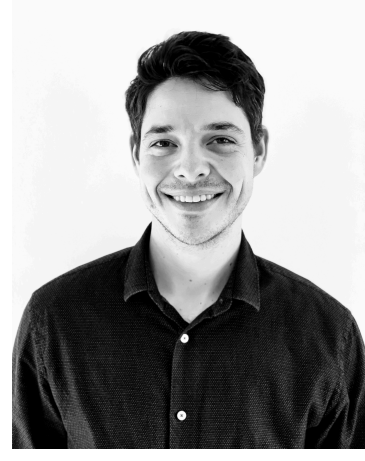
Surinam. After graduating in 2016, Tim started with the research project described in this thesis: "Novel strategies to address disrupted sensing and signalling of satiety", supervised by Prof. dr. A.A.M. Masclee, Dr. D. Keszthelyi, and Dr. F.J. Troost at Maastricht University. During this project, Tim had the opportunity to publish manuscripts in international peer reviewed journals and to present his work at several conferences. In January 2021 he started his residency Gastroenterology-Hepatology under the supervision of Dr. J.W. Kruimel. 
